Osama Tayeb Adnan Zahed Jozef Ritzen Editors
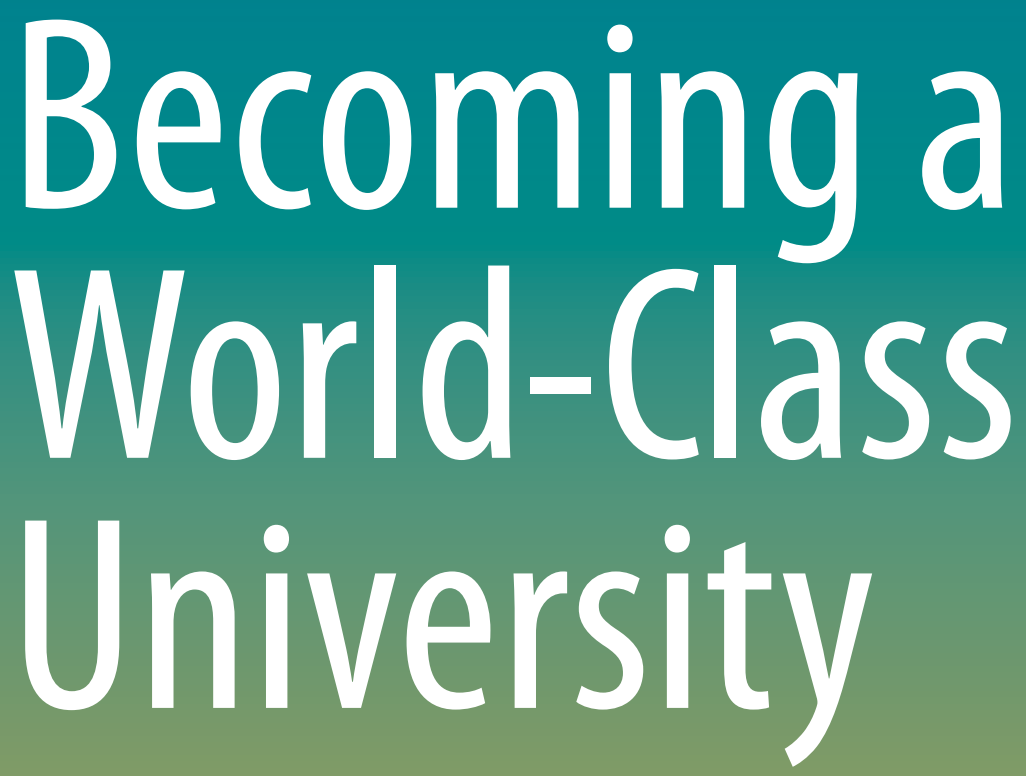

The Case of King Abdulaziz University

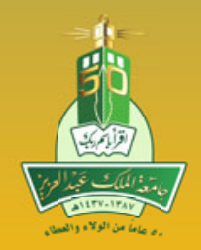

Springer Open 
Becoming a World-Class University 
Osama Tayeb · Adnan Zahed · Jozef Ritzen Editors

\section{Becoming a World-Class University}

The Case of King Abdulaziz University

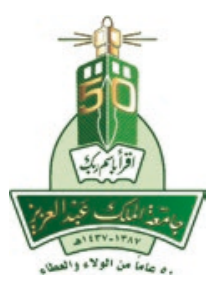


Editors

Osama Tayeb

King Abdulaziz University

Jeddah

Saudi Arabia

Adnan Zahed

King Abdulaziz University

Jeddah

Saudi Arabia
Jozef Ritzen

Maastricht University

Maastricht

The Netherlands

ISBN 978-3-319-26379-3

ISBN 978-3-319-26380-9 (eBook)

DOI 10.1007/978-3-319-26380-9

Library of Congress Control Number: 2015954592

Springer Cham Heidelberg New York Dordrecht London

(C) King Abdulaziz University 2016. The book is published with open access at SpringerLink.com.

Open Access This book is distributed under the terms of the Creative Commons Attribution Noncommercial License, which permits any noncommercial use, distribution, and reproduction in any medium, provided the original author(s) and source are credited.

All commercial rights are reserved by the Publisher, whether the whole or part of the material is concerned, specifically the rights of translation, reprinting, reuse of illustrations, recitation, broadcasting, reproduction on microfilms or in any other physical way, and transmission or information storage and retrieval, electronic adaptation, computer software, or by similar or dissimilar methodology now known or hereafter developed.

The use of general descriptive names, registered names, trademarks, service marks, etc. in this publication does not imply, even in the absence of a specific statement, that such names are exempt from the relevant protective laws and regulations and therefore free for general use.

The publisher, the authors and the editors are safe to assume that the advice and information in this book are believed to be true and accurate at the date of publication. Neither the publisher nor the authors or the editors give a warranty, express or implied, with respect to the material contained herein or for any errors or omissions that may have been made.

Printed on acid-free paper

Springer International Publishing AG Switzerland is part of Springer Science+Business Media (www.springer.com) 


\section{Acknowledgments}

The editors would like to express their sincere appreciation and gratitude to all the contributors. It is also a pleasure to acknowledge the outstanding help of Profs. Mahmoud Nadim Nahas, Ahmad Abousree Hegazy and Maher Gaber Mohamed during the course of preparing the manuscripts of the book. Many thanks are also due to Dr. Abdullah Al-Bargi, Mr. Lance Cutler and Mr. Michael Taylor for editing and proofreading the chapters of the book. 


\section{Contents}

Roadmap to Become a World-Class University . . . . . . . . . . . . 1

Osama Tayeb

International Advisory Boards in the World . . . . . . . . . . . 21

Adnan Zahed

Excellence as Duty. . . . . . . . . . . . . . . . . . . . 41

Jozef Ritzen

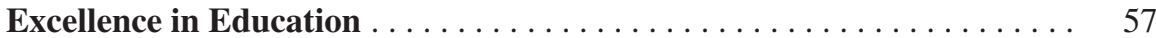

Guaning $\mathrm{Su}$

Excellence in $\operatorname{Research} \ldots \ldots \ldots \ldots \ldots \ldots \ldots$. . . . . . . . . . . . . . . . . . .

Michael Arthur

Excellence in Serving Society and Mankind. . . . . . . . . . . . . . 91

Thomas Wilhelmsson

Excellence in Strategic Planning . . . . . . . . . . . . . . . . . . 105

Georg Winckler

Excellence in Innovation and Knowledge Economy . . . . . . . . . . . . 117

Yücel Altunbaşak

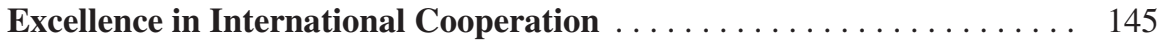

Adnan Zahed

Change Towards Excellence. . . . . . . . . . . . . . . . . . . . 175

Jozef Ritzen 


\section{Editors and Contributors}

\section{About the Editors}

Prof. Osama Tayeb served as president of King Abdulaziz University (KAU), Jeddah, Saudi Arabia, from 2003 to 2015. He is a professor of pharmacology at KAU. During his presidency at KAU, Prof. Tayeb also served as acting president of various newly established Saudi universities, including Taiba University, Jazan University and the Northern Borders University. As president of KAU, Prof. Tayeb spearheaded and presided over the major transformation that KAU underwent in order to achieve its current internationally recognized world-class university status. During this process, the majority of KAU's academic programmes were awarded accreditation from international accreditation agencies. KAU has consequently achieved its rightful ranking amongst the World's top 400 universities in the international ranking lists of Shanghai, QS, and the Times. Prof. Tayeb was the founder of the KAU International Advisory Board (IAB) and served as the chairman of IAB.

Prof. Adnan Zahed has been the vice-president for Graduate Studies and Scientific Research at King Abdulaziz University (KAU) since 2009. He is a professor of chemical engineering at KAU. As vice-president for Graduate Studies and Scientific Research, Prof. Zahed has maintained a high profile and has played a proactive role in the transformation of KAU into a university that is currently ranked as being of world-class status. Prof. Zahed's tenure has witnessed a huge increase in the numbers of scholarly publications of academic staff of KAU featured in ISIranked journals, which increased from 260 in 2009, up to 3600 in 2014. Various incentive programmes, initiated and implemented under Prof. Zahed's supervision and guidance, have resulted in notable increases in citation numbers, which also increased from 1100 in 2009 up to 21,000 in 2014. Prof. Zahed is the secretary general of the KAU IAB. 
Prof. Jozef Ritzen a Dutch national, has been an honorary professor at Maastricht University since 2011 (chair at the International Economics of Higher Education, Science and Technology). Prof. Ritzen was president of Maastricht University from February 2003 to January 2011 and special adviser and vice-president of the World Bank from 1998 to 2003. He served as Minister of Education, Culture, and Science of the Netherlands from 1989 to 1999. Prof. Ritzen has academic appointments at Nijmegen University, Erasmus University in the Netherlands, the University of California, Berkeley, and the University of Wisconsin-Madison, in the US. Prof. Ritzen is a member of the KAU IAB.

\section{Contributors}

Prof. Dr. Yücel Altunbaşak has served as the 9th president of the Scientific and Technological Council of Turkey (TUBITAK) since 2011. He has a BS in Electrical and Electronics Engineering from Bilkent University (1992) and an MS (1993) and PhD (1996) from University of Rochester. He started his early career in Hewlett-Packard's Palo Alto Laboratories in Silicon Valley and at Stanford University. His research work has focused on the intersection of key scientific advances and industrial application with over 200 papers and 50 patent and grant applications. He obtained his professorship from the Department of Electrical and Computer Engineering, Georgia Institute of Technology. From 2009 to 2011, Prof. Dr. Altunbaşak was president of TOBB University of Economics and Technology in Turkey where he licensed and successfully prototyped an MPEG processing device for a satellite and cable TV company. Prof. Altunbaşak initiated and was the driving force behind an image processing technology called "Pixellence" that has been awarded the Special Jury Award of the Turkish Industry and Business Association. Prof. Dr. Altunbaşak is a member of the KAU IAB.

Prof. Michael Arthur is president and provost of University College London (UCL). Prior to this, he was vice chancellor of the University of Leeds (20042013), and formerly dean of the Faculty of Medicine, Health and Life Sciences in Southampton. He is a hepatologist with research interests in liver cell biology. These interests developed initially at the University of California, San Francisco (19861988), and further developed whilst he was a Fulbright Distinguished Scholar at Mount Sinai School of Medicine in New York (2002). Prof. Arthur became a Fellow of the Academy of Medical Sciences in 1998. He was a member of the Medical Research Council (2006-2014). He has also been a US/UK Fulbright commissioner and is a former chair of both the Worldwide Universities Network and the Russell Group of Universities. Prof. Arthur is a member of the KAU IAB. 
Prof. Guaning Su is president emeritus and professor of electrical and electronic engineering at Nanyang Technological University (NTU), Singapore. As president from 2003 to 2011, he led the transformation of NTU from an engineering and business teaching-focused university into a research intensive, science and technology-focused comprehensive university. Prof. Su is a member of the KAU $\mathrm{IAB}$.

Chancellor Thomas Wilhelmsson Thomas Wilhelmsson, Doctor of Legal Science, has been professor of civil and commercial law at the University of Helsinki, Finland, since 1982. From 1998 to 2008, he was university vice-rector, in charge of international affairs. Prof. Wilhelmsson served as university rector from 2008 to 2013 and has served as university chancellor since 2013. As rector, Prof. Wilhelmsson presided over comprehensive university reforms, which transformed the university from a state institution into an independent public legal entity. He has been awarded the title Doctor Iuris Honoris Causa by the Uppsala, Oslo and Tartu universities. Prof. Wilhelmsson is a member of the KAU IAB.

Prof. Georg Winckler was appointed professor of economics at the University of Vienna in 1978 and has held visiting professorships at universities in the USA, Switzerland and Austria. In 1999, Prof. Winckler was elected as rector of the University of Vienna and served in this position for 12 years from 1999 to 2011. From 2001 to 2005, he was vice-president of the European University Association (EUA), the umbrella organization of nearly one thousand European universities. $\mathrm{He}$ was EUA President from 2005 to 2009. From 2004 to 2012, he was a member of the European Research Area Board, a top advisory board for the European Commission on Research Strategies. Prof. Winckler is currently president of ERSTE Stiftung, Vienna, Trustee of the Educational Testing Service (ETS), Princeton, and serves on boards of German and Austrian universities. Prof. Winckler is a member of the KAU IAB. 


\section{Introduction}

This book is essentially a description of one phase of the fascinating expedition of exploration that has been undertaken by King Abdulaziz University (KAU) as it enthusiastically seeks to achieve the standards of educational and academic excellence that will consequently facilitate the realization of its ambition to become one of the world's leading universities. This book describes the manner in which the university went about seeking, identifying and locating internationally recognized authoritative educational and academic experts. Their expertise and advice were sought for constructive input on the necessary steps to be followed in the process of the pursuit of this ambition, and on the nature and composition of those steps. We describe the background of this process, the manner in which the KAU leadership committed itself to the journey and exploration, and the diverse and valuable advice obtained during the process. We hope and believe that this book will prove to be a useful guidebook for other universities which are also considering embarking upon this long and arduous, but nevertheless, immensely worthwhile journey in pursuit of academic and educational excellence. It is compiled by some members of the International Advisory Board of KAU. ${ }^{1}$

The book addresses excellence in research universities. Excellence in universities is often regarded in the context of the university rankings as originated by the Academic Ranking of World Universities (AWRU), also called the Shanghai ranking. Shanghai Jiao Tong University publishes annually a list ordering universities according to the quality of their research, including a list by discipline, starting in 2003. This ranking is one of the three most influential rankings together with the QS World University Rankings and the Times Higher Education World University Rankings. They have shaken the academic community and policy makers alike. ${ }^{2}$ They are also highly disputed as they capture only part of the accomplishments of

\footnotetext{
${ }^{1}$ This introduction greatly benefitted from comments by Prof. Tatiana Kliachko and Prof. Vladimir Mau.

${ }^{2}$ See, Ellen Hazelkorn, Rankings and the Reshaping of Higher Education. The Battle for World-Class Excellence, Palgrave Macmillan, 2015.
} 
universities. Excellence in universities is broader than the measures taken into account in the rankings, as is evidenced in quality criteria embedded in quality insurance systems. The measures of the rankings are not relevant for those universities which do not engage in research but provide education of high quality or universities of "applied science" (in Germany: the Fachhochschule) who engage mostly in research close to development.

Universities are part of a national and international eco-system of science, technology and innovation. Their role is becoming increasingly important in this system in the gradual changes on the labour market towards a greater demand for non-routine workers with high competencies ${ }^{3}$ and the gradual changes in the economy where knowledge has become more important. These changes also affect notions of excellence in teaching and research in universities, making entrepreneurship and problem-solving abilities more important.

Chapter "Roadmap to Become a World-Class University" is by the former president of KAU (2003-2015), and co-editor of this text, Prof. Osama Tayeb. This chapter describes the overarching aims of KAU's ambitious quest, which are to raise the university's educational and academic status so as to achieve recognition and ranking amongst the elite grouping of internationally accepted world-class universities. The scientific, educational and academic inclinations of KAU's leadership presuppose the use of examples and models drawn from the international academic and educational arena. International higher educational and academic best practice is seen as beacon shedding light and guiding the university on its lengthy and demanding journey on the road being followed in this quest for excellence. This chapter outlines the thinking behind the strategy employed, and the manner in which KAU sought out the valued advice of international experts to proffer valuable assistance to the university in seeking the achievement of its goals.

Chapter "International Advisory Boards in the World" is by the second co-editor, the secretary general of the International Advisory Board and vicepresident for Graduate Studies and Scientific Research of KAU, Prof. Adnan Zahed. This chapter provides an overview of international advisory boards utilized by scientific institutions and major organizations around the world. It is pointed out how advisory boards complement and reinforce organizational executive boards' strategies, procedures and operations by offering them authoritative advice and guidance to aid in the successful performance of their tasks and duties.

Chapter "Excellence as Duty", is by the third co-editor, Prof. Jozef Ritzen, former president of Maastricht University. This chapter starts with the premise that every university should do its utmost to contribute to society through its education programme and research. The visible profile of an excellent research university therefore becomes not only internal to the concerned university, but broader and external in terms of the degrees of its contribution to society, including, but not limited to, the innovation levels of the country or region of the university's

${ }^{3}$ See, Autor, H., F. Levy and R. Murnane, The skill content of recent technological change: an empirical exploration, The Quarterly Journal of Economics, November 2003, pp. 1279-1333. 
location. The implication of this is that being excellent should be considered within the framework of shared responsibilities wherein the university strives to perform to its utmost capacity in terms of twenty-first-century skills, capabilities and research. The aims of these efforts should be both to develop increased public knowledge and to acquire patents and develop spin-offs. It is pointed out that the process is mutually beneficial for the concerned university and its environs as the region and the country engage in ensuring feedback, investment, venture capital and adequate regulation.

The massification of higher education and its accessibility to the representatives of social groups for which it was previously closed has created a quality challenge for all universities, but especially for research universities. They are essential for strong economic growth. Research universities should improve the quality of education by means of its individualization, engagement of students in research and instillation of an entrepreneurial spirit in them (entrepreneurship training, stimulating start-ups and spin-offs).

Chapter "Excellence in Education" is by Prof. Guaning Su, former president of Nanyang Technological University of Singapore (NTU). This chapter is devoted to the educational side of research universities that are deemed as displaying academic and educational excellence. His point of view is that the demands from societies for excellence in universities are similar throughout the world. In the course of his NTU presidential term from 2003 to 2011, the author transformed NTU and guided the improvements that led to the university's status being raised to that of world-class, and to its eventual international recognition as a major global research university. He focuses on undergraduate education and postgraduate professional education up to the master's level. This chapter concentrates on KAU in the context of Saudi Arabia as an example of a university striving for excellence well realizing that both for KAU as for NTU sufficient funding was a precondition for excellence.

The Singapore story is a "poor boy makes good story", of a small tropical island, devoid of natural resources other than its maritime location, striving against the odds to succeed and prosper. Saudi Arabia has gone through changes no less remarkable. In a matter of a mere two generations, the lives of Saudi Arabia's population have undergone a complete transformation. The past nomadic way of life, where everyday life involved struggling against the elements, has been transformed to the current situation, where Saudis are now citizens of one of the most prosperous nations in the world. Religion plays an important role in both nations, but in contrasting ways. As a result of its special position in the Islamic world and the influence that stems from it being one of the world's major oil producers, able to exert huge influence on the direction of world oil prices, Saudi Arabia has worldwide influence and a stature unmatched in West Asia or the Arab and Islamic world. An important role of leading universities, such as King Abdulaziz University in Saudi Arabia, must inevitably involve the education of such an important nation's future leaders. In order to do so, and as a crucial element in its 
pursuit of academic and educational excellence, King Abdulaziz University must ensure that a broad international world view and perspective is inculcated in all its students.

Chapter "Excellence in Research", on the research profile of internationally outstanding universities, is by Prof. Michael Arthur, president of University College London. He identifies and discusses five key recommended actions to be undertaken to enable and facilitate KAU to enhance research performance: building a critical mass of researchers and a concentration of research excellence in a defined and clearly identified number of high-quality fields of research, a clear "youth policy" with respect to training the next generation, attracting external research funding from high-quality research funding agencies, the enhancement of cross-disciplinary research and the development of systems to drive and support innovation. Only 1000 universities out of about 17,000 conduct world-class scientific research. New players (universities) can only enter this narrow circle if they can rely on sufficient financial backing. The author examines the experience of University College London (UCL), as well as some universities in the USA providing high-quality research. The educational system also includes engagement of students in research, preparation of doctoral theses to obtain $\mathrm{Ph} . \mathrm{D}$. degree and involvement of postdoctoral researchers in research teams. An important factor in the organization of scientific research, according to the author, is the creation of cross-disciplinary research teams and carrying out cross-disciplinary researches. The author insists on the fact that cross-disciplinary studies are more effective when compared with interdisciplinary and trans-disciplinary ones. Crossdisciplinary research teams consist of researchers from different fields of science and even different countries to solve mega problems of the modern society.

Science funding arrangements are of great importance too as the author identifies with the UK experience. These arrangements have greatly contributed to research quality.

Chapter "Excellence in Serving Society and Mankind", on the "third mission" of universities, is by Prof. Thomas Wilhelmsson, chancellor and professor of civil and commercial law, University of Helsinki. He points out that it is often the case that the third mission of social responsibility or the community service of universities is undervalued. He identifies strategies and makes recommendations as to how this situation can be remedied. He provides pertinent examples of how the third mission is currently being successfully incorporated into some universities' overall educational and academic influence and stresses the beneficial importance of universities' third mission for the societies in which universities are located, and for mankind in general.

Chapter "Excellence in Strategic Planning" is by Prof. Georg Winckler, former president of Vienna University. In this chapter, he discusses "excellence" from a different perspective. He examines and investigates how academic and educational excellence can be arrived at by means of tailored, targeted, carefully overseen and implemented strategic planning. He explores and delineates the steps necessary to be followed in the planning process. He states that this should begin with a clear decision concerning the nature and characteristics of the concerned university's 
profile. This involves key fundamental groundwork, such as identification of the areas in which the university aspires to excel and the identification of its core values. It is pointed out that there are considerable potential hazards and pitfalls in this process.

Chapter "Excellence in Innovation and Knowledge Economy" is by Prof. Dr. Yücel Altunbaşak, president of TÜBİTAK (Scientific and Technological Research Council of Turkey). This chapter deals with innovation and the knowledge economy. In this chapter, he investigates the subject from the perspective of countries wishing to reach what he terms the "production frontier" in order to enable concerned nations to be fully competitive worldwide in hightech and high-value-added production. He recommends that universities should explore and exploit innovation options and avenues. He provides examples from Turkey and other countries where the components of science and innovation systems are designed and intended to overcome the gap between existing frontiers and "production frontiers".

Chapter "Excellence in International Cooperation" is by Prof. Adnan Zahed, as is Chapter "International Advisory Boards in the World". This chapter focuses on international cooperation between universities and between their components and constituents. It includes student exchange, joint education programmes and research cooperation. He points out that all the cooperative examples given differ and are subject to their own idiosyncrasies. He stresses that these dimensional inconsistencies necessitate the adoption of a variety of approaches, dependent on the nature of the intended academic, educational and research cooperation and that, in a nutshell, "one size does not fit all".

Chapter "Change Towards Excellence", the concluding chapter, is by Prof. Jozef Ritzen again. In this chapter, he draws on his experience as a minister, responsible for education, science and culture in the Netherlands in the 1990s and on his experience as President of Maastricht University in the first decade of the twenty-first century. He deals with the challenges of change towards excellence for universities which find themselves caught up in the turmoil of globalization and "informatization". University leaderships have crucial roles to play in ensuring that change towards excellence is achieved by developing strategies which are owned by the concerned universities. He elucidates on how university leaderships are also responsible for the design and provision of means for such strategies' implementation.

We hope that this book contributes to a better understanding of the way research universities can achieve superiority in education and scientific research by drawing on the rich experience in the world in dealing with the quality question in learning and research in higher education.

Osama Tayeb

Adnan Zahed

Jozef Ritzen 


\title{
Roadmap to Become a World-Class University
}

\author{
Osama Tayeb
}

\section{Introduction}

Raising the educational and academic status and ranking of universities to that of internationally accepted world-class universities has become the goal of many university higher administrators around the globe in recent years. This trend has been made possible and accelerated by rapid global economic growth and development. Such efforts inevitably involve the progressive evolution of successful strategies dealing with issues concerning academic and educational excellence, funding, support facilities' suitability, academic staff qualifications, and graduates' competencies. Within this global academic context, an initiative for attaining world-class university rank and status was undertaken by King Abdulaziz University (KAU). The aim of this initiative was not primarily to compete with leading internationally recognized universities, but was rather a means of showcasing the academic and educational strengths and potential of KAU, and of creating an appropriate and navigable roadmap to facilitate genuine, academically credible, and enduring improvements in the quality of the higher education provided.

Before discussing KAU's approach to this venture, it is necessary to differentiate between the two concepts "university internationalization" and "world-class university" which are sometimes used interchangeably, although their meanings are dissimilar. KAU has selected to seek the status and ranking of "world-class university".

O. Tayeb $(\square)$

King Abdulaziz University, Jeddah, Saudi Arabia

e-mail: tayeb@kau.edu.sa 


\section{Internationalization in Higher Education}

The term "internationalization" covers a broad range of concepts of varying scope and emphasis concerning various aspects of higher education. A number of viewpoints have been adopted concerning university internationalization, and consequently differences in understanding of the term have become apparent. Internationalization can involve international contributions on syllabi, literature in other languages, exchange of professors and students, international studies, international technical collaboration, and academic staff mobility.

Internationalization in terms of activities includes academic and non-academic activities such as the development of curricula, scholar and student exchange, technological assistance, intercultural teaching, and joint research activities. The level of concentration of activities varies, depending on the specific educational and academic situation and geographical location of the concerned universities.

The European Association for International Education (EAIE) defines internationalization as the entire range of procedures by which higher education becomes less national, and more internationally oriented [1]. The Association of Universities and Colleges of Canada (AUCC) (now it is called Universities Canada) defines internationalization as a multitude of activities aimed at providing an educational practice within an environment that integrates a global perspective [2].

Others define internationalization as the integration of international aspects into teaching, research, and community services. This involves the integration of an international/intercultural/global perspective into a university's major functions whereby the university's higher education system develops an international orientation [3].

Internationalization can also refer to interactions between cultures through teaching, research, and community service functions, with the aim of attaining understanding, communication, and discussion across cultural and geographical borders.

This explains why internationalization is frequently referred to in relation to cultural integration and conflicts in some countries. In Asia, for example, cultural and ideological implications have been incorporated in the internationalization concept resulting in meanings such as "Westernization," and "Liberalization". This is the reason some scholars pose the question: how can a university rooted in its values open itself to thoughts and ethics derived from other knowledge sources [4]?

Internationalization is also sometimes described in terms of the process of learning the languages, social systems, and broader cultures of other countries.

As a result of the above, it is clear that any given understanding of internationalization depends on the particular socio-cultural context.

\section{World-Class University}

World-class universities, usually referred to as the most prominent research universities, are essential in developing competitiveness in the international knowledge economy. These universities play key roles in generating and circulating 
knowledge, educating highly skilled personnel for leadership, and serving the needs of society. In recent years, the development of world-class universities has featured prominently in the strategic planning of a range of countries. Various developmental strategies at national and institutional levels have been drawn up and implemented. In this context, Shanghai Jiao Tong University has initiated the International Conference on World-Class Universities, to bring together university administrators and top researchers from around the globe to discuss issues related to world-class universities, in the context of an increasing number of countries and higher educational institutions facing up to the challenge of the achievement of academic excellence. Universities in developing countries are making every effort to improve their ability to boost their research performance to achieve and maintain their worldwide positions and status [5-10].

There are important questions that must be answered:

- How does a university develop its status to become a world-class university?

- Are all universities facing identical issues and challenges?

- Can one university's successful strategies be transferred to other universities in other countries?

World-class universities are sometimes referred to as global research universities. World-class universities are academic institutions dedicated to creating and spreading knowledge in a range of disciplines and fields, delivering quality higher education at all levels, serving national needs, and furthering international public interest. Scholars and institutional administrators define "world-class" as attaining the standard to be included in the Lists of World University Rankings, which focuses on quality of education, internationalization, research output, status, and impact. Key attributes of world-class universities include qualified faculty, academically gifted and successful students, excellence in research, quality teaching at an international standard, high levels of funding, and well-equipped facilities. A world-class university is able to attract the most academically able students and the most highly qualified professors and researchers. It should also have access to plentiful funding sources and offer a rich learning and research environment, so as to respond flexibly and appropriately to the demands of a changing international market.

\section{Important Considerations Related to World-Class University Status}

For a university to become world-class, it has to ceaselessly strive for excellence. This has obvious implications for the quality of higher education. The distinction of a university and its academic preeminence is dependent on the maintenance of enduring and prolonged high levels of academic and educational excellence and accomplishment. 
Expectations of quality differ from one viewpoint to another depending on factors such as educational situation, processes, input and output, vision and mission, university objectives, teaching and research outcomes, graduates' employment status, and student involvement.

There are other dimensions to definitions of quality such as excellence, consistency with set standards, appropriateness, and stakeholders' satisfaction.

Quality in higher education is not straightforward to define, but the substantial increase in international competition and variation in the higher educational sector, which has created a rich diversity of courses, programs, and degrees, has resulted in an increasingly necessary requirement for quality evaluation and assurance. In fact, quality assurance is a phrase with a wide range of interpretations encompassing a continuous process of assessing, observing, securing, maintaining, and improving the quality of higher educational institutions. Improvement in practice is a result of the persistence of quality assurance. Thus, it is inseparably related to standards in education, which are used to measure outcomes to be used for comparison against indicators. Quality assurance can be assessed by inspection and accreditation. High quality is indicative of high status and high ranking which is a recognized measure of world-class excellence [11-15].

With regard to ranking, there are three global university rankings employing different methodologies. These are the Academic Ranking of World Universities (ARWU), which is conducted by Shanghai Jiao Tong University [16], the Times Higher Education (THE) World University Rankings [17], and the Quacquarelli Symonds (QS) World University Rankings [18]. Many organizations and companies believe that the quality of a university is measured by its position in the ranking tables. Uppermost universities in the ranking lists are recognized as being of uppermost quality. This is the reason for ranking being regarded as a means to draw higher educational institutions into the global knowledge market, despite the fact that more weight is put on research output rather than the quality of teaching by most of the rankings. This is due to the fact that research performance can be easily ascertained from international data sources without subjective measures having to be undertaken.

Since educational quality encompasses all three primary functions of higher educational institutions: teaching, research, and community service, KAU has strived for excellence in all three functions. In addition to seeking to be placed in the ranking tables, KAU has also made great efforts to obtain accreditations for all of its academic programs. This is an important stage on the pathway we have elected to follow for the establishment of a world-class university.

\section{Strategies to Achieve World-Class Status}

World-class university status entails certain essential defining characteristics to be in place. These are a high concentration of talent, plentiful resources, and policies designed to encourage the pursuit of academic and educational excellence. 
KAU is a state university and receives abundant budgetary resources and favorable care from the Ministry of Education in Saudi Arabia. The higher administration of KAU has worked with dedication to utilize its available budget to acquire the academic talents commensurate with its bid for excellence. Unlike other excellence programs of universities, such as the German Excellence Initiative, which mainly focuses on excellence in research, KAU has sought to improve quality of all aspects of its higher education encompassing teaching and research. World-class universities play a critical role within the higher educational system in training the professionals, scientists, and researchers required for economic development and for the generation of new knowledge in support of national growth and innovative progress.

KAU's success to date in this regard has been achieved due to unstinting and generous support from the government of the Kingdom, and in particular from the Ministry of Education, which has an ambitious strategic plan for the future of the country's higher educational sector. This support is crucial for a world-class institution. Additionally, KAU has abundant resources which are necessary to maintain a thriving university. Furthermore, KAU has a concentration of talent, a dynamic leadership team, appropriate financial resources and incentives, and a modern and suitable technological infrastructure. The successful combination of these elements has been of critical importance in the creation of the academic and educational environment that has proved so conducive to KAU's progress.

\section{Infrastructure}

The foundation for the venture toward international recognition and world-class academic status was the establishment of a campus with an excellent and appropriate infrastructure. Great care was attached to the design and construction of facilities to provide the required infrastructural environment to facilitate creation of academic and educational excellence. This is certainly crucial for both students and researchers. Adequate state-of-the-art laboratories are essential for the production of scientific work of a high academic caliber. Although all existing KAU faculties are of a high standard, new buildings are currently under construction for many faculties in order to modernize the infrastructure. Some faculties have already moved to their new locations, which are equipped with state-of-the-art facilities, while other faculties are preparing to do so.

Since innovative pedagogy requires appropriate facilities, KAU is ensuring the provision of facilities for active learning, problem- and project-based learning, and teamwork and peer learning, in addition to conventional lecture halls and classrooms. Computer laboratories and facilities are being made available throughout the university. 


\section{Accreditations}

KAU outlined its academically and educationally ambitious forward-looking vision and mission for the future with an established set of objectives based on encompassing, underlying, and deep-seated traditions. KAU has striven to ensure that its academic operations, including curriculum design and development, are tailored to achieve a substantial completion percentage of its strategic plans. The university recognizes that well-designed curricula (in line with the vision, mission, and objectives), along with highly qualified academics, constitute the cornerstone of higher education [19].

Although KAU curricula are of internationally recognized educational and academic standards, they are not imported from foreign universities. KAU undertakes the lengthy process of designing and reviewing its own curricula because it is recognized that this process contributes toward the goal of creating the academic culture required for the achievement of standards of educational and academic excellence. This process assists curriculum designers to also focus on catering for the competencies and skills requirements of the local employment market and that of the Kingdom of Saudi Arabia.

In order to ensure the establishment of an academically and educationally rigorous culture, KAU has ambitiously been expanding quantitative targets. Some fifty years ago, KAU began with a small number of programs and students, whereas currently it has more than 200 undergraduate programs, and approximately 190 graduate programs, all enhanced and supported with high-quality teaching and research. This has been accomplished over time with stable leadership, continuous development, and persistence in the pursuit of academic and educational excellence, that has led to the creation of the vigorous scientific traditions required for the production of cutting-edge research and for the judicious and effective application of educational technology.

The university has witnessed significant development on many fronts and has succeeded in achieving successful academic accreditations for the majority of its academic programs from internationally recognized academic accreditation bodies. This development is a result of carefully staged planning and process management. The first KAU Faculty to obtain accreditation was the Faculty of Engineering. The Accreditation Board for Engineering and Technology (ABET) has to date accredited the 12 Engineering programs on two occasions, 2002 and 2008. Currently the Faculty of Engineering is preparing for its third re-accreditation.

The National Commission for Academic Accreditation and Assessment (NCAAA) has been established by the Higher Council of Education as an independent authority with responsibility for accreditation and quality assurance in post-secondary education in the Kingdom of Saudi Arabia. Its mission is to encourage, support, and evaluate the quality of post-secondary institutions and the programs they offer to ensure that the quality of student learning outcomes, the management and support services provided within institutions, and the 
contributions to research and the communities served by post-secondary institutions are consistent with, and equal to, internationally accepted higher educational standards.

The Commission is recognized within Saudi Arabia and internationally for the quality and effectiveness of its contributions to continuing improvement in the quality of post-secondary education in the Kingdom of Saudi Arabia. Currently all KAU programs are required to achieve successful NCAAA accreditation prior to seeking accreditation from international bodies.

\section{Admitting Academically Gifted and Able Students}

KAU planned to create its own human resource pool from the early stages of its development. All admitted graduates and undergraduates are selected from academically elite student applicants. One admission condition is that successful applicants have high scores in the examinations of the National Center for Assessment in Higher Education. These Saudi National Matriculation Tests are required by most Saudi universities for the admission of new students. However, the universities' admission requirements differ in terms of score levels required.

KAU has adopted the Preparatory Year scheme in which all students study compulsory courses to prepare them for university academic life and their selected major study fields. There are two streams in this year, one for science students and one for arts and humanities students. Students who demonstrate a lack of required levels of academic ability during this year usually leave the university or transfer to Community Colleges that provide short-cycle degrees (Diplomas and Professional Certificates), or to Vocational Technical Education Colleges.

\section{Scholarships Program for Academically High Performing Graduates}

In the initial phase of its development, KAU hired primarily foreign academics, which was necessary at that time to assist in the acceleration of its launch by utilizing the expertise of experienced teachers and researchers. The foreign academics at KAU at that time were also instrumental in the training of young national academics. Currently, in excess of $60 \%$ of KAU academics are Saudi nationals.

KAU selects the highest achievers academically from its graduates in all disciplines to offer them scholarships to pursue graduate studies abroad for Master's and Doctoral degrees in top ranked world-class universities to prepare them to return to KAU and become KAU academic staff members. By so doing KAU guarantees future highly qualified academic staff members and acquires in-depth awareness of their academic profiles. 
Almost $50 \%$ of the scholarships are to USA top ranked universities, while approximately $25 \%$ are to UK top ranked universities. The remaining scholarships are to Canada, Australia, and Europe. This is shown in Fig. 1.

The number of scholarships has increased annually as shown in Fig. 2. Scholarships are for both male and female graduates (in an approximately 50-50 ratio).

There are some female students who are not able to travel abroad for full time study due to family circumstances. To ensure that these students are enabled to attain their full academic potential, KAU has signed agreements with a number of top ranked British universities to allow them to study at home under a joint supervision program. Each student is assigned a supervisor at the British university and a supervisor at KAU. There are regular supervisor exchanges and meetings including the involved students to solve any issues and problems, while continuous email

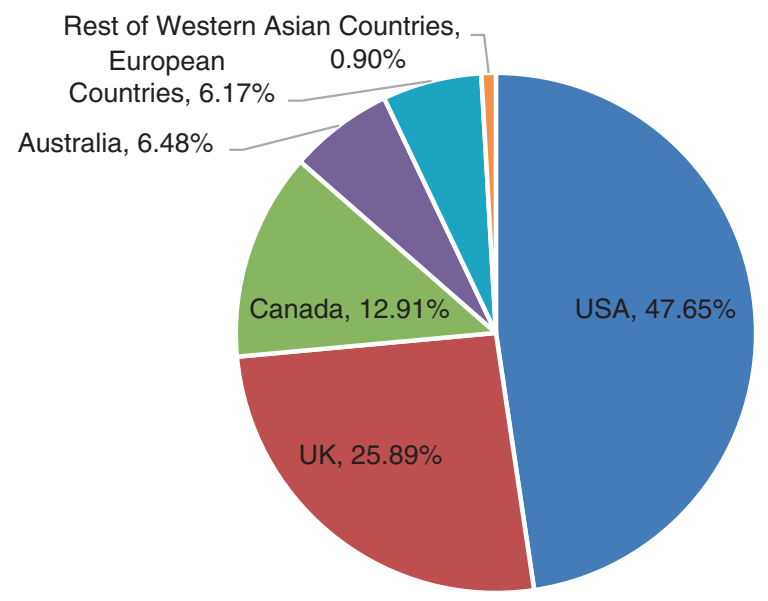

Fig. 1 Percentage of scholarships to top ranked universities

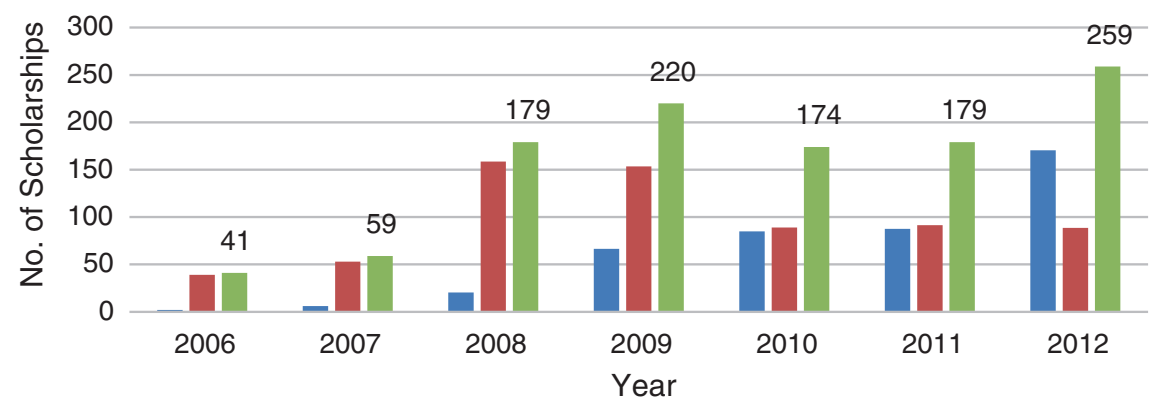

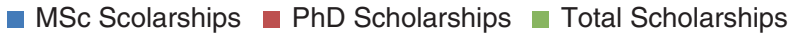

Fig. 2 Number of scholarships between 2006 and 2012 


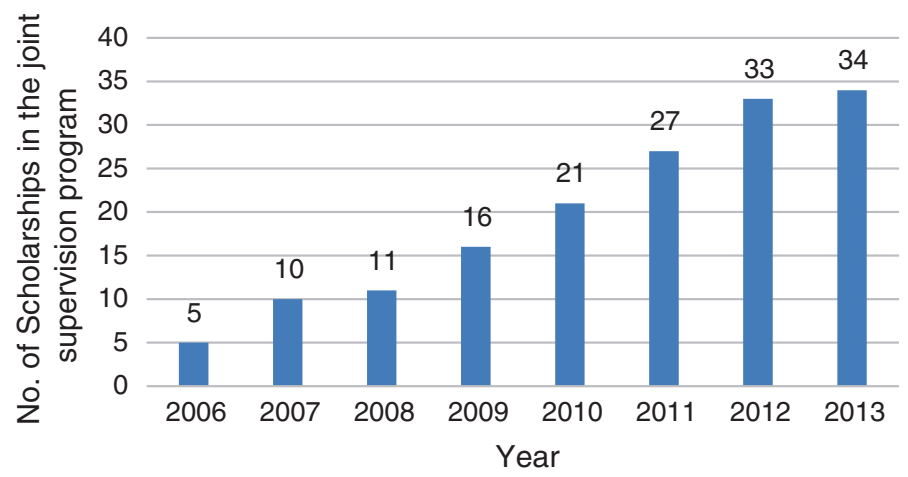

Fig. 3 Number of scholarships in the joint supervision program

contact is maintained throughout the year. Figure 3 shows the number of female students in this joint supervision program.

\section{Graduate Studies Programs}

Graduate students are in the front line of scientific research. This is the reason KAU started its graduate programs so soon after its foundation. Currently, KAU has 190 graduate programs in all of its specializations, $22 \%$ of which are $\mathrm{PhD}$ programs, while the remainder are Master's programs. The total number of students in these programs is 7260 graduate students (male and female), including foreign students. The international graduate students program started five years ago and is successfully attracting students from different countries. KAU grants scholarships to top international students to pursue their studies in various university graduate programs.

For graduate courses, the total number of new entrants has significantly increased, and this growth has necessitated strengthening and invigorating all aspects of higher educational academic research at the university. This has helped to ensure that when KAU graduates enter the employment market their competencies and qualifications are sought after and welcomed by local and national employers.

KAU has become the recognized national venue for "elite higher education". It has a reputation for academic excellence and is considered to represent quality higher education in keeping with the requirements of the nation and society's rapid economic development. These factors enable KAU to have the privilege of receiving high levels of funding and to recruit the most academically talented students.

Figure 4 shows the increase in numbers of those who were awarded Master's or $\mathrm{PhD}$ degrees on completion of KAU graduate programs. 


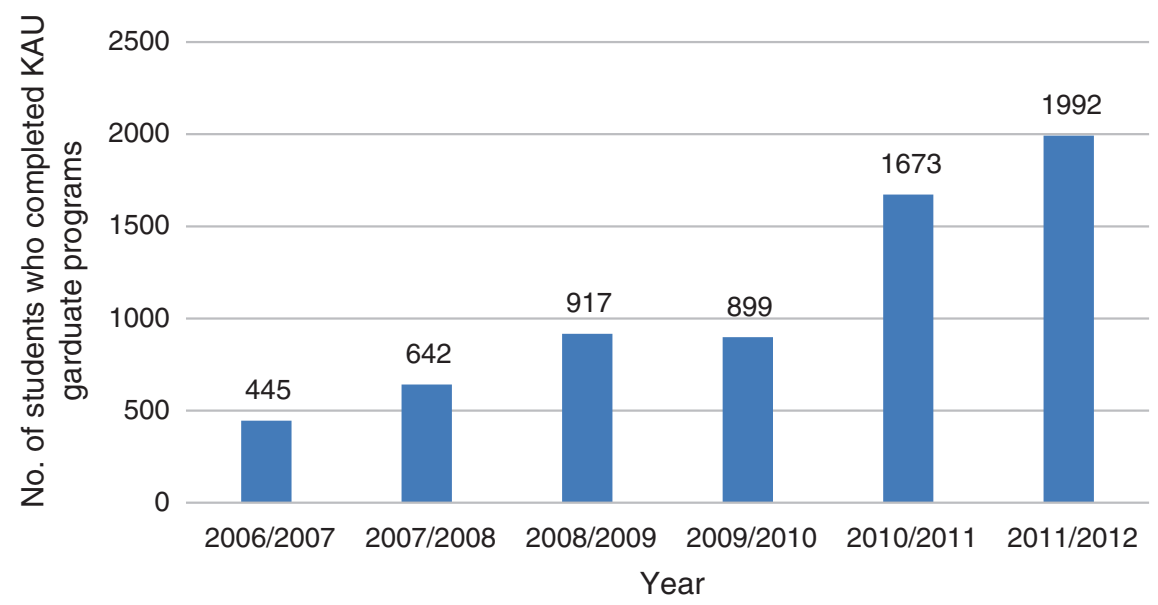

Fig. 4 Numbers of those who were awarded Master's or PhD degrees

\section{KAU Research Prizes}

KAU has always encouraged its academic staff by all possible means. One such means of encouragement are research prizes. The latest list of research prizes includes:

- Prize for publishing papers in "Nature" and "Science";

- Prize for publishing in ISI ranked journals;

- Prize for publishing in ranked human sciences journals;

- Best Researcher Prize;

- Best Student Researcher Prize;

- Distinguished Scientist Prize;

- Citation Prize;

- Prize for Winners of International Prizes;

- Best College in Research Prize;

- Patent Prize;

- Translation Prize.

The amounts awarded vary, but can be as much as SR 150,000 (US\$ 40,000) for publishing in "Nature" and "Science". In excess of 800 prizes are awarded annually.

\section{Encouraging Conference Attendance by Academic Staff}

Conferences are venues for the exchange of knowledge and experience. KAU encourage its academic staff to attend international conferences to enable them to meet with prominent scientists and witness presentations of the results of the 
latest research. Several hundred academic staff members are sponsored annually to participate in international conferences, to present academic research papers, and to network with international scholars. In many cases, ongoing and mutually beneficial collaboration between KAU scientists and others emerge from these events. KAU's encouragement of its academic staff's participation in such events has resulted in the name of KAU being widely recognized and acknowledged by the international scientific community. This recognition and acknowledgement has resulted in many members of this community showing willingness to cooperate and work on joint research projects with KAU.

\section{Scientific Research Funding}

One important factor that affects the dissemination of the culture of scientific research among academic staff is the availability of funds enabling academic concepts and ideas to be explored, investigated, and realized through conducting research. A prime factor in ensuring funding is that would-be researchers are required to provide substantive evidence that proposed work is eligible for publishing in ranked ISI journals or their academic status equivalents.

Several hundred research projects are funded every year under different schemes. In addition, KAU acts as a mediator between its scholars and other organizations which provide funds for scientific research, such as King Abdulaziz City for Science and Technology, King Abdullah City for Atomic and Renewable Energy, and SABIC Company. These bodies support approximately one hundred KAU research projects annually. This policy, in conjunction with the prize policy, has resulted in a dramatic increase in the volume of publications and citations of KAU in ranked ISI journals. Figure 5 shows the increase in KAU publications and citations for the last fifteen years.
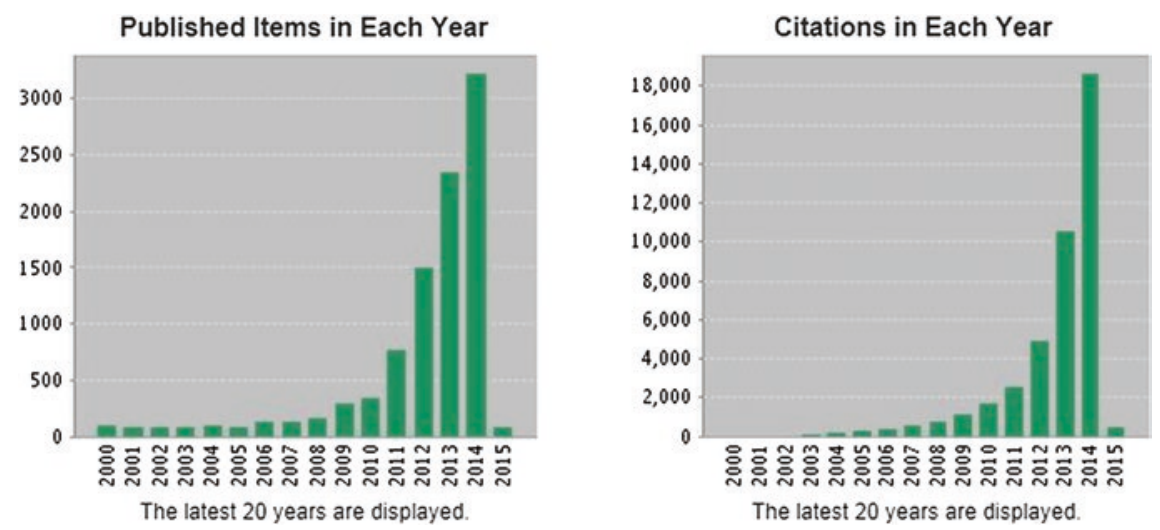

Fig. 5 KAU published papers and citations in ISI ranked journals 


\section{Research Groups}

KAU initiated the idea of forming research groups to enhance cooperation between researchers from different specializations. Each group consists of up to 15 researchers under the leadership of one prominent scientist. It includes one adjunct professor and academics of all ranks including fresh academics and graduate students. Each research group has a main broad specialization that is different from the specializations of other groups. The research proposals submitted by research groups are prioritized in terms of funding over proposals submitted by individuals. To date, 45 research groups have been formed covering a wide spectrum of specializations including: the Diabetes Research Group; the Oral and Dental Diseases Research Group; the Renewable Energy Group; the Software Engineering and Distributed Systems Group; the Economic and Market Research Group; the Nonlinear Analysis and Applied Mathematics Group and the Biotechnology Group.

In addition to publishing papers in ISI ranked journals, the research groups are requested to work on projects that benefit the local Saudi community and wider society.

\section{Patents Unit}

To encourage scholars to patent their scientific results, KAU has established a unit which is assigned the task of assisting scientists with the paperwork and procedures required for patent registration. The unit conducts patent documentations and pays all required fees. The unit also handles all legal issues relating to patent registration.

Scholars endeavoring to secure patent registration are required to sign contracts with KAU, whereupon KAU has the right to share with the scholars subsequent benefits stemming from the patent. To date, KAU originating patents have been registered in the USA, the UK, Europe, Japan, and the Kingdom of Saudi Arabia.

\section{Scientific and Academic Chairs}

A Chair is an academic honor bestowed on scientists in recognition of achievements in their field of study or their potential to contribute to an area of study. The chairs are funded by individuals, companies, or organizations to enhance the excellence and high caliber of research in certain areas.

All scientific chairs at KAU are endowed chairs. They are intended to enhance the recruitment, retention, and support of outstanding individuals working to advance the strategic interests of KAU by enhancing knowledge in a particular 
discipline or field. Endowed chairs at KAU are responsible for leading research and academic activities in a variety of disciplines throughout the university and have made significant contributions to the academic and research community.

The KAU Research Chairs Program is part of the university's strategy to become a distinguished research and development university by attracting and retaining some of the most accomplished and promising academically talented individuals. Candidates for the Research Chairs are nominated by KAU higher administration and are required to be of full professor status.

KAU is now home to approximately 30 scientific chairs, and the number is increasing annually. Current chairs include: the Prince Naif Chair for Moral Values, the SABIC Chair in Heterogeneous Catalysts, the Al-Amoudi Chair for Diabetic Foot Research, the ARAMCO Non-Destructive Testing Chair, and the Bin Zoma Group Chair for Bottled Water Research.

\section{The International Advisory Board}

One of the steps toward achieving world-class university status that KAU has taken is the formation of its International Advisory Board (IAB). The goals of the $\mathrm{IAB}$ are to review, evaluate, and introduce innovative ideas and analysis drawn from the experience and expertise of international academic and industrial authorities in order to assist KAU in the enhancement of its academic and educational status. IAB members are prominent university presidents and other luminaries associated with the employment market. Meetings are biannual and involve brainstorming sessions where discussions are held concerning significant matters related to KAU. Time is also devoted by IAB members at home to prepare advice on KAU issues. Some sessions are to meet with professors, students, and top KAU management to acquire hands-on experience of the facts on the ground at the university. Topics that have been discussed to date in IAB meetings include internationalization, strategies to boost and enhance scientific research, creativity and innovation, sustaining excellence in teaching and learning, and other macro issues. The first meeting of the IAB was devoted to providing information on KAU and its Strategic Plan while the subsequent meetings were for in-depth discussion on the aforementioned issues. The majority of the outcome ideas of the IAB are implemented as they are recognized as representing current best practice approaches from distinguished and acclaimed international authorities and institutions.

\section{Distinguished Scientists Program}

The second meeting of KAU International Advisory Board (IAB), which was dedicated to identify suitable ways of upgrading the university's scientific research, stressed the necessity of utilizing distinguished scholars to support and enrich the 
university's scientific research. Consequently, KAU began the process of attracting a number of eminent scholars, widely cited by other researchers, in line with the IAB's recommendations.

In compliance with IAB advice which aims to strengthen KAU academics' and graduate students' competencies, to create closer academic contact with qualified outside scholars and researchers, and to help transfer the experiences and expertise of international scholars and researchers, KAU is currently collaborating with some 60 international distinguished scientists. This program has produced fruitful results including:

- the promotion of scientific research;

- the exchange of ideas between local and international researchers;

- the issuance of world-class scientific journals;

- the provision of a supportive academic environment conducive to motivating innovation;

- promotion and encouragement of excellence, invention, and talents;

- the encouragement support and upgrading of scientific research, particularly applied scientific research intended for service to, and the development of, the local community and Saudi society.

\section{Endowment}

Several years ago, KAU announced an exceedingly generous "Research Endowment Fund" with the intention of ensuring the sustainability of its scientific research.

Endowment played a memorable role in the history of Islamic civilization. Endowment was the basis of the historical Islamic Scientific Renaissance. It provided a stable environment for scientists and science students and ensured sustainable resources which allowed Islamic scholars a degree of freedom of research and enabled them to dedicate time to scientific output. The result was a rich heritage of knowledge in various fields stemming from the renaissance.

KAU decided to revive this important role of financing Islamic civilizationconstructive projects, particularly concerning scientific research and technological development.

\section{Research Centers}

The creation of capacity for research excellence is a critical strategy driven by national governments. Research universities are central to the quest for world-class university status. Research missions are also integral to representing and achieving value for money concerning all aspects of research. 
KAU has established several independent research centers to provide graduate education, conduct increasing fundamental research crossover in all major subjects, and attract additional qualified academic staff to participate in the global knowledge market. In order to enhance the international status and visible profile of its research capacity, KAU has placed great efforts on intensifying research missions in research centers, including enlarging the scale of graduate education, increasing funding, and creating foundations for the promotion of research projects.

Research centers form an integral part of the academic system of KAU, where all academic staff who desire to work in research are brought together to create a cross-disciplinary research environment for knowledge development. The King Fahd Center for Medical Research, the Center of Nanotechnology, and the Water Research Center are examples of currently available research centers.

Some of the research centers are classified as Centers of Excellence and hence receive direct budgets from the Ministry of Education. These centers are unique in the Kingdom. They are required to offer their facilities as platforms and venues for researchers from all the Kingdom's universities. The Center of Excellence of Genomic Medicine Research, the Center of Excellence in Environmental Studies, and the Center of Excellence for Osteoporosis Research are examples of KAU Centers of Excellence.

\section{5 and Beyond}

During 2014, KAU was working on its 3rd Strategic Plan (2015-2019). It was presented to the IAB in its 7th meeting that was held in November 2014, and valuable comments were obtained. Figure 6 shows the differences between the various strategic plans of KAU. The 1st Strategic Plan (2005-2009) was to place KAU in an advanced position. The 2nd Strategic Plan (2009-2014) was to place KAU in a pioneering position, and the 3rd Strategic Plan (2015-2019) is intended to position $\mathrm{KAU}$ as an internationally recognized higher educational and academic benchmark of excellence. More details are shown in Fig. 7. Overall, the 1st Strategic Plan worked in breadth, the 2nd Strategic Plan worked in depth, while the 3rd Strategic Plan is to work 'in focus' toward achievement of internationally recognized World-Class University status and ranking. 


\section{The Philosophy Behind KAU Strategic Plans}

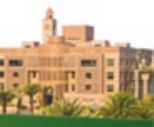

- Each strategic plan was established to accomplish a certain theme

- Each theme represents one step ahead

- Each step represents strategic scope of work

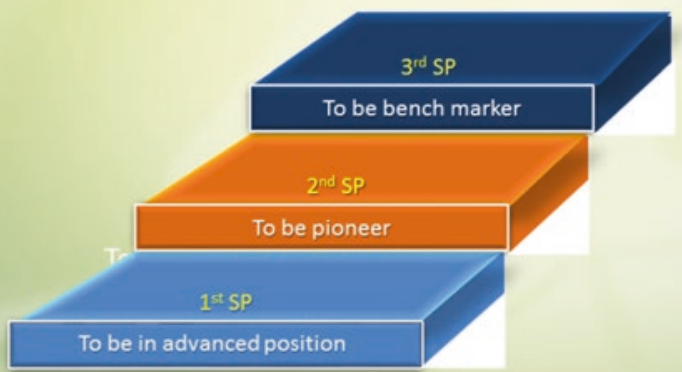

Fig. 6 The philosophy behind KAU strategic plans

\section{The Philosophy Behind KAU Strategic Plans}

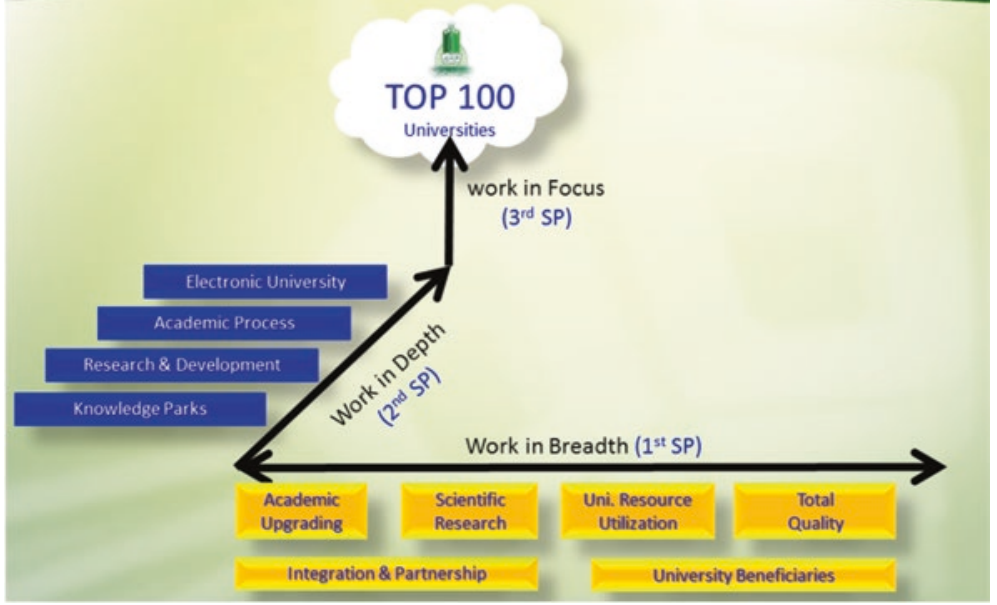

Fig. 7 The scope of each KAU strategic plan 


\section{Conclusion}

In conclusion, KAU sought to achieve the highest possible standards in academic excellence in order to build a world-class university. This is in alignment with the Kingdom of Saudi Arabia's national higher education strategy. It is concluded that with realistic planning it is possible to achieve the worthy and vital objective of academic and educational world-class excellence in higher education.

The process of construction of the steps of building a world-class university in order to increase its international profile's visibility and its ability to compete educationally and academically in the global academic arena needs to be accelerated. KAU has identified and implemented appropriate strategies in order to improve educational and academic quality and achieve world-class university status. Achievement of this status inevitably involves an improvement in the overall quality in higher education. Well-oriented development plans have been adopted to enhance the current position of KAU in the different ranking systems. Other factors have equal importance, including quality improvement, research centers' development, and the critical factor of quality assurance.

Funding is recognized as a crucial factor for preparing to create a world-class university. Public funding from the governmental budget is integral to the operation of higher educational institutions in Saudi Arabia. Due to the size of its learning community, instructional and research capacity, and infrastructural facilities, KAU is inevitably more expensive to manage and requires more resources and funds to maintain than are required by some other universities in the Kingdom. However, it is an eminently worthwhile investment for the Ministry of Education to fund KAU's quest to achieve world-class university status, as allocated funds are carefully, scientifically, and accurately directed by concerned researchers and authorities. This careful and precise utilization of financial resources in conjunction with all the factors previously outlined ensures a high probability of achievement of the desired and expected results. The results of these efforts will ensure that KAU satisfies the criteria for world-class university status by the achievement of genuine and credible internationally recognized higher academic and educational excellence and the creation of a university offering a fully comprehensive range of undergraduate and graduate programs. These concerted and focused efforts represent a concentrated and carefully directed investment in Saudi human resources, which without doubt, will enrich the local community and Saudi society.

The continuous gracious and generous support received from the Government of Saudi Arabia has been of crucial importance in the transformation of King Abdulaziz University to a modern university of internationally recognized educational and academic standing. In recent years, the university has received concrete evidence of its emerging and improving internationally recognized academic and educational status. KAU has been placed among the top 400 universities of the world, in the three major international university ranking lists: the Academic Ranking of World Universities (ARWA), the Times Higher Education ranking, and QS ranking. 
Open Access This chapter is distributed under the terms of the Creative Commons Attribution Noncommercial License, which permits any noncommercial use, distribution, and reproduction in any medium, provided the original author(s) and source are credited.

\section{References}

1. The European Association of International Education (EAIE), http://www.eaie.org/ home.html

2. Universities Canada, http://www.univcan.ca

3. Teichler, U. (2010). The challenges of almost universal higher education. In Organizing Committee of Sino Finnish Higher Education Symposium (Ed.), The Challenges and Experience in the Post Massification Era (pp. 10-19). Beijing.

4. Teichler, U. (2007). Changing views in europe about diversification of higher education. In U. Teichler (Ed.), Higher Education Systems: Conceptual Frameworks, Comparative Perspectives, Empirical Findings (pp. 107-117). Rotterdam/Taipei: Sense Publishers.

5. Salmi, J. (2009). The challenge of establishing world-class universities. Washington, DC: World Bank Publications.

6. Ministry of Education of the People's Republic of China. (2010). Education statistics 2009: Higher education. Retrieved from http://www.moe.edu.cn/publicfiles/business/htmlfiles/moe/ s4960/index.html

7. Liu, S. X., \& Liu, N. C. (2005). Classification of Chinese higher education institutions. Journal of Higher Education, 26(7), 40-44.

8. MüllerBöling, D., \& Federkeil, G. (2007). The CHE ranking of German, Swiss and Austrian universities. In J. Sadlak \& N. C. Liu (Eds.), The world-class university and ranking: Aiming beyond status (pp. 189-203). Bucharest: UNESCO-CEPES.

9. Ritzen, J. (2010). A CHANCE FOR EUROPEAN UNIVERSITIES. Amsterdam University Press.

10. Ma, W. (2007). The flagship university and China's economic reform. In P. G. Altbach \& J. Balán (Eds.), World class worldwide: Transforming research universities in Asia and Latin America (pp. 31-53). Baltimore, MD: The Johns Hopkins University Press.

11. Harvey, L. (2006). Understanding quality. In E. Froment, J. Kohler, L. Purser, \& L. Wilson (Eds.), EUA Bologna Handbook: Making Bologna Work. B 4.1-1, (pp. 1-29). Berlin: Raabe Academic.

12. Harvey, L., \& Green, D. (1993). Defining Quality. Assessment \& Evaluation in Higher Education, 18(1), 9-34.

13. Harvey, L. \& Newton, J. (2007). Transforming quality evaluation: Moving on. In D. F. Westerheijden, B. Stensaker, B. \& M. J. Rosa (Eds.), Quality assurance in higher education: Trends in regulation, translation and transformation. (pp. 225-245). Dordrecht: Springer.

14. Hazelkorn, E. (2008). The emperor has no clothes? Rankings and the shift from quality assurance to the pursuit of world-class excellence. In L. Bollaert, B. Carapinha, B. Curvale, L. Harvey, E. Helle, H. T. Jensen, T. Loukkola, et al. (Eds.), Trends in quality assurance: A selection of papers from the 3rd European quality assurance forum (pp. 10-18). Brussels: European University Association.

15. Kohler, J. (2009). Quality in higher education. In J. Sadlak, K. Hüfner, R. Pricopie, \& L. Grünberg (Eds.), Topical contributions and outcomes: UNESCO forum on higher education in the Europe region: Access, values, quality and competitiveness (pp. 175-278). Bucharest: UNESCO-CEPES.

16. ARWU Ranking. Retrieved from http://www.shanghairanking.com 
17. Times Higher Education World University Rankings. Retrieved from http://www. timeshighereducation.co.uk

18. QS Ranking. Retrieved from http://www.topuniversities.com

19. Vlãsceanu, L., Grünberg, L., \& Pârlea, D. (2004). Quality assurance and accreditation: A glossary of basic terms and definitions. Bucharest: UNESCO-CEPES. 


\title{
International Advisory Boards in the World
}

\author{
Adnan Zahed
}

\section{Introduction}

Many scientific institutions and major industrial organizations, in their keenness to benefit from the experience of internationally prestigious advisory and consultative bodies, draw up long and short-term plans for their formation. These advisory and consultative bodies comprise of elite and authoritative groups of scientific, industrial, and administrative experts. The assistance of such bodies is sought to support educational institutions' efforts to achieve quality enhancements and improvements of such credibility as to be worthy of international recognition [1-3]. Advisory boards are not, and are not intended to be, substitutes for statutory boards of directors, which are responsible for internal operational planning and implementation within the concerned institutions. Indeed, if properly constituted, advisory boards are intended to complement and strengthen existing executive boards, by offering advice and guidance to aid them in the successful performance of their tasks. Advisory boards' targets and the criteria for board members' selection have to be clearly enunciated from the very beginning, in order for maximum benefit to be obtained from such boards by concerned institutions.

The motive for following this strategy could be to ensure that concerned educational institutions receive expert advice on new high technology and scientific advances, or to enable them to gain insight into conducting business in diverse global markets. This chapter provides an overview of International Advisory Boards (IABs), consulted by a sample of universities and major organizations in the world. We have outlined the definition, objectives, composition, and meeting schedules of the IABs in such institutions and organizations.

The following section covers the definition, objectives, and function of the International Advisory Board at King Abdulaziz University. It also provides examples of other distinguished universities and organizations globally, that have established international advisory bodies.

\footnotetext{
A. Zahed $(\square)$

King Abdulaziz University, Jeddah, Saudi Arabia e-mail: azahed@kau.edu.sa 


\section{International Advisory Board Definition}

IABs, or International Advisory Councils (IACs), are "international consultative bodies purposely created with the intention that the experience, deliberations and ideas of their members are able to be utilized, so as to make substantive contributions to various fields of development" [4]. IABs and IACs do not have decisionmaking powers, but attempt to inform higher administrative teams or university councils on strategic matters and imperatives, and provide expert consultative mechanisms.

\section{Who Should Serve on an International Advisory Board or International Advisory Council?}

For brevity's sake in the present context, the terms 'board' or 'advisory board' are subsequently used predominately and refer to either IABs or IACs.

The composition of an advisory board should be based on an organization's goals and priorities. Hence, a board intended to provide an institution with advice on higher educational planning is likely to differ significantly from one formed in order to offer insight into the latest medical or engineering research [1].

Any such advisory board membership composition is entirely dependent on its intended role and on its aims being affirmed with absolute clarity. Is it intended to be a business development tool aiming to raise an institute's or organization's profile and initiate appropriate commercial introductions, or is the intention to increase the main executive board's knowledge base and understanding of specialist issues? Overall, the board's objective will determine its composition [1], and a judicious combination of experience and knowledge can help enhance its performance. Therefore, most advisory board members have experience gained from a wide range of higher educational institutions, research bodies, commercial and industrial sectors, and functional disciplines.

\section{IAB/IAC Functions}

The main functions of IABs/IACs include [2-4]:

- Providing independent external advice, through board meetings and engagement with projects and new initiatives.

- Assisting in developing corporate and institutional relationships at the national and international level.

- Assisting in building and delivering cases for institutional change as and when perceived and required. 
- Helping to increase contributions of practitioners into research, learning, and teaching, including creating and maintaining direct contact with institutions' academic staff and students.

- Transferring world-class international universities' and companies' accumulated expertise to the concerned local organizations in matters of education, research, technology transfer, international cooperation, marketing, and other relevant issues.

- Enhancing the level of international cooperation between concerned local universities and distinguished world-class universities.

- Advising on the overall strategy and direction of institutions, particularly in terms of research and education, and on improving their external profiles, and advising on appropriate responses to other related issues, as and when they arise.

- Providing informed viewpoints in the evaluation concerning the educational aspects of entrepreneurial programs, and on effective collaboration with the business sector.

- Assisting and guiding universities to achieve their visions of academic excellence and service to community.

\section{Examples of International Advisory Boards/Councils}

As previously mentioned, many institutions and companies decide to create advisory boards when it is apparent that there is a subject area where experts can positively reinforce the knowledge, understanding, and strategic thinking of boards and management teams. Experienced advisory board members can provide specialist advice and extend the range of skills and understanding of management teams in areas outside of their day-to-day fields of expertise. In the following section are some examples of universities and associations that have established advisory boards to positively impact their efforts toward the achievement of their missions and goals.

The following section is intended to provide an in-depth understanding of King Abdulaziz University's International Advisory Board (IAB), its objectives, and the criteria applied in its membership selection. It also enumerates the last seven meetings' topics and themes [2, 5-12].

\section{International Advisory Board of King Abdulaziz University (KAU), Saudi Arabia}

\subsection{Introduction}

King Abdulaziz University (KAU) is a distinguished educational institution in the Middle East that has undertaken substantial transformational steps to establish partnerships and cooperative programs with national and international educational and industrial institutions in order to enhance and improve its academic 
and educational profile and status. In pursuit of achieving a substantive leap forward of quality in levels of performance in education, academic research, and community services, KAU created an IAB in 2010. It was constituted to enable $\mathrm{KAU}$ to benefit from the experience of internationally acclaimed intellectual pioneers in industry and higher education who have made significant contributions to the development of higher education world-wide. The KAU President, Osama Tayeb, states, "This board will represent a major driving force that will guide KAU towards consolidating the cohesion and consistency of all its subsystems for optimum performance" [6].

The aim of the advisory board is to ensure the university leadership's ready access to diverse input and ideas from the international academic and business communities during scheduled consultations. It is intended that this input, advice, and guidance will assist and support KAU in its quest for academic and educational excellence and international recognition.

To ensure that we receive a diversity of perspectives of ideas and views, the advisory board represents, not only a variety of disciplines, but also an extensive range of cultural backgrounds. KAU's IAB meetings are held in diverse countries in order to further underscore the goal of achieving a truly global view and spirit.

\subsection{IAB Objectives}

- To participate in reformulating KAU's strategic objectives, priorities, procedures, and performance tracks in order to facilitate the achievement of its goals in the educational process, scientific research, and community service.

- To capitalize on the board members' knowledge, intellect, experience, and authority in supporting KAU's fields, opportunities, and domains to enable the university to excel and attain distinction in achievements in knowledge, science, and technology.

- To enhance the university's status and international profile through its achievements, especially, in the fields of research and innovation.

- To contribute to the formation of strategic alliances between the university and service sectors, productive establishments in the local community, and international industrial companies and scientific knowledge institutions.

- To establish and activate partnerships with international universities and research centers.

- To deliver consultation and advice with respect to the topics studied by the board.

- To provide technical, academic, and administrative consultancy to KAU as well as to other national institutions wishing to take advantage of the expertise, experience, and qualifications of the board's members. 


\subsection{IAB Members}

KAU has carefully selected the IAB members to include an array of eminent authoritative figures from industry and higher education and other fields, who are renowned for their achievements and internationally recognized contributions in their respective fields.

The IAB has 18 members, initially appointed for two years, and who may be reappointed for second and third terms for up to six consecutive years of service. The initial search for suitable members lasted over two years. The IAB's first membership included presidents of international universities, namely; Ohio State University, USA; Maastricht University, The Netherlands; University of Vienna, Austria; University of Helsinki, Finland; University of Copenhagen, Denmark; Nanyang Technological University (NTU), Singapore; IE University, Spain; Bilkent University, Turkey; Fudan University, China; and Nagoya University, Japan. In addition, there were two prominent academics, namely: the Dean of Harvard School of Public Health (USA) and the Founder and Chairman of the Institute of Plant Biotechnology for Developing Countries. International professional associations were represented by the President of the European Medical Association and the Executive Director of the Council for International Exchange of Scholars. The international employment market was represented by the President and Executive Officer of Hitachi Company, Japan, and the President and Chief Executive Officer of Nissan Motor Company, Japan. The local employment market was represented by the President and Chief Executive Officer of Al-Amoudi Group and the Founder and Chief Executive Officer of Gulf One Investment Bank. The KAU President is the IAB Chairman, while the Secretary-General is the KAU VicePresident for Graduate Studies and Scientific Research [5, 8-12].

Figures 1, 2 and 3 show the IAB members during three different meetings at different venues: King Abdulaziz University in Jeddah, Vienna University, Austria, and IE University in Spain.

The IAB held its first meeting on the King Abdulaziz University premises on the 29th and 30th of January, 2011, providing an opportunity for the members to acquaint themselves with the university facilities, academic programs, and activities. This meeting was the starting point on the ambitious journey intended to take the university toward the realization of KAU's objective of earning and securing its place among the world's most distinguished international universities.

KAU provides commensurate remuneration, flight tickets, and accommodation to IAB board members for board meetings.

\subsection{IAB Meetings}

IAB meetings are held biannually. One meeting is held on KAU's home campus in Jeddah, Saudi Arabia, while the other is held at an international location on the university campus of a board member based outside the Kingdom. Each meeting 


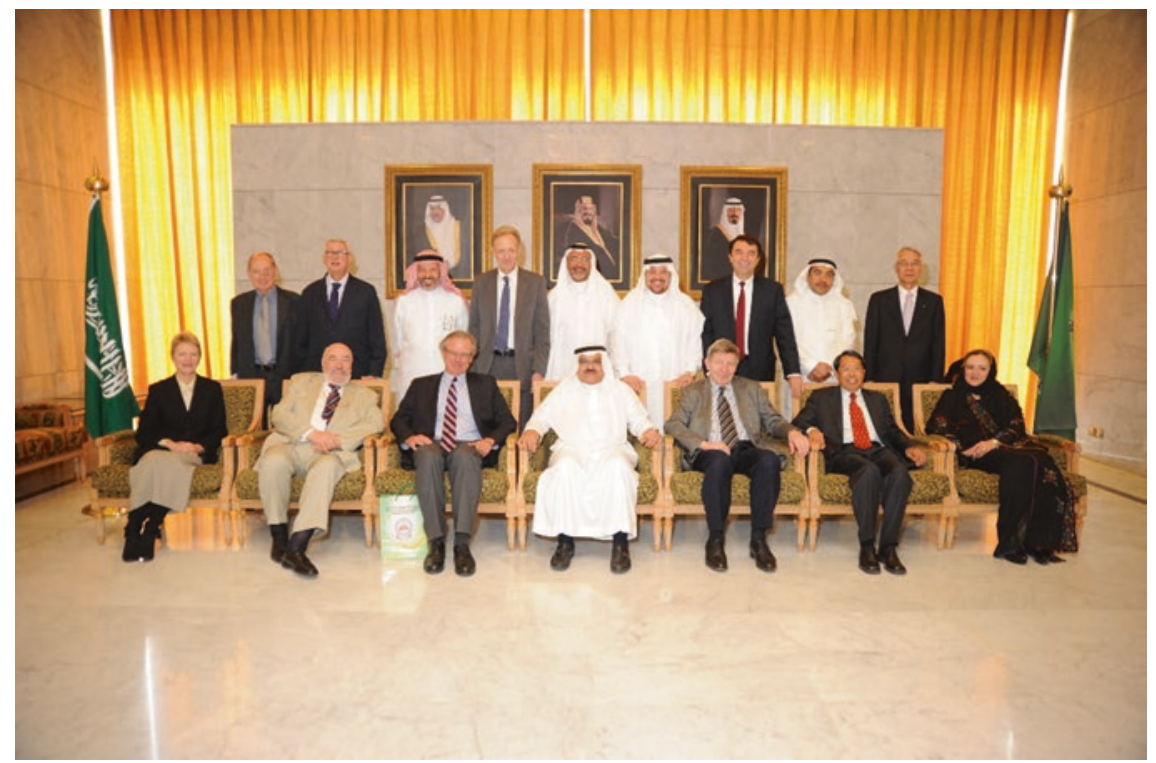

Fig. 1 IAB first meeting at King Abdulaziz University, Jeddah, KSA

Fig. 2 IAB second meeting at Vienna University, Austria

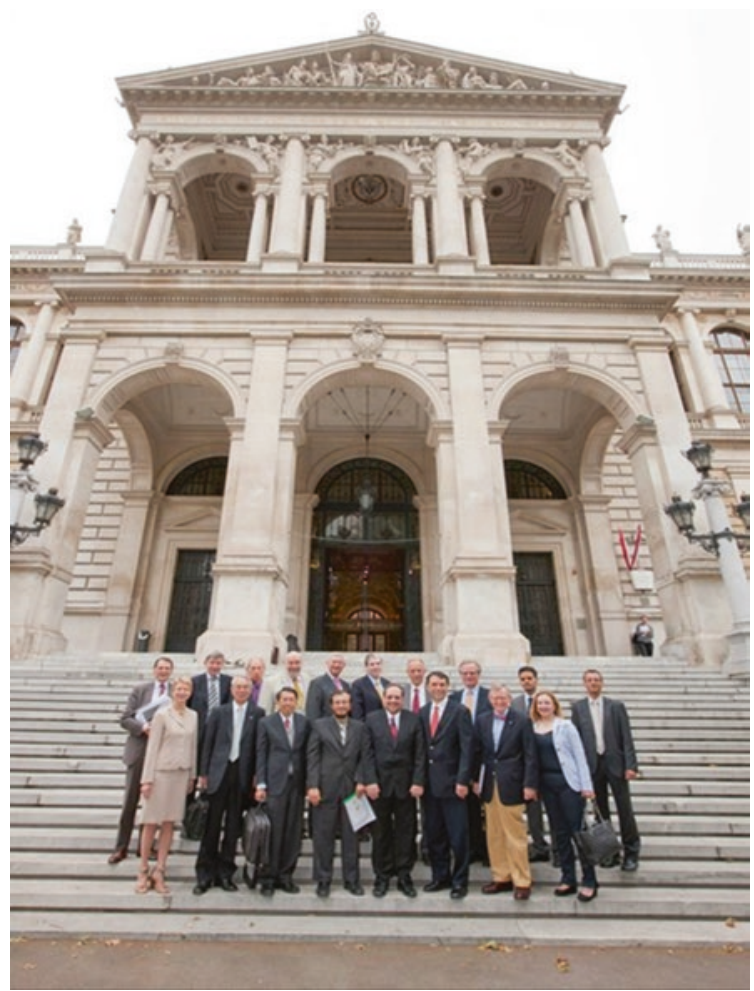




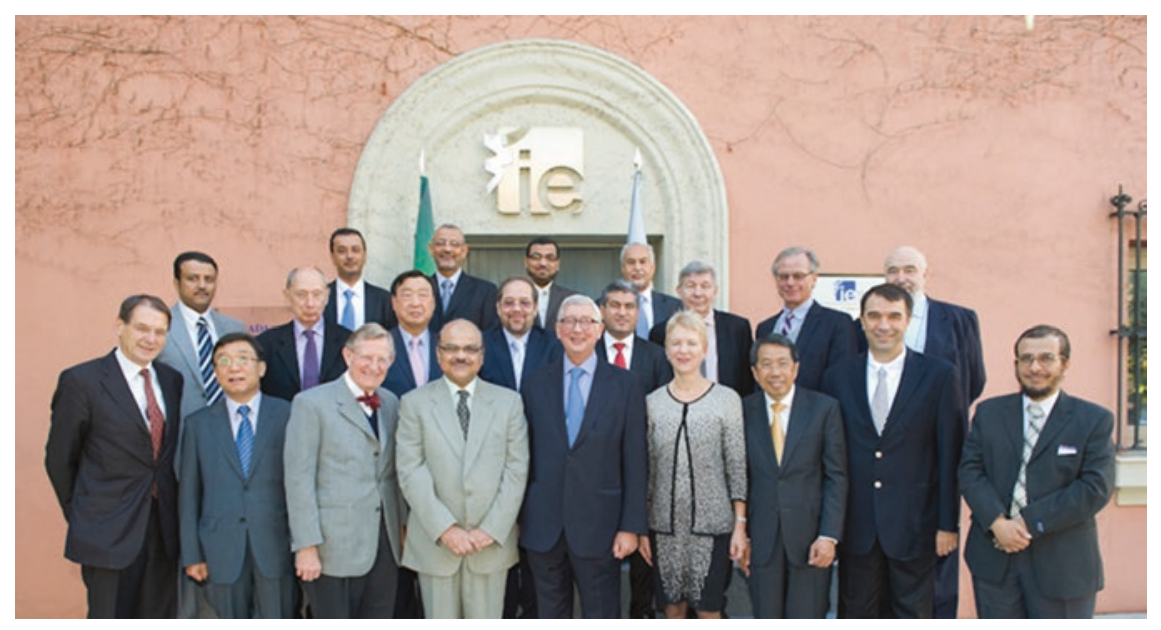

Fig. 3 IAB fourth meeting at IE University, Spain

has a maximum duration of three days. Figure $4 \mathrm{a}-\mathrm{c}$ show the IAB members during meeting sessions.

The principal point of contact between the university and the IAB members is via the Vice-President for Graduate Studies and Research, who acts as Board Secretary General. In most meetings, all KAU Vice-Presidents and selected KAU faculty members (non-permanent board members) are invited to attend and participate, so as to ensure the creation and maintenance of close links between the IAB members and the management team responsible for the operational oversight and day-to-day running of the university. The selection of non-permanent board members for invitation depends on the specialization and main theme of the meeting's discussion and deliberations.

Since the establishment of the KAU IAB, seven meetings have been held to date as detailed in the following table, while the agenda of the sixth meeting is presented in the Appendix:

\begin{tabular}{|c|c|c|c|}
\hline Meeting & Place & Date & The main subject of the meeting \\
\hline First & KAU, Jeddah, K.S.A. & $\begin{array}{l}25-26 / 2 / 1432 \mathrm{H} \\
(29-30 / 1 / 2011 \mathrm{G})\end{array}$ & $\begin{array}{l}\text { Introduction of KAU and its strategic plan } \\
\text { to the IAB members }\end{array}$ \\
\hline Second & $\begin{array}{l}\text { Vienna University, } \\
\text { Austria }\end{array}$ & $\begin{array}{l}1-2 / 8 / 1432 \mathrm{H} \\
(2-3 / 7 / 2011 \mathrm{G})\end{array}$ & $\begin{array}{l}\text { Ways and means of developing scientific } \\
\text { research at KAU }\end{array}$ \\
\hline Third & KAU, Jeddah, K.S.A. & $\begin{array}{l}26-27 / 3 / 1433 \mathrm{H} \\
(18-19 / 1 / 2012 \mathrm{G})\end{array}$ & $\begin{array}{l}\text { KAU steps toward innovation and creativity } \\
\text { (Part 1) }\end{array}$ \\
\hline Fourth & IE University, Spain & $\begin{array}{l}27-28 / 11 / 1432 \mathrm{H} \\
(13-14 / 10 / 2012 \mathrm{G})\end{array}$ & $\begin{array}{l}\text { KAU steps toward innovation and creativity } \\
\text { (Part 2) }\end{array}$ \\
\hline Fifth & KAU, Jeddah, K.S.A. & $\begin{array}{l}1-2 / 7 / 1434 \mathrm{H} \\
(11-12 / 5 / 2013 \mathrm{G})\end{array}$ & $\begin{array}{l}\text { Ways and means to excel and achieve dis- } \\
\text { tinction in educating and learning (Part 1) }\end{array}$ \\
\hline Sixth & $\begin{array}{l}\text { Bilkent University, } \\
\text { Turkey }\end{array}$ & $\begin{array}{l}\text { 19-21/1/1435H } \\
(22-24 / 11 / 2013 \mathrm{G})\end{array}$ & $\begin{array}{l}\text { Ways and means to excel and achieve dis- } \\
\text { tinction in educating and learning (Part 2) }\end{array}$ \\
\hline Seventh & KAU, Jeddah, K.S.A. & $\begin{array}{l}25-26 / 11 / 1435 \mathrm{H} \\
(20-21 / 9 / 2014 \mathrm{G})\end{array}$ & KAU Third Strategic Plan for WCU \\
\hline
\end{tabular}



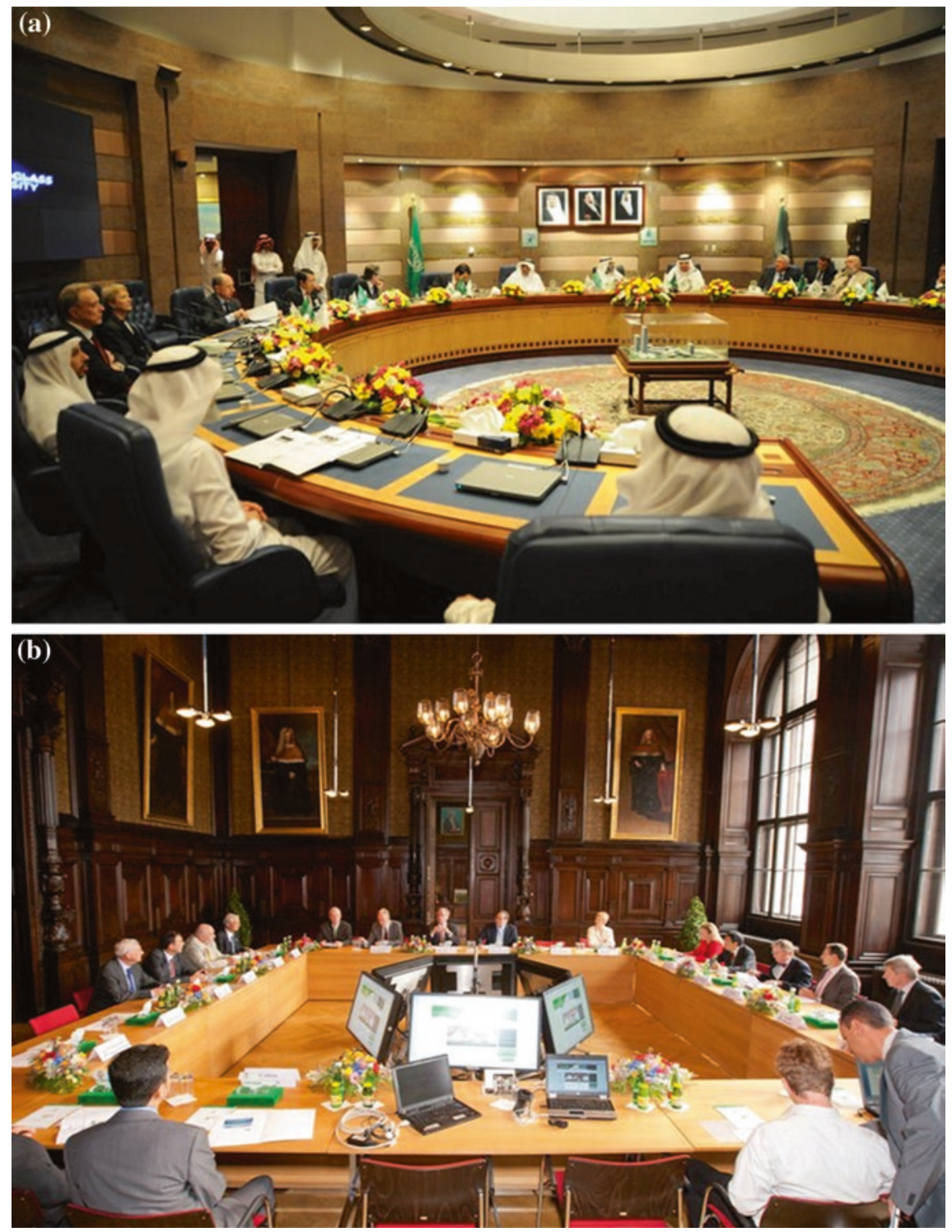

Fig. 4 a-c IAB meeting sessions in progress 


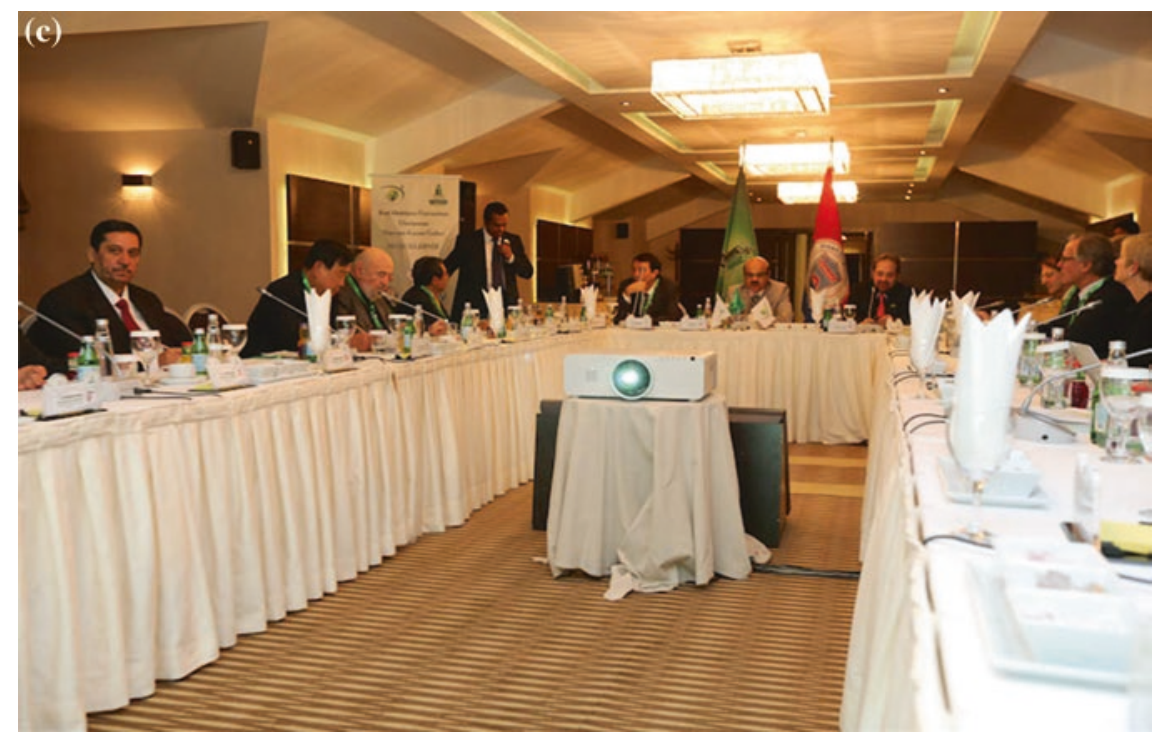

Fig. 4 (continued)

\section{Examples of International Advisory Boards and International Advisory Councils at Other Universities}

As previously mentioned, numerous universities and institutions around the world have established international advisory bodies in order to benefit from their members' expertise. Some of these universities are ranked within the top 500 world universities, while others are, as yet, unranked.

The following section contains examples of universities in the US, Europe, Asia, and Australia which have established IABs. The following list is not exhaustive.

\subsection{International Advisory Council of King Abdullah University for Science and Technology, KSA}

King Abdullah University for Science and Technology (KAUST) is an international, graduate-level research university in Saudi Arabia dedicated to inspiring a new age of scientific achievement in the Kingdom that will benefit the nation, the region, and the world. The President's IAC supports and advises the KAUST President on the overall academic development of the university. This development is intended to firmly establish KAUST as a globally renowned graduate university and a major and significant contributor to scientific and technological advances [13]. 
The IAC is an eminent body of widely respected scholars, researchers, and academic leaders, in addition to those with other areas of domain expertise deemed supportive to the president. Council members are selected on the basis of their leadership, expertise, and experience in scientific, technical, business, and academic domains.

The internationally diverse council membership reflects cultural and geographical diversity spanning Asia, Europe, and North America. The board membership is complemented by Saudi council members, who are able to advise the president on certain relationships and other issues specific to Saudi Arabia. The IAC consists of 14 members representing a number of disciplines, including:

- Professor Richard Friend (Chair), Cavendish Professor of Physics, Cavendish Laboratory, University of Cambridge, UK

- Professor Alice M. Agogino, Roscoe and Elizabeth Hughes Professor of Mechanical Engineering, University of California, Berkeley, United States

- Mr. Mohamed H. Al-Mady, Vice Chairman \& CEO, Saudi Basic Industries Corporation (SABIC), Saudi Arabia

- Dr. Mohammed ibn Ibrahim Al-Suwaiyel, President, King Abdulaziz City for Science and Technology (KACST), Saudi Arabia.

\subsection{International Advisory Board, University of Edinburgh, $U K$}

The Quacquarelli Symonds World University Rankings (QS World University Rankings) were first compiled in 2004, evaluating 700 universities in the world and ranking the top 400. University of Edinburgh has consistently been ranked within the top 20 institutions since 2004. The university ranked at 17 in the QS world rankings in 2014 [14].

The IAB was established to provide independent, external, and commercially orientated advice to the University of Edinburgh's Business School [4]. The principal points of contact between the school and the IAB are via the University Dean and the University Corporate Engagement Manager, the latter acting as IAB Secretary. Members of the executive team have a standing invitation to board meetings in order to ensure tight linkage between the school's external advisors and the team responsible for its day-to-day running.

The board contains a broad range of members of the international business community, diverse in gender and representative of both the public and private sectors [4]. It consists of 16 members representing different area specialties, including:

- Mark Astaire, Chairman, Investment Banking and Vice Chairman EMEA, ECMC, Barclays

- Simon Bray, Director of Santander Universities UK

- John D. Campbell OBE, FRSA (Chair), Senior Managing Director, State Street Global Services UK, Middle East and Africa (UKMEA) 
- Melanie A Czarra, Managing Director, Head of Primary Debt Markets, Mizuho International plc.

The board holds two or three face-to-face meetings a year and meets on an asneeded basis by teleconference. Board members are kept abreast of school events by email.

\subsection{International Advisory Council of Università Bocconi, Italy}

Università Bocconi is a private Italian university, founded in 1902. The university is an example of an unranked institution, not appearing within the top 500 world university rankings. The university has established an IAC to assist the board of directors in designing and defining the university's international strategy [15]. The council brings together business leaders, policy makers, and academics from Europe and the rest of the world. Its fundamental mission is to provide feedback on the projects proposed by the University Rector and its Chief Executive Officer, to suggest new avenues for strategic development and to guide innovative thinking on the university's future.

The IAC consists of prominent international figures, bringing their European and global perspectives and vision to Bocconi. These global corporate managers and international academics are joined by leading Italian managers who are active in the internationalization of their businesses. Three representatives of Università Bocconi are also members [15].

\subsection{International Advisory Board, University of Oxford, UK}

The University of Oxford has consistently been ranked within the top six institutions since the QS World University Rankings were started in 2004. The university ranked at five in the QS World University Rankings in 2014 [14].

The University of Oxford is the oldest university in the English-speaking world. It is one of the world's leading universities, and it occupied the fourth place in the world in the Times Higher Education (THE) World University Ranking in 2013/2014. The University of Oxford established an IAB for its Business School that draws on the talents and knowledge of renowned leaders from many parts of the world.

The board was formed to advise the school's management on its future direction. The IAB is comprised of 12 globally distinguished business scholars and leaders, including [16]:

- Mark Carney, Governor of the Bank of England

- W.J. Clinton, 42nd President of the United States 
- N.O. Lweala, Minister of Finance and Coordinating Minister of the Economy, Nigeria

- P. Arida, Managing Partner and Chairman of Asset Management, BTG Pactual.

Additional information concerning this IAB and its members can be accessed via link [16].

\subsection{International Advisory Board of Sri Ramaswamy Memorial (SRM) University, India}

SRM University's IAB is actively involved in the creation of an increasingly robust international dimension in curriculum, research, and teaching methodology, by bringing together students and faculty from renowned overseas universities.

The IAB has helped create an upbeat environment at SRM University by opening up possibilities for students and faculty, creating avenues for research, and establishing the necessary foundations for successful careers.

The IAB comprises of approximately 60 members from around the world, drawn from different specializations, including [17]:

- Dr. Al Lieberman, Professor of Marketing, Executive Director Entertainment, Media and Technology Program, Stern School of Business, NYU

- Professor Allan Baker, Associate Dean, Administration and International Projects, School of Cinematic Arts, University of Southern California

- Mr. Allan L. Fisher, Senior Vice President for Product Strategy and Development, Laureate Higher Education Group; Ex-President and CEO iCarnegie Inc., Pittsburgh

- Dr. Bob Hoekstra, Former CEO, Philips R\&D Center, The Netherlands; CEO, Opportunity India Consulting, The Netherlands.

\subsection{International Advisory Board of Texas A\&M University, USA}

Texas A\&M University has consistently been ranked within the top 200 institutions in ranking systems. It was ranked at 165 in the QS world rankings in 2014 [14].

The IAB of Texas A\&M University, consisting of approximately 40 members from business, government, education, and other areas, was created in 1992. The board advises the university on international program development and other areas of major concern. Its members participate in the university's international activities and assist in the creation of an international network for the university. The board also promotes awareness of international programs and issues [18]. 
Board members include:

- Francisco Alcalá, President of Frajal, S.C., a consulting firm specializing in the areas of corporate governance, agribusiness, education, and management.

- Alberto Alemán Zubieta, CEO of the Panama Canal Authority (ACP), the autonomous agency that manages the Panama Canal which is the leading interoceanic waterway that serves world maritime commerce.

- Klaus Aurisch, business consultant in European Union matters, German attorney, and university lecturer in international relations.

- Jorge Bermudez, President and CEO of the Byebrook Group, a small firm dedicated to research and advisory work in the financial services industry.

Additional information concerning this IAB and its members can be accessed via link [18].

\subsection{Lund University International Advisory Board, Sweden}

Lund University was ranked at 65 in the world and as the top Swedish university in the 2014 QS Ranking [14].

The IAB is made up of prominent international academics with extensive leadership experience, drawn from a variety of academic disciplines. The board's function is to monitor and assess research, education, and management at the university. It also has an advisory function with regard to strategy, development, innovation, and education and research goals [19]. The Deputy Vice-Chancellor is responsible for coordination of work between the university and the IAB.

The following are a selection of members of the 2010-2014 IAB:

- Provost Judyth Sachs, Macquarie University, Sydney, Australia

- Professor Jan-Anders Månsson, École Polytechnique Fédérale de Lausanne (EPFL), Switzerland

- Dr. John Hood, Robertson Foundation, USA.

\subsection{International Advisory Board of James Cook University, Australia}

The function of the IAB is to advise the Deputy Vice-Chancellor (Research and Innovation), the Management Committee, and the Director. Advice is sought on strategic and academic matters that are conducive to the realization of the vision of the Cairns Institute at James Cook University and to the implementation of its strategic intent. Its members are distinguished, internationally renowned individuals, recognized by their peers as having made outstanding contributions to one or more of the academic disciplines represented within the institute. The board normally 
meets at least once a year in Cairns with the Vice-Chancellor, Deputy ViceChancellor (Research and Innovation), Management Committee, Director, and academic leaders of the Cairns Institute, as part of its review and planning cycle.

The IAB is comprised of nine members appointed by the Vice-Chancellor for a period of five years and includes the following [20]:

- Professor Chris Cocklin (ex-officio), Senior Deputy Vice-Chancellor, James Cook University

- Professor Barbara Glowczewski, Director of Research, Centre National de la Recherche Scientifique, Laboratoire d'Anthropologie Sociale, Collège de France

- Professor Jon Tikivanotau M. Jonassen, Department of Political Science, College of Business, Computing and Government, Brigham Young University, Hawaii

- Professor Bruce Kapferer, Professor of Anthropology, University of Bergen, Norway.

\subsection{The International Advisory Board, University of Helsinki, Finland}

The University of Helsinki has consistently been ranked within the top hundred institutions in the various ranking systems. It was ranked 67 in the 2014 QS World Rankings [14].

The IAB is made up of nine scholars and practitioners of environmental and applied aesthetics from around the world. The board promotes research in aesthetics, international exchange, and cooperation between universities and research centers. IAB tasks also include evaluating and commenting on the International Institute of Applied Aesthetics (IIAA) project plans. Many IAB members attend events in Finland to pool and share their scholarly expertise in their specialized fields [21]. The IAB has nine members including:

- Professor Emeritus Arnold Berleant, Castine, ME, USA

- Dr. Emily Brady, University of Edinburgh, UK

- Professor Wangheng Chen, Wuhan University, China

- Professor Kenneth Olwig, SLU-Arnap, Department of Landscape Planning, Sweden.

\subsection{The International Advisory Board, King Fahd University of Petroleum and Minerals (KFUPM), KSA}

King Fahd University of Petroleum and Minerals (KFUPM), Kingdom of Saudi Arabia, was ranked at 225 in the world, in the 2014 QS World Rankings [14]. Its groundbreaking IAB was established in March 2007. The IAB is a highly prestigious panel composed of senior academic and corporate leaders [22]. The IAB 
membership was selected from world-class organizations. The board fulfills important advisory functions concerning the university's strategic planning. It also focuses on the provision of advice and guidance on the university's outreach to peer institutions for the acquisition, implementation, and utilization of innovations and developments in research and curriculum. It also guides and assists KFUPM's academic administration, and the university's provision of community service.

The IAB was established for the purpose of providing advice and guidance on important issues to the university and its community. The IAB features leading experts, currently or formerly affiliated with some of the most successful and respected companies and universities. The IAB has 14 members selected from world-class organizations, including [23]:

- Martin Jischke, President Emeritus, Purdue University, Indiana, USA

- Andrew F. Gould, Non-Executive Chairman of the Board, BG Group Plc, UK

- Robert J. Birgeneau, Chancellor, University of California, Berkeley, USA

- Olivier Appert, Chairman and Chief Executive Officer, Institut Francais du Petrole (IFP). He is also a Director of Technip, Director of Storengy and of the Institut de Physique du Globe de Paris, France.

\section{Additional Examples of International Advisory Boards and International Advisory Committees}

There are a considerable number of established organizations and consulting bodies that offer advice and help executive boards in the successful performance of their duties. They are too numerous to all have places in this chapter, but we include the three following bodies, as we deem them as being of particular significance, and as of having especially significant impact.

\subsection{International Advisory Board (IAB) of the Academic Ranking of World Universities, China}

The Academic Ranking of World Universities (ARWU) was first published in June 2003 by the Graduate School of Education of Shanghai Jiao Tong University, China, and is updated annually. ARWU uses six objective indicators to rank world universities including: the number of alumni and staff winning Nobel Prizes and Fields Medals; the number of highly cited researchers selected by Thomson Reuters; the number of articles published in journals of Nature and Science; the number of articles indexed in the Science Citation Index; the number of articles indexed in the Expanded and Social Sciences Citation Index; and the university's per capita performance. In excess of 1200 universities are ranked by ARWU annually and the top 500 published [24]. 
The ARWU IAB was established to provide the ARWU Team with global and academic perspectives on ARWU's current practice and future prospects. The IAB is comprised of 10 members of world renowned scholars, top policy researchers, and higher education leaders, including [25]:

- Professor Dr. Philip G. Altbach, Director, Center for International Higher Education, Boston College, USA

- Dr. Ghislaine Filliatreau, Director, Observatoire des Sciences et des Techniques, France

- Professor Dr. Charles A. Goldman, Senior Economist, RAND Corporation, USA

- Professor Dr. Pierre de Maret, Former Rector, Université Libre de Bruxelles, Belgium.

The first meeting of the ARWU IAB was held on October 30, 2011, in Shanghai, China. Additional information is accessible via link [25].

\subsection{International Advisory Committee of UNESCO}

The United Nations Educational, Scientific and Cultural organization (UNESCO) is a specialized agency of the United Nations (UN). Its purpose is to contribute to global peace and security by promoting international collaboration through education, science, and culture in order to further universal respect for justice, the rule of law, human rights, and the fundamental freedoms proclaimed in the United Nations Charter. UNESCO has 195 member states [26] and nine associate members [27].

The IAC is the body ultimately responsible for advising UNESCO on the planning and implementation of the program as a whole. It comprises 14 members serving in a personal capacity, appointed by the UNESCO Director-General, and selected for their authority in the field of the safeguarding of documentary heritage. The Director-General convenes the IAC in ordinary session every two years.

To organize its work, the IAC establishes and amends its own Rules of Procedure, which are regularly updated on its website, and maintains appropriate subsidiary bodies or subcommittees [27].

In particular, the IAC maintains an overview of the policy and strategy of the Memory of the World Program. It therefore monitors the global progress of the program, considers reports from its subcommittees, from regional committees and from the Secretariat, and in turn advises these bodies on their functions and responsibilities. As necessary, it revises and updates the General Guidelines of the Memory of the World International Register and is responsible for approving additions to, or deletions from, the register. It builds the structures of the Program with the intent of creating a sound framework for the future maturing of Memory of the World into the status of a UNESCO Recommendation and ultimately a UNESCO Convention. 
The operation of each subcommittee and regional committee is reviewed at every ordinary session of the IAC, in order to ensure that structures are kept relevant to current needs. The IAC consists of 14 members representing 14 countries. Members of the IAC (2013/2014) included [26]:

- Ms. Helena R Asamoah-Hassan, Ghana

- Ms. Alla Aslitdinova, Tajikistan

- Ms. Luciana Duranti, Italy

- Mr. Michael Heaney, United Kingdom

- Ms. Nada Moutassem Itani, Lebanon

- Mr. Hedi Jallab, Tunisia.

\subsection{International Advisory Council, APCO, Worldwide}

APCO is an independent global communication, stakeholder engagement, and business strategy firm. APCO Worldwide has more than 30 offices in major business, financial, political, and media capitals throughout the Americas, Europe, the Middle East, Africa, and Asia [28]. The organization's IAC and its three subgroups are comprised of more than 40 recognized global leaders and include: former elected politicians; leaders of business and industry; academics at leading universities; world-class journalists and editors; diplomats and policy experts [28]. Each member offers clients invaluable real-world knowledge. They are individuals who understand the complex issues faced by clients because they have encountered, and successfully exploited and overcome, similar opportunities and challenges in their own careers. Clients are able to obtain informed and valuable guidance from either individual members or from a select group of members containing varying perspectives to enable them to make the right decisions for their particular situations.

\section{How Can an IAB/IAC Be Effective and Beneficial?}

In order for an IAB/IAC to be effective and beneficial for an organization, it is crucially important to ensure that the main management team of the institution supports the concept of the board's establishment and fully comprehends its purpose and function. It is also of paramount importance for its president to encourage and establish a good working relationship among the members, and between the board and senior management. The duties of the board should be unambiguously understood by the university council or senate, and by the board members. The board should focus on broad subjects relevant to goals, policy and program issues and not on the detailed managerial and operational aspects of the organization. 
The IAB/IAC should work collaboratively with the organization's main management team, for example with the University Council. Its efforts should be directed toward the measurement and evaluation of the organization's activities aimed at meeting the objectives outlined in the organization's strategic plan, and in addressing relevant recommendations. As previously mentioned, the board does not have decision-making powers, but assists by enlightening and guiding the institutional management on strategic matters and provides an expert consultative mechanism. The management team is ultimately responsible for applying board recommendations and advice in accordance with their needs and priorities.

\section{Summary}

In this chapter, we have outlined the definition, objectives, composition, and functions of IABs and IACs in a number of institutions and organizations. The main role of IABs and IACs is to offer advice and guidance, especially on strategic matters, to assist and empower organizations' executive boards to enable their operational tasks to be successfully conducted and completed. Most boards and councils mentioned in this chapter have memberships of less than 20, and meet biannually.

IABs and IACs provide invaluable aid to concerned institutions in helping to concentrate their focus on strategic imperatives. They are also able to provide substantive and effective support in the building of international status, recognition, and reputation.

\section{Appendix}

Agenda of the sixth meeting of the IAB of KAU

King Abdulaziz University (KAU), International Advisory Board (IAB)

Sixth Meeting, 22-24 November 2013, Bilkent University, Ankara, Turkey

Theme: Towards Excellence in Teaching and Learning, Part 2

AGENDA

Day 1, Friday 22nd November 2013

\begin{tabular}{l|l}
\hline Time & Item \\
\hline $07.00-08.30$ p.m. & $\begin{array}{l}\bullet \text { KAU Strategic Plan III } \\
\bullet \text { KAU will present its Strategic Plan III (2015-2019) }\end{array}$ \\
\hline $09.00-11.00$ p.m. & $\bullet$ KAU Banquet Dinner \\
\hline
\end{tabular}


Day 2, Saturday 23rd November 2013

\begin{tabular}{|c|c|}
\hline Time & Item \\
\hline 08.30-09.30 a.m. & $\begin{array}{l}\text { - Opening Session: } \\
\text { - Welcoming Words by KAU President and Bilkent President } \\
\text { - Brief presentation on the summary of IAB-5 by Prof. Adnan Zahed } \\
\text { - Presentation on Bilkent University by Prof. Abdullah Atalar }\end{array}$ \\
\hline 09.30-11.00 a.m. & $\begin{array}{l}\text { - Group Meetings } 1 \\
\text { - Group A and Group B will meet to formulate draft programs initialized } \\
\text { during e-communications between board members }\end{array}$ \\
\hline $11.00-11.30$ a.m. & Break \\
\hline $11.30-01.00$ p.m. & $\begin{array}{l}\text { - Group Meetings } 2 \\
\text { - A continuation of Group Meetings } 1\end{array}$ \\
\hline 01.00-02.00 p.m. & Lunch \\
\hline 02.00-03.30 p.m. & $\begin{array}{l}\text { - Group A: Draft Program Presentation } \\
\text { - Group A will present its draft program } \\
\text { - The program will be discussed by all IAB members to enrich its } \\
\text { contents }\end{array}$ \\
\hline 03.30-05.00 p.m. & $\begin{array}{l}\text { - Group B: Draft Program Presentation } \\
\text { - Group B will present its draft program } \\
\text { - The program will be discussed by all IAB members to enrich its } \\
\text { contents }\end{array}$ \\
\hline 08.00-10.00 p.m. & Bilkent University Occasion \\
\hline
\end{tabular}

Day 3, Sunday 24th November 2013

\begin{tabular}{l|l}
\hline Time & Item \\
\hline $09.00-10.50$ a.m. & $\begin{array}{l}\text { ・ Group Meetings 3 } \\
\text { Group A and Group B will each meet to formulate their final pro- } \\
\text { grams, taking into account the previous day (Saturday) IAB members' } \\
\text { comments }\end{array}$ \\
\hline $10.50-11.10$ a.m. & Break \\
\hline $11.10-01.00$ p.m. & $\begin{array}{l}\bullet \text { Group Meetings 4 } \\
\text { • A continuation of Group Meetings 3 }\end{array}$ \\
\hline $01.00-02.00$ p.m. & Lunch \\
\hline $02.00-03.30$ p.m. & Group A: Final Program Presentation and Discussion \\
\hline $03.30-03.45$ p.m. & Break \\
\hline $03.45-05.15$ p.m. & Group B: Final Program Presentation and Discussion \\
\hline $05.15-05.30$ p.m. & Conclusion and Final Remarks \\
\hline
\end{tabular}

Open Access This chapter is distributed under the terms of the Creative Commons Attribution Noncommercial License, which permits any noncommercial use, distribution, and reproduction in any medium, provided the original author(s) and source are credited. 


\section{References}

1. http://www.odgersberndtson.co.uk/fileadmin/uploads/united-kingdom/Documents/K_I/ The_Role_of_Advisory_Boards_-_Who_What_Why_and_How.pdf

2. Zahed, A., Hegazy, A., \& Nahas, M. N. (2011). Establishing the International Advisory Board for King Abdulaziz University. Final Report (in Arabic), March 2011.

3. http://business.leeds.ac.uk/about-us/our-advisory-board/

4. http://www.business-school.ed.ac.uk/about/structure/advisory-board

5. Tayeb, O., \& Zahed, A. (2013). Towards a world-class university the role of international advisers. A paper presented at the 5th International Conference on World Class University, November 3-6, 2013, Shanghai, China.

6. http://iab.kau.edu.sa/Default.aspx?Site_ID $=975 \& \operatorname{lng}=\mathrm{EN}$

7. http://kau.edu.sa

8. Zahed, A., Hegazy, A., \& Nahas, M. N. (2011). Activating the International Advisory Board for King Abdulaziz University. Final Report (in Arabic), October 2011.

9. Zahed, A., Hegazy, A., \& Nahas, M. N. (2012). Performance evaluation of the International Advisory Board for King Abdulaziz University. Final Report (in Arabic), May 2012.

10. Zahed, A., Hegazy, A., \& Nahas, M. N. (2012). Preparation for the fourth meeting of the International Advisory Board for King Abdulaziz University. Final Report (in Arabic), December 2012.

11. Zahed, A., Hegazy, A., \& Nahas, M. N. Documentation of the fifth meeting of the International Advisory Board for King Abdulaziz University. Final Report (in Arabic), June 2013.

12. Zahed, A., Hegazy, A., \& Nahas, M. N. (2014). Documentation of the sixth meeting of the International Advisory Board for King Abdulaziz University. Final Report (in Arabic), January 2014.

13. http://www.kaust.edu.sa/presidents-international-advisory-council.html

14. http://www.lunduniversity.lu.se/about/about-lu/university-world-rankings

15. http://www.unibocconi.eu/wps/wcm/connect/Bocconi/SitoPubblico_EN/Navigation+Tree/ Home/About+Bocconi/Organization/International+Advisory+Council/

16. http://www.bsg.ox.ac.uk/people/international-advisory-board1.

17. http://www.srmuniv.ac.in/acdemics/international-advisory-board

18. http://provost.tamu.edu/initiatives/councils-task-forces-folder/international-advisoryboard-inclusive/international-advisory-board

19. http://www.lunduniversity.lu.se/

20. http://www.jcu.edu.au/cairnsinstitute/people/JCUTST_057670.html

21. http://www.helsinki.fi/iiaa/introduction/iab.htm

22. http://www1.kfupm.edu.sa/iab/about.html

23. http://www1.kfupm.edu.sa/iab/newsletter.html

24. http://www.shanghairanking.com/aboutarwu.html

25. http://www.shanghairanking.com/aboutiab.html

26. http://www.unesco.org/new/en/communication-and-information/flagship-project-activities/ memory-of-the-world/about-the-programme/international-advisory-committee-iac/

27. http://en.wikipedia.org/wiki/UNESCO

28. http://www.apcoworldwide.com/content/aboutapco/international_advisorycouncil.aspx

29. http://www.apcoworldwide.com/content/aboutapco/about_apco.aspx 


\title{
Excellence as Duty
}

\author{
Jozef Ritzen
}

\section{Introduction}

"Excellence as duty" is our title and it is intended to encompass some of the main issues, which a university striving-for-excellence encounters and for which appropriate and effective responses need to be formulated. First and foremost, the university believes it is duty-bound to produce graduates who, when they look back at their university careers, will view them as inspirational stages of their lives which brought out the best of their talents. University education today is vastly different from university education in the past (Sect. 2). In Sect. 3, we show the manner in which university education in Europe underwent a transformation from being exclusively available to societies' elites to the present where education is available to the masses, sometimes in the process losing the perspective of "excellence" as a result of insufficient adjustment. It is only in recent times that international comparisons for the quality of universities and education in the form of rankings and of educational performance indicators, such as the Project International Student Assessment (PISA), have become available. These comparators enable tracking and measurement of quantum leaps in excellence as are being currently witnessed in Asia and in the Middle East (Sect. 4). Some elements of excellence in university education are discussed in Sect. 5, while Sect. 6 discusses the manner in which universities can become acquainted with "good practices" through the exchange of knowledge. The final section presents a summary and conclusion.

\footnotetext{
J. Ritzen ( $ه)$

Maastricht University, Maastricht, The Netherlands

e-mail: j.ritzen@maastrichtuniversity.nl 


\section{Graduates as Drivers of Socio-Economic Development}

\subsection{On Excellence and the Quality of Education}

The world has become familiar with the notion that education is not only essential for the development of a person, but that it also is an investment, which, just as with other investments, can subsequently yield beneficial returns. The investment notion implies costs and potential benefits, where the costs have to be met prior to benefits being reaped.

Since the early 1950s, schools have been recognized as being essential for economic development. The first use of the term 'human capital' was in countries which provided quality education. These also were the countries with the highest rates of economic growth. Causality was discussed: are high economic growth rates the cause for high levels of investment in human capital or is the reverse the case? It was likely to be the second, with a kind of spiral upward effect, because high growth countries would be in a position to invest a substantial part of that growth in education. Education also became recognized as a fast track for growth by low and middle-income countries. Korea, Hong Kong, and Singapore are prime examples of such countries and such outcomes.

"Doing well" in education is more than enrolling children in education, as has been shown repeatedly. Those economists who tried to explain statistically the difference in economic growth rates across countries from the perspective of differences in the levels of education achieved in the working population by merely looking at numbers became disillusioned. "Where has all the education gone?" was the title of one of these studies [1]. It was the outcry of a researcher who had investigated the total number of education years in the labor force to explain statistically the contribution of education to economic development. He was unable to discover a significant relationship between that measure of human capital and economic growth.

Pritchett's efforts were soon overtaken by researchers who applied quality standards to the years under scrutiny, often fairly clumsily as there is a danger of perceptible imprecision when measuring the quality of a year of education which a student has enjoyed. Barro and Lee [2] and Hanushek [3] are the pioneers in these efforts by using the scores in the Project International Student Achievement and the scores in the Project International Assessment of Adult Competences (PIAAC), respectively, as indicators of education system quality. The not-so-surprising finding is that the contribution of quality education to economic growth is indeed substantial. A no-brainer: education is not simply concerned with being enrolled in education, but is concerned with learning. Quality has a face: where more is learned, the quality is better. 'Excellence' then can emerge from the shadows of vagueness and imprecision of meaning to become recognizable and identifiable. Excellence is about improving quality. The standards in this regard are no longer local or national, but have international standard implications and applications, as there is no reason why youngsters of other localities or other nations would learn 


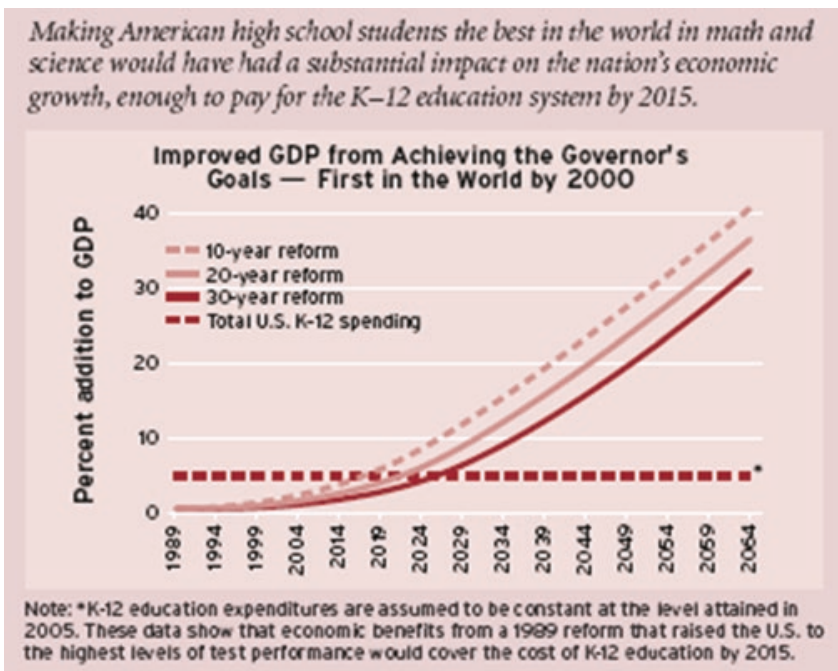

Fig. 1 The economic benefits of education reform. Source Hanushek et al. [5]

less in a year of education than those whose education occurs locally or nationally. Or, as Derek Bok, the Harvard President from 1971 to 1991 and from 2006 to 2007 recapped in 2014: "the number of college degrees is not nearly as important as how well students develop cognitive skills, such as critical thinking and problem solving" [4]. This is best demonstrated with Fig. 1 for the US, where the effects of education reform which would improve the quality of the skills of the labor force on economic growth are shown.

\subsection{Higher Education}

Recent insights into the importance of graduates for socio-economic development have placed universities at center stage. All quality education has an enduring impact on economic development, but it seems that university education in particular plays a central role in the current stage of globalized development where knowledge and its creative and problem solving use plays such an important role, while routine work is increasingly mechanized or robotized.

Research universities seem often not fully aware of the tremendous role of their graduates in economic development. They seem to primarily pride themselves on the quality of their research, not realizing that research does not need to take place in a university, but can well be housed in separate institutions, as is done for example in Germany where the Max Planck Institutes are independent organizations without an educational role. They point to the excellence in research, demonstrated for example in Nobel Prizes or Fields Medals won by their researchers 
or by the number of citations of publications of their researchers. There is often less pride taken in the education quality even though we understand its importance from all the evidence on the role of quality education in stimulation of economic growth. No doubt, this may also result from difficulties concerning education quality visibility. Of course, good research may be an asset to providing good education, if good researchers are intensely involved in the education process. But it is unlikely that there is a direct and identifiable causal relation between good research and good education. This inevitably depends a great deal on the manner in which this relation between research and education is organized.

While we have measures for a substantial number of countries on the quality of education in primary and secondary school through the Project International Student Achievement (PISA), measuring language and math abilities of 16 year olds, there is a virtual absence of international comparable data on the quality of university education. We have some impressions from what graduates think themselves about the education they received, but these are highly subjective and difficult to compare with the judgments in other countries, as there is no standard by which the answers are measured. The same applies to employers' judgments on the quality of the graduates they employ. This is clearly an area requiring international research. The Organization for Economic Cooperation and Development (OECD) of industrialized countries made an attempt to create an international comparable measurement mechanism in the Assessment of Higher Education Learning Outcomes (AHELO) project, but to date it has not been able to bring it to a practical implementation.

\subsection{Components of Graduate Quality}

There are two ways to establish what makes graduates "excellent", i.e., what they need to have at their disposal in order to function well in society. One way is to ask them and their employers. The other is to measure traits of graduates and to analyze statistically how important these traits are in relation to their levels of earnings. Both approaches have been used in the recent past (see, for example, van der Velden [6, 7]). The conclusions are identical:

- Cognitive achievement and knowledge of the field are important. Yet, equally important is the capacity to use that knowledge in "problem solving".

- Most work is done in communication and cooperation with others. How to work in teams, how to communicate is an essential part of the job, for which the graduate needs to be prepared.

- Intercultural understanding is important as many graduates work in an international environment.

- Graduates need to have a good understanding of information and communication technology (ICT). 
Universities, which want to excel, believe they are responsible for producing graduates that satisfy the requirements for being successful in society. For them excellence is not a mere notion: it is a duty. The research of those universities is, besides being important in its own right, supporting education quality through the involvement of researchers in the education process, as in for example researchbased education.

\subsection{Excellence in Higher Education}

Excellence in higher education is, for the leadership and staff of a university, not merely a gimmick or jargon term to which they pay lip service, but rather something at the heart of the university. It involves enabling the university to contribute to society by supporting the maximum development of students' talents through an organization in which research may play an important role.

In the following sections, we focus on universities that are highly engaged in research (research universities).

\section{Three European Stages and Excellence}

\subsection{Universities in the World}

Universities have an extensive history dating back at least some thousand years with early, yet very small-scale learning venues for example in the East, in China and Korea, on the Arabian Peninsula, and in Europe. Excellence was visible in the contributions of the graduates in all important fields, be it in governance, in the natural sciences (Archimedes could be considered a graduate of Alexandria University around $300 \mathrm{BC}$ ), in philosophy, in agriculture, or in medicine. Professor Winckler in chapter "Excellence in Strategic Planning" also gives a brief overview of the history of universities.

The role of universities in society changed when there was a drastic increase in the proportion of the age group of 18-24 year olds who participated in universities. Some call this the massification of higher education. There were times when it was a rare exception when a youngster went to university. The massification of universities almost implied that it was an exception if a youngster did not go to university. Obviously, this is an exaggeration, but serves to illustrate a dramatic increase in university attendance levels from some $1 \%$ of the age group to $40-50 \%$ of the age group.

Massification first took place in the US in the years following the end of the Second World War in 1945. It was followed by Europe after around 1960, and later by other countries which had made substantive leaps in economic development. 
During the process of massification, the notion of excellence as providing graduates with the necessary skills to function well in society never changed. Yet, it manifested itself within universities quite differently as we shall illustrate with the example of Europe.

\subsection{Massification and Excellence in Europe}

For Europe, we can distinguish roughly four periods in terms of the position of research universities in society, and the corresponding notions of excellence:

- The period before the Second World War. Universities were elite and had a strong research base, which was interwoven with teaching. The graduates almost by definition became the leaders of society in all important fields. In the US, European Universities were used as the example of excellence in the Flexner report of 1930 [8].

- 1945-1965. Universities on the continent had difficulty in recovering from the war as so many professors, either were killed or had fled to the US, where many of them found the US a more rewarding place to work. Research universities recovered or were newly founded for a limited proportion of the 18-24 age group with strong ties to national or regional development (agriculture, electronics, national or regional production). However, the pre-war dominance of German universities in excellence was a thing of the past.

- 1965-1995 was the period of massification of European universities and the loss of contact with regional development. Many new universities were established to accommodate the increase in enrolment levels. Enrolments increased mostly because of "social demand". Societies were engaged in exploiting the pool of talent. While in the past access to universities was mainly for the privileged few from wealthier families, now it was also the turn for talented youngsters from more humble backgrounds. Financial aid was introduced for those students to allow them to participate in higher education.

The rapid expansion of universities definitely took a toll on "excellence" in the quality of graduates. Hiring requirements for new staff were relaxed. There was little debate within universities about "excellence" in university education or on excellence in research. The massification continued in many countries along with "democratization" as a response to student protests in the late 1960s. The "new" students, from more humble backgrounds, did not feel at ease with the old elite structure and the old ways of communication. Governments often answered the protests of students about "outmoded structures" by allowing students and staff to have a substantial, often decisive influence on budget allocation, the curriculum, and other elements of university policy. This influence may have had some benefits, but was also in many cases used to serve the personal interests, not as much of the students, but of the new, often inexperienced, staff. It is likely that the overall impact has been a decline in quality. 
There were also concerns about the absorption capacity of the labor market for the upcoming flood of fresh graduates. In retrospect, it is very surprising to see that those concerns turned out to be unwarranted: the flood was easily absorbed, even though the quality of the graduates may have been less than it had been in the earlier period. Some may say that it was world economic growth, which caused European countries to boom economically and demand more graduates. Yet, all the evidence (see, for example, Acemoglu [9]) points in another direction: it was the inflow of university graduates itself which contributed to economic growth.

- We are now (since approximately 1995) in a period where full attention is focused on excellence and quality. Most countries have installed accreditation procedures for degree courses or for institutions (sometimes for both). Within universities, quality and excellence is part of a constant debate. This debate is always about the graduate: what does she or he need to know, need to be able to do, and need to function well in terms of attitudes and capabilities? The links with the external environment reinvigorate this debate. The ivory tower in Europe is closed. The university has become an open forum, well organized and recognized, transparent, with a keen eye for the demands from stakeholders in society and close links with its socio-economic environment, yet with still many challenges (see: Ritzen [10]).

Since 2005, the information and technology revolution brought about by the Internet has created a vast potential for on-line learning through so-called MOOCs (massive open online courses). The challenge for universities is to "blend" on-line learning in university education with the curriculum.

\section{Quantum Leaps and Excellence}

It is only recently that we have begun to gain insight into quality and excellence in university education across internationally recognized standards. PISA (Project International Student Achievement) has been a leading standard for university quality, even though PISA's sphere is the performance of 16 year olds in math, the sciences, and reading. Yet, where that performance is low, we cannot expect universities to compensate entirely for the quality losses incurred earlier in primary and secondary education, while conversely, when performance of 16 year olds is high, university education can stand on the shoulders of what has been mastered at earlier ages.

The now renowned university rankings, such as the Shanghai ranking or that of the Times Higher Education (THE), focus mostly on research, albeit that the attraction for foreign students is also included in the THE ranking. Yet, for example, employment of graduates or registered unemployment is not taken into account in international comparisons, nor are other more subtle measures, like international comparable figures on knowledge, skills, and competences. 
Still, it appears that countries like Korea and Singapore have been able to make the transition from elite to mass higher education more smoothly than has been the case in Europe. Also Kingdom of Saudi Arabia (KSA) is doing well: 3 out 27 Saudi State universities are now in the top 500 lists, and King Abdulaziz University (KAU) is in the top 10 in mathematics. The number of universities in the top 500 from these countries is increasing in the Shanghai ranking, along with an increase in the number of graduates and substantial economic growth. Universities appear to be major contributors to the knowledge-based economies of these countries and are recognized as such. This would be impossible without due attention to quality and excellence within the universities. The degree to which they focus on quality and excellence, not only in research, but also in education is easily ascertained from the strategic plans of several of the universities. Partnerships with the regional environment are also an important element in ensuring excellence.

Yet, world-wide universities, also in emerging economies, struggle to take excellence on board. Newer universities are too easily inclined to model themselves on some of the old research universities with the professor who teaches in large lecture halls according to a curriculum which is based on what used to be understood to contain the main elements of knowledge in that discipline, without much reflection on its contribution to the required traits of graduates in the labor market. Older universities also face difficulties in reinventing themselves in light of the tremendous changes which have taken place in the way societies are organized.

\section{Organizing Universities for the Knowledge Economy}

\subsection{Focus on Research-Based Learning}

Many universities around the world organize themselves to be excellent in research, some more effectively than others, according to the ranking criteria of the Shanghai ranking. The general criteria that universities want is to excel in a number of fields in research, as measured by citations, patents, and levels of attractiveness to national and foreign researchers. They also want to at least have a minimum standard in other fields. This is a good starting point for the achievement of excellence.

Universities are first and foremost concerned with education. A casual look into the strategic plans of universities shows their dedication to excellence in the education dimension as well as along the research axis. Yet, a clear-cut reliance on the needs of graduates is mostly absent. Systematic research on those evolving needs, including the use of the opinions of alumni and their employers in curriculum reform, is more often the exception than the rule. In accreditation procedures there is some attention to these aspects (differing by country), but mostly it is merely lip service. Also systematic thinking about effective learning of students and the 
related educational methods is not always well developed within universities. Educational departments (focusing on university education within their own university) have not always been well received by the "professionals" in other departments and sometimes have lacked the support of the university leadership.

An obvious way for creating a culture of excellence in education is a strong education-research group, which supports the talent development of students from the perspective of the needs of graduates to function well. Such groups also can help greatly in educational innovations, such as problem-based learning or blended learning. International visibility of such groups in terms of publications in journals on learning for the needs of graduates can be helpful in establishing a reputation within their own university. An example is Maastricht University, which pioneered the problem-based approach to medical education with a strong medical education-research group headed by a professor. They also invited dialog with the medical education community through a journal on medical education. Other departments followed along the same lines.

The introduction of university-education research in universities as in Maastricht is certainly not unique. Often such education-research divisions, however, languished and were abolished after a few years of existence. They were not considered by the peers in the different departments as being sufficiently relevant. The key to the importance of their role in Maastricht University seems to have been that they were both general and department specific. Every department has its own professor(s) of medicine, law, economics, and so forth, with a sufficiently conscientious staff to be involved in measurement of education outcomes and feedback on the manner in which examinations are conducted or the way in which curriculum is composed. These groups work together across departments. They are also actively involved in training educators (nowadays in the form of competency as defined by certificate levels).

The context in which the university operates is an important factor in realizing excellence. It is surprising that even new or expanding universities choose to establish themselves as closed shops, even if there are opportunities to locate (for parts of the university) in a business- or industrial park. Medical departments have always been established close to and often jointly with medical (academic) hospitals. Students learn early on what it takes to be a good doctor by combining theoretical learning with learning in practice. Why is this not happening in other areas, such as engineering, the sciences, or business economics if there are private research establishments in the area? Is it fear for mixing the private with the public sector and losing the public edge in the process? Or is it the desire to maintain its own university world comfort zone, keeping at bay and defending the walls against the potentially problematic and threatening world outside? 


\subsection{Universities Actively Engage in Entrepreneurship Education for Graduates}

The twenty-first century graduate is in many respects an intrapreneur or entrepreneur. Routine work will be less and less his or her province. The graduate will have to be a problem solver under situations of uncertainty; playing the role of the troubleshooting Wolf, who steps into fix the awkward problem, in the popular Pulp Fiction movie. The graduate can of course seek the advice of colleagues while working in a team, and higher-ups in the hierarchy may have to take decisions formally, yet it is the graduate who does the ground work for those decisions and is familiar with their ins and outs. This is not discipline-dependent but pertains to all fields and activities. As soon as a problem becomes routine, it can be answered by a machine. Consider the manner in which a computer replies to your questions on airline or rail transport. All of the routine questions are, as a rule, answered automatically.

Problem solving not only concerns the use of knowledge, but also concerns the communication of the solution. It concerns the risks taken in one decision versus the alternative, as most problems in reality are more complicated than the mathematical one of the secondary school where you were presented with certain data, with a question, and only one answer for the problem that you can derive and confirm proudly by q.e.d. (quod erat demonstrandum). They involve considering the consequences of different decisions and looking for the balance in terms of risks and rewards.

These are some of the essential elements of entrepreneurship or intrapreneurship. Intrapreneurship is now a reality for many graduates: they have a great deal of responsibility and freedom to develop their own course of action in the organization in which they work, sometimes on their own, but often in groups. They have to think about alternative actions, using their problem-solving capacities in weighing the alternatives and the risks and rewards attached to them. Yet intra-, or the classical entrepreneurship (establishing and running a business of your own) is broader, as it involves knowledge not only about the product and the way it is produced, but also, however rudimentary, knowledge about finance, marketing, and sales.

Intra- and entrepreneurship are keys to lasting economic development. For too long universities have stood with their backs to intra- and entrepreneurship, not realizing that one can learn how to run a business more or less in the same manner as one can learn other things. Some students may be so qualified that they do not need the university training in entrepreneurship to run a business successfully. Conversely, some students may never learn it. But a major proportion of university graduates would be much better off if they had had the training and indeed were able to start a business. Excellent universities are highly engaged in entrepreneurship education in all faculties.

In US universities, the entrepreneurship of students and graduates has played a role in their history. The Stanford University graduates Hewlett and Packard who 
started their company in a one-car garage in 1939 are an early example. HewlettPackard emerged as a leader in technology and corporate culture, inspiring innovators and entrepreneurs around the globe. Europe also had a wave of entrepreneurship of graduates (in particular from technical universities) in the years following the Second World War, but this virtually ceased in the 1960s and 1970s. Since around 2000, however, there has been a revival, so that for example in the Netherlands, some $3 \%$ of the students start their own company and some $5 \%$ of the graduates do (in 2013). Government, organizations of employers, and universities all work together to encourage and facilitate students and graduates to become entrepreneurs.

\subsection{Universities, Patents and Start-Ups}

University research has mostly found its reward in the contribution to knowledge through publicly available knowledge published in peer-reviewed journals. Individual researchers are often promoted on the basis of such accomplishments. Only recently, some universities also recognized the contribution to knowledge by individual researchers through protected knowledge in the form of patents or in the form of start-ups. For economic development in the country, measures of the quality of universities in terms of the number of patents and the number of start-ups are equally as relevant as the traditional measures.

Not every patent is going to be an industrial revolution to put it mildly. Often patents will end up on the shelf. But so is the case with publications, many of which will be forgotten in a couple of years after having had little or no impact on subsequent publications. It remains a fact, however, that publications in peerreviewed journals and patents have been important as a potential for furthering insights and knowledge.

Equally important to the university as academic research published in peerreviewed journals could be university staff engendered start-ups. The university might well view this as one of the contributions of its research to society and may want this to be formally recognized as such. If this is the case, then also the incentives need to be in place to reward staff members who help start new enterprises in the same manner as those who publish high profile academic journals are rewarded.

\subsection{Venture Capital and "Free" Zones Around University Industrial Parks}

Economic growth is generally achieved by raising labor productivity while boosting overall productivity or "total factor productivity" as economists call it. New 
and increasingly innovative businesses help to achieve this. Excellence in university education and research combined with entrepreneurship are major drivers of innovative businesses. The availability of venture capital and the absence of throttling regulations can contribute to innovation.

Venture capital can be created at the university from university resources or through resources organized by the university, but is more likely to occur in close collaboration between the university and financial institutions or governments without direct responsibility and risk on the university's part as far as these funds are concerned. Venture capital is important for start-ups and essential for spin-offs from the university. Part of the additional economic growth of the US compared to the EU is explained by the substantially higher availability of venture capital in the $\mathrm{US}^{1}$ [11]. In chapter "Excellence in Innovation and Knowledge Economy", Professor Altunbaşak gives examples of the organization of venture capital around universities in Turkey.

The World Bank has demonstrated the impact of regulations in the domains of, for example, applying for a permit to start a business, dealing with construction permits, obtaining electricity connection, and paying taxes on the level of innovation, showing the throttling effect of overregulation. The 2014 Annual "Doing Business" guide documents the regulations according to 11 sets of indicators for 189 countries. Countries that score high on quality of regulation criteria are also the fastest growing countries (World Bank, Doing Business, 2014 [12]).

"Free" zones around university industrial parks could help society to benefit from universities that strive for excellence. "Free" can be a relative notion. Some regulations (for example for environmental protection) can already be considered to be minimal. Yet in others, it would be wise for Governments to learn from international experience in reducing regulation on an experimental basis in some regions. China started to experiment with free economic zones in the 1980s. It has made a remarkable contribution to China's development. Such experiments are useful for the country in order to see which deregulation makes sense for the country as a whole.

\subsection{Build Regional Partnerships}

All of our societies suffer from fragmentation in policy. Educational policy is the domain of the Ministry of Education and Economic Policy is that of the Ministry of Economic affairs, even if the best economic policy is the one that makes the best use of the available talents and their development, in other words: an education policy. This underlines the need for attuning economic and educational policies. This is just an example. Fragmentation is broader than solely between the

\footnotetext{
${ }^{1}$ Venture capital investments represent a very small percentage of GDP, e.g., often less than $0.03 \%$. Exceptions are the United States, where the venture capital industry is more mature and represented in 2012 around $0.17 \%$ of GDP.
} 
economic and the educational spheres. Germany has understood this as part of its drive to create a more sustainable economy, which is more energy efficient and involves reduced $\mathrm{CO}_{2}$ emissions. All German universities are involved in mapping and following this strategic direction of the Federal State.

Building regional partnerships between national governments, regional governments, local and national industry, and universities for extended (say 10-year) periods might well be a way in which universities can best realize their excellence. Such partnerships could serve as the basis for investment plans, supported by Ministries such as Economic Affairs and Education and Science and Technology alike and might well attract additional investment into the region.

\subsection{Excellence in the Knowledge Economy}

University excellence in teaching and in research is not an abstract notion. It is clearly discernable in the development of the region, even taking into account graduates' and university staff's mobility. The development of the region can be reinforced by complementing efforts in the area of venture capital and in overall regional investment plans (of public and private parties).

\section{Good Practice and International Advice}

Education is about learning. Universities are generally good at learning from national and international practice. Practically in all of the areas of excellence discussed, we realize that there are front-runners in educating for twenty-first century skills and in research for socio-economic development. The strategy of a university is based on the insights acquired and developed by front-runners. These insights are documented and translated to their own specific localized situation for implementation. Young universities would like to understand why some have made it to the "top 50 under 50" in rankings and what can be learned from them. Older universities would equally like to understand why in particular more Asian universities are appearing among the top 200. What have they done to accomplish this? "Institutional research" under the leadership of the university President is an essential prerequisite for a university to improve its quality. This should not only cover the research area, but even more so the education and learning agenda of the university, as that is where presumably the greatest contribution to society lies.

An International Advisory Board can help to contribute to the knowledge on good practice. I have myself been a beneficiary of such an international advisory board as President of Maastricht University. Subsequently I was able to contribute to the University of Siegen, the Presidential University of Russia (the Russian Academy for National Economy and Public Administration, RANEPA) and King Abdulaziz University, Jeddah, Saudi Arabia. The experiences showed that 
international advice can help to remove the mental blocks imposed by history that limit the room for a focused strategy and its implementation.

\section{Summary and Conclusion: Excellence Revisited}

Excellent universities are not only high in education and research rankings but are also part of a region that ranks high on the innovation index. This is to say that being excellent should be considered within the framework of shared responsibilities. The university achieves its utmost potential in terms of $21^{\text {st }}$ century skills and capabilities as well as in research, both to develop more public knowledge and to acquire patents and develop spin-offs. The region and the country engage in ensuring feedback, investment, venture capital, and adequate regulation.

It is the duty of the university to strive for the best it can do to ensure that the students can fully develop themselves so as to be well prepared for the future both in the labor market and in wider society, while realizing that university education is now broadly available in society and not reserved only for the privileged few. Rankings and measurements of education output help the university to clarify where it stands internationally in terms of its performance in education and research.

We view world-wide striving-for-excellence as taking research-based learning on board, by embracing problem-based learning, often in settings of developing entrepreneurship and by being proactive with start-ups and patents. The opportunities of blended learning (combining online learning with the regular curriculum) also have far-reaching implications and consequences.

Open Access This chapter is distributed under the terms of the Creative Commons Attribution Noncommercial License, which permits any noncommercial use, distribution, and reproduction in any medium, provided the original author(s) and source are credited.

\section{References}

1. Pritchett, L. (2001). Where has all the education gone? World Bank Economic Review, 15(3), 367-391.

2. Barro, R. J. \& Lee, J. (2010). A new data set of educational attainment in the world, 19502010 (No. 15902). Retrieved from http://www.nber.org/papers/w15902

3. Hanushek, E. A., \& Woessman, L. (2012). Do better schools lead to more growth? Cognitive skills, economic outcomes and causation. Journal of Economic Growth, 17, 267-321.

4. Bok, D. (2014). Higher education misconceived, project syndicate. Retrieved from http://www.project-syndicate.org/commentary/derek-bok-on-policymakers- misconceptions-of-the-role-of-higherlearning

5. Hanushek, E. A., Jamison, D. T., Jamison, E. A., \& Woessmann, L. (2008). Education and economic growth: It's not just going to school, but learning something while there that matters. Education Next, 8(2), 62-70. 
6. van der Velden G. M. (2014). Student engagement in quality assurance and enhancement: Institutional and student body practices. London: Keynote, Westminster Higher Education Forum, January 16, 2014.

7. van der Velden G. M. (2014). Student engagement in learning and teaching quality. In Enhancing Student Experience Conference, Universities UK, London, December 4, (2014).

8. Flexner, A. (1930). Universities: American-English-German. Oxford: Oxford University Press.

9. Acemoglu, D. (2002). Technological change: Inequality and the labor market. Journal of Economic Literature, 40(1), 7-72.

10. Ritzen, J. (2010). A chance for European universities. Amsterdam: Amsterdam University Press.

11. OECD Entrepreneurship at a Glance 2013.

12. World Bank Group. (2013). Doing business 2014: Understanding regulations for small and medium-size enterprises. International Bank for Reconstruction and Development. Washington, DC: The World Bank. 


\title{
Excellence in Education
}

\author{
Guaning Su
}

\section{Introduction}

The most predictable feature of modern society is its unpredictability. We no longer believe that tomorrow will look much like today. Universities must find ways to sustain the most cherished aspects of their core values, while discovering new ways to respond vigorously to the opportunities of a rapidly evolving world.

James Duderstadt, President Emeritus, University of Michigan [1]

These words of wisdom at the beginning of the seminal work "A University for the twenty-first Century" by one of the most respected American university presidents of one of the world's best public universities, describe succinctly the mega-trend of change, challenge, modernization and globalization sweeping the world. Whether we reside in Singapore or Saudi Arabia, this mega-trend cannot be avoided. An excellent education system, culminating in the education provided by a major university, must equip our students and graduates to meet this mega-trend head-on and benefit from its ramifications, whether he or she is a Singaporean, a Saudi or one of the foreign students enrolled in our universities.

King Abdulaziz University (KAU), by embarking on strategic planning and convening its International Advisory Board (IAB), seeks to utilize and exploit this mega-trend of challenge, change, modernization and globalization, and harness and exploit the opportunities it provides to develop a university model of excellence. This chapter proposes the philosophy and approach for KAU to develop an educational model of excellence, drawing significantly from the author's experience in Nanyang Technological University (NTU) in Singapore. The author led the transformation of NTU into a major global research university during his term as President from 2003 to 2011. This required fundamental changes in structure, process, staffing, funding and education. KAU is well on its way towards its own

\footnotetext{
G. Su $(\bowtie)$

Nanyang Technological University, Singapore, Singapore

e-mail: guaning@ntu.edu.sg 
transformation, promoted by a dedicated, wise and resourceful leadership and assisted by close engagement with the IAB.

While the changes envisaged by KAU are all encompassing, this particular chapter focuses on undergraduate education and professional education up to the Master's level. Education of Ph.D. level researchers and academics is closely tied to the research enterprise in the university and best left to this book's other authors (see chapter "Excellence in Research", by Professor Michael Arthur).

\section{Internationalization of University Education and Its Application to Saudi Arabia}

Each nation among the 193 members of the United Nations has its own particular characteristics resulting in continuous changes in international position and standing. Prominent among them, in contrasting ways, are the special cases of Singapore and Saudi Arabia.

Singapore Skyline at Marina Bay (photo by Guaning Su)

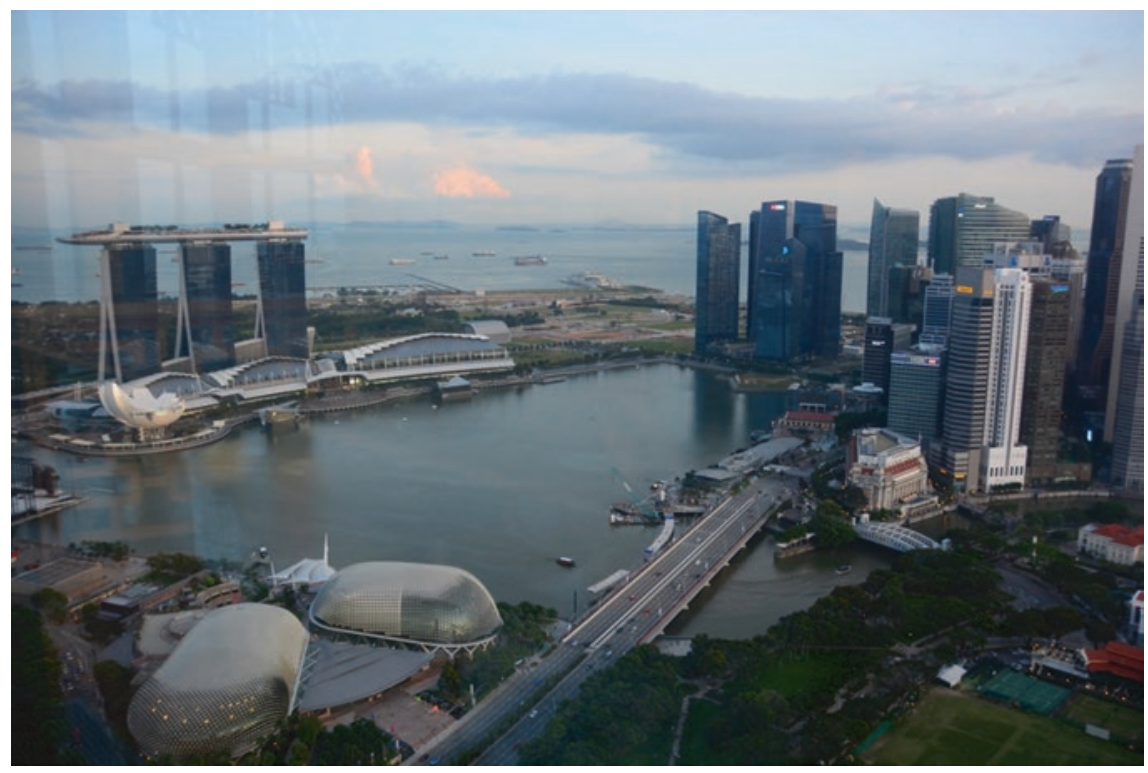

The Singapore story is a "poor boy made good" story of a small tropical island, devoid of natural resources other than its maritime location, striving against the odds to succeed and prosper. There is always a degree of angst in the Singaporean psyche, almost as if we cannot quite believe that we have come thus far. Singaporeans tend to have nagging doubts that it may be all be a mirage that can disappear like Cinderella's outfit, horses and coach on the stroke of midnight 
in the well-known fairy tale. As a result, we are obsessed with planning for the worst-case scenario and are overly cautious when considering possible courses of action that have not already been tried and tested by others. Engineering fundamental change with such a prevailing culture is always a challenge.

Saudi Arabia has gone through changes no less remarkable than Singapore. In a mere two generations the lives of most Saudi citizens have undergone complete transformation, from a predominantly nomadic way of life, struggling against the elements, to being citizens of one of the world's most prosperous countries [2]. Saudi Arabia today is a modern nation with every conceivable convenience and a high standard of living secured by an enviable position as the nation with some of the world's largest proven petroleum reserves [3]. Even so, the far-sighted Saudi leadership is already working on a post-petroleum future and embarking on the development of alternative industries. There is also concern among the leadership about the effect of petroleum wealth on the levels of motivation and energy among some Saudi youth. Reliance on foreign workers and its implications for national resilience is yet another concern. Universities such as KAU play leading roles in creating an increasingly diverse, robust, resilient and promising national future by educating its future leaders, professionals and citizens. Universities, as the main instrument in the process of the preparation of young people for high skilled jobs, must also help to overcome the inertia generated by a population accustomed to government largesse.

Alternative energy costs converging with oil and gas [4]

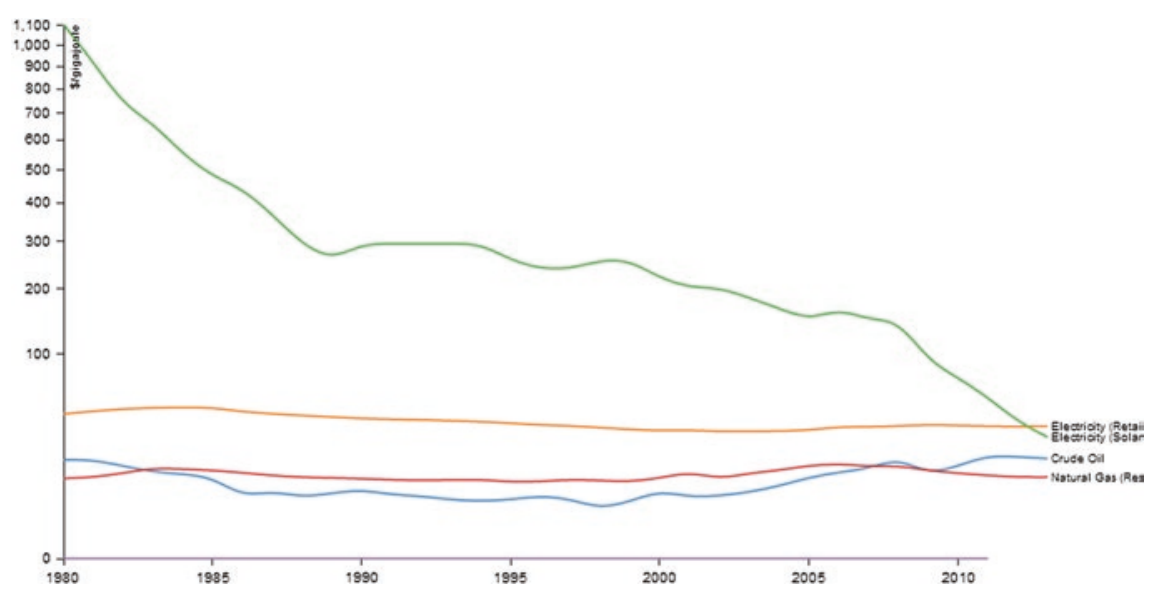

\section{The Role of Religion}

Religion plays an important part in both nations but in contrasting ways. Singapore is a multi-ethnic, multi-religious nation that has an enviable record of racial and religious harmony over the five decades since independence. One 
interesting illustration that is highly symbolic of the Singaporean approach towards multiple religious coexistence is the commissioned military officer corps, which is blessed by leaders of no less than seven different religions.

Saudi Arabia is the guardian of the two holiest places in Islam: Mecca and Medina. The nation hosts millions of pilgrims annually with remarkable levels of efficiency and hospitality. This unique position in Islam, along with the influence consequential to it being one of the world's largest oil producers, bestows on Saudi Arabia a commensurate level of global influence and a stature unmatched in West Asia and in the Arab and Islamic world. An important role of leading universities such as KAU in Saudi Arabia must be to educate the future leaders of such an important nation. This educational process requires KAU to inculcate in all its students a broad education with an international and global outlook, a worldview. Graduates possessing this kind of outlook and who have benefitted from wideranging internationally oriented education would be suitably prepared to provide leadership in an enlightened administration in support of the nation's leadership. KAU graduates need practical hands-on experience and need to make active contributions in professions relevant to the needs of Saudi society and its economic structure. In order to fulfil such requirements, KAU is therefore required to educate the nation's youth in a wide range of specializations and for a wide variety of professions. Although particular curricula depend on the expected fields of endeavour of future graduates, it is a well-accepted view among the world's best universities that a broad preparation in the humanities and sciences encompassing a wide range of professions would be of benefit to both the graduates and the nation.

King Faisal Convention Center at King Abdulaziz University (photo by Guaning Su)

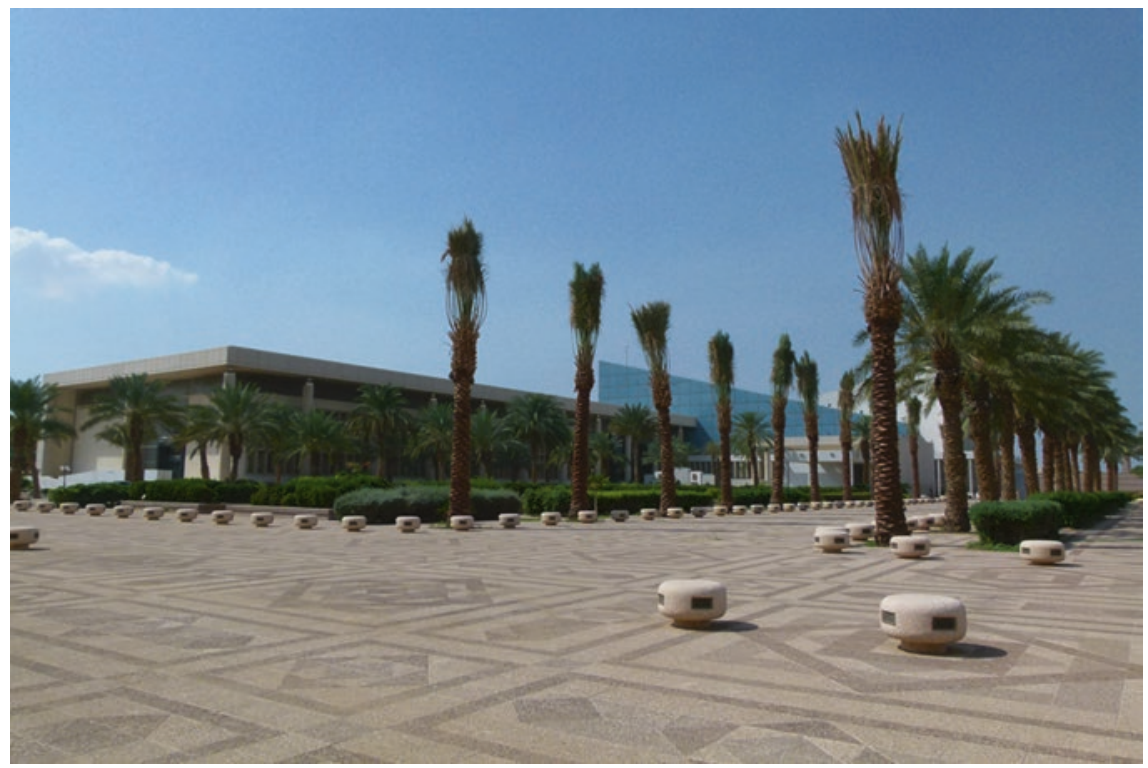


Internationalization of the education model in KAU involves creation of opportunities for KAU students to be exposed to international ethnic and religious diversity and international, interdisciplinary and interfaith dialogue. Judicious exploitation of such opportunities will enable KAU graduates to adapt and tailor best international practices to create a uniquely Saudi outlook that takes into account the globalized world's complexities. As the graduates advance in their careers they will be able to assist in the formulation of appropriate effective responses of a modern Islamic country to the pressures and impact of globalization. Successful reconciliation between traditional Islamic values and the impact of rapid economic development and modern technology can in turn serve to accentuate Saudi Arabia's leading position among the world's Muslim nations.

\section{Issues Faced by a Mainstream Saudi University in Internationalization}

By virtue of its history, Saudi Arabia is by and large a conservative society. Not only was the traditional nomadic way of life common until a couple of generations ago, the special position of the Saudi monarchy and religious establishment as the guardians of the two holiest places in Islam, the cities of Mecca and Medina, confer upon the Saudi population a special status and obligation to be exemplars of the virtues extolled in the Holy Quran. This conservatism is a national strength in that it provides the Saudi population with solid cultural heritage and stamina. This enables them to resist corrosion by unwanted and undesirable aspects and influences of modernization and allows Saudi Arabia to develop societal resilience. This can also be a liability if, as a result, Saudi Arabia concentrates too much of its gaze inwards and shuts out too much of the outside world in an effort to keep corrupting influences at bay. KAU has a key role to play in reconciling the apparent differences between conflicting values.

A university is positioned as a summit of learning. In today's world, this must include learning in an intellectual and questioning manner, rigorously addressing the complexities abounding in the kaleidoscopic outside world. Among Saudi universities, KAU is unique in the kingdom in terms of historical position and geographic location. Not only is KAU holding the name of the founder of Saudi Arabia, King Abdul Aziz, it is also located in the major Red Sea Port of Jeddah housing one of the country's main airports and is well connected internationally. It is also close to Mecca and Medina, the two most potent symbols of Islamic culture and values. The port and airport open the doors of the world for KAU students so that they can understand and absorb and adapt to influences from the outside world. The proximity of Islam's Holy Shrines is a perpetual reminder to KAU's learning community of Saudi Arabia's unique position and responsibilities.

As KAU embarks on its Third Strategic Plan, there is an opportunity of exceptional potential for the university to stand out from the pack, not just in Saudi 
Arabia, but also globally, by creating a new model of education- "KAU Education - the Best of Both Worlds: the modern world and the Islamic World".

Sun sets on Jeddah Seaport (photo by Guaning Su)

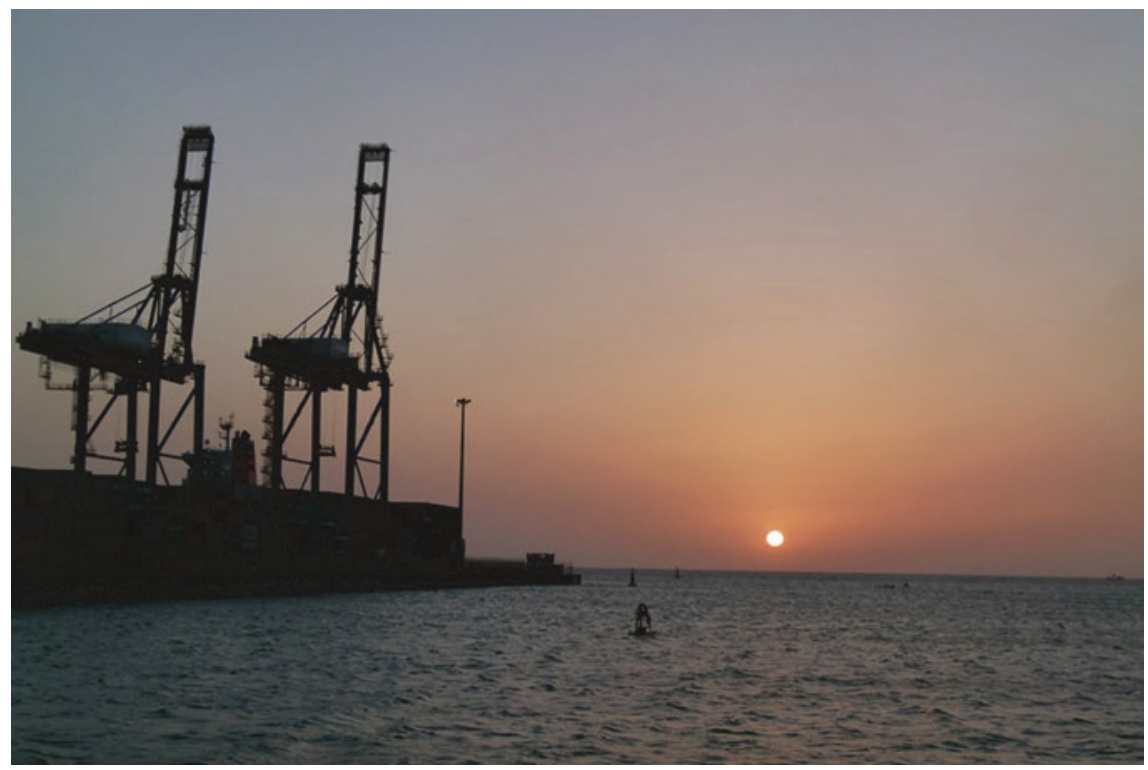

\section{Importance for Saudi Students to Understand and Tap World Mega-Trends}

KAU education can be seen as a bridge between the modern world and the Islamic World. The modern world has witnessed an exponential explosion of knowledge and rapid proliferation of pathways to access knowledge. Such an explosion of knowledge has however brought in its wake untruths, half-truths, unverifiable claims, propaganda and misinformation of every conceivable variety. The world is only now beginning to attempt to sift the gems from the chaff.

Another modern trend is the proliferation of new discoveries at the boundaries between disciplines, the so-called trans-disciplinary research and holistic approach to problem solving. Saudi Arabia itself is an excellent example. Being energy-rich and water-poor gives rise to opportunities for synergy between petroleum, environmental and agricultural disciplines, due to the close link between water availability and food production, as well as the trade-offs between water recovery, desalination and energy consumption. The opportunity to discover and develop solutions at the boundaries of these very divergent fields could result in a leading position for Saudi research, innovation and industry. Saudi Arabia can take a leading role in development of results that optimize the input of energy for agricultural production and clean water output. 
On the humanities front, there is the challenge to develop the interface between the traditional Islamic values of the historically mainly nomadic Arabian Peninsula on the one hand, the highly developed infrastructure of modern Saudi Arabia on the other, and the prosperous and well-travelled Saudi populace. This poses important questions concerning Islamic values and culture in a modern context. Results from research on these areas can be readily embedded in undergraduate and professional education programmes at KAU.

Prince Faisal bin Salman, Governor of Madina, (right) receives in his office in Feb. 2015 the KAU team who conducted a study on the volcanic regions in Madina as KAU Vice-President for Graduate Studies and Research (back) looks on

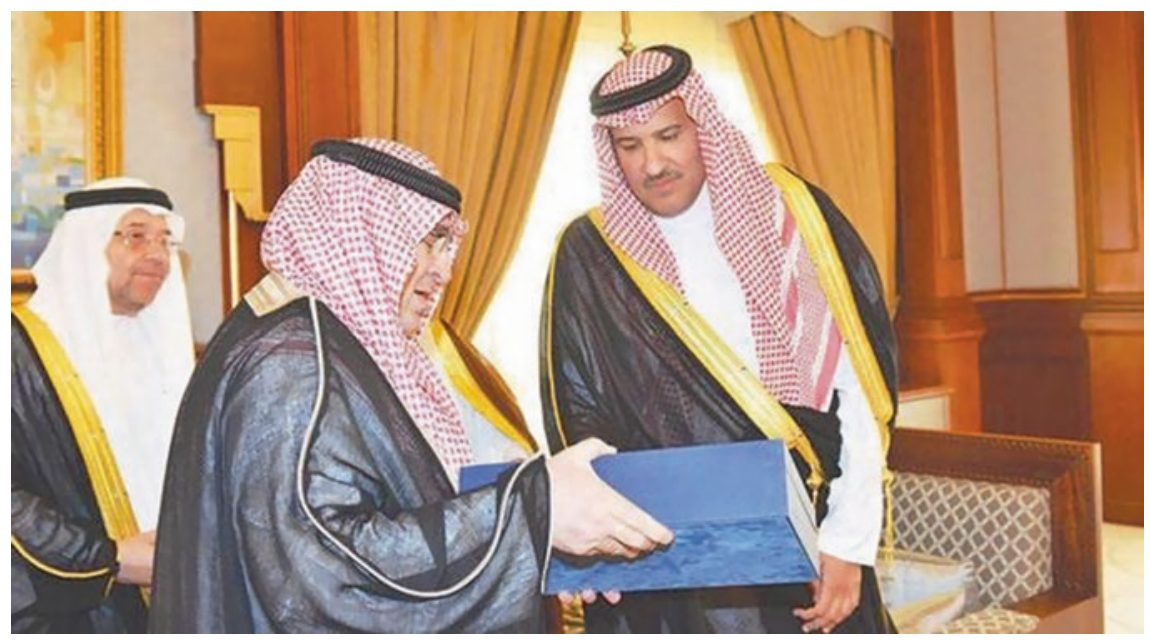

History tells of the regular rhythm of the rise and fall of great powers and civilizations. Both Asia and the Middle East had glorious periods of pre-eminence historically but it has so happened that modern technology has been mainly led by Western Europe in the last 300 years. The United States only began the progress that led to its present position of prominence some 100 years ago. From the perspective of the time scale of millennia, the dominance of the West in technology might perhaps be seen to be a transient phenomenon.

Asia is already starting to reclaim its past stature, led by China, Japan and Korea, proving that technological progress is not the sole preserve of the West. If we look back at the flowering of Islamic culture during the period the Moors were in Southern Europe and the Caliphate of the successors of Prophet Mohammed (p.b.u.h) spanned the entire Middle East and Southern Europe, it is clear that Islam has historically provided fertile soil beneficial to a society of intellectual excellence. Ideas and inventions with enduring world impact flowered under Islam at that time.

This can reoccur with the Islamic world and with Saudi Arabia. KAU can be an important agent of change, leading the way with an educational model of 
excellence. The convergence of Islamic values, modern technology and the internet provides fertile ground for the grooming of KAU students. As a major university with close to 100,000 students, KAU can be the reliable portal to the world for its students in the first instance, and the students themselves can, in their turn, likewise serve as an important portal for Saudi Arabia.

Photo of the 1st KAU International Advisory Board meeting held on KAU Main Campus

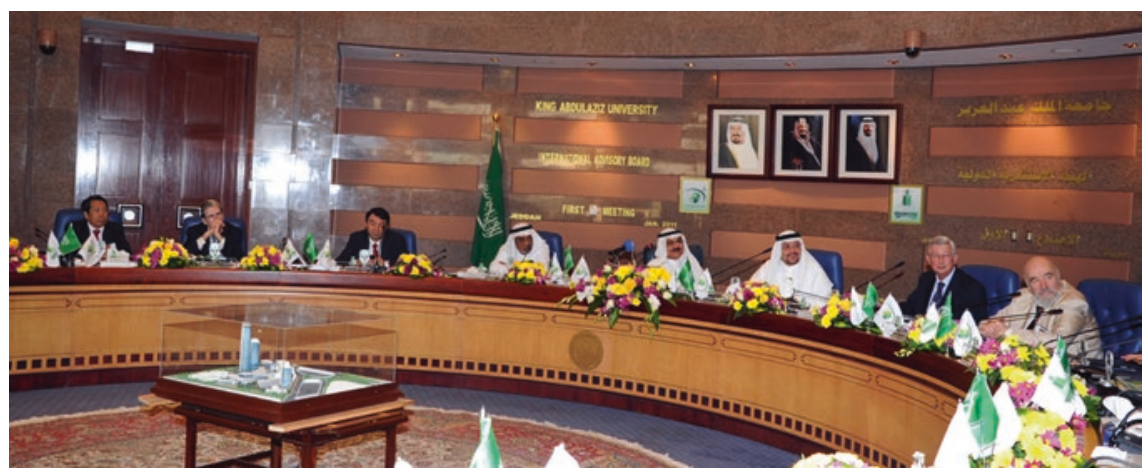

Such a role as an internationalization portal has major implications for KAU. This can be seen as one of the driving forces that led the university to establish the IAB. It is also an important driving force behind the establishment of KAU's first two strategic plans and the current preparation of the third strategic plan. Indirectly, it provides part of the impetus that the university leadership has drawn on to enhance KAU's international reputation that has resulted in increasingly higher international rankings.

Preparing such a large university for strategic re-positioning is by no means an easy feat. It starts with an administration open to ideas, open to and able to implement change. It needs highly qualified, active research faculty who are not only international authorities, but who are also knowledgeable about Saudi Arabia and able to apply their expertise to the country's benefit. Many of the strategic plan initiatives are driven by such considerations. Guided by the university leadership and with the support of the IAB, they will be implemented progressively over the course of the next few years. 
KAU Dean of Student Affairs (4th from right) and KAU Dean of Admission and Registration (4th from left) pose in a photo with new graduates

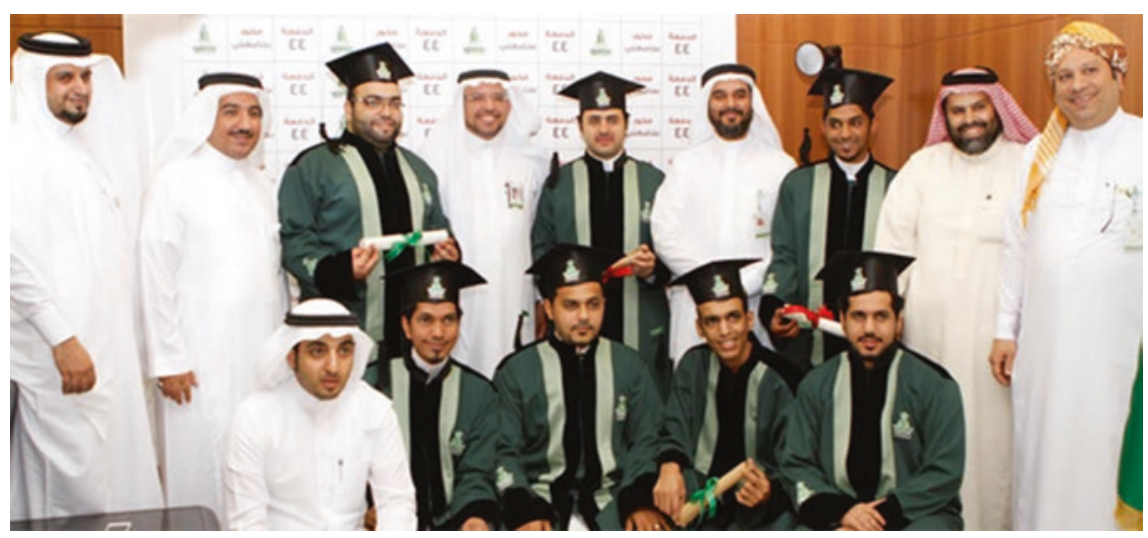

\section{KAU Education}

The KAU Education model must be tailored to Saudi Arabia's national and regional circumstances and requirements. Therefore, the model can be expected to be different from other international universities. However, there are common threads running through the best models of university education despite cultural differences.

In 2007, responding to Singapore's national need for economic transformation as a high value added society, Nanyang Technological University in Singapore convened a "Blue Ribbon Commission" to undertake a bottom-up review of NTU's undergraduate education. The recommendations of this Blue Ribbon Commission review have been implemented progressively over many years. It was also a key element of the requirements driving the NTU Campus Master Plan completed in 2010, the recommendations of which are being implemented in phases [5]. Some of the methods and outcomes of the NTU review as well as reviews conducted by other universities could be adapted for KAU. The following sections shall suggest aspects that may be applicable to the development of a KAU Model of Education.

First develop qualities and virtues of the self. So equipped, establish a harmonious and strong family. When all families are strong, the country is resilient and well governed.

Only then can we solve the world's problem successfully - Confucius

Taking heed of the advice of the ancient Chinese sage Confucius, what should be the profile of a KAU graduate?

I am sure many will agree on the following five desired attributes:

- Moral character

- Disciplinary depth and life-long learning 
- Creativity and innovation

- Leadership and teamwork

- Professionalism and public service

There may be other possible classifications and combinations but these characteristics are basic to an educated person, whether in Saudi Arabia or Singapore. As Islam is of paramount importance, permeating all aspects of life in Saudi Arabia, the five attributes should be interpreted in the Islamic context.

\section{The Importance of Residential Education}

I am a fervent believer in the benefits of residential education delivered by teachers who are outstanding role models inculcating the desired values in our graduates. The 18-22 age group attending university is at a formative and impressionable stage. Providing them opportunities to develop in a microcosm of society with light-touch supervision develops social abilities that stand them in good stead when they graduate and proceed to the wide outside world. Residential education requires the organization of residential halls on campus and training of appropriate academic mentors. This being Saudi Arabia, Islam is of paramount significance in all aspects of life including campus life. Maturing into adulthood on an Islamic campus dedicated to the pursuit of knowledge has the additional benefit of showing the youth how they can reconcile traditional Islamic beliefs and values with the activities necessary for a modern society and nation.

There are of course difficulties in implementing residential education in a 100,000 strong student body like that at KAU. However, many of KAU's students are part time. Of the remaining, perhaps the highest performing students can be given priority in terms of eligibility for on-campus residence, especially if they are engaged in scientific or entrepreneurial pursuits. By this means, at least the best of the graduates would receive the benefit of a residential education.

Another important issue relates to the idea of co-educational campuses where men and women study together. This is common among international universities. While an experimental institution such as the King Abdullah University of Science and Technology (KAUST) can obtain special permission for such an educational model, KAU as a mainstream Saudi university is unlikely to be able to do so under prevailing circumstances. While this is a constraint on a broad education, it is reflective of current Saudi society and is readily accepted as such. There is no need to be dogmatic on this topic. 


\section{Student Governance}

Regardless of whether the student resides on or off campus, an effective system of student government is a key to life skills education and effective governance of students in the university. At NTU, there are three categories of student organizations. One is residence based, organized by campus residential halls. This is the most robust of the three categories. Then there are student organizations in each school based on major study disciplines. The third, purely voluntary, are student initiated interest groups covering areas such as music, sports, community service and culture. Above all these organizations is the umbrella organization, the Students Union headed by an elected President. KAU may wish to develop its own model taking references from universities around the world. Two features are important in my view. Fundamental building blocks such as residential halls provide a sense of belonging at a more human scale in a mega-university. A central unified organizational structure that truly represents the students and is regularly engaged by university administration is also required.

The purpose of student government is not only to allow students to prepare themselves for their future adult political environments. It provides opportunities for the natural emergence of student leaders. It is also an effective means of communication between the university leadership and the student community, especially during times of crisis. A case in point being at NTU, where having such a communication mechanism in place proved to be invaluable during the 2003 SARS crisis.

\section{A Broad Arts-Science Education as the Foundation}

An enquiring mind is a great asset for intellectual curiosity, motivation to explore and life-long learning. In the best universities of the world, a strong foundation in the Arts and Sciences is incorporated in the educational model. This has also been the direction set at the two major Singaporean universities: Nanyang Technological University and National University of Singapore, both of which have risen steadily in rankings in recent years.

For example, at Stanford University, renowned as the source of Silicon Valley, Integrated Humanities was a requirement for all entering freshmen with readings assigned even before arrival on campus. In addition, science requirements were satisfied through course requirements and electives. This broad foundation is common among the very best universities such as the Ivy League in the US, Stanford, MIT and Caltech, as well as the best public universities such as University of California, Berkeley and University of Michigan.

Such a foundation programme would need to take into account local Saudi conditions. There is a rich trove of literary tradition in Arabic to draw upon for the humanities. Islamic art and mosque architecture could perhaps be fertile domains 
for the arts, while the rich Islamic and Arab heritages in the fields of mathematics and science could prove rich knowledge resources for the sciences. Islamic history and other regional history might also be considered for inclusion as suitable foundation studies subjects.

Former KAU Vice President for Development (left) receives the ABET site reviewers during their visit to KAU

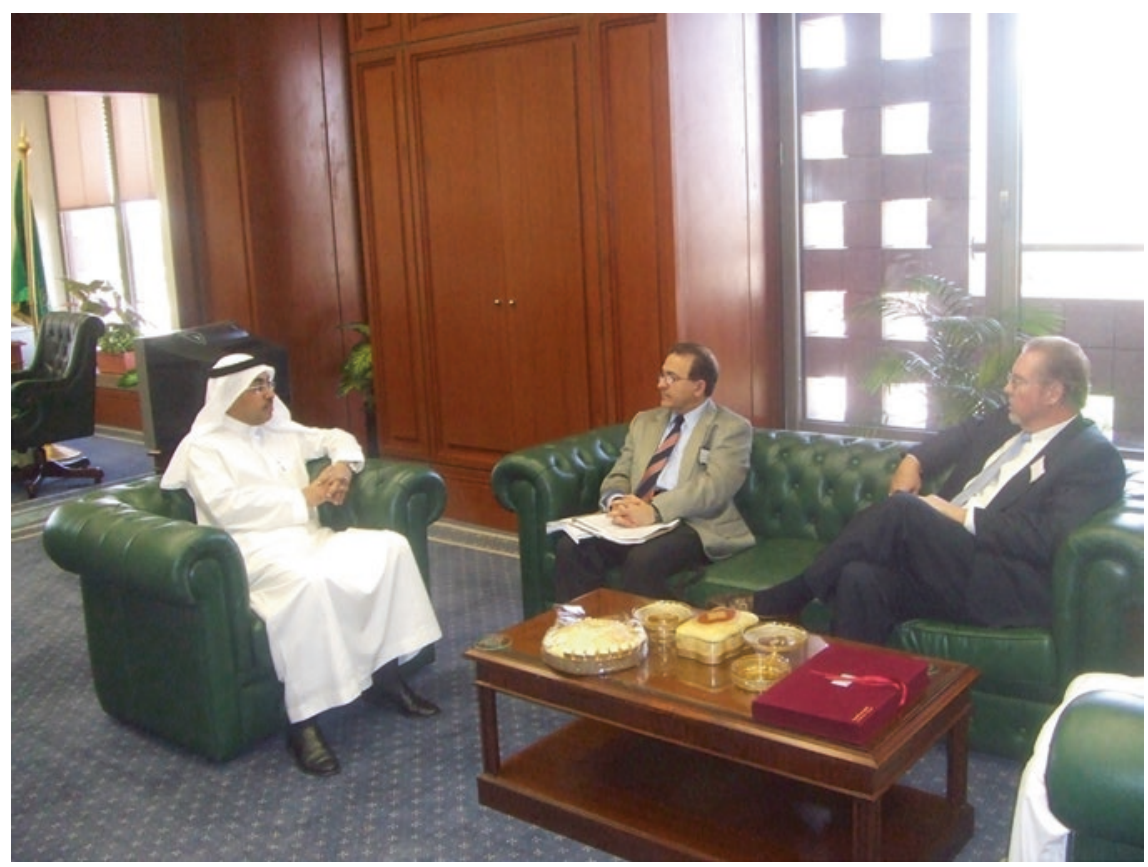

\section{Professional Education}

For a developing country such as Saudi Arabia, professional education is particularly important. Graduate engineers build infrastructure and staff the growing industries. Business graduates enable enterprises through marketing and finance and accountants assure the markets of transparency and objectivities. Architects, doctors, dentists and numerous other professions can be added to the list. KAU has taken the wise decision of seeking accreditation as far as possible, for such international standards help KAU graduates stand out among the crowd. KAU will, I am sure, continue to enhance the professional education based on international quality standards and assurance. Providing a common Arts-Science foundation to all may however pose a challenge due to curriculum overcrowding. I am sure KAU will find its own solution. In the case of NTU, many specialized courses that overloaded students were eliminated from the curriculum. Instead, the emphasis 
was redirected and is now on practical work place experience through internships, which often lead directly to employment.

\section{Undergraduate Research and Elite Science and Technology Programmes}

A common problem faced by mega-universities such as KAU is the wide spectrum of academic abilities among the large student population. It is clearly necessary to tailor courses and programmes for the majority of students. This however leaves exceptionally capable students in the lurch. They may get bored and distracted by the normal curriculum. Some of these able students may have the potential, with the right preparation, to become the new generation of Saudi academic leaders.

A strong undergraduate research programme is an important component of elite science and technology programmes. It can also serve to kindle interest in research among undergraduates. A good undergraduate research record with publications gives students a distinct advantage when applying to the best graduate schools. To be effective, such a programme should be well funded, open to as many applicants as possible and engage the best research-intensive faculty members as supervisors. This is already possible given the rapid increase of research at KAU.

In addition, intensifying and extending the scope of programmes for the very best of KAU science and engineering students would complement the undergraduate research scheme in the interests of producing the next generation of Saudi academics.

\section{Internships}

The career opportunities open to KAU graduates will become increasingly diverse with the spread of the effects of globalization. It is no longer cost effective, nor is it feasible, to train graduates for every kind of job. Thus, there is a need for professional education to return to fundamentals. Additional learning is often acquired on the job or by specialized training programmes arranged by employers.

KAU graduates can get a head start with on-the-job learning by interning with employers of interest. Although this is time consuming, it provides a form of learning impossible to duplicate in a classroom. Often, good performers on internship are snapped up by the employers as their worth has already been proven during their internship.

Although the range of industries and businesses in Saudi Arabia may not provide all the varieties of internships desired, an effective means of overcoming this problem is by seeking internships outside the country. Such foreign internships have the added advantage of also providing valuable international experience. 


\section{International Experience}

To prepare students for the globalized environment they will face after graduation, it is very helpful if, during their period of study at KAU, they spend some time; say up to a semester, in one or more foreign countries. The most common arrangement for this is by means of student exchange. As English is becoming the language for international exchange, it is imperative that English standards and language proficiency be maintained at a high level at KAU. It is also important for KAU to develop courses in English for incoming exchange students, as the number under exchange with any partner institution tends to be driven by equity considerations.

A photo taken at University of Vienna during one of the KAU IAB meetings (photo by Guaning Su)

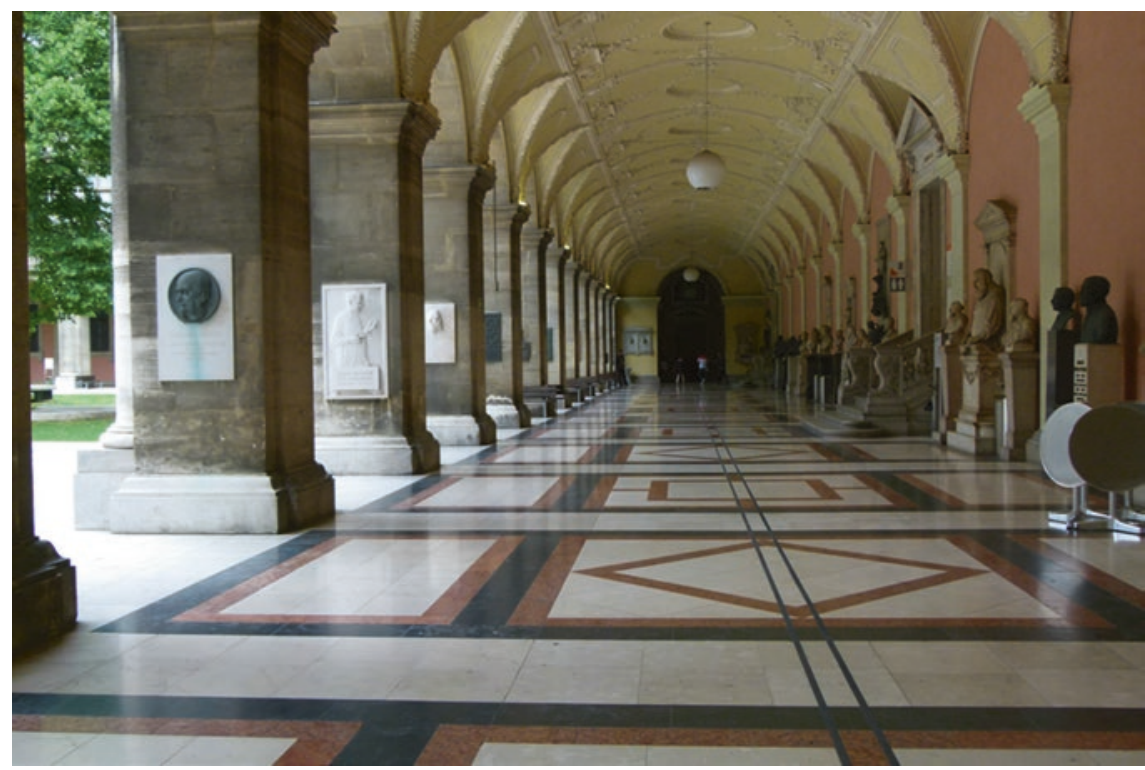

\section{Internationalized Education Promoting Understanding of Saudi Arabia to the Outside World}

KAU students going international are the best ambassadors for the country. Because of the special position of Saudi Arabia, they also represent the Islamic world. Just as it was an eye opener for the members of the KAU IAB to visit Saudi Arabia, to interact with academically gifted students and dedicated high performing faculty, international experience for KAU students would change foreign countries' perception of Saudi Arabia and its citizens for the better. 
KAU President Osama Tayeb (left) and KAU Vice-President for Business and Knowledge Innovation (center) and KAU Vice-President for Academic Affairs (right) during one of the IAB meetings held on campus

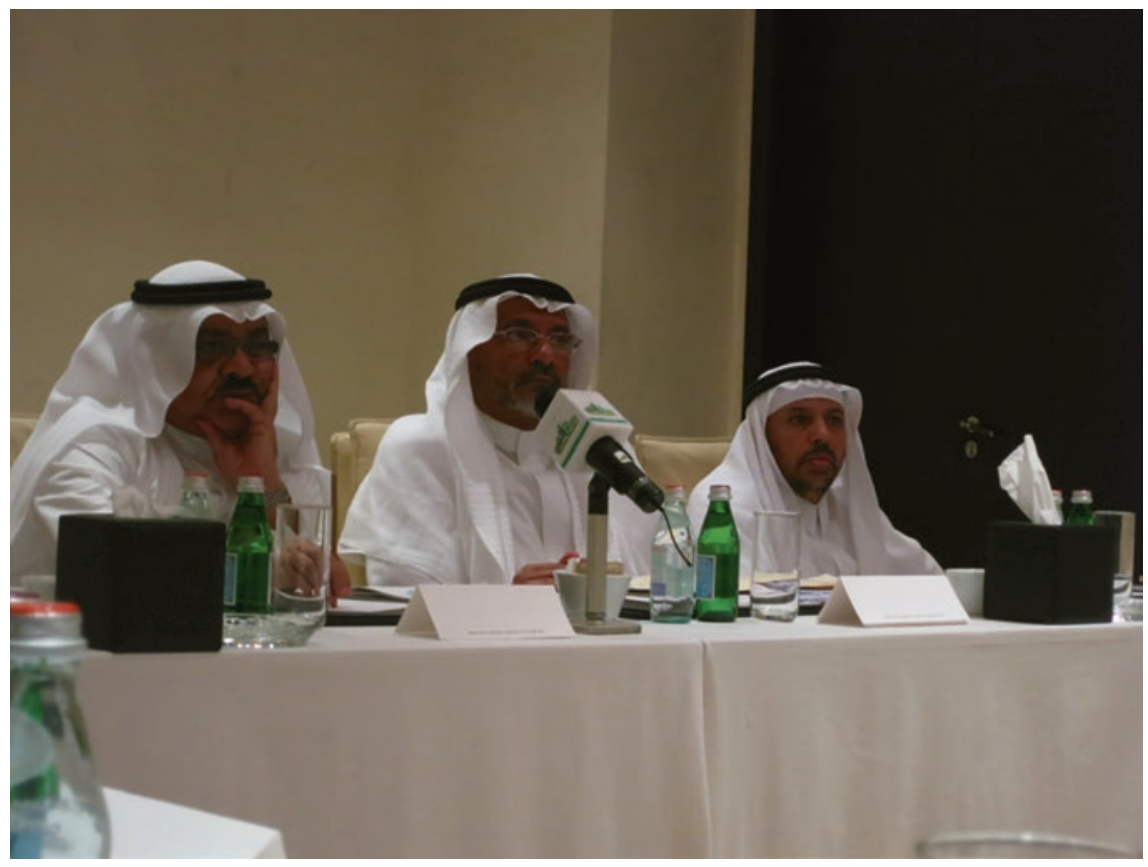

\section{Adaptation of Best Practices Abroad}

Internationalization of KAU education spreads the university's wings by the frequent presence of its faculty and students on foreign soil. Such contacts often require the support of foreign universities' leadership. Investing time in developing KAU's international network to support its educational model provides KAU leadership with opportunities to interact with and observe the operations of renowned and distinguished global universities. Such interactions often yield important "ah ha!" moments of revelation in understanding the practices of good role models. In addition, the development of such networks and links cannot but succeed in raising KAU's international profile and provide its leadership with case studies from which important KAU initiatives can be launched and ideas adapted. 
KAU Vice-President for Graduate Studies and Scientific Research (right), KAU Acting President (2nd right), Saudi business tycoon Sheikh Saleh Kamel (2nd left), and KAU Vice-President for business and knowledge innovation take part in the 10th board meeting of Wadi Jeddah

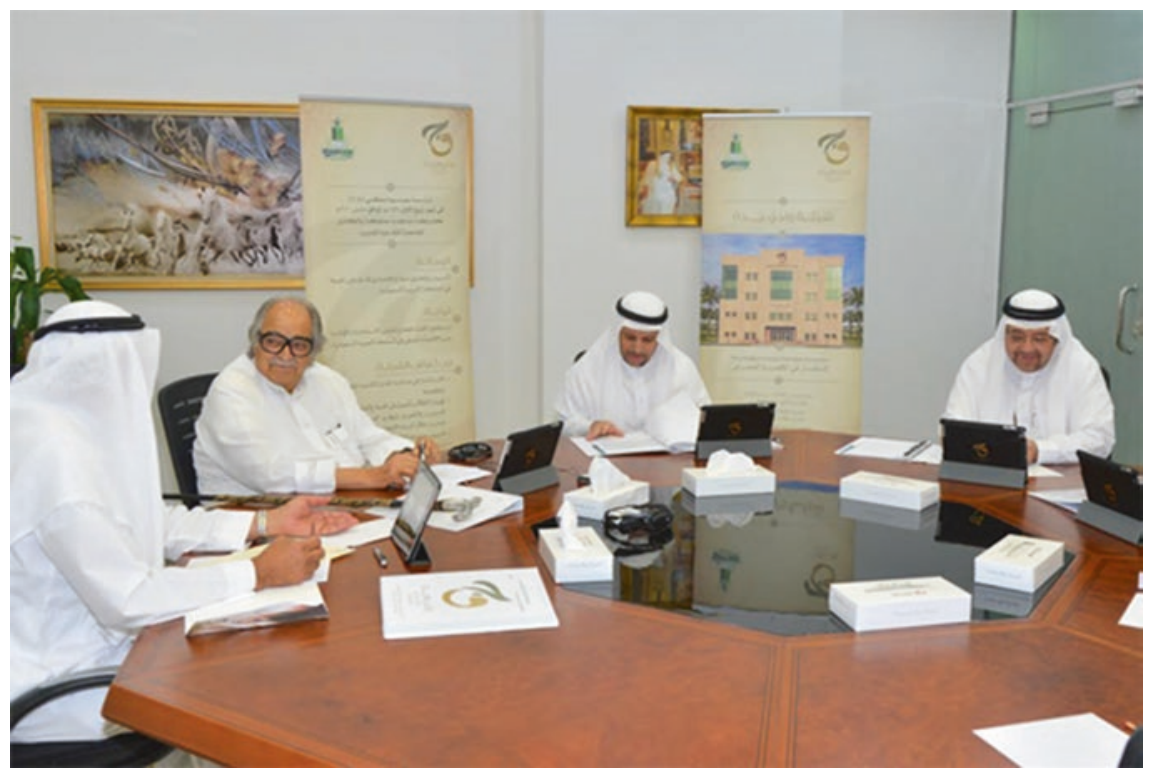

\section{Innovation: Linking up Industry, Faculty and Students}

Saudi Arabia did not have an industrial economy until the advent of petroleum as the principal fuel driving the modern technological revolution. Today, modern technology continues to rely heavily on the burning of fossil fuels despite the development of advanced nuclear generation technologies. However, the world is facing an inflexion point.

Increasingly, the world is coming to the realization that the human population on this planet and the technology at its command are now capable of influencing the macro environment on Earth. The rising consciousness of climate change caused by human activity, coupled with development of advanced materials and techniques for power conservation, is now increasingly turning the tide of public opinion in favour of sustainable power generation technologies. Solar energy is approaching parity in cost with conventional fossil fuel fired power plants, wind energy use is widespread, and electric/hybrid vehicles and improved building techniques are reducing the growth of energy consumption. This is a mega-trend of the 21 st century and holds both risks and promise for Saudi Arabia.

The obvious risk is the reduction of the importance of petroleum to the world's energy needs, resulting in the worst-case scenario in a collapse of oil prices 
adversely affecting the dominating mainstay of the Saudi economy. While this is an unlikely scenario, Saudi Arabia would be well advised to prepare for the day when its position as one of the major producers of the planet's dominant energy source is no longer to be taken for granted. Among other things, KAU should ensure that its graduates are well prepared to contribute to the economic transformation of Saudi Arabia that is likely to take place within their working lives. One possible opportunity is tapping the Arabian Peninsula's abundance of sunlight to develop solar power plants in the largely empty desert interior.

Preparation for a post-oil future for Saudi Arabia has already begun. Specialized courses on these issues should be provided to KAU students on topics such as Sustainable Energy, Ecology of the Arabian Peninsula, the Water-EnergyIndustry nexus, Advanced Materials and Economics of Sustainability.

At the same time, KAU must lead the way in generating innovations for the future diversification of the Saudi economy. A focused approach as KAU develops its research intensity is necessary to complement the national economic development plans. Entrepreneurship education should be provided to those who are so inclined so as to maximize the likelihood of practical applications of research results. In so doing, engagement of existing industries is necessary but is not in itself sufficient. To give these efforts a boost, industries where Saudi Arabia has comparative advantage should be engaged, even if they are foreign, since many of the industries needed for Saudi Arabia may not exist in the country yet. With the financial strength of Saudi Arabia and research excellence in the university, combined with students inclined towards innovation and enterprise, the work being accomplished at KAU today can lay the groundwork for the industries of Saudi Arabia tomorrow.

In this context, two programmes can be considered. One programme we found useful in Singapore is to develop an Entrepreneurship Minor Programme open to all students. It helps to create an enterprising entrepreneurial atmosphere on campus. Whether the students become entrepreneurs on campus, upon graduation or subsequent to gaining working experience is not important. The main result is planting the seeds of entrepreneurship in KAU graduates. The design of such a programme should however be tailored to the specific needs of the university and the nation.

The other programme that is helpful is to build incubators or accelerators on campus that allow researchers and innovators, including undergraduates, to trial their ideas and apply their research to the real world through the building of prototypes and demonstrators to spark the interest of customers, industry and investors. It takes a considerable period of time to build such mindsets and habits among students and professors and it is therefore important to start early to build the habit on campus and to engage industry, angel investors and venture capital. Wadi Jeddah, set up by KAU to commercialize KAU innovations and to encourage innovation and entrepreneurship, links KAU closely with industry, a most worthwhile objective. 


\section{Building National Resilience}

An important role of any national university such as KAU is to build national resilience as a hallmark of an excellent education.

National resilience requires first of all a confident self-image. Regardless of the diversity and range of opinions in the world concerning Saudi Arabia, it is important for Saudi citizens to have a consistent self-image that debunks any negativity in the perception of the rest of the world. Such an effect is best developed in the Arts-Science Foundation Courses that all KAU graduates should go through. For example, in studying the religion of Islam, beyond learning of the rules and requirements and studying the Holy Quran, KAU graduates should be able to engage in intellectual discussions on religions other than Islam and if need be, explain to adherents of other religions how Islam serves as guidance for life and contributes to the common good. As another example, students should learn how Saudi Arabia works as a monarchy. They should also understand the benefits and pitfalls of the endowment of rich petroleum reserves and the necessity to create a future Saudi Arabia that plays its role in sustaining the Earth's resources. There is no need to be dogmatic in building national resilience in this manner. It should be structured, not as propaganda, but as objective learning that is helpful for Saudi citizens to ensure kinship with their fellow citizens and solidarity within the nation.

\section{Conclusion}

In this chapter we have outlined how educational excellence can be built in King Abdulaziz University. As doctoral education is closely tied to the research enterprise, it is left to the appropriate chapters on research. This chapter therefore focuses on undergraduate and professional education. Another area left uncovered is education in the practice of medicine which is normally the preserve of the university medical sectors and hospitals.

A discussion of national requirements of Saudi Arabia was followed by proposals to build 'excellence in education' from its foundation building blocks upwards. We started with desired attributes of KAU graduates and advocated a strong ArtsScience Foundation for all students. This was accentuated by 'undergraduate research for selected students', 'residential education' and 'international experience'. Life skills were practiced through 'student governance'. Finally, we touched on how we can maximize the societal contributions of KAU and its graduates through 'innovation and entrepreneurship' thereby helping to develop next generation industries and most importantly of all, adding to and reinforcing the "national resilience' of Saudi Arabia. 
Open Access This chapter is distributed under the terms of the Creative Commons Attribution Noncommercial License, which permits any noncommercial use, distribution, and reproduction in any medium, provided the original author(s) and source are credited.

\section{References}

1. Duderstadt, J. A. (2000). University for the 21st century. Ann Arbor: University of Michigan Press.

2. Encyclopedia Britannica. (2015). Saudi Arabia. Retrieved from http://global. britannica.com/EBchecked/topic/525348/Saudi-Arabia/259142/Other-resources

3. Knipfer, C. (2013). Arriving at the kingdom: 'A journey to Saudi Arabia Pt.2'. Retrieved from www.reallygoodblog.com

4. McConnell, B. (2013). Solar energy: This is what a disruptive technology looks like. Retrieved from www.medium.com

5. Shah, H. et al. (2007). The blue ribbon commission report on undergraduate education. Singapore: Nanyang Technological University. 


\title{
Excellence in Research
}

\author{
Michael Arthur
}

\section{Introduction}

World-class universities are defined as providing an excellent undergraduate and postgraduate education, informed by both the quality and extent of their research activity and profile. They conduct research of the very highest international quality and their work informs some of the most important scientific, technical, arts, humanities and social developments in global human society.

Although such world-leading research features prominently, most world-class universities pride themselves in the quality of their graduates and their ability to contribute to global society. To be recognised as being among the very best universities in the world, both education and research must be at the very highest international level of quality, and there is evidence that both are having a significant impact on global society, through translation, innovation and policy formation.

The relentless pursuit of new knowledge is a characteristic of global human endeavour that is of fundamental importance to the future of our planet. Research excellence may be provided by universities, national institutes, government agencies or by industry, but it is critically important that it develops widely across the entire spectrum of global cultures. This diversity of engaged cultures is a critically important element of the most creative research environments and it is an essential element of solving the world's most complex problems.

\section{Definition of Research}

There are many different definitions of research. The OECD defines research as "creative work undertaken on a systematic basis in order to increase the stock of knowledge, including knowledge of man, culture and society, and the use of this stock of knowledge

\footnotetext{
M. Arthur $(\triangle)$

University College London, London, UK

e-mail: michael.arthur@ucl.ac.uk 
to devise new applications" [1]. This definition works well across the panoply of disciplines, particularly if the phrase 'new applications' is interpreted broadly to include learned contributions to the arts and humanities and to social and public policy.

\section{What Does Research Excellence Look Like}

Research excellence is clearly discipline specific, but a common characteristic of world-class researchers is that they are involved in shifting paradigms and creating new models of human understanding. They are actively involved in constructively criticising perceived wisdom in a specific field. Their views are usually based on new observations, including qualitative observations or quantitative scientific evidence, or new interpretations that ultimately support logical conclusions. Not infrequently, such observations are stimulated by the application of new technologies and methodological advances.

The world's greatest universities have a critical mass of individual researchers, or research teams, capable of performing at this level and a concentration of research excellence that allows or facilitates highly creative approaches to tackling some of the world's most complex and difficult problems across disciplines [2]. Such 'concentration' of research excellence is a fundamental concept that every institutional leader must foster and support. At the very highest levels of worldclass performance universities demonstrate this level of excellence, not only at the level of specific individuals, but also within and across multiple disciplines.

World-class research universities are typically engaged in trying to solve the most complex and intractable problems facing their own societies, or global society, in a coordinated and systemic manner across multiple departments, and in confident partnerships with other world-class institutions, local or global industry, governments and ministries and their health care, education, social care and public policy systems. Being an effective and seriously engaged partner is now an essential aspect of being a world-class university.

No world-class university can be universally excellent at everything and thus each institution must decide where to focus institutional efforts and resources. Institutional leaders must be bold enough to focus resources where they might have the greatest impact on research performance and profile. Deciding where an individual university can be truly distinctive and have the greatest international impact in its research activity is of fundamental importance to achieving world-class status.

\section{The Integration of Research and Teaching in World Leading Universities}

There are somewhere in the order of 17,000 higher education institutions across the globe and a conservative estimate suggests that at least 1,000 of these are actively and effectively engaged in research at scale. It should also be 
acknowledged that this research is equalled in volume by research conducted in non-university public institutions and by industry. This is an incredible force for the advancement of global human society and it is clear that high quality research is now widely distributed across the world.

Universities that are truly research-intensive must focus on ensuring that their students benefit from an education that is carefully and fully integrated with the research profile of the institution and its research partnerships. My personal philosophy is that all students (UG or PGT or PGR) should benefit from becoming involved in the process of 'research', irrespective of discipline. This is fundamentally important in developing students' life skills and equipping them for their future. By engaging in the research process, students will learn to become critical independent thinkers and problem solvers. They will understand how knowledge is created, how it inevitably shifts with time, and they will be exposed to, and become personally experienced in, dealing with uncertainties at the 'edge of knowledge'. They will also become more experienced in working in a team and actively engaged in improving their ability to communicate effectively. Graduates with this background experience are highly creative and of great value to the organisations that they join for employment. Many will become 'leaders of the future' because of their ability to research background information and analyse problems from first principles and subsequently exhibit confidence in employing innovative approaches and methods of problem solution.

\section{The Role of High Quality Doctoral Research Training}

There is a wide variety in the approach to doctoral level study across the globe. Most systems select the highest performing students at undergraduate and master's level study and then engage such individuals in developing their research skills through a combination of more detailed taught programmes on research methodologies and techniques as well as their own individual research projects. High quality and dedicated research supervision by experienced supervisors is essential and dual supervision (by primary and secondary supervisors, usually bringing different expertise) is now commonplace. In the UK, research funders, together with universities, have been involved in creating the concept of high quality doctoral training centres that provide world-class doctoral training and experienced supervision of the highest quality. Doctoral students must be exposed to training in ethics, research integrity and the importance of engaging the public in their research findings as well as being intensely focused in their own independent research projects. A critical mass of $\mathrm{PhD}$ students is essential to creating a sense of community and collegiality in a research-intensive university. This relates not only to the absolute number of PhD students in the university, but also to the manner in which they are organised. The concept of high quality experience as PhD students is a central feature of many graduate schools and doctoral training centres. At UCL we currently have in the order of $4900 \mathrm{PhD}$ students in our graduate school and doctoral training centres, in a total student population of just over 30,000 students. 
The duration of doctoral level training and research varies across the globe from 3 to 7 years and is also quite discipline specific. A typical such duration in the UK is four years. The centre piece of $\mathrm{PhD}$ student training is the creation of a doctoral thesis that is ultimately subject to detailed external scrutiny by the world's preeminent expert reviewers. The creation of new knowledge and an ability to demonstrate a logical and integrated set of arguments and research findings lies at the heart of every successful doctoral thesis.

\section{The Postdoctoral Period and Breaking Through as an Individual Researcher and Principal Investigator}

Successful completion of a $\mathrm{PhD}$ thesis is, however, only the beginning of a research career in most disciplines. A period of postdoctoral work and further study in the order of 3-9 years is now commonplace in most world-class universities, prior to individuals taking up their first academic appointment. This period usually involves moving to a different institution, or country, exposing postdoctoral students to a different research culture and, most importantly, to fresh ideas and techniques. In my opinion, this is the most formative period of any research career.

A world-class university will create a supportive and superb ongoing training environment for its postdoctoral staff, with continued expert oversight, support and advice, coupled with constructive challenge. During this period, postdoctoral staff will usually begin to develop and pursue their own independent ideas and acquire an increased level of expertise in their specific field. Wherever possible, highly talented postdoctoral staff should be encouraged to write grants for their own fellowship funding, such that they can formally, and more readily, branch out into an independent research career. Postdoctoral staff intending to pursue an academic career should also start to learn how to teach and ideally, they should gain experience and professional qualifications specific to teaching in a higher education institution during this period.

Inevitably, this period of development of the early stages of an academic career is highly variable around the globe. In some countries, it is possible to progress at an earlier stage to the junior phases of an academic career. There are also discipline specific variations. If however, you want to create a world-class research environment and profile for a university, then giving specific attention to this period of development of an independent research career is essential, as is the provision of ongoing mentorship, support and guidance. In the Western world, this is a phase of development through which only the very best successfully progress to develop their independent careers as principal investigators and this selectivity contributes to creating long-term world-class research performance in an institution. 


\section{The Importance of Cross-Disciplinary Research}

While a great deal of research of world-class quality will be confined to individual disciplines, there is an increasing recognition that many of the world's greatest problems need to be tackled by teams of researchers pulled together from different disciplines. At UCL we prefer the notion that each individual in a cross-disciplinary team brings their own disciplinary excellence to tackling a major problem and we therefore prefer the term 'cross-disciplinary' rather than 'inter-disciplinary' or 'trans-disciplinary'. These terms are often used interchangeably, but the latter two are perhaps more indicative of individuals from one discipline beginning to work in another disciplinary area. Such discipline hopping may be productive, but it is not always successful, and in our view it is important to bring disciplinary excellence to the table as research teams are formed. When tackling complex problems a cross-disciplinary approach is highly creative as individuals bring their discipline specific approaches to the table and share ideas and concepts across the team.

There are numerous perceived barriers to the creation of effective cross-disciplinary research teams and it is important that they are recognized and dealt with by institutional leaders. The most common problems relate to the discipline specific nature of financial and other organisational structures within our institutions. Moreover most external organisations, for example many research funders, journals and learned societies are organised by discipline and this creates the perception that it is easier to obtain funding, to publish and to achieve personal recognition and promotion by remaining safely within a discipline's confines.

It is important for institutional leaders to set a clear tone concerning the importance of cross-disciplinary research and to create opportunities for these activities to flourish. The rewards from getting this right are significant in terms of an institution's global research profile. How best to achieve this will vary from one institution to another. At UCL we have developed the concept of a 'grand challenge' approach, and have actively promoted these via a series of 'town meetings' with expert panels, informed debate and open discussion. This has been sufficient to initiate collaborative cross-disciplinary discussion that has led on to new research and educational activities.

Each grand challenge is guided forward by a senior academic executive team. Small pump-priming grants are available to help new projects get off the ground, but as new activities develop, external grants are sought. Our current grand challenges are in Global Health, Human Well-Being, Intercultural Interaction and Sustainable Cities [3]. This approach is now sufficiently embedded in our research culture that it is also informing our Global Engagement (internationalisation) strategy and our approach to massive open on-line courses (MOOCs) and online distance learning.

Other approaches to promoting cross-disciplinary activity in research and education can also be taken. In higher education environments where philanthropy is 
commonplace and generous, then it is not uncommon to see very large donations given specifically to promote such new 'centres'.

Another model is one that I learnt about from colleagues at Penn State University, USA, and then deployed at the University of Leeds, during my time there as Vice-Chancellor. This can be described as a 'co-funding model' and in my experience, it is highly successful. In essence monies are gathered into a central strategic fund on an annual basis (for example by applying a $1 \%$ strategic surcharge), such that there is a central pot of recurrent funds to support cross-disciplinary activities of the highest quality. The highest quality projects are selected competitively via a bottom-up process, led by teams of faculty members. Such projects are then co-funded 50:50 by the centre jointly with the relevant departments, schools or faculties involved. Milestones of performance are set at the beginning of the co-funding award and these must include a significant return on investment in terms of raising external funding, industrial interaction, etc. Each cross-disciplinary activity funded in this manner is reviewed on a quinquennial basis and if successful, funding is continued for a second five-year period. One striking example of great success using this co-funding model was the creation of a new cross-disciplinary group in Leeds, who were interested in Water and its management in flood and drought, called Water@Leeds [4]. This is now a highly successful and internationally renowned group, achieving a return on investment (research $£$ raised, compared to $£$ invested), of greater than 10:1.

\section{The Importance of Competitive Research Funding}

The principal routes for funding of university research may vary considerably from country to country. There may be direct government funding of university faculty, research staff, projects and programmes, or there may be competitive government grant funding systems, charitable and generous funding, endowment support or funding directly from industry. Faculty members may have some or all of their salary funded directly by government, but in other jurisdictions, particularly the USA, many faculty members raise some or all of their salary via grant funding. There are relatively few sources of funding for international collaborative funding, with the most important being the European Union framework funding (the current programme is called Horizon 2020). More recently, the European Research Council has become a very important international source of funds for high quality response mode funding.

In the UK there is a dual funding system for the support of research. Each university receives a direct government grant, the size of which depends on an intermittent assessment of research performance, which is undertaken every 6-7 years. This used to be called the Research Assessment Exercise (RAE), or as it is known in its most recent form, the Research Excellence Framework. A detailed description of this process is available at [5]. 
In brief, it involves each member of academic staff submitting their best four research outputs over the preceding period, together with a description of the research environment, research strategy and plan, and evidence of the impact of that research activity in the form of 'impact case studies'. For UCL this system currently informs the award of approximately $£ 115 \mathrm{M}$ per annum, as one limb of the dual support system.

The other element of dual support comes through government funding of the UK research councils, which is a typical peer-reviewed grant awarding system, largely organised by cognate groups of disciplines. This system drives the funding of individual research projects and programmes through a system of peer-reviewed grant awards, made to research teams or individual researchers via their institutions. From such government and other sources (charities, EU, Industry, other government departments and the UK National Institutes of Health Research) UCL achieved a total research income of $£ 375 \mathrm{M}$ last year.

Competition for research funding based on peer-reviewed grant submissions is commonplace across many countries, as it is held up as the best way of distributing scarce research funds (and in many cases, public money) to the highest quality research. In my experience, this mode of funding is a critically important element in driving forward personal research excellence. It is very demanding and exacting to write a grant that competes at the highest level, but in doing so, the quality of thought, preparation, methodology and preliminary data must all be in place, together with a carefully laid out research plan, prior to funding being ultimately awarded.

In many fields, this drives individual researchers to either acquire or develop the most advanced research methodologies that then allow them to tackle the more interesting and complex problems. This is particularly, but perhaps not exclusively, evident in Biomedicine and Biomedical Engineering in recent years, with the explosion of, for example, genetic manipulation techniques.

This competitive nature of research funding inexorably drives quality upwards across the entire research endeavour. It is clearly not a prerequisite for research excellence, but it certainly helps to drive it forward on a system-wide basis. In my opinion, the highly competitive nature of both limbs of our dual funding system is the key factor underlying the excellent, internationally competitive, research performance of the UK.

\section{Writing Successful Research Grants}

One of the most important transitions that every successful researcher has to undergo is to develop from being a good researcher at the bench, or in the library, into an independent principal investigator (PI). This is a difficult transition, but it is often the time when new ideas are born and exciting new paradigms develop. Critical to becoming a PI is the ability to attract competitive peer-reviewed grant funding, to allow you to explore your own ideas. 
Grants that are funded have several key elements.

- First and foremost, they must tackle an interesting problem or concept that excites the funding agencies and their boards and peer-reviewers to the extent that they envisage the results of the research having a significant impact on the field.

- Many will have substantial arguments and/or preliminary data that support the case being made for funding. In my view, time spent on acquiring additional preliminary data to strengthen the case is extremely valuable.

- They must have a clear and testable hypothesis and seek to deploy advanced technologies to help address some of the most complex of problems. For example, within the sciences, research that determines new mechanisms is of greater importance than that which is merely descriptive.

- They must be very clearly written, such that peers can quickly assimilate the key points and are thus guided through the grant in the direction of a supportive decision.

In many years of active research, I gave the utmost care and attention to my grant writing skills and fortunately enjoyed considerable success. I was never complacent and I always asked my close colleagues and fellow professors (at least two independent and knowledgeable scientists) to read and critique my grants, well in advance of their submission. If that meant that I had to miss a grant deadline and submit later, then I always accepted that outcome. There is nothing more important than ensuring that grants are of the very highest calibre at the time of submission.

\section{Research Leadership}

World-class universities will typically be home to a significant number of outstanding research leaders and they will support and develop others to take up research leadership roles. Great research leaders have a number of important characteristics. First and foremost they are prominent figures in their respective fields through their own proven research excellence, which has usually been sustained over a prolonged period of time. They will be publishing at the highest international level, giving plenary session keynote speeches at international meetings, and perhaps winning major awards such as the Nobel Prize, the Kavli Prize, the Lasker Award or the Fields Medal.

They typically have a great awareness of the history of and a good feel for the future of their discipline. They are influential, set the pace for others to follow and tend to shape the future direction of the field. This is typically associated with an ability to constantly evolve their own research strategy, a significant level of personal persistence in seeking answers to complex research questions and a willingness to take risks in their approach. 
Research leaders also support and nurture younger researchers and act as their mentors. The very best are generous with their time and create a research environment where others can flourish and follow in their footsteps. They are usually exceptionally talented, highly creative and effective at pulling together significant levels of research funding and they act as a centripetal force in terms of attracting the very best of the next generation (PhD students, postdoctoral staff and new faculty members) to come and work with them. They generate excitement and great research momentum in their home institution and act as role models for future generations of researchers.

Many of the skills required to become an excellent leader can be identified and taught through research leadership programmes that are aimed at up-skilling the younger generation of researchers. We have one such course at UCL, called 'Leadership in Action' [6].

This course is a three-day intensive programme designed to prepare researchers for leadership in their chosen research field or within the wider university community. The course is aimed at helping early career researchers to explore the concept of leadership and to develop confidence in their leadership style. It is intended to expose individuals to a variety of choices in how they lead and to provide them with understanding of the impact that may have on those they are leading. It is intended that course participants will learn how to influence people effectively towards a shared goal and that they will understand how all these skills will benefit them in their current research roles and beyond. The course is based on practical, experiential learning, rather than lectures, and it includes opportunities for all participants to lead a group project. Support and feedback are provided throughout the course on leadership style by expert coaches. It is our intention that this course will generate a cadre of early career researchers, equipped and skilled to become the distinguished research leaders of the future.

\section{Research Integrity, Handling Research Data and Research Misconduct}

It is incumbent on every world-class university to adhere to and promote the very highest standards of research integrity. This means creating an environment, which ensures that all research is conducted against a background of awareness of the key issues of transparency, honesty, collegiality, fairness and personal responsibility. Individual researchers (staff and students alike) must be trained in, and aware of, the institution's, research funding agency's and publisher's research policies and practices, and must adhere to them and to the highest possible standards of good research conduct in their daily activity. This must include excellence in the design of research projects and frameworks, their subsequent operation and adherence to the principle that it is the personal responsibility of all involved to ensure 
that research data is robust and reproducible. Researchers must therefore demonstrate intellectual honesty at all times.

The very highest standards of research integrity encompass many different elements, all of which require compliance. In addition to those outlined above, these include:

- Research ethics - all research should be conducted within the overarching framework of an ethical code. This is particularly important (and in most countries mandatory) if the research involves human subjects or animals.

- The requirement to declare any actual, potential or perceived conflict of interest, whether pecuniary or non-pecuniary.

- A responsibility to ask questions, to be aware and to report any reasonable suspicion of research or ethical misconduct.

- A responsibility to record and store original research data in a format that substantiates the reporting and publication of research findings and that is accessible to others, if required. Many funding agencies and publishers have specific requirements for the duration of data storage of original data and it is critically important that such requirements are strictly adhered to. Research data must be stored in a secure manner, such that it remains authentic and complete.

- Fairness and collegiality when dealing with research colleagues and collaborators, including the need to demonstrate fairness in peer review.

- A requirement to avoid misrepresentation of personal contribution to a specific research project or publication.

It is important that institutions also have systems to identify, investigate and deal with research misconduct when and if it occurs. The latter takes many forms and this has been outlined by Research Councils UK as follows [7]:

- Fabrication, or creation, of false data, or research documentation, such as consent to participate.

- Falsification, which comprises the inappropriate manipulation and/or selection of data, imagery or consent.

- Plagiarism, which comprises the misappropriation or use of others' ideas, intellectual property or work (written or otherwise) without acknowledgement or permission.

- Misrepresentation of data, duplication of publication, material interests, qualifications or experience, and of involvement in research.

- Breach of duty of care, whether deliberately, recklessly or by gross negligence to include breach of confidentiality, placing individual research subjects in harm's way, or not observing legal, ethical or statutory requirements and improper conduct in peer review, including failure to disclose conflicts of interest.

- Improper dealing with allegations of misconduct, including attempts at 'coverup' or reprisals against whistle-blowers, and failing to deal appropriately with malicious allegations. 
The websites [8-10] provide a more detailed background to this subject for those looking for more in-depth information and for further guidance on how to promote good research conduct or how to further handle research misconduct.

\section{From Research to Innovation and Enterprise}

World-class universities drive innovation, entrepreneurship and enterprise through the generation of intellectual property and new ideas. They contribute to supporting local, national and international businesses and entrepreneurs and they help to generate economic growth. This relates, of course, to the commercial exploitation of their research activities, but is also related to the supply of graduates as highly talented individuals that contribute to the ongoing development of an economy. There are many different ways in which universities can contribute to economic growth through their own enterprise activities. These include:

- The identification, protection and exploitation of intellectual property. All staff should be trained and supported by the University to recognise intellectual property and to learn how to protect it and where relevant, to exploit it. A dedicated professional team should be created to provide support for identifying novel concepts and ideas, which will not only develop strategies for their commercialisation, but also find investors to support them financially. The intention is that such a combined academic and professional endeavour, not only creates intellectual property, but also converts it into products of commercial value that can be licensed, and in some cases facilitated, to generate new spin-out companies. These, in turn, will create new products and businesses of long-term enduring commercial value. The complexity and risks involved in generating this level of success should not be underestimated, but the rewards for getting it right can also be significant. Guidance and advice should be sought from individuals that have successfully negotiated this space and that have first-hand experience of creating such high tech companies from their own intellectual property. Universities increasingly need to demonstrate to their own governments, and other funding agencies, that both their basic and applied research can bear such fruit.

- The recognition that world-class universities must also support their students and staff to be entrepreneurial at a personal level is an increasingly important paradigm. This should include the recognition that new student and staff entrepreneurs will need advice to support and develop their own independent commercial ideas and business practice with potential for leading to new and successful businesses. Where possible, universities should provide the facilities within which student and staff entrepreneurs can conduct research of the highest calibre and further develop their own ideas. The facilities and the expertise contained therein should be readily accessible to businesses external to the University so that research and development ideas can be positively exploited. 
- World-class universities also need dedicated individuals and systems to interact with the external business world to provide expert consultancy and to support corporate partnerships. These are specialist areas, and individuals or teams dedicated to this sphere of external partnerships are important in presenting a professional interface for interaction with the business and corporate world. Such teams can also be extraordinarily important in improving the profile and reputation of a university with the corporate world on a global scale. Dedicated teams in this area are also extremely helpful in guiding academic staff's navigation around this (perhaps previously) unfamiliar world and this helps enormously in managing risk and reputation.

\section{Five Key Actions for KAU to Enhance Research Performance}

King Abdulaziz University (KAU) is already a highly successful research-intensive university and a leading institution in the Middle East, with an established international profile. It is well led and has chosen to pull together a highly experienced, high profile International Advisory Board, of which I have the pleasure of being a member. I am still learning about KAU, and the following advice on five key actions is offered against that background.

(1) It is essential to build both a critical mass of researchers and a concentration of research excellence in a defined and clearly identified number of high quality fields of research. Choices must therefore be made and resources focused on ensuring that these 'peaks of excellence' can perform at the highest level. Human capital in the form of world-class academic and research staff is the most important element of building this level of success.

(2) As research performance improves, it is essential to think of the research pipeline and to recognise the importance of a clear 'youth policy' with respect to training the next generation. High quality doctoral training is essential, but this must also be aligned to very clear ongoing support and training during the postdoctoral period and into the early phases of a junior academic career.

(3) Seeking external research funding from high quality research funding agencies that use international quality peer review is an excellent way of sharpening research protocols and for enhancing research programmes. It also drives the need to stay abreast of methodological advances, which ultimately feed into promoting the international quality of research activity.

(4) Systems should be put in place to support and enhance cross-disciplinary research, allowing teams of researchers from many different disciplines to come together in order to tackle complex global and societal problems. Contributions to teamwork and working across disciplines must be recognised within the university's promotion and reward systems. 
(5) Research findings are at the forefront of the process of innovation, but research alone does not drive economic growth and prosperity. Systems must be put in place to drive and support innovation such that new products can be licensed and/or new companies spun out of the university. This should include the concept of expert teams to encourage and support entrepreneurship, consultancy and greater interaction with industry.

\section{Summary and Conclusions}

The advancement of human society is critically dependent on the creation of new knowledge through the conduct of research in universities, institutes, government agencies and industry. In our global future, the world's greatest problems will be tackled by teams of researchers from diverse cultures working across disciplinary, sectoral and national boundaries. World-class universities will be at the heart of this endeavour in many different ways. Our academic staff will not only be leading the immediate and long-term research effort, but they will also be closely involved in the training of the next generation of researchers through undergraduate, master's, and doctoral level education and research supervision. The close integration of education of students (at every level) with research activity will continue to define the world's leading universities.

Building a successful research-intensive university requires excellent institutional leadership that focuses on building world-leading quality in a defined number of research areas, as well as providing world-class research facilities. The ability to attract the very best research-active academic and postdoctoral staff and $\mathrm{PhD}$ students is of fundamental importance. Bidirectional student and staff mobility are of crucial importance for the creation of a positive research environment. Supporting these staff in their competitive grant writing is also critically important. Instruction on the key elements of ethics, research integrity and the manner in which primary research data should be handled and stored are now fundamentally important aspects of research training.

The future of the world's leading universities is very exciting as we continue our current journey along the road of the ever-increasing globalisation of higher education. Those universities that rise to the challenges outlined in this chapter will be best placed to make significant impact and thereby achieve world-class university status in recognition of their contribution to the advancement of knowledge and the future of humankind.

Open Access This chapter is distributed under the terms of the Creative Commons Attribution Noncommercial License, which permits any noncommercial use, distribution, and reproduction in any medium, provided the original author(s) and source are credited. 


\section{References}

1. OECD. (2002). Frascati manual: Proposed standard practice for surveys on research and experimental development (6th ed). Retrieved 27 May 2012 from www.oecd.org/sti/frascatimanual

2. Jewels in the Crown: The importance and characteristics of the UK's world-class universities. http://russellgroup.org/JewelsInTheCrown.pdf

3. http://www.ucl.ac.uk/grand-challenges

4. http://www.wateratleeds.org

5. http://www.ref.ac.uk

6. http://www.ucl.ac.uk/hr/od/pdp/sdlia/index.php

7. http://www.rcuk.ac.uk/Publications/researchers/grc

8. http://www.grad.ucl.ac.uk/research-integrity

9. http://www.admin.ox.ac.uk/researchsupport/integrity

10. http://www.universitiesuk.ac.uk/aboutus/AssociatedOrganisations/Partnerships/Pages/Resear chIntegrity.aspx 


\title{
Excellence in Serving Society and Mankind
}

\author{
Thomas Wilhelmsson
}

\section{Introduction}

The third mission of universities, serving society, has received much attention in international debate on university policy. It is increasingly presented as one of the key tasks of universities, in addition to their traditional tasks of research and teaching.

Universities can serve society in multifarious ways, while at the same time performing the basic tasks of research and teaching for the benefit of society. It is therefore not surprising that both the definitions of the issue and the terminology vary greatly between individuals and countries. In this chapter, both the terminology including 'third mission', plus expressions such as 'social responsibility', 'community engagement', 'community services', 'outreach', and 'societal interaction', are discussed and analyzed, as are the various means and methods by which society can be served.

The reasons for the increasing importance of the third mission vary. For some it stems from the insight that education and research have a direct role in the globalized knowledge society and profoundly influence its competitive strength. Others stress the indirect function of universities as hubs of creativity, attracting and supporting talent for the benefit of society. The pursuit of the third mission is not, however, purely 'altruistic'. A well-functioning interaction with society enhances the quality of both university teaching and research.

It is therefore difficult to classify universities that are underperforming in terms of effort and focus in this regard as being world-class universities. This chapter's discussion focuses on the means of enhancing societal interaction qualitatively and quantitatively. What can and should universities do, in order to achieve excellence in serving society and mankind?

\footnotetext{
T. Wilhelmsson $(\square)$

University of Helsinki, Helsinki, Finland

e-mail: thomas.wilhelmsson@ helsinki.fi
} 


\section{The Third Mission}

The International Exhibition and Conference on Higher Education (IECHE) in Riyadh in 2013 [1] was devoted to a very topical issue, 'The Social Responsibility of Universities'. The Riyadh Conference Statement begins by unambiguously declaring:

Universities have three key functions - teaching, research, and service. Often, the service responsibility of universities is undervalued. Yet, service to society and to the academic community is of central importance, and a key element of service is social responsibility.

The traditional and arguably mistaken understanding of universities has pictured them as ivory towers, in which teaching and research take place in a state of splendid isolation from contemporary society. Criticism of this ideal of isolation has become one of the key issues in international debate on the role and development of the university system. In the knowledge society the approach is the opposite. As important players in the knowledge ecosystem, universities can and should, in addition to research and teaching, serve their societies and mankind.

Conceptually the discussion is somewhat confusing. Many concepts have been used to denote issues that involve considerable overlap. In this context, one encounters expressions such as 'the social responsibility of universities', 'community engagement of universities', 'community services', 'outreach', and 'societal interaction'. Some of the expressions clearly have a broader scope than others, and some usages are preferred in some parts of the world while others predominate elsewhere.

There is little need for engaging further in conceptual exegesis. It is of more importance to discuss the issue at hand, the need for interaction between universities and the societies in which they are located. Therefore, I will use the most neutral and frequently used terms, 'the third task' or 'the third mission'. As the two basic tasks of universities are teaching and research, discussion of the third mission highlights the question of whether and in what manner are universities supposed to serve society, in addition to fulfilling the two aforementioned tasks.

Discussion of the third mission does not necessarily imply it being an independent task on the same level as the two basic tasks. Rather, it could and should be viewed more as a different perspective on the basic tasks. Excellent teaching and research as such serve society in a profound manner. Discussion of the third mission emphasizes the fact that teaching and research, and other activities of universities relating to teaching and research, can be more actively and consistently geared toward society's service. The societal interaction of universities should be based on the basic tasks, but the third mission perspective can provide the means by which they can be developed to better serve society. It has been said, for example, that universities understanding their responsibility for global sustainability should:

- "transform education to educate, engage, empower and energize the next generation of problem-solvers";

- "drive a research agenda designed to identify, invent, test and deploy solutions designed to address the formidable challenges of global sustainability"; 
- "insist on building both disciplinary depth and trans-disciplinary breadth of research and education, connecting science, engineering, technology, mathematics, social sciences, arts and humanities disciplines in service to society";

- "assess the need for societal action, to transmit authoritative information to stakeholders and then take ownership of the process of transition of knowledge to application, working in new partnerships" [2].

In different discourses and different locations the emphasis on the various elements of the third mission might vary somewhat. Sometimes ethical elements are strongly stressed. Many of the contributions to the IECHE 2013 Conference adopted this perspective, as can be seen in the Conference Statement:

\begin{abstract}
A university's social responsibility can be defined as the obligation to represent and practice a set of principles and values ... a commitment to fairness, truth, and excellence; promotion of social equity and sustainable development; recognition of an individual's dignity and liberty; appreciation of diversity and multiculturalism; and promotion of human rights and civic responsibility.
\end{abstract}

In other discourses and legal mission statements the focus is rather on regional development. Universities are asked to function as important drivers of social and economic development in their immediate environs. In a still broader perspective the role of universities as drivers of the economy, culture, and social relations of entire societies is emphasized. In some discourses, the emphasis is on the capacity of universities to support the societies in which they operate, while others stress their services for the whole of mankind.

All these perspectives are important, and none of them should be neglected. The third mission of universities is ethical and economic, cultural and social, regional, national, and global. Of course, the relative weight and visibility of the elements are greatly dependent on the nature and situation of each university and of the societies in which they function.

Universities' contribution to the innovation chain and to the innovation economy in general is an important part of their societal interactions. Many definitions of the third mission include the dissemination of research into economically useful innovations and business opportunities. However, as in this book the innovation economy is dealt with in a separate chapter, I will not examine this issue in more detail in the present context. Other forms of societal interaction will be the focus of this chapter.

\title{
3 Why Is the Third Mission Important?
}

The third task, having an ethical, social, cultural, and economic impact on society, has always been a part of the mission of universities, even though it has not been expressly singled out for recognition and named as a particular task. Medieval European universities were founded to educate good administrators and priests for the benefit of society. Ever since, many universities have played a crucial role in 
the development of their societies. The task to raise ethically aware citizens for the benefit of society has been an almost self-evident, taken for granted part of their self-understanding.

However, during recent decades, there has been a clear change in the narrative concerning the third mission. The perspective has shifted from understanding it as a more or less implied by-product of teaching and research to emphasizing it expressly as a task in itself to be promoted and furthered. The shift of emphasis is obviously a consequence of profound changes in society and the wider world.

There is a growing insight into the central role of education and research in the globalized knowledge society. The competitiveness of societies is seen as directly connected with the manner in which they can position themselves within the framework of production and use of knowledge. With the accelerating production of knowledge, the ability to access, create, and use knowledge becomes a key success factor.

The role of universities is crucial in creating such ability. They are key players in the knowledge production and dissemination game, and therefore impact societies and economies in many ways. Besides educating both new leaders and workforce, and creating and supporting innovations, they are often pivotal players in importing new knowledge into societies more generally, in attracting new brains from other countries, and in introducing new patterns of thinking and being into societies.

Globally, universities are also perceived as perhaps the most important producers of knowledge which is urgently needed to cope with the grand challenges that mankind is currently facing. As is clear in the final statement from the UNESCO World Conference on Higher Education 2009 [3]:

\footnotetext{
Higher education has the social responsibility to advance our understanding of multifaceted issues. It should lead society in generating global knowledge to address global challenges, inter alia, food security, climate change, water management, intercultural dialogue, renewable energy and public health.
}

It is important to stress, however, that universities do not only bring knowledge as such to the disposal of societies. A catchword in the knowledge society debate is creativity. Good universities are hubs of creativity in which new bold critical thinking flourishes. The interactions of such hubs with surrounding societal environments are in many ways energizing for the concerned societies. In his wellknown work, 'The Rise of the Creative Class' [4], Richard Florida has shown how members of what he calls the creative class are drawn to settings with a creative ethos. Such flourishing concentrations of creative potential are often centered on universities in close interaction with other creative players in society. As creativity inspirers, universities may have an impact both on societies' global competitiveness and localized regional developments.

Universities also reinforce, create, use, and teach values for societies. In postmodern and globalized societies, traditional value systems are breaking down and the sphere of joint and self-evident values is diminishing. As a result of these tendencies, there is a growing demand for professional discussion and production of values, as well as presentation of those values to society. As previously mentioned, societal interaction is, and has to be, value-laden. 
Universities successfully performing the basic tasks of teaching and research will necessarily, to some extent, impact societies in the manner described above. The very existence of (good) universities as such has an impact on societies. The emphasis on the explicit third mission in the debate is founded on the belief that this impact can be increased, perhaps even multiplied, if expressly and strategically promoted. The societal demand for discourse concerning the third mission is obvious.

Demands concerning efficient fulfillment of the third mission are often made to predominantly publicly funded universities. The public sector and politics inevitably have an interest in funding being used as efficiently as possible to societies' advantage. In view of the perceived importance of universities with regard to the well-being of societies, such pressure both from the political sectors, the media and the public at large is understandable. Universities eager to preserve their brand have to be able to engage in such discussions. Engaging in the third mission should not however be solely driven by an eagerness to fulfill demands of politicians or the public, or, as the case may be, of private sponsors. The third mission can be successfully accomplished only if it is also based on the values of the universities themselves, on the genuine belief within universities that they are there to work for the betterment of society and the world. As I will note later, this is an issue that requires strategic leadership within universities.

A firm root in universities' own specific values is also crucial with regard to the excellence vision. In public debate there is often an emphasis on fast and concrete, or at least visibly measurable and demonstrable, results. Short-term societal applicability should not, however, become the driver of universities' development. Without sufficient commitment to long-term basic research and stable education, the quality of universities' performance deteriorates. An excellent university has to be true to its own vision of its social impact.

However, excellent universities fulfill their third mission not only because of engagement in certain 'altruistic' values. Universities need societal interaction also for the sake of their own improvement. Well-functioning interaction is not a one-way process in which universities serve and societies receive the benefit of the service. Real interaction creates benefits for both parties of the interaction. At universities, both research and education are gaining from active and mutual communication with societal players. Some research could not even be undertaken, or at least not so well undertaken, without close cooperation with businesses and other societal actors, and it is obvious that well-organized (and university-controlled) societal input in the educational processes can enhance their quality. The engagement of higher education institutions in the societies in which they operate should be built on "reciprocity and mutuality in learning and education through such engagement" (UNESCO Chair on Community Based Research and Social Responsibility in Higher Education. A Framework for Action 2012-2016) [5].

Excellent universities need their third mission. Excellent universities need to understand that their third mission has a global context. What can universities do to promote such a third mission? 


\section{Various Ways to Serve Society}

As discussed in the Introduction, the third mission of universities is not an easily and clearly definable task. Universities can and do serve society in multifarious ways. In the wide definition of the third mission, including all forms of societal interaction, used, for example, in Swedish and Finnish university legislation, the possible interaction measures are innumerable. The discussion concerning indicators for measuring third mission activities of universities in the following section illustrates this very well.

The educational task of universities obviously profoundly affects the well-being of the societies in which they are located. The interaction between universities and the labor market is important with regard to the quality and impact of the educational task. The needs of the labor market are explored in various ways and used in decision-making in the quality frameworks of universities, and often beyond in external accreditation requirements, as is the case in Germany, Italy, and the Netherlands. In a well-functioning curriculum, the students are connected to the labor market through internships and by other means. The role of serving the labor market could be, and occasionally is, seen as an element of the third mission, but it should also be understood to be an integral part of a qualitatively well-developed educational task as such. The first mission is education for employment.

More obvious elements of a particular third mission approach in relation to education are reflected in the understanding that universities should serve their surrounding societies by means of activities that are likely to instill in students a sense of responsibility for the impact of their actions on these societies and on mankind in general. An operationally feasible option in this regard might be, for example, to discuss how to involve students of all departments in community activities as part of the curriculum. This kind of educational mission seems to be emphasized in the IECHE 2013 approach. Again, this could be viewed as an integral element of a qualitatively well-developed educational task.

When discussing the educational task, some reflect primarily on education leading to an academic degree. A possible responsibility for organizing life-long learning would then be seen as a part of the third mission. In universities and university systems in which continuing education is to a considerable extent administered in separate institutes, this often seems natural. In many university strategies this issue is dealt with as a part of the social responsibility of universities. Be it as it may, the importance of life-long learning in the knowledge society has been assigned a highly visible profile on the agenda in numerous countries as well as in the EU, and universities cannot ignore this.

The societal impact of the research task is equally obvious. The concept linking research and society is innovation. As previously mentioned, I will not analyze this issue further, as it is dealt with in a separate chapter.

However, as the fostering of student responsibility for contributing to the good of society has been emphasized as an important element of the third mission, I cannot refrain from mentioning the innovative capacity of students in this context. If favorable conditions and useful platforms for student innovation activities are 
created, the new ideas of students, not bound by entrenched thinking traditions, might prove very useful for society. Both student start-ups and the broader innovative activities of students are often based on strong value-commitments.

More generally, universities carry a societal responsibility for the socio-economic environment in which they operate, not only via research and education, but also by means of other activities. Also, by playing active roles themselves, universities are capable of promoting sustainable, equal, democratic, culturally and economically advanced societies.

A traditional way of serving society to achieve such ends is by participation in the public discourse. The outreach of universities is performed by universities and their researchers in both traditional media and increasingly via social media. University communication departments and media centers have become increasingly important, as there is a growing insight that universities and researchers are expected to share their knowledge in the public discourse arena.

Direct communication to the public through public lectures and seminars is a part of an active communication strategy. The academic interest of children may be supported and encouraged by informative visits to schools and by the reception of school classes on campus. In order to obtain good results, this can be implemented in an organized fashion. As a pertinent example I can mention the LUMA Centre of the University of Helsinki, which is "an umbrella organization for the collaboration of schools, university and business sector, with the aim to promote and support life-long learning, studying and teaching of $\mathrm{STEM}^{1}$ subjects on all levels of education" [6].

In addition to their presentation to the general public, knowledge produced at universities and university expertise are, and should be, used in public and private decision-making processes. In fact, in many countries, the most important influence of researchers often occurs through participation in expert committees, public hearings, law drafting processes, and other decision-making procedures. Universities can make strategic decisions to emphasize such tasks as particular contributions to the third mission. For example, the Australian National University has designated supporting and shaping public policy in its country as its means of engagement with the community, and it has established an institute for that purpose [7].

As universities are often important regional players, their social responsibility has a regional aspect, the relative nature of which varies depending on the location and profile of the individual universities. Regional responsibility implies yet another set of stakeholders to interact with. Both local authorities and local businesses may play very important roles and be partners in universities' societal interactions.

As value-leaders, universities may also, by their own performance and example, support the values they seek to promote in society. A university that preaches, for example, environmental awareness, is not very convincing if such awareness is lacking in its own activities as an organization. Just to mention an example, it was for this reason a natural step for my own university, the University of Helsinki,

\footnotetext{
${ }^{1}$ STEM is an acronym referring to the academic disciplines of science, technology, engineering, and mathematics.
} 
to join the WWF Green Office scheme, and sign on to its responsibilities under this scheme. In the US, the American College and University Presidents' Climate Commitment (2006) has gained considerable visibility in the discussions concerning how to address climate change [8].

Universities fulfill their third mission through a complex set of activities, differing in scope and content. Such activities can be weighted and combined in many beneficial ways. There is no blueprint for the best way to perform the third mission. It all depends on the environment of the concerned universities, on the structure and disciplines of the universities themselves and, of course, on their values.

The needs of the surrounding societies affect the social demand for university interaction. For example, when the University of Nairobi, with the display of huge signs on campus, announces the campus to be a corruption-free zone, it is a powerful political statement intended to affect society. In some other country, perhaps less plagued by corruption, other issues may seem more urgently in need of addressing, perhaps by other means. In some environments, universities are called to fight for democracy and human rights, while in others this need is felt to be less pressing, at least with regard to the home ground.

The disciplines of universities have an impact on how universities interact with society in their daily activities. Professors of, for example, law and medicine are almost routinely involved in tasks falling within the definition of the third mission, be it through consultation, expert opinions, or in other ways. Also the treatment of patients in university hospitals is usually understood as community service. Climate research has a different impact agenda and stakeholders than do some fields of social sciences and humanities. In some areas of basic science, identifying the natural point of contact with society may require more creative thinking and decision-making.

In good universities, one therefore always encounters a great variety of third mission activities, as should certainly be the case. Universities should promote and offer incentives for such activities. The difficult question of how to measure and incentivize third mission activities is discussed in the next section of the chapter.

Universities that seek to appear as excellent in serving society and mankind cannot, however, be content with merely general promotion of the third mission. They have to proceed further toward more strategic enhancement of the area. Designing and constructing strategies in this area requires choice of the most important third mission activities of universities and their place in universities' branding. This of course is closely connected with the definition of universities' values. I will return to the strategic issues in a later section of the chapter.

\section{Measuring Societal Interaction}

The performance of the two basic tasks of universities is measured and monitored in many ways. University rankings are based on indicators predominantly measuring features of these tasks. What is measured unavoidably, and to some extent 
unfortunately, becomes more visible in universities' policy discourses. A university leadership that takes the third task seriously therefore should make an effort to measure and monitor the performance of the task.

It is easy to enumerate indicators measuring some aspects of the third mission. I will provide some examples below. However, one may still claim that measuring societal interaction is a difficult task that can be easily misleading for a variety of reasons.

First, as described above, the range of the manner and means available for achieving worthwhile interaction is so broad as to be virtually limitless. The definition of the third mission does not have any clear boundaries, and a comprehensive measurement therefore is impossible. However, if universities, as indicated above, have attempted to strategically single out certain forms of interaction as their core third mission activities, finding some indicators for these forms of interaction might prove beneficial. For example, if universities emphasize the particular task of fostering the social responsibility of students (as described in contributions to the IECHE Conference 2013), the impact of community services on the attitudes of students can be measured, and has indeed been measured at many universities. It is important to recognize, however, that such indicators only measure a part, and probably only a minor part of all third mission activities universities are engaged in, and want to be engaged in.

Secondly, multidisciplinary universities face an additional challenge because of the fact that different disciplines tend to interact with society in markedly different ways. As mentioned above, faculties of law, medicine, humanities, and science legitimately have different patterns of social interaction. Any indicators chosen almost necessarily are more advantageous for some faculties and departments than for others. It is therefore difficult to use the indicators as such for comparing the third mission performance of different disciplines, or the performance of universities with different ranges of disciplines.

Thirdly, many of the possible indicators are either wanting in terms of reliability or extremely time-consuming to collect. Unlike some research and education indicators, many third mission indicators require particular collection of data from the researchers, or separate studies or questionnaires. Good universities try not to put excessive bureaucratic data-collection obligations on the shoulders of their personnel.

In spite of these considerations, measuring and monitoring of societal interaction take place in numerous universities and many countries. There are many examples of indicators, used as proxies of interaction. For Swedish legislationdrafting purposes I collected the indicators used to measure third mission (as defined by each university) activities by Finnish universities. To illustrate the variations that occur even within one country, I give as an example the indicators chosen by the largest multidisciplinary Finnish universities:

- University of Helsinki: employment ratio of graduates, number of active alumni, and fundraising results.

- Aalto University: stakeholder groups, non-academic funding, employees and turnover of start-ups, and important positions of trust. 
- University of Turku: outside participation, open forums, patents, business funding, textbooks, development projects, and important positions of trust.

- University of Oulu: employment of graduates, master theses made for externals, invention notifications, and study credits at the Open University.

- University of Eastern Finland: reputation barometer, external expert assignments, start-ups, strategic partners, visibility levels in science news, and discussion.

The recent societal interaction barometer of the University of Jyväskylä has often been referred to and contains several items: education services to stakeholders, publications to stakeholders, expert services, stakeholder events, applied research and development activity, student theses for stakeholders, industrial property rights, spin-offs, employment ratio, internships, and infrastructure cooperation.

Often such third mission indicators tend to measure the interaction between research or academic expertise and society. Many of them therefore relate to the innovation issue analyzed more closely in Chapter "Excellence in Innovation and Knowledge Economy". Indicators on the interaction between education and society are less frequent, but do exist, as the previous examples show. When focusing in particular on the social responsibility of universities to promote certain values and to ensure students internalize such values, a comprehensive measuring of the complete picture is probably impossible, but the development of the attitudes of students can certainly be measured, as is mentioned above.

Even though a large variety of indicators of the above type are used, and have their natural place among the instruments available to university leadership, such measuring and measurements only provide a partial picture. It is basically most useful for monitoring the development over time of particular activities within particular departments. A comprehensive and trustworthy understanding of the role of universities and their components, and a reliable and credible comparison of the performance of these components at a particular point of time, cannot be achieved through the use of indicators alone.

A strategic vision of how universities should fulfill their third mission and efficient measures to support the development toward the vision requires, in addition to the indicator-based purely quantitative assessment of the social interaction of universities, more qualitative means of assessment. Only such qualitative assessment, preferably to be performed at regular intervals, can adequately take into account the varying opportunities, traditions, and applied usefulness of different disciplines. Understanding of the states of affairs under consideration can be reached by means of regular qualitative assessments without overburdening organizations with continuous collection of large amounts of data.

From the point of view of international excellence, such broad assessment is of particular importance. The indicators used to measure third mission activities, as described above, are often not very effective for pinpointing activities reflecting universities' global responsibilities. 


\section{Strategy and Incentives for Interaction}

The success of universities in the field of the third mission is very much dependent on the active role of university strategies and leadership. As shown above, universities may engage in a large variety of third mission activities, and excellent performance in this area necessitates strategic choices. The third mission is not as self-evident as teaching and research on the academic agenda and because of this, if concerted and directed effort from the leadership is lacking, then it is at risk of being neglected.

In part the third mission is promoted directly by the networking activities of universities' leaders, as often only leaders are in positions such that it enables them to create ties to other large and influential organizations. Still more important though, is the creation of a fertile and productive academic and educational atmosphere throughout universities. Successful partnerships with societies in which universities are located must involve high proportions of university staff and take place in many forms on many levels. This happens only if there are clear and persistent messages from leadership stressing the importance of societal interaction.

As the performance of the third mission is a value-based activity, this only further enhances the role of the leadership. The social responsibility of universities must go hand in hand with the universities' values, and the values of an organization have no worth if the leadership is not expressly and visibly committed to them.

The third task must be appropriately addressed in universities' strategies, as is usually the case. Normally the mission and vision statements already contain references to universities' values in relation to their surrounding societies. For example, in its Strategic Plan 2013-2016 (as in previous plans) the University of Helsinki commits itself as a part of its vision, to promote "the wellbeing of humanity and a just society" [9].

A good strategy should not only set the direction of development. It should also provide tools for making strategic choices and prioritizations. In the complex field of the third mission, such strategic decision-making is important if one aspires to achieve excellence in the service of society and mankind.

Many questions have to be addressed in such a strategy. First and foremost, a good strategy should be able to operationalize the definition of the third mission, in order to provide a basis for discussing, assessing, and promoting the relevant activities. The understanding of the third mission in its relationship to the primary tasks of teaching and research should be defined. Rather than being an independent task, the third mission can be viewed as a perspective on the primary tasks, driven by a commitment by universities to promote important social values.

The strategy should be based on the realization that universities have different roles to play in the interaction ecosystem. Most universities have, and should have, international, national, and regional interaction. However, the proportional balance of these elements varies according to the universities' roles. It is an important question to ask, "To what extent should universities focus on interaction on each 
level?" Local universities can have a central role in supporting the well-being of their region, while others more clearly play a national role. In some ways, all universities also work for the benefit of mankind in general. Universities that aspire to be placed within the elite, among the world-class universities, should expressly and actively expand their societal impact beyond the confines of their own society's borders.

Education is, for example, an important tool for aiding development, and can be offered in cooperation with various organizations and agents in this area. The development of MOOCs was, at least initially, seen as a service to an international society that was eager to learn. Such measures cannot, however, flourish without express strategic choices on the part of universities to serve mankind in this way.

When leading the development of third mission activities at universities, other crucial questions should also be addressed. Which fields of interaction are regarded as the most important for universities and how should activities in these areas be supported? Is it possible and desirable to build strategic partnerships to particular societal actors to promote third mission activities?

Finally, strategic leadership requires decisions about the incentives to promote the fulfillment of the strategic choices. How can departments and individual employees who perform well be recognized and supported? As the indicators reflecting the third mission are not able to provide a comprehensive picture of the complex field that would appear balanced in relation to the opportunities of various disciplines, a purely indicator-based remuneration strategy is not recommendable. As was noted above, in addition to possible incentives based on indicators, universities also need more comprehensive qualitative assessments of their third mission activities, which also can be used for informing decisions concerning remuneration.

In addition to university incentives, the research funding market also increasingly incentivizes societal interaction of university research. Many funding agencies favor projects and themes in which both universities and societal actors participate. In international university discourse, a key concept with regard to the service of mankind is the concept of grand challenges. Much discussion on the role of universities has related their particular importance to their ability to contribute to solving challenges, such as climate change, world peace, and poverty among other things. Many research funders also, notably the EU Horizon 2020 program, have started to focus their activities on such grand challenges and much of international outreach will certainly be organized under this heading in years to come. This is dealt with in more detail in the chapter dealing with innovation and knowledge economy.

\section{The Role of the IAB}

Excellence in service to society and mankind can be achieved only through strong strategic leadership. University leaders and their strategies have to set the tone for active societal interaction. Leaders have to make strategic choices on what to 
achieve based on universities' values. As the task of the International Advisory Board is to support the university leadership on strategic issues, it clearly has a role to play in this context.

The IAB can help in focusing strategies on important issues and in supporting the building of international interaction. As far as decisions concerning activities and partners on the local and national level are concerned, the IAB's contribution naturally has to remain on the level of principles. The society within which the third mission is to be performed is familiar territory for the locals, and it is difficult for outsiders to have well-founded views on issues relating to the realities on the ground at the local level.

As mentioned, it is strategically important to have a clear view on several issues related to the fulfillment of the third mission:

- The strategic position and the values of the third mission within the university.

- The respective weights of regional, national, and international societal interaction.

- The priority of third mission fields and activities of the university.

- Possible partnerships in third mission activities.

- Measurement, assessment, and incentives for the third mission.

Such issues can and should be regularly discussed with the IAB.

In particular, an international board may usefully contribute to the analysis of the role of societal interaction in the process of the university's internationalization. In addition to strategic discussions, the IAB may offer help and support in identifying and locating suitable international partners and networks and worthwhile targets for service to foreign societies and mankind. One fundamental aim of the strategic plan of King Abdulaziz University was "to promote the University's partnerships with distinguished scientific, research and industrial institutions" [10]. The IAB was appointed to support the university in this respect.

An IAB is expected to, and should be expected to, have an impact on the discussions and developments of strategic issues, such as have been discussed in the present chapter. The IAB of King Abdulaziz University hopes that it has, at least to some extent, managed to fulfill the expectations of its host in this respect.

\section{Conclusion}

For the many reasons analyzed in this chapter, the third mission plays an increasingly important role in contributing to university excellence. It is also a challenging function, as it can be performed in a multitude of ways depending on the values, disciplines, and societal environs of the university.

Striving for excellence in serving society and mankind requires active and strong university leadership, committed to the promotion of its societal interaction. The chosen forms of interaction should have clear and direct connection to university values and strategic planning. The strategy should not only emphasize the 
importance of the third mission, but also operationalize its definition and assert the strategic choices made in this area.

The strategic choices are important, as different universities have different roles to play in the interaction ecosystem. Some may focus more on regional forms of interaction, while others also work more conspicuously for the benefit of mankind in general. A world-class university should actively reach beyond the national borders. The International Advisory Board of the university may in particular contribute to the integration of societal interaction in the process of the university's internationalization.

As stated previously, developing the third mission requires leadership. This includes incentivizing activities in this area. However, the creation of proper incentives is difficult, as the measuring of societal interaction is problematic and can be easily misleading. There is an abundance of possible indicators available, but they all measure only limited parts of the activity. Successful leadership in this area therefore must always rely not only on indicators, but also on qualitative assessments of the third mission activities of the university. Active leadership involves strategic qualitative decision-making.

Open Access This chapter is distributed under the terms of the Creative Commons Attribution Noncommercial License, which permits any noncommercial use, distribution, and reproduction in any medium, provided the original author(s) and source are credited.

\section{References}

1. The International Exhibition and Conference on Higher Education (IECHE). (2013). The 4th IECHE statement. Riyadh, Saudi Arabia. Retrieved from http://www.ieche.com.sa/en/ exhibition

2. Weber, L. and Duderstadt, J. (eds). (2012). Global sustainability and the responsibilities of universities. London, Paris, and Geneva: Economica.

3. UNESCO. (2009). Final report on the UNESCO world conference on higher education 2009. Paris: UNESCO Headquarters.

4. Florida, R. (2002). the rise of the creative class: And how it's transforming work, leisure, community and everyday life. New York: Basic Books.

5. Tandon, R., \& Hall, B. (2012). unesco chair on community based research and social responsibility in higher education: A framework for action 2012-2016. Victoria, Canada: University of Victoria.

6. http://www.helsinki.fi/luma/english

7. Young, I. (2013). Building community engagement in a research intensive university. In Paper presented at the 4th International Exhibition and Conference on Higher EducationThe Social Responsibility of Universities. Riyadh, Saudi Arabia, April 16-17, 2013.

8. Alutto, J. (2013). The global commitment. In Paper presented at the 4th International Exhibition and Conference on Higher Education-The Social Responsibility of Universities. Riyadh, Saudi Arabia, April 16-17, 2013.

9. University of Helsinki. Strategic Plan 2013-2016. Retrieved from http://www.helsinki.fi/ strategy

10. King Abdulaziz University. Second Strategic Plan 2010-2014. Retrieved from http://css.kau. edu.sa/Pages-Strategic-KAUPlan.aspx 


\title{
Excellence in Strategic Planning
}

\author{
Georg Winckler
}

\section{Introduction}

Strategic planning is a means for a university to tackle the big issues with which it is confronted and to improve its competitive position. In order to gain the status of excellence, it is worthwhile that the university studies past models of success. Interesting examples are the so-called research-intensive university, the entrepreneurial university, or the university as knowledge enterprise. Ultimately, excellence depends on transforming the existing profile to one that successfully copes with future challenges.

\section{Designing the Planning Process}

\subsection{General Remarks}

In business administration studies, there is a common understanding that a strategy has to deal with the central issues of an establishment. It should focus on factors that determine the company's success. As a consequence, a strategic plan needs to answer the "big" questions a company is confronted with. In game theory, however, the term "strategy" is more generally defined. There, a strategy is any of the options a player can choose within more or less well-defined rules, where the outcome of choosing an option depends not only on a player's actions, but also on the actions of others. Strategic planning then looks for those strategies that are best, depending on other players' actions.

When designing a strategic plan for a university one should be aware of both definitions: (1) focusing on the "big" decisions an institution has to make and (2) taking into account the strategic interdependence with the outside world.

\footnotetext{
G. Winckler $(\bowtie)$

University of Vienna, Vienna, Austria

e-mail: georg.winckler@univie.ac.at
} 
Finding a strategy for a university raises other issues too. A strategic plan should shape its identity and its profile. To do so, the plan needs to be consistent and longterm oriented. Since any identity is also defined by the values and standards an institution or an individual stands for, a strategic plan should explicitly indicate the value orientation on which it is based. In addition, the planning and the implementation of a strategy have to motivate the individuals who work for an institution. These individuals must readily recognize the chosen strategy as useful in tackling the "big" issues and as being potentially feasible. The pursuit of a strategy, however ambitiously its goals are set, should not be perceived as beyond reach.

Of course, a strategic plan should not only specify the long-term options, nor should it only articulate the values and standards within the framework of which these choices are made. It should also include the concrete actions, which are required or recommended when implementing a given strategy. This action plan has to indicate when and by which means intermediate steps will be taken. Finally, strategic controlling should provide feedback for correcting the course of action during the implementation phase.

\subsection{Pitfalls in the Process of Strategic Planning}

The process of strategic planning is fraught with many problems and pitfalls.

How to avoid them?

The first pitfall consists of excessive egocentric thinking. Any institution has to be aware of the outside world, which does not only react, but also acts. There are fierce competitors on all sides. Opportunities for cooperation abound. In order to assess how the outside world perceives an institution and what potential for joint actions with cooperators exists, an institution should start the process of strategic planning with an analysis of the added value it yields to its relevant stakeholders.

To conduct this analysis of added value, it is helpful to examine the overall value which is created and then to remove the institution which wants to start the planning process from the picture. The analysis has to determine exactly which stakeholders will suffer which losses when the planning institution is out of the picture. In that way, the extra value an institution creates can be ascertained. Game theory now teaches us how to structure interactions with stakeholders so that the value added can be maintained or even increased. This approach to strategic planning helps to focus on others and avoids inward looking thinking and planning.

A second pitfall lies in accepting too many existing rules of the game. Excellence in performance, in contrast, is often achieved by complying with most of the rules, but in also inventing some new rules. Often, inventing these new rules seems to be difficult at the beginning, but after they have been decided upon and adapted, the result seems simple and clear. The critical question for finding such new rules is how to effectively organize collective intelligence within an institution. Outside advisors may also be helpful. 
A third pitfall might be mentioned too: the lack of backward reasoning. Many planners desire to reach the future by updating the present. Yet, a strategic approach requires that an aspiring vision is developed, that the values of the institution are stated, and that a point of time in the future is specified when the aspiring vision is supposed to be realized, while the stated values are maintained and in place. Then, given the endpoint of planning, backward reasoning should be used in order to derive what actions are necessary and when. Forward reasoning used exclusively might lead the planning institution to a state of uncontrolled dynamics. Note that backward deduction is the tool used in the theory of dynamic optimization.

\subsection{How to Begin a Strategic Planning Process Within a University?}

Let us illustrate how to begin a strategic planning process in the context of an excellent university. As an example, reference is made to Princeton University, a rather small Ivy League research university in the US, with only about 8000 students, but which is consistently ranked among the top ten universities in the world.

In a university such as Princeton University, the question of what its future should look like is regarded as very legitimate. However, when trying to answer this question within the framework of strategic planning, allergic reactions on campus emerge. Committees that collect data, lead assessments, and work out reports are quickly denounced as part of a bureaucratic, cumbersome effort that only leads to a nebulous "wish list". Many on campus think that the best way is to just let the future happen, through decentralized actions of departments only.

Yet, to overcome this fragmented approach, the newly appointed university president suggested another framework. To better shape Princeton's thinking about its future and about how the "big" issues with which Princeton University is confronted can be tackled, the president proposed to engage in strategic planning, so that Princeton's thinking is structured along prescribed lines. In addition, since the allocation of resources needs to be optimized, strategic planning has to set spending priorities for Princeton's budget.

As a consequence, the president started the process of strategic planning by raising four key questions (quotes from [1]).

- "How best can Princeton sustain teaching and research excellence that makes a difference in the world?" To offer the highest quality in research and scholarship is taken for granted at Princeton. The open issue, however, is what the university can actually do to make a difference in the world.

- "What new academic initiatives should Princeton pursue to address long-term issues of fundamental importance?" Addressing that question means moving into new fields of research such as neuroscience, but it also entails embracing old knowledge in a new way, e.g., to discuss ethical issues in the context of a globalized, digitalized world. 
- "What must we do to make service central to the mission of the University?" Princeton wants to better prepare its students for careers and lives "in the service of humanity". To serve humanity will become increasingly important, so Princeton wishes to be prominently engaged in this task.

- "How can Princeton enable more undergraduate students to contribute to the world"? Princeton aims at creating additional places for undergraduates. It will increase its socioeconomic diversity and the number of international exchange students. Undergraduate education has always been a cornerstone at Princeton and that obviously should remain so.

Princeton University will work through fall 2015 to develop a new strategic plan within which it will prioritize new initiatives over the next five to ten years. During that process, values and standards will be articulated against which Princeton will judge proposals that come forward later.

\subsection{Design of the Planning Process}

To summarize: any planning process should start with the assessment of challenges and evolving needs so that the planning institution focuses on its "big" issues. So as not to indulge in an egocentric planning process, the university should also learn how it is perceived from the outside. A first step in doing so is to develop a SWOT analysis (strengths, weaknesses, opportunities, threats). Then it should assess the added value it yields to its stakeholders.

A vision and a mission have to be determined which motivate staff and generate a specific profile. They should incorporate ambitious and coherent goals that are regarded as worth aspiring to and which are deemed to be potentially feasible. Values and quality standards such as academic freedom, diversity of students and staff, or community engagement have to be articulated and any strategic proposals will have to be evaluated against them. Finally, specific goals for a future date have to be set and then, with backward reasoning and by inventing some new rules in the game, an action plan should be decided upon. Instruments of strategic controlling have to be set up to guarantee that these goals are actually reached and to enable corrective measures when necessary.

\section{Examples of Strategy Models for Universities}

\subsection{Historic Perspective}

Nowadays it seems evident that leading universities place themselves somewhere in the triangle of higher education, research and innovation and, as a third mission, community service. This placement corresponds to the nature of a university 
as perceived today and all three items regularly appear in any university strategic plan. Yet, it is worth remembering that universities started their history differently and it may be that the future will again bring changes, with new challenges for universities' strategic planning.

For many centuries, the main task of universities consisted of teaching and learning only. The university was a community of masters and students ("universitas magistrorum et scholarium"), living together in colleges so that the transfer of knowledge, skills, and values from one generation to the next could easily take place on campus. The programs of these communities and their missions were ambitious and based on humanistic principles. In the charter of the University of Vienna, written in 1365, for example, the university was summoned to understand faith and thereby further it (in the faculty of theology), to enhance judicial equity (in the faculty of law), to serve the public good (in the faculty of medicine), and to foster human reasoning (in the faculty of philosophy).

There was no research. To listen to good teachers, students moved around Europe.

University rankings did not exist. However, it was well known around the year 1500 for example, that law was best taught at the University of Bologna, medicine at the University of Padova, and philosophy (the seven "artes liberales") at the Sorbonne in Paris [2]. The strategy of excellence for a university consisted in hiring the best teachers. Consequently, students would be attracted and thereby the university would be funded. At that time, the majority of university funding came from students.

As the advancement of the sciences gained momentum in the 18th century, and with the increased interest of the then emerging nation states in applying scientific knowledge to solve societal, economic, and military problems, European universities gradually evolved into research institutions dependent on state funding. Finally, innovation became a buzzword of the 21 st century. It originated in an economic debate, stressing the importance of science-based innovations for upgrading jobs and triggering growth in a globalized world.

\subsection{The Research-Intensive University and Its Strategies (Humboldt Model)}

The idea of a university as a "true" research university, which concentrates mainly on scientific discoveries and new scholarly insights, was developed in Germany approximately two hundred years ago. Then Wilhelm von Humboldt convinced the king and the state of Prussia to establish the Berlin University [3]. Prior to Humboldt, scholars such as Baruch Spinoza in the Netherlands had already stressed the role of scientific reasoning in explaining empirical observations and how reason may help to improve the conditions of life. These insights had already paved the way for the secularization of universities. 
This new type of university was designed according to philosophical ideas concerning the nature and the relevance of research. From there, a strategic plan of excellence was derived for the universities. Humboldt's proposal to establish the Berlin University was also a reaction to French state utilitarianism which, at that time, led to the closure of universities in France and in neighboring countries, and to the foundation of "écoles spéciales" (now "grandes écoles"), such as the École Polytechnique in 1794. With these drastic measures, France wanted to rapidly educate a technocratic, science trained, meritocratic elite who could make the new bourgeois state more powerful and more effective. In contrast to these state efforts in France, the Berlin University was freed from any necessity of purpose to be useful. The university was supposed to search for the scientific truth only and that was its goal per se. The strategy of engaging staff and students in pure research was the key for the idea of a university as advocated by Humboldt.

As a consequence, emphasis was laid on the basic sciences, the humanities, and research-oriented doctoral studies. Research and teaching should form a unity, not only in theory, but also in practice. Of course, Humboldt hoped that by only allowing pure and open research, not serving practical needs, the university would ultimately, via the publication of results and via the doctoral formation of students as young researchers ("Bildung durch Forschung"), generate wellbeing for the state, the society, and the economy.

In fact, the huge success of German research efforts in the 19th century, especially in the sciences such as physics or chemistry, in medicine, and in electrical engineering, led to the foundation of the industrial powerhouse of Germany which continues to flourish today. To emulate this success, Humboldt's idea of a research university was replicated in many European countries and even attained by, for example, the United States and Japan. There, new research universities with Ph.D programs started first in Baltimore in 1876 (Johns Hopkins University), then in Chicago in 1890 (University of Chicago), and in other places, and led to the foundation of universities in Tokyo and Kyoto. Ivy League universities in the US and the universities of Cambridge and Oxford in England followed with Ph.D programs in the 20th century.

The strategy and structure of the Humboldtian research university were designed in a simple way. Research and teaching strategies were fixed by a faculty, assuming that the professors of a faculty knew best what to do. Professorial freedom of research and teaching were even constitutionally guaranteed. All professors and students were obliged to strive after scientific truth only, and everyone was expected and encouraged to come up with new scientific insights. The academic freedom was complemented by a light collegial governance structure in the faculties, which were ruled by professorial collegial bodies. Adequate funding of the university came from the state in order to make sure that the university was not forced to pursue practical needs and was free to conduct basic research. Governmental supervision concentrated on preserving this true nature of research universities. University presidency was reduced to a representative function. Strategic planning for the future was carried out by the faculties where the existence of scientific wisdom in abundance was automatically assumed. 
Today, this elitist concept of a "true" Humboldtian research university is no longer possible. The massification of higher education within many universities, the specialization of knowledge within faculties, the quest for quickly applying new knowledge to industry, and the increased amounts of investments needed to bring the infrastructure of a university up to date, all necessitate institutional, not faculty strategies. In addition, governments were not able or not willing to increase the funding of research universities relative to the massification of higher education. As a consequence, universities were forced to specialize in some fields, to better allocate their resources internally, and to search for new ways of financing their activities besides state funding. What then remains from the elitist Humboldtian model of a research university in the 21 st century?

To answer that question it may be worthwhile to look at the recent strategy plan of the legal successor of the Berlin University, namely the Humboldt University of Berlin. Its plan was developed when this university participated in the German Excellence Initiative of 2012. Now Humboldt University can claim to have presented a strategic plan, which was honored by the federal government of Germany within its initiative to establish universities of excellence in the country.

The new Strategic Plan of the Humboldt University [4] named "Educating Enquiring Minds. Individuality-Openness-Guidance" accepts that some, not all, research areas will be strengthened. This extra funding of some excellent research clusters and newly established integrative research institutes implies that the university faculties no longer receive their traditional share of the budget. Consequently, the power of decision-making shifts increasingly to the university leadership.

Areas of excellence at Humboldt University refer to the life sciences, the research for global sustainability, the field of hybrid materials and functional systems and to the humanities. Although a disproportionate funding of faculties is now practiced, the targeted areas still constitute, all in all, a broad range of subjects of a traditional research university.

Besides these targeted research efforts in which $60 \%$ of the additional money of the excellence initiative of the government flows, young researchers get promoted. About $30 \%$ of the additional money is spent in recognizing personal strengths, allowing individuals to develop their research potential, and promoting the young research generation in their careers. The initiatives under this second heading contain programs such as "Humboldt Goes to School", quality programs for the bachelor studies (more research-based learning), the expansion of the "Humboldt Graduate School", research tracks for graduate students, the promotion of postdocs via fellowships and, finally, the setting up of a strategic innovation fund.

The third area of the new strategy plan addresses governance issues. About $10 \%$ of the extra money of the excellence initiative will be spent in this third area of administrative reform, which endeavors to establish a culture of enablement among administrative staff. It also involves a reform of existing faculties and aims at regrouping faculties and departments. Another program strengthens the deans in their decision-making powers and reinforces them as strategic links between 
the faculties and the university management. It is not yet clear what the outcome of the excellence strategy of Humboldt University will be and to what extent it will revive Humboldt's original ideas. At the end of 2017, the funding decision of the German government has to be renewed. Therefore, the result of implementing the new strategy is due for evaluation at that time by external peers. Yet the main aims of the strategy, to reinvigorate the Humboldtian ideas of strengthening pure research and of providing formation through research, all by extra state funding, and the aim to modernize the governance structure, will be implemented in a university with high student-staff ratios in many study programs. Mass university-wide education remains the norm. Potential conflicts among faculties and fields in which many students study may therefore arise. One of Humboldt's ideas, namely to create a uniformity of excellence within the whole university, will be at stake. Hence the sustainability of the new strategic plan of Humboldt University of Berlin hinges decisively on the adequacy of future funds, and on the strength of the new institutional leadership to overcome fragmented faculty interests.

\subsection{The Strategic Concept of an Entrepreneurial University}

The Humboldt model of a pure research university is based on a philosophical idea about the nature and relevance of research. This idea was put into practice about two hundred years ago. In contrast, the strategic concept of an entrepreneurial university is a construct suggested by Burton R. Clark who derived this construct from empirically observed cases of pro-active universities in the 1980s and 1990s. Prototypes of such pro-active universities, termed as entrepreneurial universities, are the University of Warwick in England, the University of Michigan in the US, and Monash University in Australia [5, 6].

The strategic plan of an entrepreneurial university typically focuses on reinforcing activities which transform the university from a state-led to an own-led institution. As a result, the university should be able to move fast, with high ambitions of its own, in the globalized environment of the 21st century. Of course, universities differ and, as a consequence, strategies need to also address the specialties of the institution. In addition, universities used the emerging entrepreneurialism to create spin-offs and start-ups, thereby bringing entrepreneurship into society.

In order to transform an originally state-led university into an entrepreneurial one, the strategic plan should concentrate on strengthening factors which act as catalysts for change. According to Clark there are five key factors to consider:

- Diversify the funding base: besides the general state funding, a university should try to secure means from other government sources and from private organized sources, especially from business firms and foundations. In addition, the university should generate some of its own income by fund-raising from alumni, from garnering research contracts, or from the transfer of knowledge. 
- Improve the steering capacity of the university. A university should display administrative strength at all levels. Change-oriented administrations are needed in all parts of a university. New administrators should increase income and control cost.

- Create units besides the traditional, discipline-centered departments. These units are best in pursuing problem-oriented research, be it interdisciplinary, trans-disciplinary, or at the margin of a traditional research field. All new units should have a high potential to gain scientific reputation and third party funding. New areas for teaching, such as lifelong learning, distance education, or the development of massively open online courses, could also be tackled by newly established units. As a consequence, the traditional departmental or faculty structure of a university is supplemented by a strong periphery, representing new research and teaching interests, challenging traditional departments and making them increasingly open to change.

- Support those departments which go for entrepreneurial actions. In doing so, teams within the traditional units become involved in the process of change. The university should ensure that these entrepreneurial actions are well managed by change-oriented administrators.

- Intensify the competition for outside reputation. Hire high-reputation academics from outside who in turn will attract excellent new faculty members and bright students. This will speed up the pace of change toward entrepreneurialism within the university.

The concept of an entrepreneurial university contains a strategic plan for change, from a state-led, bureaucratic, and slow-moving institution to a university being able to steer itself and to move fast. Clark's advice concerning the key factors of change was heeded by many world universities in their strategic plans, which aim to strengthen their autonomy and their world standings.

Note that entrepreneurialism does not necessarily imply a commercialization of the university. Rather the contrary: the more a university is successful in steering the above-mentioned activities, the more it is able to and capable of attaining increased reputation. By increasing and enhancing its reputation, a university will attract more long run, general research grants, thus reinforcing the freedom of research. The less a university is successful, the more it will become dependent on money only given for short-term purposes and for specific applications.

\subsection{The University as a Knowledge Enterprise in an Innovation-Driven Society}

An interesting further move toward knowledge entrepreneurialism of universities is offered by the "New American University" model, introduced by Arizona State University (ASU). Approximately ten years ago, this university reformulated its 
mission and strategic plan, endeavoring to inspire more creativity and innovation within the institution [7].

The main ideas of the new strategic concept have been derived in the context of new policies in the U.S. state of Arizona. This state, unlike the area of nearby Los Angeles, is characterized by an underbuilt and undifferentiated university infrastructure. Yet, this backward position allowed new pathways for development, which were laid down in an unconventional strategic plan for 2002-2012. The plan opted for a reconceptualization of a university.

There are four basic strategic goals.

- "Access and quality for all": This goal seems to be a contradiction in terms. This is especially so when an institution is confronted with limited financial means. Yet, ASU would appear to be on a growth trajectory where both strategic goals, access and quality, seem to be attainable. In 2013, for example, the number of enrollments had already approached 77,000 undergraduate, graduate, and professional students. Freshman numbers have increased in size by about $50 \%$ since 2002. Access for students from poor families (with annual income below 60.000 USD) has risen by $500 \%$. These students are able to graduate debt free from the university. By hiring new faculty, quality could also be improved.

- "National standings for colleges and schools in every field": ASU is constantly ranked among the top hundred universities in the world. Its research strength lies especially in engineering and computer sciences. Standings seem to improve according to various benchmarks.

- "Becoming a national comprehensive university": This goal is meant to build national and global distinction on the basis of comprehensiveness of the university.

- "Enhancing our local impact and social embeddedness": Although the university wants to be a top-notch research institution, it is strongly committed not to advance abstract knowledge per se. Instead, the university looks at the social, economic, cultural, and environmental impact of its knowledge advancement. In light of this perspective, the university has founded a school of sustainability, introduced a study of religion and conflict, and established a biodesign institute. Yet, at the same time, it has eliminated departments such as biology, anthropology, geology, or sociology.

What makes ASU's Strategic Plan particularly interesting is that it strives for combining two objectives: (1) the plan will increase the university's size and expand its intellectual, pedagogical, and functional breadth. By engaging in a growth path, the university is endeavoring to simultaneously implement accessibility, inclusiveness, and quality; (2) the university has changed its organization, away from the departmental structure, to inter- and transdisciplinary centers, thereby hoping to increase its societal impact by tackling present and future grand challenges. Inevitably, with the momentum of growth and with the new design of the university, ASU was able to attract excellent academics that foster the culture of curiosity and creativity. 


\section{What Is Excellence in Strategic Planning?}

Excellence in strategic planning in universities not only requires a well-designed planning process, as described in the first part of this chapter. It also needs to focus on which profile the university would like to adapt. Should good teaching, even with an emphasis on excellent undergraduate education as at Princeton University, be a key factor? How research intensive should the university be? Should it pursue excellent research in targeted areas? How much will it strengthen research-based learning for students and foster the promotion of early stage researchers? Which entrepreneurial activities does a strategic plan need to have to better fund and change a university? How much can one rely on increasing the scale of a university, when combining the access of a more diverse student body with high quality of research and teaching? To what extent should a university tackle grand challenges and be engaged in solving problems of local communities? All these key issues were described in the chapter's second part. There are no clear-cut answers. They depend on the existing profile of an institution, external conditions, innovation challenges, and on the potential funding sources.

To complicate the search for an excellent strategic plan even further, let us remember that universities are likely to experience another big change in the near future. Higher education, through massively open online courses, as well as research, through online publications and the general availability of data in all fields, will become significantly more open and accessible. Higher education and research will be more accessible at low costs throughout the world. The innovation process will also be more open as firms will practice more outsourcing with respect to obtaining new ideas concerning products and production processes. Many more scientists and organizations, especially from developing countries and from outside of universities, will be able to engage in innovation issues. As with crowd funding of activities, there will be crowd research and crowd innovation.

"Open learning", "open science", and "open innovation" will make the borders of universities more permeable. As a consequence, education, and particular graduate education at universities, may become more important than research per se. Universities will enable people to participate in research and innovation endeavors of others, meeting research and innovation demands defined by society or by firms. Universities may then become certifying agents for those who actively engage in research and innovation elsewhere. They might then become marketing institutions to bring research and innovation more directly to the society and to the economy. In the future, a university will only thrive when it is well placed in a host of surrounding start-ups and applied or interdisciplinary research centers.

There will be more pressures on universities to meet the demands of knowledge societies to educate good researchers, particularly in the case of Ph.D. candidates [8]. The Ph.D. Education in many universities is still organized along traditional academic lines, with too narrow specializations, if it is organized at all. Interdisciplinary research and research in teams are rarely practiced in universities. 
Oversupply in the job markets for Ph.D.s in Germany or in the US indicates that the research formation at universities has to change in order to meet the new demands of knowledge societies.

\section{Summary}

What do we learn from international experiences on the role of strategic planning for an excellent university? Take into account the strengths and values of your traditions, and formulate high ambitions and coherent goals, which should be attainable at a specific date. Be ready to change the organization of the university. However, look closely at how the world is evolving. What ultimately counts is to attain an inherent resilience to uncertain developments. Egocentric, wishful thinking is misleading.

Open Access This chapter is distributed under the terms of the Creative Commons Attribution Noncommercial License, which permits any noncommercial use, distribution, and reproduction in any medium, provided the original author(s) and source are credited.

\section{References}

1. Christopher L. Eisgruber, A Strategic Look into Princeton's Future. Princeton Alumni Weekly, The President's Page, April 23, 2014, Vol.114, No.11.

2. Rexroth, Frank. (2011). Frankfurter Allgemeine Zeitung, 9(2), 33.

3. Wilhelm von Humboldt, Antrag auf Errichtung der Universität Berlin, Juli 1809, reprinted in: J.J.Engel et al., Gelegentliche Gedanken über Universitäten. Reclam-Verlag Leipzig 1990, pp. 267-283.

4. www.exzellenz.hu-berlin.de

5. Clark, B. R. (1998). Creating entrepreneurial universities. Organizational pathways to transformation. Oxford: Pergamon Press.

6. Clark, B. R. (2004). Delineating the Character of the Entrepreneurial University. Higher Education Policy, 17, 355-370.

7. Michael M. Crow, The Research University as Comprehensive Knowledge Enterprise: A Prototype for a New American University. In: Luc E. Weber, James J. Duderstadt (eds.), University Research for Innovation. Economica London-Paris-Geneva 2010, pp.211-225.

8. Nature, 472, 261. 


\title{
Excellence in Innovation and Knowledge Economy
}

\author{
Yücel Altunbaşak
}

\section{Introduction}

This chapter addresses the challenge for middle-income and technologically developing countries to reach sustainable high levels of welfare based on $R \& D$, innovation, and education. The initial discussion focuses on the middle-income trap, and subsequently proceeds to the discussion of the key components of an R\&D, innovation, and entrepreneurship system intended to overcome this trap. The key components are built upon four categories of best practices. The first two categories are best practices to foster entrepreneurship (techno-entrepreneurship, venture, entrepreneurship culture) and mission-oriented programs, including mega projects. The third and fourth categories are stimulating research quality (performance-based funding schemes) and supporting the innovation system with $R \& D$ awareness. The best practices are drawn from leading examples of policy mechanisms from the Republic of Turkey, the US, South Korea, Japan, Brazil, India, China, Singapore, Mexico, and EU countries (UK, Sweden, Finland, and the Czech Republic). The chapter concludes with policy advice and key recommendations to improve innovation excellence in technologically developing countries, including implications for oil-rich countries.

\section{R\&D and Innovation to Overcome the Middle-Income Trap}

The fast pace of technological developments in our age imposes a challenge to middle-income and less technologically developed, high-income countries to strive to reach the highest peak in $R \& D$ and innovation. This challenge is none

Y. Altunbaşak ( $\square)$

Scientific and Technological Council of Turkey (TUBITAK), Ankara, Turkey

e-mail: yucel.altunbasak@gmail.com 
other than the ambitious process of seeking to ascend an apex of excellence in a pursuit of 'excellence in innovation.' On this path, countries may be faced with barriers that may hinder them from making full use of their potential in order to rise toward the peak. Most notably, these barriers may be associated with the state of the innovation system and its integrity when compared to the progress of economic growth. In such a situation, countries must surmount another hurdle, this time to rise up to the challenge of transforming their economy into one that is based on knowledge and innovation. In a technical sense, countries must overcome the situation of what is known as the "middle-income trap" to reach the status of a knowledge-based economy in a relatively short period of time.

The concept of the 'middle-income trap' defines a condition in which middleincome countries are restricted in their ability to increase gross national income (GNI) per capita despite their efforts to do so. A similar situation applies to technologically less advanced, high-income countries, such as the Kingdom of Saudi Arabia (KSA), which need to develop ascending strategies other than the exploitation of natural resources. In this condition, the income of a country increases sufficiently to enable it to advance beyond low-skilled labor-intensive activities. Yet, since the innovation system, including its physical and human capital, has not been developed sufficiently, the quality of the outputs of the country remains underdeveloped. This limits the country's capability to compete with high-income countries in highly sophisticated products. The country continues to remain behind advanced economies in higher-value products, that in turn affects their relative standing in GNI per capita values [1,2].

Figure 1 compares countries based on the level of their progress in GNI per capita values over a 50-year timeframe. The axes are based on GNI per capita in 1963 and 2013, respectively. In Fig. 1, those countries that sustained their growth are positioned in the top-right corner, while those that escaped the middle income trap and experienced a quantum leap in GNI per capita values are grouped top center. The countries that remained in the middle-income trap are situated in the boxed area in the center of Fig. 1 (see red box), while those countries that become poorer are located in the bottom half. The axes are the logarithm of the ratio of GNI per capita values relative to the US values in 1963.

\subsection{Comparative Perspectives for the Middle-Income Trap}

Numerically, the threshold for escaping the middle-income trap and graduating to the high-income status is defined as requiring a GNI per capita of $\$ 12,746$ at 2011 prices [3]. The number of economies that made this transition is limited [4]. Only about one quarter of the current OECD member countries succeeded in doing so [5]. The middle-income trap is also persistent in emerging economies since economic growth tends to slow down once the lower hanging fruits of technology transfer are harvested. In contrast, those countries that succeeded in making the transition have one important feature in common: they have excelled in developing advanced, indigenous technologies and in investing in education. 


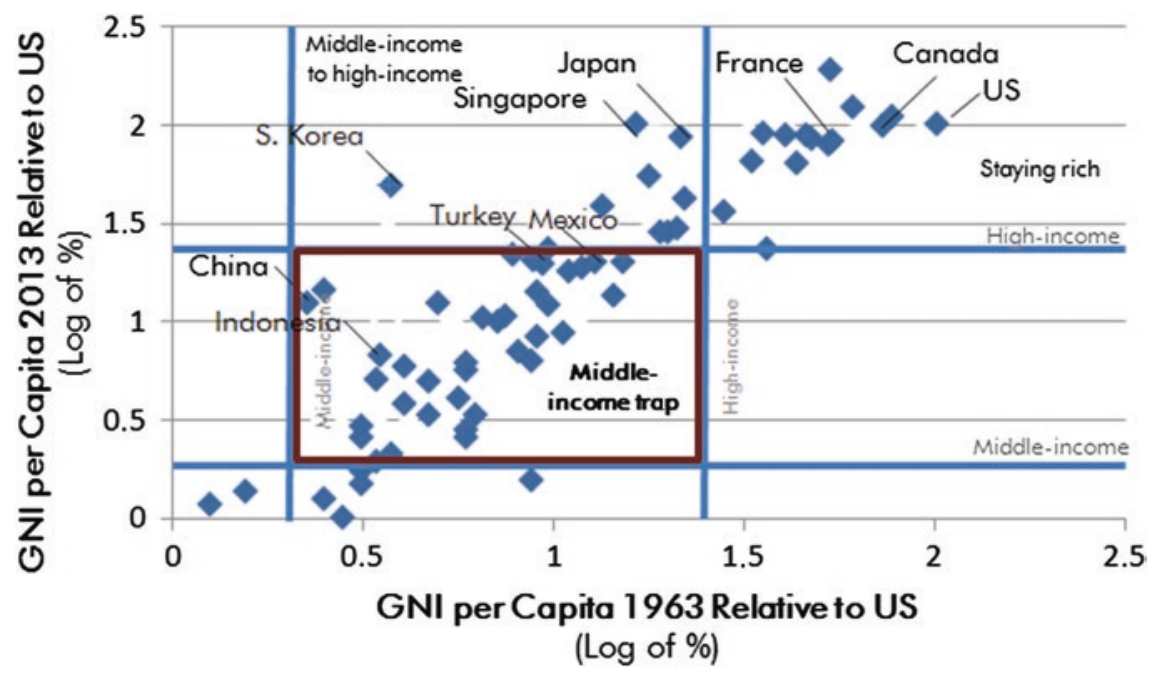

Fig. 1 Depiction of the relative standing of countries over a 50-year timeframe (redrawn for current years based on World Bank dataset [3]. Original graph is provided for 1960 and 2008 in Ref. [4] )

Based on relative GNI per capita values over the course of 50 years, Fig. 1 indicates that countries such as the US, Canada, and France have sustained their economic growth. South Korea, Japan, and Ireland have overcome the middle-income trap and are now their challengers. The next group of countries is the group that remains in the middle-income trap. China, Indonesia, Mexico, and Turkey are examples of countries in this area, although this does not necessarily signify lack of progress. Based on the Global Competitiveness Report [6], both Mexico and Turkey are indicated as countries in 'transition' to innovation-based economies. In contrast, some of the oil-rich countries, such as Saudi Arabia, will be placed above the middle-income trap. The GNI per capita of Saudi Arabia was \$26,260 [3] (log of percentage relative to US GNI per capita in 1963 is 1.71), close to the level of South Korea. ${ }^{1}$

Table 1 compares three countries that have overcome the middle-income trap to become innovation-based economies with four countries that remain in the trap, but exhibit important signs of progress. The latter also includes the efficiencybased economies of China and Indonesia. For the sampled countries, Table 1 provides the values of gross domestic expenditure on research and development (GERD) and educational investment, both given as percentages over the values of gross domestic product (GDP).

For the innovation-based economies in Table 1, the average value of GERD over GDP is $3.2 \%$. For South Korea, Japan, and Taiwan the values are 3.4, 3.3 , and $2.9 \%$, respectively. The average value for educational investment as a

\footnotetext{
${ }^{1}$ Saudi Arabia is not included in Fig. 1 due to lack of data for 1963 in the World Bank dataset.
} 
Table 1 Comparison of countries based on GERD and educational investment over GDP (2012) [7-12]

\begin{tabular}{l|l|l}
\hline \multicolumn{1}{l}{ Innovation-based economies } \\
\hline Countries & GERD/GDP (\%) & $\begin{array}{l}\text { Educational } \\
\text { investment/GDP (\%) }\end{array}$ \\
\hline South Korea & 3.4 & 7.6 \\
\hline Japan & 3.3 & 4.9 \\
\hline Taiwan & 2.9 & 5.8 \\
\hline
\end{tabular}

In transition to innovation-based economies

\begin{tabular}{l|l|l}
\hline Mexico & 0.4 & 3.5 \\
\hline Turkey & 0.9 & 3.2 \\
\hline
\end{tabular}

Efficiency-based economies

\begin{tabular}{l|l|l}
\hline China & 1.7 & 3.3 \\
\hline Indonesia & 0.7 & 3.3 \\
\hline
\end{tabular}

percentage of GDP is $6.1 \%$. For example, South Korea invests in education at $7.6 \%$ of its GDP, whereas Taiwan and Japan invest at 5.8 and $4.9 \%$, respectively. Certainly, GERD and educational investments over GDP are relatively high in these countries.

For those countries that are in the middle-income trap, the values of GERD and educational investment over GDP are comparably lower. The average values for Mexico and Turkey that are in the middle-income trap, but in the process of transition to innovation-based economies, are $0.7 \%$ for GERD and $3.4 \%$ for educational investments, both over GDP. The GERD of Mexico stands at $0.4 \%$ of GDP while investment in education is relatively higher at $3.5 \%$ of GDP. The GERD of Turkey is higher at $0.9 \%$ of GDP and the investment in education is $3.2 \%$ of GDP. The average values for China and Indonesia, which are in the middle-income trap as efficiency-based economies, are $1.2 \%$ for GERD and $3.3 \%$ for investment in education, both over GDP. Indonesia invests the same share in educational investments as China but spends less on R\&D as a share of GDP. In contrast, while the value of GERD over GDP is only $0.7 \%$ in Indonesia, it is $1.7 \%$ in China. Even within the middle-income trap, GERD and educational investments over GDP vary for countries that are in a state of transition to innovation-based economies and efficiency-based economies.

\subsection{The Key Role of $R \& D$, Innovation, and Education}

Clearly, the ability of countries to realize an 'exit strategy' to escape the middleincome trap requires an intense effort marked by high levels of investment in GERD and education as shares of GDP. At the same time, these key investments must be matched by an efficient innovation system to transform these inputs into high value-added outputs. This two-pronged approach defines the paradigm shift that countries must implement in order to provide the necessary groundwork for the opportunity to escape from the middle-income trap and become 
innovation-based economies. While there is no single method for countries to execute such a paradigm shift, countries have to develop strategies to increase outputs of knowledge-intensive technologies and high value-added products. This, in turn, depends on the ability to establish the necessary "ecosystem" between actors to trigger R\&D, innovation, and entrepreneurship activities as a launch pad to excel in innovation.

A diverse array of tools and mechanisms are implemented by various countries to promote a flourishing ecosystem for the innovation actors. These mechanisms are discussed from the perspective of international comparison in Sect. 3, based on best practices in emerging, fast-growing, and developed countries. For the purposes of this chapter, these best practices are grouped into four main headings that define ways and means to stimulate and sustain the R\&D, innovation, and the entrepreneurship ecosystem. The first two headings are best practices to foster entrepreneurship, including techno-entrepreneurship and venture capital, and best practices in mission-oriented programs and mega projects. The subsequent two headings involve best practices for the stimulation of research quality and best practices for supporting the innovation system through raising awareness and fostering a culture in $R \& D$, innovation, and entrepreneurship among the related actors. In analogy, these best practices provide some of the "keys" that countries can use to "unlock" a path to exit the middle-income trap. For ease of reference, the key concepts can be identified as entrepreneurship, prioritization, fostering research quality and quantity, and raising awareness of R\&D culture.

Some of these best practices may be equally valid for countries that appear to be high-income economies. Some countries have attained this level based on the abundance of their natural resources. Other countries have combined assets from both their stocks of human and natural capital in creating new value-added products and technologies. These best practices will allow innovation systems to rely, not only on abundances in natural resources, but also on wealth in human capital. KSA for example, as a high-income economy, invests only $0.07 \%$ of GDP as GERD [4]. For oil-rich countries such as KSA and other similar countries, this implies that further investment in GERD and education can better mobilize their potential to ameliorate human welfare. For this reason, in a highly competitive world, even those countries that have reached the status of high-income economies need to pursue excellence in innovation to maintain their performance and allow their innovation systems to flourish and excel to the next level.

\section{Best Practices to Be an Innovation and Knowledge Economy}

For a well-functioning innovation system, it is crucial to strengthen each component of the "ecosystem" in a systems approach. The business sector and entrepreneurs should be at the core of this ecosystem and interact robustly with all other actors. Research activities without business sector linkages will not yield 
the desired results, especially for the aim of escaping the middle-income trap. Therefore, it is mandatory to develop the correct set of support tools and mechanisms to manage a 'complex ecosystem', while strengthening even the weakest component. These mechanisms should also provide a particular emphasis to the process of commercialization. From the perspective of policy-making and policy design, this approach requires a strategic combination of both qualitative and quantitative policy tools.

\subsection{Best Practices to Foster Entrepreneurship}

One of the vital aspects of improving the efficiency of the R\&D and innovation ecosystem is promoting entrepreneurship based on technological and innovation-driven research. Recently, many countries have realized that the main challenge for the innovation system is not the lack of knowledge or technology, but often the inability to drive these innovations to the market. This realization has resulted in a shift of focus in direct $R \& D$ funding among OECD countries. Most OECD countries have now channeled their funding opportunities across the entire R\&D and innovation value chain, including the integrated processes leading to commercialization.

Direct support to aid commercialization includes support to encourage collaboration and knowledge transfer among or between firms and scientific institutions. It further includes direct support to foster the growth of high technology start-up firms, stimulate venture capital activity, and accelerate innovation activity relevant to societal challenges. Such forms of direct support allow governments to target specific barriers that persistently affect innovation performance. For entrepreneurship, these barriers may include the lack of co-operation, barriers for small businesses and individual entrepreneurs to commercialize, or high risk in areas that also have high social returns [13]. In this context, best practices to foster entrepreneurship are examined under the topics of techno-entrepreneurship, venture capital, and entrepreneurship culture. These best practices can further improve the ease of doing business within the ecosystem [14].

\subsubsection{Techno-Entrepreneurship}

The value of an innovative idea increases with commercialization potential. It further increases with the presence of a skilled and qualified techno-entrepreneur capable of taking the idea to the market. For this reason, countries have designed and implemented support mechanisms and programs to encourage techno-entrepreneurship endeavors. Programs that encourage small domestic businesses and/ or individuals to engage in $\mathrm{R} \& \mathrm{D}$ and innovation activities with commercialization 
potential include the SBIR Program (USA), the Individual Entrepreneurship Multi-Phased Support and Co-Financing Programs (Turkey), and the PRISM Program (India).

The Small Business Innovative Research (SBIR) Program, coordinated by the US Small Business Administration, is one of the most well-known schemes. The program enables small businesses to explore their ideas' technological potential and provides an incentive to profit from their commercialization potential. Eleven federal agencies that have a total extramural R\&D budget in excess of $\$ 100$ million allocate a certain percentage of their budget to the SBIR Program. Approximately $\$ 2.5$ billion is awarded through this program annually [15]. The program has three phases with monetary contracts and/or grants awarded in Phases I and II [16]. At the end of the third phase, small businesses are expected to meet specific R\&D government needs and commercialize their ideas.

- Phase I (start-up phase) supports the exploration of the technical merit or feasibility of an idea or technology and awards up to $\$ 150,000$ for approximately six months.

- Phase II provides grants to facilitate the expansion of the results that are obtained from the start-up phase. Up to \$1 million for two years is awarded to Phase II grant holders, who will perform R\&D work and evaluate the commercialization potential of their idea.

- Phase III is designed to accommodate the time for an innovation to move from the laboratory into the marketplace. Small businesses must find private sector funding or non-SBIR federal agency funding. No SBIR funds are awarded in this phase.

The National Science Foundation's (NSF) implementation of the SBIR Program provides direct linkages between SBIR and some of the other support programs. As one of the schemes, I-Corps provides private sector co-financing and mentorship. Similarly, the National Institutes of Health (NIH) presents the Commercialization Assistance Program (CAP) as a supplementary tool to the SBIR program. CAP aims to provide small businesses in the health sector with business mentorship to raise the commercialization potential of the outputs of SBIR projects.

In Turkey, entrepreneurs are supported for their activities across the entire spectrum from the idea creation to the commercialization stage in an integrated manner. The Individual Entrepreneurship Multi-Phased Support Program (TÜBİTAK 1512) [17] aims to support individuals or technology-based start-up firms with ideas that hold promise for transformation into innovative products and services for the domestic or international markets. The program, which is designed and implemented by the Scientific and Technological Research Council of Turkey (TÜBITAK), targets various stages of maturity in R\&D-based entrepreneurship activities. The program, which has a total of four phases, integrates grant-based financial support with mentorship support opportunities. Entrepreneurs, including academics not familiar with business matters, are given opportunities to receive 
training on technical, commercial, and executive issues, as well as mentorship from industrially experienced mentors.

- Phase 1: The program starts with the presentation of a business idea by the entrepreneur to TÜBITTAK. Upon a positive evaluation, the entrepreneur is provided the option of obtaining entrepreneurship training. Phase 1 corresponds to the stage of idea creation and ends with the detailed preparation of the business plan and training.

- Phase 2: Upon further successful evaluation, the entrepreneur receives grant support to realize the business plan and establish the start-up. The start-up is supported with about $\$ 50,000$ of seed capital with the aim of having a technological validation of the proposed idea within 12 months. The activities that may be undertaken at this phase include conceptual design, technical and economic feasibility studies, and technological affirmation (pre-prototype, demonstration, simulation, code algorithm, etc.). The entrepreneur also has the option to request mentorship support. Those firms that demonstrate commercial potential in their outputs may directly skip to Phase 4.

- Phase 3: This phase provides grant support to conduct any additional R\&D studies that may be needed to further develop the commercialization potential of the outputs of the previous phase. To receive funding for this phase, the entrepreneur must submit a project application, now as an established firm, to the SME R\&D Grant Program (TÜBİTAK 1507). In this phase, $75 \%$ of eligible project expenses up to $\$ 250,000$ are grant support entitled. These activities may include detailed design, development of a commercial prototype, experiments, and field tests. Projects that pass the technological affirmation phase are evaluated using special criteria. For those projects that complete this phase successfully, firms may receive approval to pass to Phase 4, upon the preparation of a robust commercialization business plan.

- Phase 4: This phase corresponds to the process of facilitating the entrepreneur's access to finance. Upon the request of the firm, TÜBITTAK sends letters to risk capital firms inviting them to be a partner to the project output. In addition, TÜBİTAK organizes project brokerage events to facilitate the commercialization process of the products.

In the two years since the program's inception, a total of 239 R\&D start-ups have been successfully created, the majority of which have commercialized their research outputs.

In addition to TÜBITTAK 1512, an additional version of the program was established as the Individual Entrepreneurship Multi-Phased Co-Financing Program (TÜBITAK 1512/B) with the purpose of facilitating the access of start-ups to equity financing. In this version, large firms are invited to partner with TÜBITTAK to support start-ups by providing incubation, co-financing, mentorship, and the potential of being the first customer of their products. The program increases the entrepreneur's chances of survival in the market. As a means to complement the TÜBITAK 1512 Program, this version enables entrepreneurs to take advantage of the experience of the private sector and their provision of seed capital 
support, office or rent support for a year, technical expert personnel, and business development [17].

In the Indian context, Promoting Innovations in Individuals, Start-Ups and MSME's Program (PRISM), is implemented by the Department of Scientific and Industrial Research (DSIR) of India and applies a multi-staged approach to supporting entrepreneurs. Any individual with an idea can be supported to transform the idea into a commercially viable product or process. In the proof-of-concept stage, up to $\$ 35,000$ or $90 \%$ of the eligible project costs are supported. In the following stage, which may include real site tests and demonstration, an additional $\$ 350,000$ or $90 \%$ of the eligible project costs can be supported. The duration of the projects can vary between six months and three years, depending on the scope of the idea. As the name of the program suggests, PRISM seeks to 'open up' the full commercialization potential of the idea [18].

\subsubsection{Venture Capital}

Since R\&D investments yield their returns in the medium or even long term, rather than the short term, finding financial support can be a cause of concern for startups. This concern has recently triggered developments in designing programs to support or establish venture capital funds. For example, in China different financing opportunities aim to support the quantity and effectiveness of venture capital firms. A government-based funding agency that is related to the Ministry of Science and Technology (MOST), namely the Torch Center, operates the Techbased SMEs Venture Capital Introductory Fund [19]. The Torch Center provides funds to venture capital firms to subsidize SMEs with seed capital in the approach of supporting the 'fund of funds.' In this scheme, Torch Center encourages and motivates venture capital firms to make equity investments in, and provide investment subsidies to, technology-based SMEs.

Another similar structure is the Start-up Enterprise Development Scheme (SEEDS), run by the government agency that supports Singapore's SMEs, namely SPRING Singapore [20]. The SEEDS Program provides additional capital opportunities for Singapore-based start-up firms that are less than 5 years old. The selection of the start-ups is based on the criteria of the products' innovativeness and/ or processes within the domain of the intellectual property of the start-up. These products and/or processes are expected to have strong growth potential across international markets as well as to be in receipt of initial investment by external investors. It is an equity-based co-financing option that enables SPRING to acquire ownership in the company proportional to its investment up to the maximum rate of $20 \%$ and an exit strategy of five years. Based on SEEDS, SPRING acquires the opportunity to be involved in managerial level decisions and to leverage start-ups that have sufficient capability to proceed to the market.

SPRING provides another investment opportunity for start-ups, namely the Business Angel Scheme, which involves a different scheme. In this scheme, the start-up firm is funded by the registered Business Angels in SPRING's portfolio 
as opposed to any other external investor. If the start-up is able to obtain investment interest and commitment from any of the Business Angel investors, SPRING has the capacity to potentially match the intended amount (dollar-for-dollar) up to a maximum of $\$ 1.5$ million [20]. In addition, like SEEDS, the Business Angel Scheme can acquire equity stakes in the company proportionate to its investments. An advantage of both schemes is that these programs involve experience sharing from SPRING to the start-up. They also provide opportunities for start-ups to benefit from SPRING's investor network.

Another emerging country, Mexico, provides venture capital funds to start-ups as a means to stimulate the entrepreneurial spirit of innovative Mexican firms. The Mexican Ministry of Economy (SE) [21] provides a seed capital co-investment fund for innovative companies, namely the Co-investment Fund Seed Capital. This fund aims to increase the accessibility of seed capital for entrepreneurs and/ or companies and seeks to promote the entrepreneurship ecosystem. The funds go directly into the assets of the fund and/or the project in exchange for equity shares in the newly established firms (up to one-year-old firms). Due to the nature of involving equity shares, the ministry invests up to $50 \%$ in the firm. This threshold is based on the concern of not capturing any control of the start-up. The ministry is careful to contribute with equity shares in the innovative firms to promote firms which have market potential. In addition, SE operates a 'fund of funds' initiative that invests in venture capital funds. The Mexico Venture Program targets domestic and foreign funds that aim to trigger innovative activities in the country. With the Venture Program, Mexico enhances the awareness of venture capital investment opportunities throughout the country by sharing risk with the other investors.

Another example from Turkey is the Venture Capital Funding Program (TÜBİTAK 1514). This program was launched to contribute to the creation of a venture capital ecosystem. The program encourages the establishment of new funds that provide venture capital to innovative SMEs by providing grants to fund managers [17]. This ensures the sustainability of the venture capital ecosystem and enhances the financial support that is specific to the maturity level of the venture capital firms. Accordingly, TÜBİTAK can provide grants to domestic and foreign venture capital funds up to $20 \%$ of the size of the fund. The fund is expected to focus on the early stages (seed and start-up) of equity investments and innovative SMEs that have the potential to develop innovative products, services, and/or production processes and domestic technology. The total size of the venture capital funds that received support from TÜBITAK and are available to invest in start-ups in Turkey has risen to about 700 million USD. Of this amount, about 470 million USD has been raised from foreign venture capital funds [22].

\subsubsection{Entrepreneurship Culture}

In the process of promoting entrepreneurship, programs that support entrepreneurial activities are a commendable start but are only one of the series of steps required to establish a sufficiently fostering environment. For this reason, 
developing 'entrepreneurial culture' is as important as launching programs to enable entrepreneurs to enter the innovation arena. At the same time, the Knowledge Triangle [23] emphasizes the key role of linkages among education, research, and innovation actors in order to utilize education and research for innovation. Fostering innovative capacity and entrepreneurship in universities has thus recently been an important policy tool.

The Singapore Government establishes a council in every university to promote the environment of innovativeness and entrepreneurship. Moreover, specific support mechanisms are used in the system to encourage such activities in universities. The University Innovation Fund provides support for various ranges of activities to generate a climate of innovation in universities, such as entrepreneurship trainings, awards, consultancy service procurement from professors with private sector experience, and internships.

As a ranking index including entrepreneurship, the Entrepreneurial and Innovative University Index was prepared for the first time in Turkey in 2012. Now in its fourth year, the 50 most entrepreneurial and innovative universities are announced annually. Through ranking universities according to their entrepreneurial and innovative performances, the index increases positive competition among universities, hence fostering an entrepreneurial and innovative ecosystem. The universities are ranked according to data collection across a set of 23 indicators in five pillars. These pillars are scientific and technological research competence, intellectual property pool, cooperation and interaction, entrepreneurship and innovativeness culture, and last but not least, economic contribution and commercialization [24].

From a system's perspective, the index is part of a larger strategy to develop a culture and entrepreneurship capability in universities. While the index measures performance, the Capacity Building for Innovation and Entrepreneurship Support Program (TÜBİTAK 1601) supports universities, NGOs, and firms to provide mechanisms for activities including mentorship, training, brokerage events, investor readiness programs, and fundraising events. Under this program, the first call was launched as the University Certification Program for Entrepreneurship (1601.1) that supported undergraduate and graduate entrepreneurship certification programs. In this call, universities are supported in implementing certification programs of a minimum of $120 \mathrm{~h}$ aimed at undergraduate and graduate students as well as academic staff for building entrepreneurship capabilities. Following the training program, certificates are granted to the successful entrepreneurs who pass the evaluation examination [17].

\subsection{Best Practices for Mission-Oriented Programs and Mega Projects}

Even the most successful countries with the most active researchers and facilities may fall short of realizing the potential of their research base. In this situation, it becomes vital to concentrate the dispersed research efforts in a country 
around mission-oriented programs. Such an approach combines the bottom-up demand coming from the research base with top-down policies, to focus the country's research effort to increase the impact of research activities. At the international level, there is an increasing trend toward designing policies that combine top-down and bottom-up approaches based on targeted policies. Policymakers, together with relevant stakeholders, tend to analyze the local dynamics as well as global technological developments in pursuit of determining the areas that are to be supported.

The rationale for these policies is generally linked to the need to stimulate innovation in areas where societal needs are pressing (e.g., energy, health, and environment) and/or where government action can complement market mechanisms with minimal financial outlays. To be efficient, such policies must target specific market or systemic failures and their objectives [13]. The priorities may be selected in areas of relative competitive advantage or in areas that need to be developed in the country to address present or future needs. In mission-oriented approaches, programs in areas of priority and large-scale "mega projects" help to accelerate the emergence of technologies for which there is an urgent and time-bound societal need.

\subsubsection{Mission-Oriented Programs}

As an example from fast-growing BRICS economies, the innovation system of China is known for its mission-oriented approaches for supporting specific R\&D and innovation projects in priority areas. China has systematically used the support instrument, namely the National High-Tech R\&D Program (863), to develop cutting-edge technologies that are identified in the "National Medium and LongTerm Program for Science and Technology Development of China." This program is intended to stimulate the development of advanced technologies in a wide range of fields, for the purpose of allowing China to increase its technological capability and to be more independent of the financial burdens of importing foreign technologies [25].

The 863 Program focuses on developing a number of key technologies in the next five to ten years and establishing technological systems of significant value for societal applications. It aims to accelerate the socio-economic development of the country and enable China to approach or catch up with international pioneers in select fields [26]. Projects are implemented and monitored by a related ministry in the sector, with project budgets differing from one subject to another. One project that has received considerable attention in China and throughout the world is the 863 Key Technology and System Integration Project for Electric Vehicles. Nearly $42 \%$ of the total budget is allocated for critical battery components and electric vehicle integration.

In Turkey, following the adoption of the National Science, Technology, and Innovation Strategy 2011-2016, there has been a paradigm shift toward mission-oriented approaches. Traditionally, project funds had solely been granted 
to researchers through a bottom-up approach where the researcher decided the area/topic on which to work as curiosity-driven research. Based on the strategy [27], nine priority areas were evaluated and adopted by the Supreme Council for Science and Technology (SCST), namely automotive, machinery-manufacturing, information and communication technologies (ICT), energy, water, food, health, space, and defense. Following the adoption of the priority areas, high-level prioritization group meetings prioritized sub-fields of the nine areas. This effectively combined top-down direction setting through the SCST with the bottom-up direction setting of the innovation actors. In yet another level of stakeholder evaluations, TÜBITAK coordinated multi-staged processes based on the use of technology foresight methods, including Delphi surveys, to determine the prioritized topics under the sub-fields. The results of these processes are used in policy design, technology roadmaps, and preparation of project calls. With the wide participation of different stakeholders, Turkey has now completed 10 technology roadmaps and launched over 150 technology roadmap-based calls.

Defining priority areas inevitably calls for revisions and elasticity in support mechanisms. Thematic and call-based programs are most useful when they are adaptable to changing needs. In 2013, TÜBİTAK developed two new call-based, mission-oriented support measures to improve R\&D performance in priority research areas. The Support Program for Research, Technological Development and Innovation Projects in Priority Areas (TÜBİTAK 1511) [28] targets private sector companies. The Support Program for Research, Technological Development and Innovation Projects in Priority Areas (TÜBITAK 1003) [29] is directed toward researchers from both academia and private/public research institutes. While the target audience that will lead the project is different, both programs incentivize the collaboration of private industry and academia/research institutes. Under the aegis of these programs, TÜBİTAK announces calls for project proposals addressing Turkey's priority areas. Applicants submit project applications in response to the calls. Each call is designed to cover specific research areas with the potential of strengthening areas in which Turkey may have a comparative advantage or a demand to accelerate the closing of technological gaps.

The calls of the TÜBITAK 1511 and 1003 coded support programs are determined using thorough analysis of technology roadmaps' outputs, high-level prioritization groups, and private sector problems capable of being solved by means of R\&D activities. Detailed analysis of foreign trade data was also integrated into the process of determining call topics. Presently, these programs satisfy the need of the ecosystem to support product and technology-oriented projects that preferably involve university-industry cooperation. These programs provide a larger budget per project in comparison to curiosity-driven programs so as to encourage R\&D activities to be conducted in prioritized topics. In addition, there are budgetrelated incentives for university-industry cooperation. The number of applications also indicates that researchers are interested in the call-based, mission-oriented approach. The number of applications to both programs has been in excess of 3700 applications. 


\subsubsection{Large-Scale Mega Projects}

In China, 16 National Mega Projects have been launched under the Development Plan (2006-2020). While three are classified as confidential, 13 are characterized as civil-purposed projects and military-purposed projects as listed below [30]. For example, the 'Mega New Drug Development Program', under the aegis of the National Mega Projects Initiative, received about $\$ 2$ billion to be used in the years from 2011 to 2015.

\section{Civil-purposed projects}

1. Core electronic devices, high-end general chips, and fundamental software

2. Mega-scale integrated circuit manufacturing technologies

3. Next generation of broadband wireless mobile networks

4. Advanced digital control machines and fundamental manufacturing equipment

5. Wastewater control and treatment

6. Key new drug innovation

7. Prevention and treatment of key infectious diseases (e.g., HIV/AIDS, hepatitis)

8. Large-scale development of oil \& gas fields and coal-bed gas

9. Breeding of new variety for transgenic biology

\section{Military-Purposed Projects}

1. Large-scale advanced pressurized water reactor and high temperature gas-cooled nuclear power plants

2. Mega-airplanes

3. High-resolution earth observation system

4. Manned space flight and lunar exploration

Similarly, the Korean Government is securing new growth engines for a sustainable economy and improving the quality of life by developing fundamental technology in biology, nano-science, energy, environment, and other promising fields. There are six thematic umbrella support programs being implemented by the National Research Foundation of Korea [31]. The themes are identified and several full-scale projects have been supported under each umbrella program. The mission-oriented, thematic programs are as follows:

1. Bio-Medical Technology Development Program

2. Nano-Material Technology Development Program

3. Next-Generation Information Computing Program

4. High Technology Convergence Technology Development Program

5. Public Welfare \& Security R\&D Program

6. Global Frontier Program

For example, the "Development of New Medicine" is one of the themes that are adopted under the aegis of the Bio-Medical Technology Development Program. This theme's target is to develop 10 commercial therapeutic drugs by the year 
2019. Another initiative for the health sector is The Korea Drug Development Fund. The Ministry of Knowledge Economy (MKE), the Ministry of Health, and the Ministry of Education, Science and Engineering have created this fund for drug development, which has received a total of 27 million USD in contributions.

In addition, mega projects, which are seen to be flagship "landmark" projects, are launched as a special kind of mission-oriented approach in Turkey. Most notably, this includes electric vehicle technology, through the Public Institutions Research and Development Projects Support Program (TÜBİTAK 1007) [32]. The aim of TÜBITTAK 1007 is to solve technological problems and satisfy public institutions' needs by means of R\&D projects. Through the use of TÜBİTAK 1007, it has been possible to launch large-scale, high budget mega projects targeting the country's needs. Examples of such projects are the high-resolution communication satellite project, the electric vehicle project, and the wind turbine project. Most of these mission-oriented projects involve large-scale budgets of over 30 million USD.

\subsection{Best Practices for Research Quality Based Stimulation}

Programs to increase the quality of R\&D and innovation outputs are as necessary as new programs to support $R \& D$, innovation, and entrepreneurship. Since R\&D and innovation are one of the main drivers of countries' future growth, prosperity, and wellbeing, it is important to ensure that money is invested in projects with the greatest potential to return effective and quality research outputs [33]. Since universities are one of the main pillars of the innovation ecosystem, increasing the quality of research outputs in the university research environment has been receiving much attention as a policy focus. One of the policy tools that have been introduced are performance-based research funding systems [34]. Overall, best practices to stimulate the quality of research outputs in the innovation system can be classified under the topics of performance-based funding schemes for universities, schemes to increase publication quality in researchers, and performancebased schemes for fast-growing, innovative firms.

\subsubsection{Performance-Based Funding Schemes for Universities}

One of the oldest performance-based research funding systems is the Research Assessment Exercise (RAE) in the UK [35]. Since its launch in 1986, many countries have followed suit and introduced performance-based research funding schemes. Such widespread adoption of performance-based funding schemes for universities has also represented shifts in the quality of research outputs, since universities are so central in many innovation systems. According to international best practices, one of the most important tools of performance-based research funding to foster R\&D facilities in universities is project overhead. Numerous countries 
exert project overhead. Recently, however, a fixed project overhead rate has been widely deemed to be less effective than varying project overhead rate based on performance. This change in methodology allows a boost in R\&D in universities since it fosters increased competition.

Countries that implement varying project overhead rate include the US, the UK, Sweden, and Ireland. The efficiency factor implementation in the UK is one of the leading examples. This practice, initiated in 2011, allows Research Councils UK (RCUK) to evaluate the funded money based on performance. This reduces amounts allocated, if needed, when there are decreases in performance [33]. In this methodology, every university determines a project overhead rate and applies to RCUK annually. At a later date, RCUK uses the method of defining efficiency groups that provides the research organization with the autonomy to make minimal impact savings. This aids in removing uncertainty and does not require the research organization to collect huge amounts of data or RCUK to build expensive monitoring systems.

In the UK, research organizations are categorized into five efficiency groups A to E. The efficiency group A represents the most efficient and E the least efficient. The association with an efficiency group is based on a research organization's absolute indirect cost rates and the relative change in the rate compared with the previous year. Higher Education Institutes (HEIs) in the least efficient group would be subject to increased scrutiny and pressure to reduce their indirect cost rates. The assignment of research organizations to efficiency groups is also subject to annual review. Furthermore, it is important that in the revised methodology to calculate the current rate, the previous year's rate is duly taken into consideration. This allows accounting for the growth rate as the percentage change for higher performing universities.

Some countries continue to exert fixed project overhead rate for universities. At the same time, the possibility of changing to the varying project overhead rate methodology is becoming increasingly up for debate. In Finland, the fixed rate is exerted, namely $46 \%$ for TEKES and $12.5 \%$ for the Academy of Finland. In Ireland, this rate is up to $35 \%$ and there are aims in place for increasing it further [36]. An average of $52 \%$ overhead is used in Sweden, which further plans to implement UK's efficiency factor model in the coming few years. Within the context of the EU Framework Programs, different models are applied with $20 \%$ fixed rate and $60 \%$, conditionally.

Since 2004, a fixed overhead rate at $10 \%$ has been exerted in Turkey for every project. In the new implementation of project overhead, the aim is to raise the rate of $R \& D$ funds in university budgets to $25 \%$ from its current rate of $2 \%$. Therefore, the practice of fixed project overhead rate has been changed and increased from 10 to $50 \%$ based on universities' performance that will be assessed annually based on objective criteria. According to new practice, the project overhead will vary from university to university depending on their performance. A higher level of performance will lead to a higher project overhead for universities. This also means an additional R\&D budget for universities that compete to raise their level of performance. 
Another example of a performance-based funding scheme for universities is awarding successful R\&D outputs, such as publications and patents, and providing incentives based on their success. Recently, such revisions have been implemented in the Czech Republic [37]. The Czech Republic aims to motivate HEIs to increase the quality and the number of students as well as to affect the universities' annually allocated budgets. The revision includes all categories of the R\&D outputs that are measured by awarding them with a certain defined amount. System indicators include several types of publications, e.g., Jimp-article in an impacted periodical, Jneimp - a critical article in an international database such as SCOPUS or ERIH, patents and other results of applied research. The proportion of points that are gained by various categories of research institutions varies according to levels of success in these categories.

\subsubsection{Performance-Based Funding Schemes for Researchers}

With the new Project Performance Award in Turkey, successfully completed projects are awarded to increase the effects of funded projects based on performance. For performance assessment, a total of 36 sub-criteria are taken into consideration. These include the number of indexed articles in A, B, and C class journals, the number of other refereed articles, and the number of citations according to nine main criteria [38]. The nine main criteria include articles, scientific papers, books, awards, patents, products/models/firms, dissemination, researcher trainings, and new projects. The points that are gained with respect to these criteria and the successfully completed projects are awarded with up to $\$ 48,000$ in addition to the project grant, incentive premium, and project overhead. In practice, this incentive bonus may pass to the researchers as an additional $\$ 1500$ in monthly income.

Another example of performance-based funding for researchers is the Incentive Program for International Scientific Publications (UBYT), which has been initiated in Turkey to boost the quality of scientific publications. The program has been revised to increase the rate of international citations per publication, which is a quality indicator. According to the program, journals that are included in international citation indexes are evaluated using objective parameters, such as the impact factor and citation half-life. In this respect, publications are compared to their counterparts in their research areas and every publication receives a certain mark. Higher incentives are granted for better quality [38].

\subsubsection{Performance-Based Funding Schemes for Firms}

In China, the Beijing Zhongguancun Sci-Tech Financing Guaranty Co. Ltd., which is a company in the Zhongguancun Park [39], known as the "Silicon Valley of China," identifies its fast-growing 'gazelle' firms and provides performance-based incentives. Based on the Gazelle Plan, the above-mentioned company determines the 3000 most innovative gazelle firms annually and facilitates banks to provide 
low-interest loans in a credit guarantee system. The expected incomes of the firms are between 1.5 million and 80 million USD and are expected to show an increase of approximately 10-20\% over the previous year's levels. According to other performance criteria, such as the number of patents and innovation activities, the firms are identified based on a ranking of up to five stars. According to the number of stars, the percentage of the project budget for which a low credit loan can be obtained by the firm from the bank is varied. For example, a five star ranking firm can receive a low credit loan for $40 \%$ of the project's budget, while a firm with one star ranking can receive a loan for only $20 \%$ of the project's budget.

\subsection{Best Practices for Supporting the Innovation System with $R \& D$ Awareness}

For any policymaker, it is crucial to sustain an ecosystem that not only utilizes the performance of the current actors to the maximum extent, but also attracts newcomers with promising potential for the system's future. From this aspect, it is vital to raise awareness and diffuse a penetration of R\&D and entrepreneurship culture to support the innovation system. There are several mechanisms that can be identified as embodying best practices in the process of raising awareness of R\&D culture. The two headings under which these best practices are discussed are diffusing $R \& D$ culture in researchers and diffusing $R \& D$ culture in society.

\subsubsection{Diffusing the Penetration of R\&D Culture in Researchers}

An increasing emphasis is placed on providing support to the build-up of technology transfer capacities in countries to enhance technological collaboration between public research institutes, HEIs, and enterprises. As an example, the Mexican Government operates a program called the Program for the Creation and Capacity Building of Knowledge Transfer Offices (KTOs). This program aims to facilitate private sector access to the knowledge produced within universities and research centers and to encourage the fulfillment of academia's 'third mission.' This 'third mission' has been identified as the commercialization of knowledge through technology transfer and academic spin-offs. The government provides vouchers for innovation through KTOs for the purpose of stimulating the demand of companies for innovative solutions produced by knowledge-generating institutions. This program also provides medium-term grants to KTOs for knowledge transfer and linkages with the private sector in an effort to promote KTO growth and development.

Other mechanisms, implemented in almost every middle- and high-income country, are policy tools to support Technology Transfer Offices (TTOs). In Turkey, the TÜBITTAK 1513 Support Program [17] provides grant support for existing and new TTOs. The aim is to trigger universities' innovation and 
entrepreneurship by improving the quality of TTO services for commercializing universities' knowledge and technology. Under TÜBITTAK 1513, five categories of activities are eligible for support. These include awareness building and training/mentorship services, services to assist in applying for R\&D project support, activities to promote university-industry collaboration, and project development/ management. It also includes services to manage intellectual property rights and licensing as well as firm establishment and entrepreneurship services. Through these activities TTOs seek to assist in transforming the technology-based assets of universities into commercial outputs. In addition, TTOs assist in the formation of university-industry collaboration and the production of knowledge and technology according to industry's needs. TTOs will be funded for 10 years under the TÜBITAK 1513 Program. The call is open for the top 50 entrepreneurial and innovative Turkish universities, and each university is eligible to receive up to approximately five million USD.

The South Korean Twinning Program is another example of such a support mechanism. This program encourages information exchange between leading TTOs and newly established or yet to be established TTOs. In this process, all South Korean TTOs are classified as leaders, novices, or newly established. Based on these classifications, leader TTOs are expected to share their experiences with novice and newly established TTOs. The amount of support given to TTOs and its duration can also be shaped by these classifications.

In Brazil, the National Incubator and Technological Park Support Program (PNI), implemented by the Ministry of Science, Technology and Innovation (MCTI), is an integrated program that provides incubators, TTOs, and technology parks with grant support [40]. Supported activities include undertaking benchmarking studies with international case studies of other incubators and TTOs outside Brazil and market analysis service provision to entrepreneurs. At the same time, the CERNE Model allows the country's 384 incubators to be classified according to their maturity levels. At each level, the incubators are expected to fulfill certain activities based on best practices.

Another support program that is initiated to boost the dissemination of R\&D project culture is the R\&D Funding Program for Beginning Researchers (TÜBITAK 3001) [28]. This new program provides opportunities for researchers who have not previously received any funding to apply for their first project and be evaluated in a separate pot from the big players. This provides a means to support researchers at the beginning of their research careers while encouraging them to gain experience. Researchers in universities and public and private organizations who have not previously received support as principal investigators can apply to this new program. The program's advantages are that it has a high support ratio, a fast evaluation process, and there is no limitation for the number of applications. The program offers grants of up to $\$ 25,000$ per project, which includes scholarships, support of trips for scientific activities, support for project dissemination costs, and an incentive premium. The total duration of the R\&D project may be up to 24 months. Since the initiation of this program, $40 \%$ of beginner researchers in Turkey have been induced into actively practicing R\&D culture. 
In Japan, new technological developments are shared within the scope of two programs that provide bi-directional exchanges between universities and industry. In New Technology Presentation Meetings, academics make presentations to industry, while the needs of the industry are shared through presentations by industry to academia within the scope of Open Innovation Seminars. Both of these programs increase knowledge diffusion within the innovation system while increasing awareness of R\&D culture. These programs also support undertakings, including the Strategic Promotion of Innovative Research and Development (S-Innovation) Program, to direct promising seeds from the project results of basic research into key technologies for new industries [41]. Such initiatives allow Japan to create the foundations of future industries and sustain economic growth.

\subsubsection{Diffusing the Penetration of R\&D Culture in Society}

Another important aspect of raising awareness of R\&D culture in society is to foster science, technology, engineering and math (STEM) education starting from early ages. STEM education is an area that receives high focus in many countries. One of the examples is the US, which supports science fairs by many government agencies. Recently, the US has further initiated a Science Fair Program under the auspices of the US President's 'Educate to Innovate' policy. The White House Science Fair featured over 100 students from more than 30 states, representing more than 40 different STEM competitions and organizations that recognize the talents of next-generation scientists, engineers, inventors, and innovators. Approximately 30 student teams had the opportunity to exhibit their projects as part of the fair. The President viewed student work exhibits in person, ranging from breakthrough basic research to new inventions, and delivered remarks to an audience of students, science educators, and business leaders on the importance of STEM education to the country's economic future [42].

Raising public awareness of science can be another area of priority as a means of diffusing the penetration of R\&D culture in society. One of the best practice examples is the European Union Contest for Young Scientists, which is an initiative of the European Commission. Within the Framework Programs for Research and Technological Development, and the European Research Area (ERA), science and societal activities aim to build an increasingly harmonious relationship between scientific endeavors and European society at large. In this context, the contest promotes the ideals of cooperation and interchange between young scientists. Young scientists also have the chance to meet others with similar abilities and interests and to be guided by some of the most prominent European scientists. The EU Contest has been the annual showcase of the best of European student scientific achievement since it was initiated as a Europe-wide student science fair in 1989. It attracts widespread media interest while giving students the opportunity to compete with the best of their contemporaries at the European level. The 25th contest in 2013 brought together 85 projects from 37 countries with 126 promising young scientists aged 14 to 21 . Winners shared $\$ 74,000$ in prize money and other prizes, such as science trips [43]. 
Serving the same objective, the USA Science \& Engineering Festival is another best practice. The mission of the festival is to stimulate and sustain the interest of youth in STEM. In addition to top-level support, festivals include hands-on activities and live performances by science celebrities, explorers, best-selling authors, entrepreneurs, and world-renowned experts.

As another example of large-scale public effort to diffuse science in society, the newly established support program in Turkey aims to create awareness of science and technology issues and to promote scientific culture among young people through science fairs at public schools. Based on the Science Fairs Support Program [44], public schools across the country are given monetary support to hold science fairs for students in Grades 5-12 in cooperation with the Ministry of Education. In the first year of the program, 1092 schools were funded. The fairs were attended by approximately one million visitors and 30,000 projects were exhibited by 64,000 students in consultation with more than 15,000 teachers.

In addition to periodic large-scale events, such as science fairs, other examples are the Science Centers that remain at the service of the public on a continuous basis. In Turkey, the SCST resolved that a science center is to be opened in every Turkish province by the year 2023, starting with the metropolitan municipalities. The Science Centers [44] will be venues for the interactive sharing of scientific knowledge with the public as well as a means of enhancing scientific culture and increasing the rate of scientific literacy in society. In line with these developments, TÜBITAK launched the Science Centers Development Support Program that is initially being used to support exhibits in metropolitan municipalities in a local partnership model.

Following the SCST's decision, contracts have been signed with four metropolitan municipalities. The Konya Science Center has recently been opened with the Prime Minister's participation in an opening ceremony. The other two science centers are expected to be opened in 2016. All centers are located in modern structures with stateof-the-art facilities. For example, the Konya Science Center is 25 thousand square meters including exhibition areas, training sections, conference halls, and libraries. It is constructed over an area of 100 thousand square meters. The Konya Science Center aims to be one of the three best science centers in the world. Currently, 235 exhibitions are designed internationally and 40 are implemented in the newly opened center. One of the forthcoming exhibitions is "Sultans of Science," which includes 50 exhibition units regarding contributions of scientists and inventors to astronomy, math, architecture, and medical sciences that were transferred to Europe as the scientific advances that laid the foundation for the European Renaissance.

\section{Recommendations for Excellence in Innovation to Escape the Middle-Income Trap}

The effort that countries must make to escape the middle-income trap requires an intense dedication to strengthening the $R \& D$, innovation, and entrepreneurship ecosystem to enable the process of attaining the peak of excellence in innovation. The pursuit of perfecting the ecosystem to the best that it can be requires boosting 
the performance of the innovation system and its actors. Ultimately, well-functioning ecosystems can enable entire economies to become knowledge based and innovation driven.

Best practices from emerging and fast-growing economies (including innovation-based economies, transition to innovation-based economies, and efficiencybased economies) have indicated that a series of support mechanisms and sound policy design are needed to effectively foster R\&D, innovation, and entrepreneurship. For ease of comparison, these support mechanisms have been grouped into entrepreneurship-oriented best practices, mission-oriented programs, and mega projects, stimulation of research quality, and supporting the innovation system through R\&D culture and awareness among innovation actors and society. Based on the overview of these best practices, four key recommendations are made:

- Support mechanisms that are designed to have varied, phased characteristics are useful for promoting entrepreneurial activities stage-by-stage. Based on best practices, these phases may address the level of maturity of start-up firm establishment, the preparation and implementation of the business plan, support for proof-of-concept and related $\mathrm{R} \& \mathrm{D}$ activities, and transition to the commercialization phase from idea to the market. At the same time, these support mechanisms should be presented in a robust policy mix that integrates mentorship support and venture capital funds' availability. If necessary, especially in emerging economies, the venture capital funds can be stimulated and encouraged through "fund of funds" approaches. In addition, best practices to promote an increase in the entrepreneurship culture in universities include the design and implementation of a novel university ranking index.

- The implementation of mission-oriented approaches that integrate both top-down direction setting and the bottom-up interests of the researchers is instrumental in allowing the channeling of resources toward the development of critical technologies. These approaches are particularly useful for gaining precious time in the process of catching up to the outputs of more sophisticated innovation systems and innovation-based economies. The flexibility, and thus the success, of mission-oriented approaches can be enhanced with the systematic implementation of call-based programs, which are crucial for increasing innovation excellence. In addition, mega projects that are implemented as special kinds of mission-oriented approaches will aid in directing innovation actors toward large-scale projects.

- Approaches that favor excellence should be able to complement the larger effort of improving the performance of the innovation ecosystem, especially toward producing the innovative outputs that will aid the country in escaping the middle-income trap. Such approaches that favor research excellence and research quality include the variability of project overheads according to research performance, as well as more innovative approaches to increase the level of positive competition between universities. This may further relate to the results of a university ranking index. Overall, tools to improve research quality may involve performance-based incentive schemes for universities, researchers, and firms. The design of policy instruments to improve research quality in the ecosystem will be as important as new programs. 
- The larger effort to escape the middle-income trap by taking as large strides as are possible toward becoming an innovation-based economy requires the intake of new innovation actors into the system. The diversity can range from $R \& D$ actors due to submit their first $R \& D$ project to the encouragement of future entrepreneurs and researchers through science fairs. At the same time, it is important that the level and penetration of science literacy is diffused within society so that the appreciation and usage of technological innovations in society can be increased.

\section{Policy Advice to Improve Innovation Excellence in Saudi Arabia}

More specific recommendations can be made for the policy-making process in Saudi Arabia to strive for innovation excellence based on the combined effect of its natural and human capital. For example, King Abdulaziz University (KAU) has already established an investment arm by Royal Decree known as the 'Wadi Jeddah' Closed Joint Stock Company. As one of Saudi Arabia's first experiments of its kind, the funds are planned to have a business model based on knowledge transfer, R\&D, and profit. For the effective use of the fund, this subsidiary may be mobilized to provide seed capital to start-ups for promoting entrepreneurship in a scheme that is similar to the multi-phased programs as overviewed in this chapter, i.e., SBIR Program, TÜBITAK 1512, and PRISM. Such a fund, or other such funds, may also be transformed into a venture capital fund to support innovative ideas with the potential to create high value-added products. Based on the best practices of the Torch Center, SPRING SEEDS, the Mexico Venture Program, and TÜBITAK 1514, it is envisioned that Saudi Arabia can establish a special scheme to stimulate the country's venture capital environment. In addition, and from another aspect, KAU can establish a certification program to promote university students' entrepreneurial activities. All three of these recommendations need to be planned in concurrence so that they may reinforce the needs of entrepreneurs and the country's entrepreneurship ecosystem.

Regarding a university ranking capable of reflecting the needs of emerging economies, the unique Turkish experience in establishing the 'Entrepreneurial and Innovative University Index' may be taken as a best practice for a similar index that meets Saudi universities' needs. For example, the 'Academic Ranking of World Universities 2014' [45] uses six indicators to rank universities. These indicators include the number of alumni and staff winning Nobel Prizes and Fields Medals, the number of highly cited researchers selected by Thomson Reuters, the number of articles published in the journals "Nature" and "Science", the number of articles indexed in the Science Citation Index-Expanded and Social Sciences Citation Index, and the per capita performance of a university. Among these, Nobel Prizes and Fields Medals may only be applicable to elite universities and may not be highly relevant for emerging economies. These particular indicators are not suited to promote a positive atmosphere of competition in universities to stimulate entrepreneurial activities. Despite the fact that KAU and three other Saudi universities 
are already included in the rankings, it would be advisable that a separate index is established based on the Turkish experience with customized indicators.

The ranking of universities may further be integrated with best practices to stimulate research quality based on ranking performance. For example, those universities that rank higher in the index may receive incentives in performance-based funding schemes similar to those in the UK. A similar scheme may also be implemented for researchers so that higher performing researchers can receive financial awards in addition to the project grant. At the same time, in addition to incentives for mature researchers, activities to foster and complement STEM education in youth can be initiated at an early age, for example by means of science fairs and festivals. Best practices in this respect may be taken from the EU Contest for Young Scientists, the USA Science \& Engineering Festival, and the Science Fairs Support Program in Turkey.

Furthermore, King Abdulaziz City for Science and Technology (KACST) is renowned for launching major projects, such as the Saudisat-4 Satellite and the decoding of the Arabian Camel Genome. The current position of KACST could be used to establish a support program for 'mega projects' that would give direction to major R\&D and innovation activities geared toward the country's priorities and/or the strategy technology sectors of KACST. In the mega projects, the topics could be determined in mission-oriented approaches and the collaboration of leading R\&D actors in the country could be promoted with financial incentives within the project budget. More specifically, the research institutes and strategic technology sectors (i.e., water technology, oil and gas technology, energy technology, petrochemicals, advanced materials, nanotechnology, and building and construction technology) could each have at least one major project that could be dedicated to improving innovation excellence in the country based on the generation of new products and technologies. Best practices may be taken from the National Mega Projects in China, the South Korean initiatives, and the TÜBİTAK 1007 program. In this manner, Saudi Arabia and other countries can take strides in coupling assets of both natural and human capital in the ascent toward furthering "excellence in innovation."

\section{Conclusions}

This chapter has provided empirical evidence and best practices related to the importance of investing in $\mathrm{R} \& \mathrm{D}$, innovation, and education to attain the highest apex of excellence in innovation. In total, 35 international best practices have been provided across the four categories of fostering entrepreneurship, mission oriented programs, research quality based stimulation, and supporting the innovation system with R\&D awareness. Table 2 summarizes the countries of these best practices along with key recommendations. These best practices are equally valid for countries that are in the process of escaping the middle-income trap and for technologically less advanced oil-rich countries that have obtained high income status based on the exploitation of natural resources. Countries with excellence in innovation need to combine assets from the stocks of both human and natural capital to create new value-added products and technologies. 


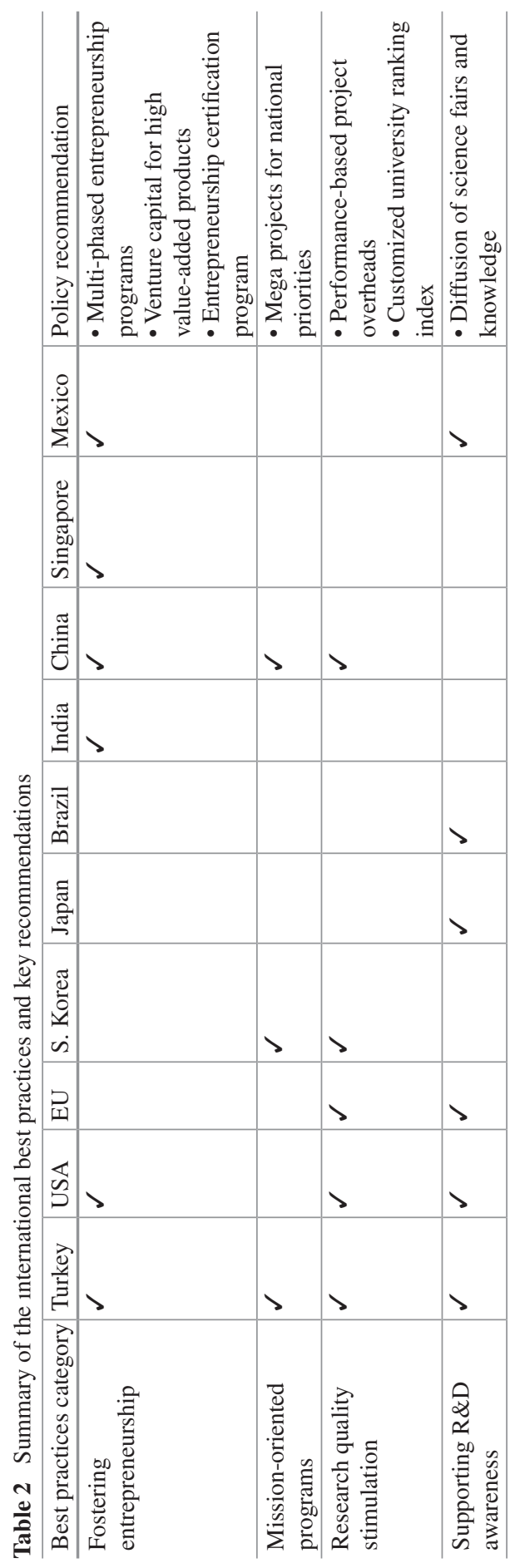


Open Access This chapter is distributed under the terms of the Creative Commons Attribution Noncommercial License, which permits any noncommercial use, distribution, and reproduction in any medium, provided the original author(s) and source are credited.

\section{References}

1. Gill, I., \& Kharas, H. (2007). An east asian renaissance: Ideas for economic growth. Washington D.C.: World Bank.

2. Im, F. G., \& Rosenblatt D. (2013). Middle-income traps, a conceptual and empirical survey. Policy Research Working Paper, World Bank.

3. World Bank Data Set, GNI Per Capita, PPP Current 2011 Dollars, http://data.worldbank.org/

4. World Bank, China 2030. (2012). Building a modern, harmonious, and creative high-income society.

5. OECD. (2013). The People's Republic of China: Avoiding the middle-income trap policies for sustained and inclusive growth (p. 3).

6. World Economic Forum. (2015). The global competitiveness report 2014-2015.

7. OECD. (2014). Education at a glance 2014: OECD indicators (p. 229)

8. World Bank, Education statistics: Education attainment.

9. Ministry of national education statistics 2011-2012 (p. 209).

10. Turkish statistical institute (TurkStat), http://www.turkstat.gov.tr/

11. OECD. (2013). Main science and technology indicators. Paris: 2013.

12. UNESCO institute for statistics, GERD as a percentage of GDP Saudi Arabia, http://www.uis.unesco.org/

13. OECD. (2011). Business innovation policies: Selected country comparisons (p. 15).

14. World Bank. (2013). Doing Business 2014 Understanding Regulations for Small and Medium-Size Enterprises (11th ed.).

15. SBIR program, http://www.acq.osd.mil/osbp/sbir/about/index.shtml

16. SBA, http://www.sba.gov/category/navigation-structure/about-sba

17. The scientific and technological research council of turkey, entrepreneurship programs, http://www.tubitak.gov.tr/tr/destekler/girisimcilik/ulusal-destek-programlari

18. Department of scientific and industrial research, PRISM program, http://www.dsir.gov. in/12plan/prism/prism.htm

19. Torch Center, http://168.160.159.71/english/areas_three.htm. Accessed July 2014

20. SPRING SEEDS, http://www.spring.gov.sg/entrepreneurship/fs/fs/Pages/business-angelscheme.aspx

21. Secretaría de Economía, http://www.economia.gob.mx/en

22. The supreme council for science and technology, presentation of TUBITAK president, http://www.tubitak.gov.tr/tr/icerik-bilim-ve-teknoloji-yuksek-kurulu-28-toplantisi-6-ocak2015

23. European Commission, Knowledge triangle and innovation, European institute of innovation and technology.

24. TÜBİTAK, Entrepreneurial and innovative University index, http://www.tubitak.gov.tr/tr/kur umsal/politikalar/icerik-girisimci-ve-yenilikci-universite-endeksi

25. Wu, H. (2000). The progress of communication technology subject of hi-tech research development plan of China. In International Conference on Communication Technology Proceedings. Beijing.

26. 863 program, http://www.most.gov.cn/eng/programmes1/200610/t20061009_36225.htm

27. TÜBİTAK, http://www.tubitak.gov.tr/tr/kurumsal/politikalar/icerik-ubtys-2011-2016

28. TÜBITTAK, Academic grant programs, http://www.tubitak.gov.tr/tr/destekler/akademik/ulu sal-destek-programlari

29. TÜBI TAK, Industrial grant programs, http://www.tubitak.gov.tr/tr/destekler/sanayi/ulusaldestek-programlari 
30. Chinese Government, National S\&T major projects, www.nmp.gov.cn

31. National Research Foundation of Korea, http://www.nrf.re.kr/nrf_eng_cms/

32. TÜBITAK, Public grant programs, http://www.tubitak.gov.tr/tr/destekler/kamu/ulusal-destekprogramlari

33. Research Councils UK. (2011). Efficiency 2011-15: Ensuring excellence with impact.

34. Hicks, D. (2011). Performance-based University research funding systems. Elsevier Research Policy.

35. Research assessment exercise, http://www.rae.ac.uk/

36. The higher education authority, report of the group on research Overheads, 2003.

37. EC European Universities forum for financial sustainability project, from incremental funding to quality \& performance indicators: Reforms of higher education funding in the Czech Republic, 2012.

38. TÜBITAK, Applications and directives, http://www.tubitak.gov.tr/tr/destekler/akademik/uygu lamalar-ve-yonergeler

39. Zhongguancun Science Park, http://en.zhongguancun.gov.cn/

40. Ministério da Ciência, Tecnologia e Inovação, http://www.mcti.gov.br/

41. Japan science and technology agency, research and development programs focused on technology transfer, http://www.jst.go.jp/EN/operations/operation_b.html

42. White house science fair fact sheet \& backgrounder, 2014, http://www.whitehouse.gov/ the-press-office/2014/05/27/white-house-science-fair-fact-sheet-backgrounder

43. EC EU contest for young scientists, http://ec.europa.eu/research/eucys/

44. TÜBITAK, Science and society grant programs, http://www.tubitak.gov.tr/tr/destekler/bilimve-toplum/ulusal-destek-programlari

45. Academic ranking of world Universities 2014, http://www.shanghairanking.com/WorldUniversity-Rankings-2014 


\title{
Excellence in International Cooperation
}

\author{
Adnan Zahed
}

\section{Introduction}

This chapter deals with 'excellence' in international cooperation. Section 2 discusses different terminologies such as cooperation, collaboration, and aid and the differences between and relationships among them. This is followed by some general insights concerning international cooperation, as a means to put university cooperation in perspective. International cooperation and university cooperation are further explored and elaborated on from this perspective in Sect. 3. Section 4 discusses student, expert, and teacher exchanges and the effects and proceeds of such exchanges. Section 5 deals with three examples of international cooperation. The first example covers international cooperation in higher education in Saudi Arabia in general, with particular attention given to King Abdulaziz University. The second example discusses international university cooperation and its application in one of the top-ranking world-class universities: the Copenhagen University in Denmark. The final example examines one of the world's leading programs for international technical cooperation: the 'Fulbright' scholarship program. Section 6 contains concluding remarks.

\section{Cooperation}

Cooperative work is a task that is accomplished by dividing it among participants, where each person is responsible for a portion of the problem solving [1]. Cooperation can be achieved if all participants do their assigned parts separately and bring their results to the table.

\footnotetext{
A. Zahed $(\bowtie)$

King Abdulaziz University, Jeddah, Saudi Arabia

e-mail: azahed@kau.edu.sa 
The concept of 'international cooperation' describes all cooperation activities with foreign countries, whether by non-governmental organizations (NGOs), bilateral (from one country to another), multilateral (involving a number of states), or decentralized (between local authorities).

The most established definition of international cooperation in the literature is by Keohane [2]. Keohane assumes a conflictive policy situation between countries at the outset of each cooperative agreement. Policy adjustments are then negotiated to bring agreements more in line with each actor's preferences. Once both policies become more compatible, the act of cooperation is completed.

'Aid' is something different from cooperation. It still has a social content, since it presupposes a relation between partners, but it does not imply sharing. It implicates inequality and it is sufficient that aid takes the initiative in favor of the other, with a certain degree of privilege [3]. Also, universities can enter into agreements in which one of the partners is 'aided' by the other (for example between a university in a developing country and one in the developed world).

The term 'collaboration' is the action of working together with other people to produce or create something. It is used, in the context of universities, mostly on the level of research. Roschelle and Teasley [1] see collaborative work as the mutual engagement of participants in a coordinated effort to solve the problem together [4].

Research collaborations can take many forms. There is a continuum ranging from the classic partnership between researchers in the same laboratory or academic department to the partnership between researchers in the same institution, to even partnership between researchers in different countries. Sometimes, two or more researchers at different institutions work separately and yet collaborate on a project. This can occur, for example, when working on different aspects of the same project, exchanging data, compiling data for the entire project, and subsequently conducting joint data analysis, reporting, and publication. Collaborations between or among researchers are particularly complicated when the researchers work at institutions in different countries. Not only can distance affect communication and project oversight, but cultural differences may further complicate communication and the project's overall conduct.

Cooperate/cooperation has been in vogue for many years, while collaborate/ collaboration is a more recent addition to selection criteria terminology. How do these terms differ? Basically, they are synonyms and both words are used interchangeably, but they represent fundamentally different ways of contributing to a group and each brings with it its own dynamics and power structures that shape groups in different ways.

In other words, cooperation can be achieved if all participants do their assigned parts separately and bring their results to the table, while collaboration implies direct interaction among individuals to produce a product and involves negotiations, discussions, and accommodating others' perspectives. The key difference between these approaches to group work is that cooperation is more focused on working together to create an end product, while successful collaboration requires participants to share in the process of knowledge creation $[1,5]$. 
Collaboration takes on particular importance on more complex projects involving multiple sections, teams, or agencies. Cooperation is more suitable for projects or agreements in which each participant is responsible to perform a certain segment of the complete task, as is the case in joint research projects. Someone might need to cooperate and collaborate with his/her team colleagues. Therefore, depending on the task, and the manner in which it is distributed and performed among the participants, the group work will either be spoken of in terms of cooperation or collaboration. The group work described in the chapter will be generally expressed in terms of cooperation.

The opposite of cooperation or collaboration is 'competition'. A small amount of competition between social agents makes for a healthy social system. It prevents it from degrading and becoming inefficient. However, excessive levels of competition have inevitable negative consequences. Many of the top universities see their colleagues as "competitors"; in part cooperating, in part collaborating in research and joint degrees, and in part in competition for the brightest and best students and staff.

\section{International and University Cooperation}

International cooperation and collaboration of universities are forms of working together to attain the best results in student learning and research. International university cooperation is part of the much wider arena of international cooperation that has evolved since the end of the Cold War.

The topic of international university cooperation has long been on the agendas of governmental and institutional bodies, but it was not until a few years ago that it began to be considered an important aspect of the processes of education and research [6]. It has been prominent in recent times and has become a significant and important university activity.

In recent years, universities have managed to include international cooperation and international relations as integral to their missions and functions by assuming the responsibility of cooperating with other institutions. However, the development of international cooperation in university life has often been a laborious process and cooperation policy has developed into a set of organizational strategies [6]. International cooperation among universities is one of many in the range of university activities which does not have a readily recognizable, directly visible profile in terms of quality improvement.

Unfortunately, the expected benefits from international cooperation in universities are as yet unclear to the majority. It is sometimes considered as an unnecessary expense, an obligation, or as an activity undertaken purely for reasons of prestige. Despite these rather negative viewpoints, university cooperation has been recently successfully incorporated into the institutional structure of an increasing number of universities. Most universities currently have an office or administration in charge of international university cooperation, with a definite strategy and 
an action plan, and carry out a series of international activities [7]. However, it is important not to confuse the mere fact of undertaking international activities with having an actual, plausible, effective, and beneficial policy of development cooperation. It must be understood that simply having a significant number of foreign students or some courses on international topics does not necessarily imply or mean that the concerned institution actually implements and practices real tangible international development cooperation.

In recent years, rising expectations have been generated with regard to the need to adopt new perspectives in actions of international university cooperation directed toward less-developed countries. However, universities need to attain a more secure and prominent situation in the arena of international development cooperation than many NGOs have apparently been able to manage in recent years. Therefore, university authorities should overcome budgetary constraints and other impediments in order to pursue the necessary efforts to enhance the incorporation of international cooperation in their institutions.

Technical international cooperation is one form of international university cooperation. Back in the nineteenth century, Alfred Nobel stated: "To spread knowledge is to spread well-being". Technical cooperation could be said to have its origins in this premise and has certainly developed to its present state in accordance with this view. The Organization for Economic Cooperation and Development (OECD) defines technical cooperation as "the activities whose primary aim is to increase the level of knowledge, technologies, practical know-how or productive attitudes of the population of developing countries, that is to say, to increase their reserve of human intellectual capital or their ability to use their current resources with greater efficiency" $[3,7]$. As technical cooperation is the key issue of this chapter, a more comprehensive definition follows.

Technical cooperation can be defined as the branch of development cooperation that uses the provision of know-how in the form of personnel, training, research, and associated costs of development. It includes contributions to development primarily through the medium of education and training to increase the level of knowledge, skills, technical know-how, or productive aptitudes of the population of developing countries, which in turn increases their stock of human intellectual capital, or their capacity for more effective use of their existing factor endowment $[3,7]$.

The basic aim of technical cooperation is to support the ability of people and organizations in creating, adapting, strengthening, and sustaining their capacity to set their own objectives. Its aims are that countries or institutions with a more advanced level of development in certain areas contribute to the solution of specific problems of less-developed countries or institutions through the transference and interchange of scientific and technological capacity and of human and material resources.

This cooperation mode considers education as the engine driving the transformation of expanding economies. Technical cooperation between developed and less-developed countries can take several forms such as expert services, scholarships, transference of equipment and supplies, sending of bibliographical material, 
and interchange of information and experience. Mobility is the area in which universities have incorporated international cooperation into their activities par excellence. Today's technical cooperation remains one of cooperation's most visible aspects.

Technical cooperation is often associated with actions intended to strengthen individual and organizational capacity through offering wide-ranging technical opportunities to its beneficiaries. Technical cooperation can be specified as:

- Education cooperation-student, expert, and teacher exchange, language learning, joint degrees, and curricula developments;

- Research cooperation-carrying out joint research activities;

- Training cooperation-developing training programs and supplying training equipment and materials;

- Cultural cooperation-development-oriented social and cultural programs; and

- Scholarships.

With increasing globalization, countries' economic and social development is increasingly determined by their scientific and technological capacity, knowledge production, and volume of information flow. Universities cannot excuse themselves from the discussion of these development issues. Universities have become fundamental actors in international cooperation, especially as far as technical cooperation is concerned.

\section{Multicultural Experiences Gained by Studying Abroad and Creativity}

The main forms of international technical cooperation in universities are student, expert, teacher, volunteer, administrative, and academic exchanges; traineeship; carrying out joint research activities with recipient countries or institutions; development-oriented social and cultural programs; and scholarships. All these forms of international technical cooperation require living and studying abroad and the attainment of multicultural experience. Multicultural experiences gained from studying and residence abroad differ significantly to experiences acquired as a result of travel or short visits, which by their nature and duration provide merely superficial introduction to new cultures.

\subsection{Studying Abroad and the Data}

Developing students' awareness and understanding of different world outlooks, perspectives, and cultures is of prime significance in properly equipping and preparing them with the knowledge and skills required to meet today's globally connected world demands [8,9]. Studying abroad is one area which promotes 
the development of students' cultural awareness. Study abroad programs can be defined as "all educational programs that occur in a foreign country outside the country of origin or citizenship, that offering students the opportunity to earn knowledge through academic credits or degrees through international experience" $[8,10]$.

Studying abroad allows students to expand their knowledge of other cultures, languages, and lifestyles to better equip themselves to face the needs, demands, and opportunities of an increasingly globalized labor market, and to increase their capacity for self-reflection, self-reliance, and self-confidence. Furthermore, it benefits students by providing an increasingly mature and objective perception of their home and of foreign countries, and equips them with intercultural communication skills. However, many of these positive outcomes of study abroad programs have overly relied on students' self-reported affective benefits such as primarily and overly subjective perceptions of personal well-being, feelings toward foreign countries, and increased levels of intercultural awareness. Some countries, particularly in the European Union, have established policies and schemes that actively seek to promote such mobility to encourage intercultural contacts and help create social networks.

In 2009, almost 3.7 million students studied in countries other than their country of citizenship or origin, representing an increase of more than $6 \%$ over the previous year. The average student age in this group was 25 and they attended universities, colleges, technical training institutes, community colleges, nursing schools, research laboratories, centers of excellence, and distance learning centers [11]. The largest numbers of students studying abroad were from China, South Korea, India, and Saudi Arabia. Asians accounted for $52 \%$ of all students studying abroad worldwide. More than 1.3 million students studied English abroad in 2011 [11].

The 32 OECD countries attract the majority of students studying worldwide in countries other than their country of citizenship or origin; just slightly less than four out of five, $(32 \%)$ of them are from other OECD countries. Asia is generally the largest source area of foreign students, contributing $51 \%$ of the total in OECD countries. They have a particularly strong presence in Australia, Japan, and South Korea, where they account for more than $75 \%$ of foreign students. Europeans form the second largest group, accounting for $24.4 \%$ of foreign students, followed by Africa with $10 \%$, Latin America and the Caribbean with $6 \%$, and North America with $3.7 \%$ [11].

The United States hosts more of the world's 4.5 million foreign students than any other country, with almost double the number hosted by the United Kingdom, the second leading host country [12]. According to the 2014 'Open Doors Report on International Educational Exchange', released on November 17, 2014, and issued by the Institute of International Education in partnership with the US Department of State's Bureau of Educational and Cultural Affairs, 886,052 foreign students joined American higher education institutions during the academic year 2013/14 [12]. The number of foreign students in the U.S. witnessed its eighth consecutive annual increase during that year, where the total number of foreign 
students increased in $2013 / 14$ by $8 \%$ to a record high of 66,408 more foreign students enrolled in US higher education compared to the previous year. Students from China and Saudi Arabia together accounted for $73 \%$ of the growth, while India, Brazil, Iran, and Kuwait together accounted for $18 \%$ of the growth.

The growth was largely driven by Chinese undergraduate student numbers. Their enrollments increased by $17 \%$ in total to more than 274,000, and by $18 \%$ at the undergraduate level. Currently $31 \%$ of all foreign students in the U.S. are from China. In 2013/2014 numbers of students from India increased by $6 \%$, to 102,673 , following three consecutive years of decline. The increase was driven by graduate level enrollment.

The fastest growing student populations in the U.S. in 2013/14 were from countries whose governments are investing heavily in scholarships for international studies, such as Brazil, Saudi Arabia, and Kuwait. There was a $22 \%$ increase in students from Brazil, to a total of more than 13,000. This increase was due to the volume of undergraduate students going to the U.S. on scholarships from the Brazilian Government's Brazil Scientific Mobility Program. There was a $21 \%$ increase in the number of students from Saudi Arabia raising their number to $6 \%$ of the total number of foreign students in the U.S. There were nearly 54,000 Saudi students in the U.S., largely funded by the Saudi government scholarship program, which was then approaching its 11 th year. On a smaller scale, the continued expansion of Kuwaiti government scholarship programs led to $43 \%$ more students coming from Kuwait. There were more than 7300 Kuwaiti students in the U.S. in 2013/14 [12].

In 2013/2014 the overall number of foreign students in the U.S. had increased by $72 \%$ since 2000 . Compared to the numbers as had been reported in Open Doors 2000, there were five times as many Chinese students on U.S. campuses, almost two and a half times as many Indian students, seven and a half times as many Vietnamese students, and more than 10 times as many Saudis.

On the other hand, there are large variations between countries in the percentage of foreign students enrolled in their tertiary student body. In Australia, foreign students represent $21.6 \%$ of tertiary students. They represent $15.3 \%$ of tertiary students in the United Kingdom, $15.1 \%$ in Austria, $14.9 \%$ in Switzerland, and $14.6 \%$ in New Zealand. In contrast, the proportion in Chile, Estonia, Poland, and Slovenia is less than $2 \%$ [8].

According to the 2014 "Open Doors Report on International Educational Exchange", 289,408 American students studied abroad for academic credit from their U.S. colleges and universities. Although the $2 \%$ increase represents a slightly slower rate of growth than the previous year, the number of U.S. students studying abroad has more than doubled in the last 15 years [12].

2013 statistics from the Saudi Ministry of Education indicate that the total number of Saudi students studying abroad was 149,742, of whom 69,235 were studying in the U.S., which was a higher number than reported in the "Open Doors" reports [13]. The number of Saudi students in the Arab countries amounted to 16,364 students. The statistics show that Britain came in third place with 14,459 Saudi students, followed by 13,801 in Canada, 8,789 in Australia, 2,049 in New 
Zealand, 1,143 in China, and 1,105 on scholarship in Malaysia. The statistical tables indicate that of the Saudi students $50.2 \%$ are undergraduates, $21.2 \%$ are master's students, $5.6 \%$ are doctoral students, and $2.0 \%$ are fellowship students, while the rest are doing English studies in preparation for getting accepted into a degree program. The tables show that the female proportion of the total scholarships amounted to $25.4 \%$, while the proportion of males is $74.6 \%$ [13].

Nearly 32,000 non-Saudi students representing more than 155 countries are currently studying in Saudi universities on KSA Government fellowships. The majority of these fellowship recipients are from the Arab and Islamic countries, including Yemen, Syria, Egypt, Sudan, Jordan, Libya, Tunisia, Algeria, Morocco, Mauritania, Pakistan, and Indonesia.

\subsection{Creativity}

The rise in creativity research is often attributed to Guildford's presidential address to the American Psychological Association, in which he acted as an advocate for the scientific research of topics related to creativity $[14,15]$. Psychological research in creativity has been ongoing for over six decades and has been applied across a wide range of disciplines.

Creativity is a phenomenon whereby something new, practical, and in some way valuable is created (such as an idea, a literary work, painting, musical composition, a solution, an invention, etc.) However, the manner in which the term creativity has been applied varies widely from study to study. Moreover, creativity is a multidimensional construct for which many different definitions have been applied [16-18]. For instance, the published definitions of creativity document a wide range of standards including uniqueness, usefulness, artistic quality, and accessibility [19].

In addition, research in creativity is multidisciplinary, including developmental studies, education, business sectors, and clinical psychology [19]. Researchers have explored various aspects of creativity including, but not limited to, cognition, motivation, personality, and environment. Therefore, creativity research can broadly be organized into four themes. They are the creative person (personality characteristics, cognition, and motivational states), the creative process (creative thinking and production), the creative product (criteria for creative products), and the creative press (environmental influences).

Creative thinking requires the abilities to generate and apply novel ideas, to divergent processing and open-ended problem solving [20-23]. In today's age of technology and global competition, creative thinking is an increasingly important skill for students to develop.

The link between studying abroad and enhanced creativity was first made by Maddux and Galinsky [24]. They found that students who spent time overseas were more likely to come up with innovative insights. However, the authors could not establish causality nor say for certain that the experience was transformative 
and admitted it was possible that people who choose to study outside their home country are more creative to begin with.

A newer published research [20] provides the best evidence yet that studying in foreign countries boosts and enhances student creativity. The research demonstrated that a semester abroad leads to higher creativity scores on two different tests.

\subsection{Multicultural Experiences and Creative Thinking}

Multicultural experiences gained from studying abroad are different experiences both quantitatively and qualitatively than the experiences resulting from traveling or short visits, which provide only a superficial or shallow introduction to a new culture. Multicultural experience depends on living abroad, and the extensive interactions with members of foreign cultures [25].

Research investigating the relationship between multicultural experience gained from studying abroad and creativity shows that individuals who studied abroad demonstrate increased interest in travel, art, foreign languages, history, and architecture which increases their assessment of esthetics, which is a frequently cited characteristic of creative individuals [26-28].

Research examining the outcomes of study abroad programs shows that studying abroad leads to several positive affective gains such as promoting students' cultural and personal development by providing experiences that facilitate international awareness, cross-cultural communication skills, and self-confidence [8, 10, 29], all of which significantly relate to greater creative performance, including the extension and combination of conceptual boundaries and flexibility in recruiting and synthesizing information [30-32].

Lee et al. [20] presented an experimental study that highlights the value of multicultural experiences for both culture specific and domain general creative thinking and concluded that studying abroad benefits creative thinking. They assembled three groups of undergraduate students from a large university in the American south. Each group consisted of 45 students, i.e., 45 students who had studied abroad, 45 who were planning to study abroad, and 45 who had no interest in studying abroad. All students in the three groups completed two creativity tests: the Cultural Creativity Test (CCT) and the Abbreviated Torrance Test for Adults (ATTA).

On both tests, the students who had studied abroad significantly outperformed the other two groups. On the Cultural Creativity Test, students who had studied abroad were deemed to have recruited and combined intellectual resources from various cultural frameworks to generate ideas and solutions that were richer in description, detail, and humor than those generated by students in the other groups, including the group planning to study abroad. Multicultural experiences involve the accumulation and integration of learned routines and conventional 
knowledge from a new culture, as well as practice switching mentally between different cultural worldviews [30, 31, 33].

The results demonstrated that students who had studied abroad generated more original ideas on both a culture specific and a domain general creativity test compared with students who had not studied abroad. There were no significant differences between students who had studied abroad and those who had not studied abroad on traditional indicators of academic achievement. However, Lee's study indicated that the actual immersion in a foreign culture is related to superior creative thinking, while this is not demonstrably the case when there is mere interest in foreign cultures without the actual immersion and its accompanying cultural experience.

In contrast to expectations, these results indicate that increased creative thinking gained from studying abroad is not limited to culture specific activities, but also transfers to performance on culturally neutral activities. The positive relationship between studying abroad and general creative thinking has important ramifications for the impact of cultural experiences on individuals' overall cognitive capacities and their approaches to creative problems.

Based on their findings, the researchers suggested that cultural experiences gained from living abroad have wide-ranging beneficial impact on students' creativity, including the facilitation of complex cognitive processes involved in developing innovative solutions and promoting creative thinking. These findings combined with the results that demonstrate superior creative thinking among students who had studied abroad support the claim that the actual immersion in a foreign culture by studying abroad enhances creative thinking. Their findings suggest that studying abroad provides a means of gaining creative thinking skills and abilities.

\section{Best Practice}

Three examples of best practices are presented: International cooperation in higher education in Saudi Arabia in general and in King Abdulaziz University (KAU) in particular, the policy of international university cooperation and its application in one of the top-ranking world-class universities: the Copenhagen University in Denmark, and one of the world's most prestigious programs for international technical cooperation: the 'Fulbright' scholarship program.

\subsection{International Cooperation in Saudi Higher Education}

International cooperation in higher education in Saudi Arabia is a crucial strategic goal of the Ministry of Education that aims to develop, improve, enhance, and raise the level of higher education in Saudi Arabia in cooperation with 
distinguished Arab, regional and international higher educational organizations and institutions. It seeks to achieve this through the signing of international agreements and alliances, and the building of international partnerships and consolidation in the areas of culture, science, academia, and research [34].

The ministry established the "General Administration for International Cooperation" within its administrative structure, and provided it with ample human and material resources. This was established in line with the ministry's strongly held conviction that international cooperation is an important mechanism and an intrinsically valuable development, when carefully implemented through higher educational policies. It also endeavors to ensure the development and documentation of cognitive and cultural relations with various internationally prestigious highly developed universities and organizations under the aegis of formal agreements, alliances, and memorandums of understanding, in line with the Kingdom's public policies and chosen strategic direction.

The general objective of the General Administration of International Cooperation is to ensure effective mutually beneficial coordination with government and private universities and higher education and academic research agencies outside the Kingdom.

The administration has an important role in building bridges of knowledge between Saudi universities and internationally prestigious and distinguished higher educational universities. It seeks to promote knowledge and cultural exchange through expansion of scholarships and exchanges. It coordinates training programs, seminars, conferences, congresses, and international exhibitions, and raises the level of performance and development of international cooperation in the various fields of knowledge. The administration is entrusted with drafting rules and regulations that govern the establishment and practicalities of relations with international higher educational establishments, bodies, and organizations. The administration is always eager to contribute to, highlight, and reinforce Saudi Arabia's general development especially in the field of higher education, which has witnessed unparalleled quantitative and qualitative expansion in all areas of the Kingdom in recent years.

The General Administration of International Cooperation has three departments: the International Cooperation Department, the Agreements and Joint Committees Department, and the Department of Exhibitions.

The ministry and the Saudi universities have signed a number of memorandums of cooperation and service contracts with ministries and prestigious international universities on different continents. They have participated in joint committees and established effective ongoing channels of communication with numerous worldwide scientific institutions.

Each Saudi university has a special administration or center for international cooperation or relations. The main responsibility of such bodies is the development, monitoring, and guidance of international partnerships, programs, and activities, and the promotion of such bodies and activities in order to facilitate international student and staff exchanges and international recruitment. They also aim to create a wider range of study opportunities for students, professors, 
and staff and to enable increasing international benchmarking of university programs. They also offer program advice and provide various training and educational opportunities. Their services are geared toward mobile student/professor exchange, promotion of international exchange research projects, international funding, and the university staff tasked with designing and developing new projects.

\subsubsection{KAU Administration of International Agreements}

KAU has established its "Administration of International Agreements" to organize, follow up, and develop international agreements between the university and international universities, research centers, and scientific institutions. The aim of such efforts is to accelerate the university's anticipated scientific progress and expedite technology transfer from the world's most prestigious universities and scientific institutes to KAU. The administration also prepares a fully automated management system of international agreements and service contracts, and ensures adequate budgetary provisions are in place for effective task design and implementation.

The structure of the administration is illustrated in Fig. 1. The administration consists of five units under the management of the general supervisor of the administration who is under the supervision of the Director (President) of the University. These units are as follows:

- Research Agreements Unit

- Educational Agreements Unit

- Creative and Innovative Agreements Unit

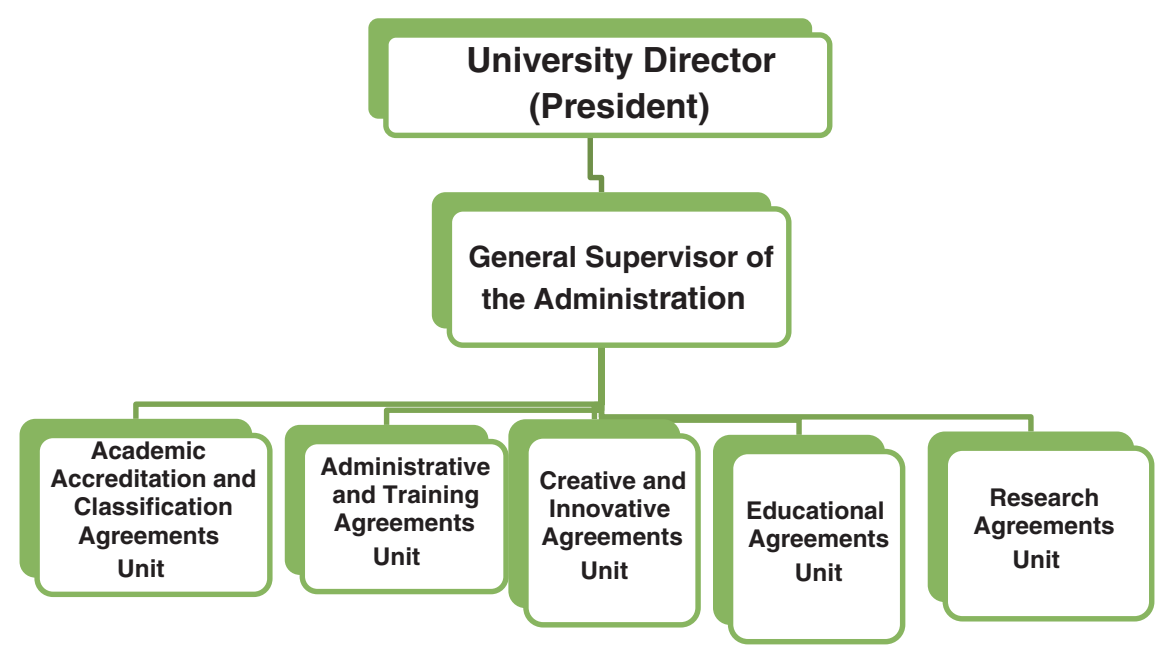

Fig. 1 The structure of the administration 
- Administrative and Training Agreements Unit

- Academic Accreditation and Classification Agreements Unit.

To ensure administrative effectiveness, the University Vice-Presidents are tasked with the following responsibilities concerning international agreements:

- The Vice-President for Graduate Studies and Scientific Research supervises agreements concerning graduate studies and scientific research.

- The Vice-President for Academic Affairs supervises agreements concerning educational services.

- The Vice-President for Business and Knowledge Creativity supervises agreements concerning creativity, innovation services, and inventions.

- The University Vice-President supervises agreements concerning administrative services and training.

- The Vice-President for Development supervises agreements concerning cultural, quality, and academic accreditation and concerning classification and ranking of the university.

King Abdulaziz University has established joint international cooperation agreements and service contracts with many of the world's distinguished universities and educational institutions. There are currently more than 75 operational service contracts and several other agreements and memorandums of understanding between KAU and universities, scientific institutions, and specialized companies in 23 countries ranging from the United Stated of America, Canada, and Argentina in the Americas to Great Britain, France, Spain, Germany, Finland, Switzerland, and Turkey in Europe to China, Korea, and Japan in Asia to Australia and New Zealand. These agreements and service contracts specialize in the implementation of joint research projects and patents; the exchange of students, staff, faculty members, and scientific expertise; the establishment of joint graduate programs; curriculum development; development of distance education; training programs and rehabilitation of medical graduate students; and training faculty members. Figures 2, 3, 4, 5 and 6 show the signing ceremonies of some recent agreements and service contracts.

The service contract signed with Tokai University in Japan in February 2012 is an example of a joint cooperation and service contract signed by the university and of its beneficial consequences. It was entered into in order to facilitate transfer of expertise in designing, manufacturing, and testing solar-powered drones (airplanes without pilots) used for civilian purposes. The contract was initially for three years. Seven KAU faculty members, $10 \mathrm{KAU}$ students, seven Tokai University faculty members, and 11 Tokai University students all jointly participated in the project. The drone was designed and manufactured with a wingspan of $3.75 \mathrm{~m}$ and was capable of flying for $8 \mathrm{~h}$ continuously in daylight at a maximum speed of $50 \mathrm{~km} / \mathrm{h}$. It was named "Solar Falcon-1" and was successfully tested. Several scientific research papers have been based on this innovative project and published. Figure 7 shows the 'Solar Falcon-1' drone. 


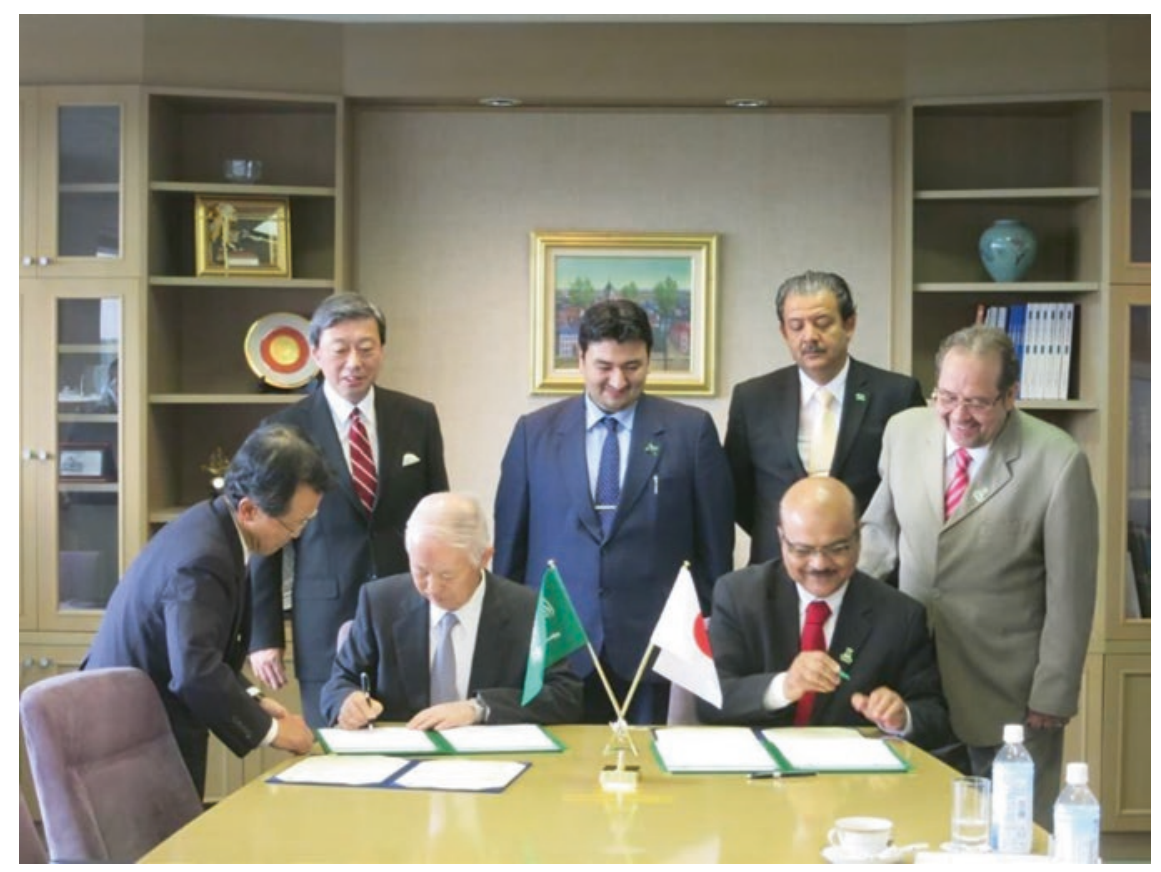

Fig. 2 Signing the extension of the Service Contract with Tokai University

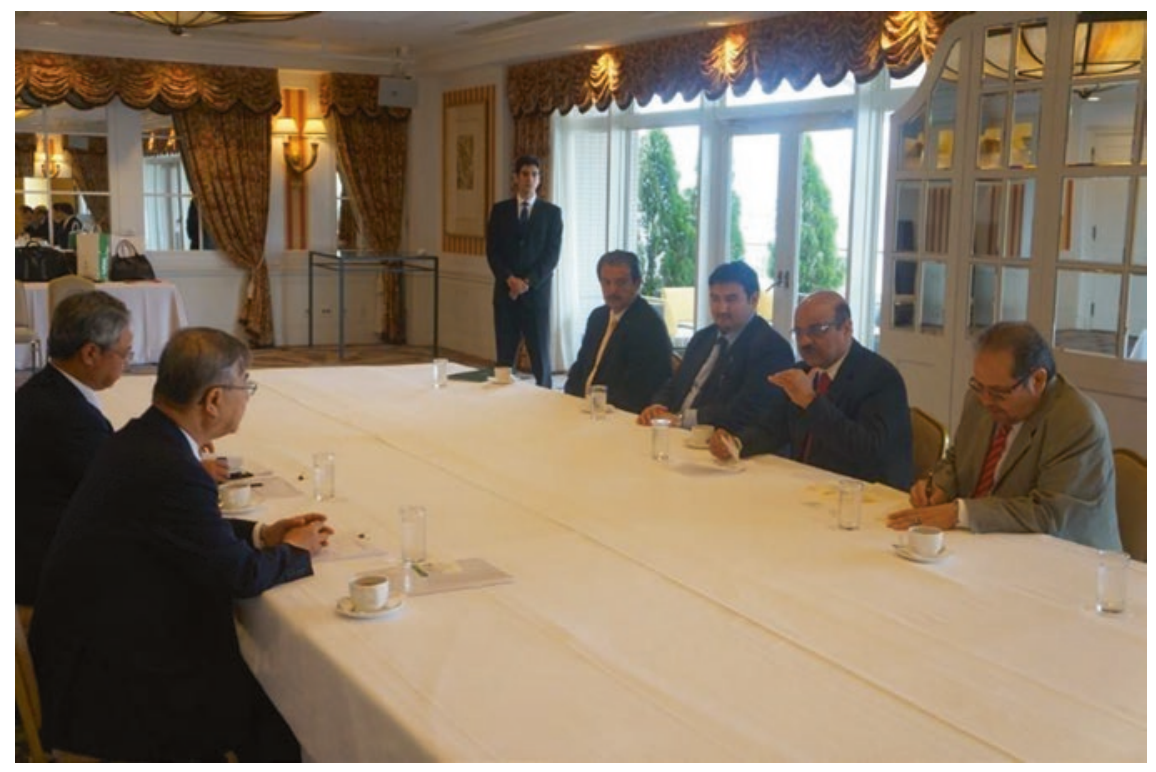

Fig. 3 Negotiating the Service Contract with Sumitomo Chemical Co., Japan 


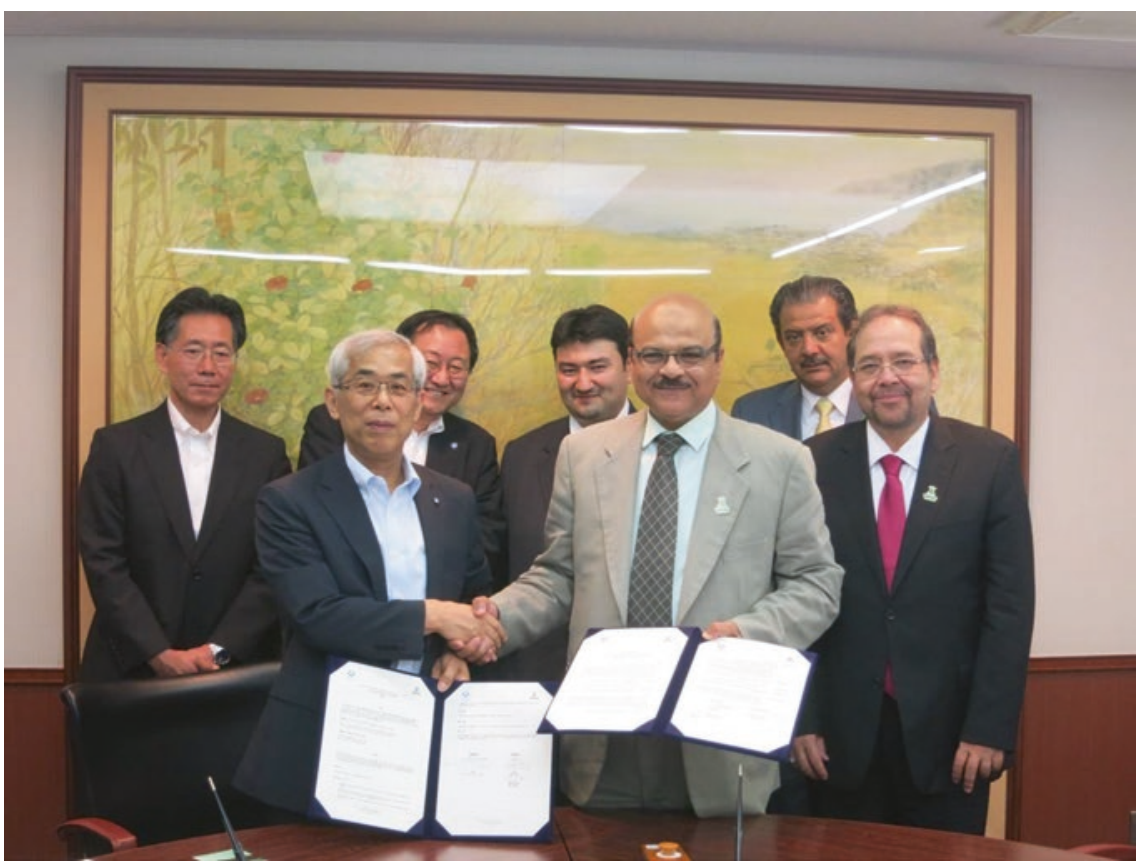

Fig. 4 Signing the memorandum of understanding with Osaka University, Japan

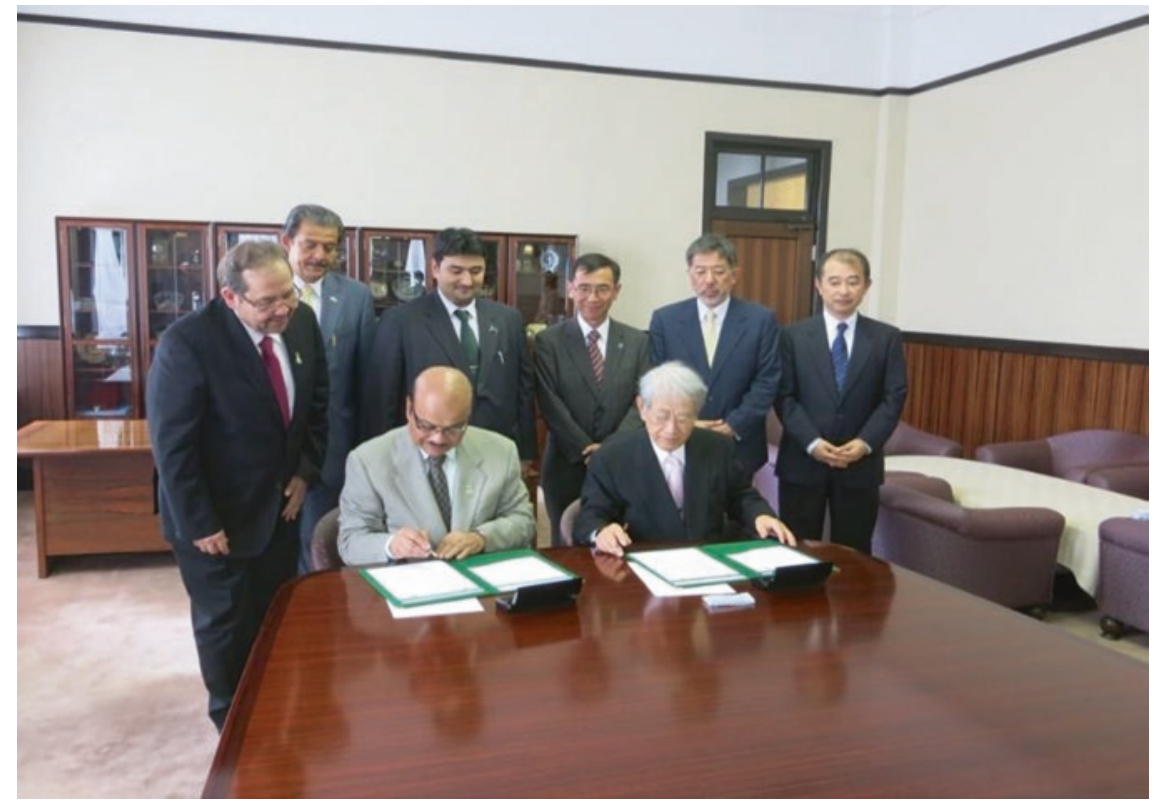

Fig. 5 Signing the memorandum of understanding with Kyoto University, Japan 


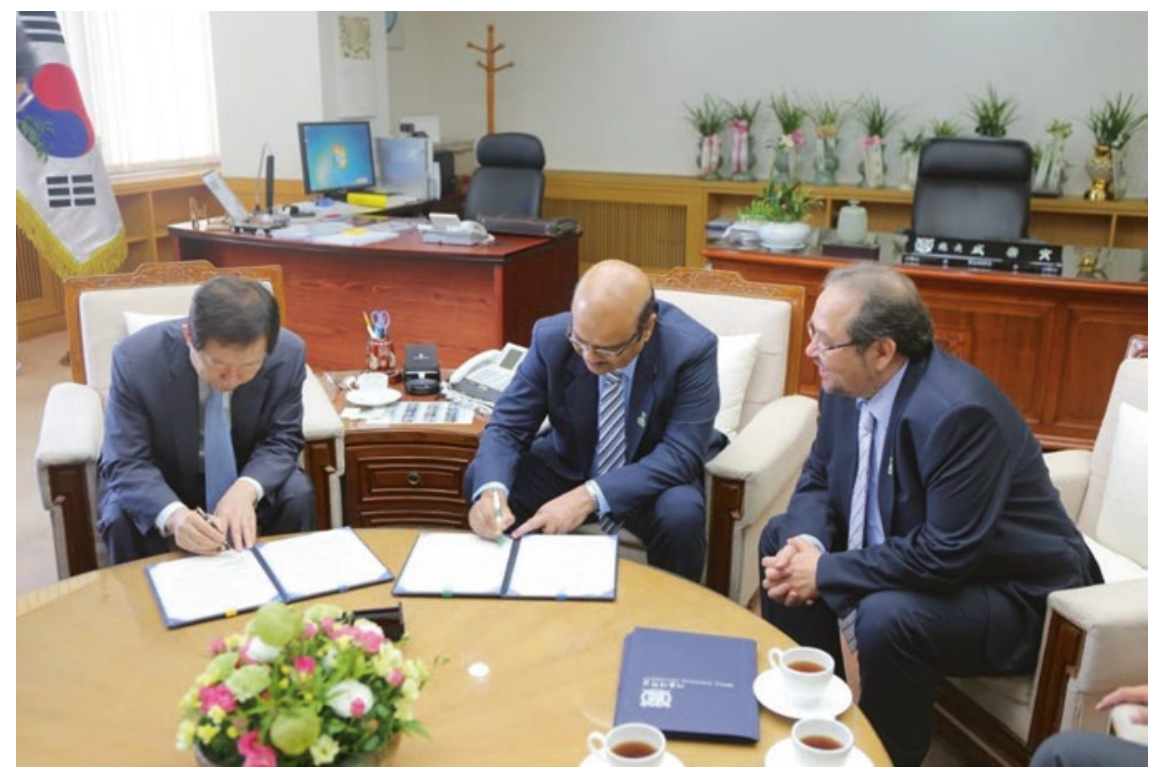

Fig. 6 Signing the momentum of understanding with Seoul National University, Korea

Due to the success achieved in the first phase, which culminated in the successful manufacture and testing of the drone, and in order to further benefit from the Japanese experience, it was agreed to extend the project's second phase so as to design, manufacture, and test the prototype drone's successor "Solar Falcon-2". This drone has a $7 \mathrm{~m}$ wingspan and is capable of flying in daylight and at night for five days consecutively at a maximum speed of $40 \mathrm{~km} / \mathrm{h}$. In view of this success, an extension of the service contract has been signed for a fourth year.

\subsection{International Cooperation at the University of Copenhagen}

The University of Copenhagen (UCPH) was founded in 1479 and is the oldest and second largest university and research institution in Denmark. It is known as Scandinavia's Harvard University. It became a center of Roman Catholic theological studies but also had faculties for the study of law, medicine, and philosophy [35]. UCPH has an annual budget of approximately one billion euros. It aims to prepare students for a broad range of employment opportunities in the private and public sectors.

The university has in excess of 43,800 enrolled students, including 23,500 undergraduate students, more than 17,000 graduate students, and more than 2,900 doctoral students. The student body also includes more than 5,700 international 

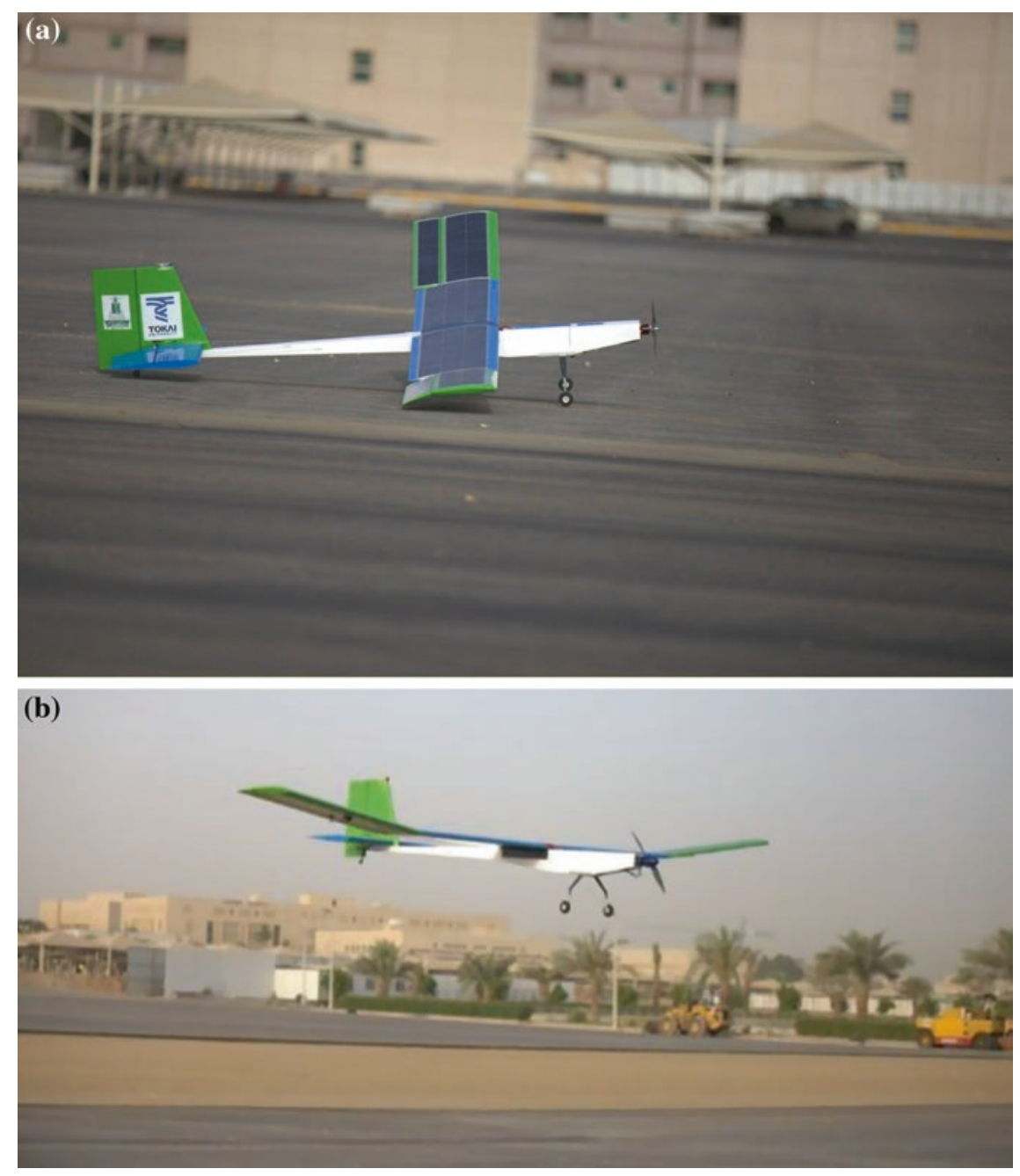

Fig. 7 shows the 'Solar Falcon-1' drone. a 'Solar Falcon-1' on the ground. b 'Solar Falcon-1' in flight above the university buildings

students including exchange students, guest students, and full-degree students. It has more than 4,800 academic staff and more than 9,600 full-time employees, more than 4,300 of whom are employed in technical and administrative capacities. The university has four campuses located in and around Copenhagen, with its headquarters located in the city center. It has six faculties and approximately 100 departments and research centers. The majority of courses are taught in Danish while many courses are also offered in English and a few are offered in German.

The 2014 Academic Ranking of World Universities, published by Shanghai Jiao Tong University, ranks UCPH as the best university in Denmark and 
Scandinavia, the 8th best university in Europe, and 39th in the Top 500 World Universities ranking [36]. It is ranked 45th in the 2014 QS World University Rankings and 13th in Europe [37-39]. However, in the Times Higher Education World University Rankings for 2014, UCPH is ranked 160th overall in the world [40]. In 2013, according to the University Ranking by Academic Performance, $\mathrm{UCPH}$ is the best university in Denmark and the 25th best university in the world [41]. The university has had eight alumni become Nobel Prize winners and has produced one Turing Award recipient [35, 42].

\subsubsection{International Cooperation: Policy and Application}

The international strategic policy of UCPH is to attract top talent from around the world. The university strenuously works to develop its position as a world-class university by providing researchers and students with excellent opportunities for cooperation and exchange with other national and international universities [35]. The university cooperates with universities worldwide.

Based on the university's scientific foundation and its continuing endeavors to strengthen research excellence, the strategy covers three selected focus areas: improving education, strengthening external collaboration worldwide, and strengthening internal collaboration and shared identity.

$\mathrm{UCPH}$ has established an international graduate talent program with grants for international graduate students and faculty. It offers more than 50 master's programs taught in English, more than 150 exchange agreements worldwide, and 800 Erasmus agreements [35].

The university has several thousand foreign students, of whom about half come from Nordic countries. In excess of 1,000 UCPH students study abroad at its international partner universities. The university offers a wide range of graduate degrees in English and numerous courses in English for exchange and guest students.

UCPH participates in a range of international networks and alliances to cooperate with partner institutions, share knowledge, and gain influence on education and research policies. It also participates in several international education programs. It is a member of the prestigious International Alliance of Research Universities (IARU) which also has members from other leading research universities in the world. UCPH is also represented at a number of institutes and centers worldwide.

\section{UNICA Network}

The "Institutional Network of the Universities from the Capitals of Europe" (UNICA), founded in 1990, is among the five leading institutional academic university networks in Europe. UNICA consists of 46 universities from 35 European capitals and has over 150,000 employees and 1,800,000 students.

UNICA provides a forum in which universities can reflect on the demands of strategic change in university research, education, and administration. It 
endeavors to promote academic knowledge and excellence as well as integration and cooperation between the member universities. It also seeks to be a driving force in the development of the Bologna process and to facilitate the integration of Eastern and Central European universities into the European Higher Education Area [33, 43]. It also provides universities with information on European initiatives and programs, and supports them in cooperative projects.

UNICA holds a student conference once every two years focusing on European educational issues and policies. The conference provides European students with the opportunity to exchange views and experiences.

UNICA has a number of working groups such as Equal Opportunities, Science Park and Incubators, Urban Issues, Disability, and groups dedicated to special needs students. It also organizes a number of annual seminars regarding relevant and current issues for the pooling of experiences concerning EU fund-raising for research.

\section{IARU Alliance}

The University of Copenhagen is a member of the prestigious "International Alliance of Research Universities" (IARU), established in 2007, along with University of California, Berkeley, University of Cambridge, University of Oxford, University of Tokyo, Yale University, the Australian National University, ETH Zürich, the National University of Singapore, and the University of Beijing $[39,44]$. These top ten world's leading research-intensive universities share similar visions and are all internationally recognized as being world-class universities, which is reflected in the nature and scope of their shared research project topics.

The alliance's main objective is to provide graduate students and researchers at member universities with the opportunity to participate in international research and research-based teaching with a global outlook. Its activities and venues in pursuit of this objective include research projects, graduate student conferences, summer programs, workshops, conferences, and congresses.

IARU members' students have the opportunity to engage critically as global citizens in an increasingly interconnected world through the Global Summer Program, and by means of fellowships and internships. Besides enriching students, the alliance also brings considerable diversity in the promotion of institutional collaborative working among its members, inter-university networking, and staff development. Members participate in the alliance's various activities in accordance with their own particular needs and objectives [45].

\subsubsection{Research Collaboration and University Partners}

The diversity of academic environments and scientific approaches is UCPH's distinguishing feature and strength. Partnerships between the university and its national and international research partners enhance the quality of its research and study programs. 
The university maintains a substantial number of partnerships with universities worldwide. More than 140 bilateral partnerships, numerous institute partnerships, and hundreds of Erasmus agreements are designed to increase students' mobility, offering them opportunities to augment their academic training abroad with the accompanying beneficial intercultural experiences. The partner universities include 46 in the US, 17 in Australia, 12 in Canada, 10 in Japan, seven in New Zealand, five in Germany, and one in each of Argentina, Cuba, Peru, Poland, Sweden, Syria, and Jordan. The university also exchanges students and staff with a large number of partner institutions through the Erasmus and Nordplus programs and by means of state bilateral agreements.

UCPH generally prefers to establish university-wide agreements when a number of faculties express such interest. University-wide agreements are intended as umbrella agreements and it is acceptable to maintain or establish department, faculty, or institutional agreements within and under the aegis of the university agreement. These partnerships are the framework for foreign students and researchers to study or conduct research at the university. Fruitful partnerships are established in a variety of ways such as:

- Student exchange

- Faculty exchange

- Joint degrees

- Joint research collaboration

- Staff exchange

- Erasmus staff training

- Erasmus teacher training

- Strategic partnerships

\subsubsection{The University of Copenhagen's Research and Innovation Council}

UCPH's Research and Innovation (R\&I) Council is responsible for identifying and pursuing the university's strategic development within research, innovation, and business collaboration, and for prioritizing how the university shall publicize its activities externally [46]. The council works in accordance with UCPH's strategic goals.

The objective of the council is to determine how strategic development is best supported by the organization, to secure increased external funding, and to initiate an increasing number of collaborative relationships with private and public entities globally. The council prompts general initiatives within research and innovation that complement the faculties' own initiatives. It also coordinates research and innovation (R\&I) work conducted at the faculties by R\&I faculty representatives and makes recommendations and suggestions aimed at improving the university's researcher-oriented service. 


\subsection{Fulbright Scholarship Program}

\subsubsection{The Fulbright Program}

The flagship Fulbright Program is a U.S.-based program of highly competitive, eligibility-based grants for international educational exchange for students, scholars, teachers, professionals, scientists, and artists to study, conduct research, or exercise their talents outside the U.S. Under the program's aegis eligible citizens of other countries outside the U.S. may qualify to do likewise in the United States. It was founded by U.S. Senator J. William Fulbright in 1946 [47].

The Fulbright Program is sponsored by the U.S. Department of State's Bureau of Educational and Cultural Affairs. Additional direct and in-kind support is provided by partner governments, foundations, corporations, and host institutions both in and outside the U.S. [48].

The program was established to promote peace and mutual understanding between individuals, institutions, and future leaders, wherever they may be, through the educational exchange of persons, knowledge, and skills, and thereby increase the likelihood of nations finally learning to live and coexist in peace and friendship [49]. During their grants, grantees meet, work, live with, and learn from host countries' inhabitants, sharing daily cultural experiences.

The program facilitates cultural exchange through direct interaction between individuals. Through engagement in the community, individuals interact with their hosts in an atmosphere of openness, academic integrity, and intellectual freedom, thereby promoting mutual cultural understanding.

The Fulbright Program is one of the most prestigious awards programs worldwide and is ultimately managed by the Institute of International Education (IIE) $[47,48,50]$. On a country by country basis, bi-national Fulbright Commissions administer and oversee the program in 50 countries. In countries that have an active program but lack a Fulbright Commission, the program is overseen and supervised by the Public Affairs Sections of US embassies.

Since its inception, the program has operated on a bi-national basis; each country active in the Fulbright Program has entered into an agreement with the U.S. Government. Approximately 325,400 Fulbrighters, 122,800 from the United States and 202,600 from other countries, have participated in the program since its start more than sixty years ago. Approximately 8,000 grants are awarded annually by the program. Currently, the program operates in over 155 countries worldwide. The Congressional appropriation for the Fulbright Program in the fiscal year 2013 was $\$ 242.8$ million.

\subsubsection{Programs and Grants}

The Fulbright Program works in two ways: eligible U.S. citizens receive funding to go to foreign countries through the U.S. Student Program, US Scholar Program, 
and Teacher Exchange Program; and eligible non-U.S. citizens receive funding to go to the U.S. via the Foreign Student Program, Visiting Scholar Program, or Teacher Exchange Program [47].

Recommended candidates for Fulbright grants should have high academic achievement, a compelling project proposal, demonstrable leadership potential, and the flexibility and adaptability required for successful interaction with the target foreign host community [47]. Fulbright grants are offered in almost all academic disciplines: fine arts, humanities, social sciences, mathematics, natural and physical sciences, and professional and applied sciences. Grants do not cover clinical medical research involving patient contact [47, 49].

\section{Student Grants}

The U.S. Student Program offers fellowships for U.S. graduating seniors, graduate students, young professionals, and artists to research, study, or teach English abroad for one academic year. Similarly, the Foreign Student Program enables graduate students, young professionals, and artists from outside the US to conduct research and study in the United States. Some scholarships are renewed after the initial year of study [47].

The program currently awards approximately 1,900 grants annually in all fields of study, and operates in more than 140 countries worldwide. It provides grants for individually designed study/research projects, English Teaching Assistant Programs, or Fulbright-mtvU musical Fellowships.

The study/research grant category includes projects in both the academic and arts fields. Applicants for these grants design their own projects and typically work with advisers at foreign universities or other institutes of higher education. The International Fulbright Science and Technology Award is intended to support doctoral study at leading U.S. institutions in science, technology, engineering, or related fields for outstanding foreign students.

The Fulbright Foreign Language Teaching Assistant Program provides opportunities for young English teachers from overseas to develop and polish their teaching skills and expand their knowledge of American culture and society while enriching the quality of instruction of foreign languages at U.S. colleges and universities. U.S. grantees are also placed in overseas schools to supplement local English language instruction and to provide a native speaker presence in classrooms [47].

The Fulbright-mtvU Fellowships award up to four U.S. students the opportunity to study the power of music as a cultural force abroad and to conduct research for one academic year on projects of their own design. The projects should concern a chosen aspect of international musical culture and focus on contemporary or popular music as a cultural force for expression [47].

Travel grants are designed to supplement an award from any source that does not provide for international travel or to supplement students' own funds for study/ research. 


\section{Scholar Grants}

Fulbright helps faculty and administrators build a "multiplier effect" by infusing cross-cultural perspectives into curricula, revitalizing teaching methods, and opening doors for international colleagues and students. The Fulbright Scholar Program includes the U.S. Scholar Program, the U.S. Specialist Program, the Visiting Scholar Program, the Scholar-in-Residence Program, and the Regional Network for Applied Research Program [47, 51, 52].

The Council for International Exchange of Scholars (CIES) is responsible for conducting international exchange programs for scholars and university administrators [49-53]. The CIES maintains strong ties with the higher education community in the U.S. and worldwide and collaborates with a network of bi-national Fulbright Commissions in 50 countries and 90 U.S. diplomatic posts around the world. To date, CIES has placed close to 50,000 scholars in over 140 countries and more than 45,000 overseas scholars have visited U.S. colleges, universities, and research institutions through programs for U.S. scholars, visiting scholars, and U.S. institutions.

The U.S. Scholar Program offers American faculty members, scholars, and professionals fellowships to go abroad to lecture and/or conduct research for up to a year [47]. The program attracts approximately 800 U.S. faculty and professionals annually to more than 140 countries to lecture, teach, and conduct research in a wide variety of academic and professional fields. Scholars contribute not only to their host institutions, but also to their home universities and colleges.

The program also includes the U.S. Distinguished Chairs Program which comprises approximately 40 distinguished lecturing, distinguished research, and distinguished lecturing/research awards for 3- to 12-month periods [47, 52]. These awards are viewed as among the most prestigious appointments in the Fulbright Scholar Program. Candidates should be outstanding scholars with significant publications to their name and outstanding teaching records [51-53].

The U.S. Specialist Program promotes linkages between U.S. faculty and professionals with their counterparts at host institutions overseas by serving as expert consultants on curriculum or faculty development, institutional planning, and related subjects at overseas academic institutions [47, 51]. The program awards grants for short-term collaborative projects in over 140 countries and 24 academic disciplines.

The International Education Administrator (IEA) Seminars is a 2-week program open to experienced U.S. international education administrators and other senior higher education officials to engage in a comparative study of the society, culture, and higher education systems of France, Germany, India, Japan, or South Korea [47].

There are other U.S. scholar programs such as the Fulbright Postdoctoral Scholar Awards for U.S. scholars who have recently completed their doctoral degree (or other terminal degree), and the Fulbright-Fogarty U.S. Scholar Grants intended to promote post-doctoral research in public health in resource-limited settings $[47,51]$. 
The Visiting Scholar Programs provide American colleges, universities, and research institutions a key resource to support their internationalization by bringing foreign scholars to lecture and/or conduct post-doctoral or advanced research for up to a year at U.S. colleges and universities [51]. Approximately 850 faculty and professionals from more than 155 countries receive Fulbright grants each year. The program links campuses around the world and introduces new ideas and contacts to students, faculty, and administrators [47].

The Visiting Scholar Enrichment Programs offer a variety of enrichment activities in different locations throughout the academic year to enable visiting scholars to better experience America and to increase mutual understanding between the people of the U.S. and other countries [51, 52].

The Scholar-in-Residence (S-I-R) Program brings foreign scholars to U.S. colleges and universities for up to a year to assist in the internationalization of U.S. campuses, curriculum, and communities, to teach in their areas of expertise, and to provide a cross-cultural or international perspective to promote curriculum and program development $[47,51,52]$.

The Outreach Lecturing Fund (OLF) provides funding for campuses to host Fulbright Visiting Scholars who are already in the United States for short-term engagements to give lectures and discuss and exchange ideas.

The Regional Network of Scholars Program brings together a network of junior scholars, professionals, and mid-career applied researchers from the United States, Brazil, Canada, and other Western Hemisphere nations for a series of three seminar meetings and a Fulbright exchange experience in a year-long program that includes multidisciplinary, team-based research. The program fosters collaborative and multidisciplinary research to address challenging regional issues and produce tangible results $[47,51]$.

The Fulbright Arctic Initiative Program for scholars, professionals, and applied researchers from the United States, Canada, Denmark, Finland, Iceland, Norway, Russia, and Sweden consists of a series of three seminar meetings and a Fulbright exchange experience.

\section{Teachers' Programs}

A portion of the Fulbright Program is a Congressional appropriation to the United States Department of Education (USDE) for the Fulbright-Hays Program. These grants are awarded to individual U.S. pre-teachers, teachers and administrators, pre-doctoral students and post-doctoral faculty, as well as to U.S. institutions and organizations. Funding supports research and overseas training efforts, which focus on non-Western foreign languages and area studies [47, 54].

The Teacher Exchange Program supports one-to-one exchanges of teachers from secondary schools and a small number of post-secondary institutions abroad for a semester to pursue individual projects, conduct research, and lead master classes or seminars [55]. 
The Hubert H. Humphrey Program for Professionals brings outstanding midcareer professionals from the developing world and societies in transition to the U.S. for one year. Fellows participate in a non-degree program of academic study and gain professional experience.

\subsubsection{Benefits of the Program}

It is worth repeating, as was previously stated, that the program was established to promote peace and mutual understanding between individuals, institutions, and future leaders, wherever they may be, through the educational exchange of persons, knowledge, and skills, thereby increasing the likelihood of nations finally learning to live and coexist in peace and harmony [49].

The program facilitates cultural exchange through direct interaction on an individual basis by enabling individuals to meet, work, live with, and learn from the host country's inhabitants, sharing daily cultural experiences. Through engagement in the community, individuals interact with their hosts on a one-to-one basis in an atmosphere of openness, academic integrity, and intellectual freedom, which invariably and inevitably aids in the promotion of mutual cultural understanding. It also assists in the internationalization of campuses, curriculum, and communities.

Fulbright alumni have occupied, and are currently occupying, key roles in government, academia, and industry, and are therefore in positions where they are able to influence national and international relations and polices. There have been 10 program alumni elected to the U.S. Congress, 18 have served as heads of state or government, and one has served as United Nations Secretary General [56]. The Nobel Prize has been awarded to 53 program alumni and 78 have received the Pulitzer Prize [57]. More Nobel Prizes have been awarded to former Fulbright recipients than to recipients of any other award program.

\section{Conclusions}

- International university cooperation is a must, especially for students and university academics and professors in the early stages of their careers.

- In recent years, universities have managed to include international cooperation and international relations as an integral element of their missions and functions. This has been accomplished by universities assuming responsibility for cooperating with other institutions internationally.

- International university cooperation can be specifically identified as education, research, training, and culture cooperation, and scholarships.

- Research cooperation among researchers is particularly complicated when the researchers work at institutions in different countries due both to geographical distance and cultural differences, which can affect communication and the research project's overall conduct. 
- The number of exchange students globally is increasing for the eighth consecutive year. The total number of Saudi students studying abroad is growing rapidly, largely funded by the Saudi government scholarship program.

- International student/staff exchanges increase the concerned individuals' capacity for self-reflection, self-reliance, and self-confidence. Such exchanges also help individuals develop more mature and objective perceptions concerning their home and foreign countries, thereby contributing to international peace by enhancing multicultural understanding. It has been demonstrated that such exchanges also crucially promote creative thinking.

- International cooperation in higher education is a strategic goal of crucial importance to the Saudi Ministry of Education. In line with this goal, the ministry is actively involved in building bridges of knowledge between Saudi universities and world distinguished educational institutions and promoting knowledge and cultural exchange.

- Each Saudi university, including King Abdulaziz University, has established joint international cooperation agreements and service contracts with many of the world's top-ranking, distinguished universities and educational institutions.

- The international strategic policy of world-class universities, such as the University of Copenhagen, is intended to improve education, strengthen both external and internal collaboration, build research partnerships with other world-class universities, and attract top talent from around the world. Success in so doing provides a diversity of academic environments and scientific approaches and is a mark of distinction and strength.

- The world-class university endeavors to develop its leading position by providing researchers and students with excellent opportunities for cooperation and exchange with other national and international universities. Successful implementation of this strategy enables the university's researchers and students to participate in international research and research-based teaching and acquire a truly global outlook. Such a strategy can be implemented by means of research projects, graduate student conferences, summer programs, workshops, conferences, and congresses.

- Cooperative grants and programs, such as the Fulbright scholarship program, promote mutual understanding between individuals and institutions in the global arena. Such mutual and mutually beneficial understanding can be accomplished through the educational and cultural exchange of persons, knowledge, and skills and is of crucial significance to mankind's aspirations to live in peace and harmony.

- Cooperative programs provide opportunities for study, lecturing, curricular development, post-doctoral research, advanced joint research grants, visits, and aid in promoting mutual cultural understanding. Such programs also assist in the internationalization of campuses, curricula, and communities.

- Programs such as those described in this chapter facilitate international educational and cultural exchange for graduating seniors, graduate students, teachers, professionals, scientists, and artists. This exchange is accomplished through 
direct interactions of individuals who are able to meet, work with, live with, and learn from host country inhabitants in a daily sharing of mutually enriching cultural experiences.

Open Access This chapter is distributed under the terms of the Creative Commons Attribution Noncommercial License, which permits any noncommercial use, distribution, and reproduction in any medium, provided the original author(s) and source are credited.

\section{References}

1. Roschelle, J., \& Teasley, S. (1995). The construction of shared knowledge in collaborative problem solving. In C. E. O'Malley (Ed.), Computer supported collaborative learning (pp. 69-97). Heidelberg: Springer.

2. Keohane, R. (1984). After hegemony: Cooperation and discord in the world political economy. Princeton: Princeton University Press.

3. Martinez Gonzales-Tablas, A. (1995). Visión Global de la Cooperación para el Desarrollo. Barcelona: Icaria Editorial.

4. Dillenbourg, P., Baker, M., Blaye, A., \& O'Malley, C. (1996). The evolution of research on collaborative learning. In E. Spada \& P. Reiman (Eds.), Learning in humans and machine: Towards an interdisciplinary learning science (pp. 189-211). Oxford: Elsevier.

5. Kozar, O. (2010). Towards Better Group Work: Seeing the difference between cooperation and collaboration. English Teaching Forum, 2, 2010.

6. Organization for Economic Cooperation and Development. http://www.oecd.org/dac

7. Perspectives Note, Technical Cooperation for Capacity Development, OECD/DAC Report, January 2011. http://www.oecd.org/dac/governance-development/48260262.pdf

8. Carlson, J. S., \& Widaman, K. F. (1988). The effects of study abroad during college on attitudes toward other cultures. International Journal of Intercultural Relations, 12(1), 1-18. doi:10.1016/0147-1767(88)90003-X.

9. McCabe, L. T. (2001). Globalization and internationalization: The impact on education abroad programs. Journal of Studies in International Education, 5, 138-145.

10. Kitsantas, A. (2004). Studying abroad: The role of college student's goals on the development of cross-cultural skills and global understanding. College Student Journal, 38(3), $441-452$.

11. OECDiLibrary, Education at a Glance. (2011). http://www.oecd.org/education/school/educati onataglance2011oecdindicators.htm

12. Press Release, Open Doors 2014: International Students in the United States and Study Abroad by American Students are at All-Time High. Institute of International Education, 17-11-2014. http://www.iie.org/Who-We-Are/News-and-Events/Press-Center/ Press-Releases/2014/17-11-2014-11-17-Open-Doors-Data

13. Sadaa Electronic Newspaper, 3-3-2013. http://www.slaati.com/2013/03/03/p17126.html\#stha sh.bPXbOIeq.dpuf

14. Guilford, J. P. (1950). Creativity. American Psychologist, 5, 444-454.

15. Beghetto, R. A., \& Kaufman, J. C. (2007). Toward a broader conception of creativity: A case for "mini-c" Creativity. Psychology of Aesthetics, Creativity, and the Arts, 1(2), 73-79.

16. Batey, M., \& Furnham, A. (2006). Creativity, intelligence, and personality: A critical review of the scattered literature. Genetic, Social, and General Psychology Monographs, 132, $355-429$.

17. Mumford, M. D. (2003). Where have we been, where are we going? Taking stock in creativity research. Creativity Research Journal, 15, 107-120. 
18. Runco, M. A. (2004). Creativity. Annual Review of Psychology, 55, 657-687.

19. Plucker, J. A., Beghetto, R. A., \& Dow, G. T. (2004). Why isn't creativity more important to educational psychologists? Potentials, pitfalls, and future directions in creativity research. Educational Psychologist, 39(2), 83-96.

20. Lee, C.S., Therriault, D. J., \& Linderholm, T. (2012). On the cognitive benefits of cultural experience: Exploring the relationship between studying abroad and creative thinking. Applied Cognitive Psychology.

21. Mumford, M. D., Antes, A. L., Caughron, J. J., Connelly, S., \& Beeler, C. (2010). Cross-field differences in creative problem-solving skills: A comparison of health, biological, and social sciences. Creativity Research Journal, 22(1), 14-26. doi:10.1080/10400410903579510.

22. Runco, M. A., \& Chand, I. (1995). Cognition and creativity. Educational Psychology Review, 7(3), 243-267.

23. Sternberg, R. J., \& Lubart, T. I. (1996). Investing in creativity. American Psychologist, 51(7), 677-688. doi:10.1037/0003-066X.51.7.677.

24. Maddux, W. W., \& Galinsky, A.D. (2009). Cultural borders and mental barriers: The relationship between living abroad and creativity. Journal of Personality and Social Psychology, 96(5).

25. Leung, A. K., Maddux, W. W., Galinksy, A. D., \& Chiu, C.-Y. (2008). Multicultural experience enhances creativity. American Psychologist, 63(3), 169-181. doi:10.1037/0003-066X.63.3.169.

26. Barron, F. (1953). Complexity-simplicity as a personality dimension. Journal of Abnormal and Social Psychology, 48, 163-172.

27. MacKinnon, D. W., \& Hall, W.B. (1971). Intelligence and creativity. In the measurement of creativity. In H. W. Peter (Ed.), International Congress of Applied Psychology 17th Liege, Belgium, kamp. chm (pp. 1183-1188). Brussels: EDITEST.

28. Barron, F., \& Harrington, D. M. (1981). Creativity, intelligence, and personality. Annual Review of Psychology, 32, 439-476.

29. Cushner, K., \& Karim, A. U. (2004). Study abroad at the university level. In D. Landis, J. Bennet, \& M. J. Bennet (Eds.), Handbook of Intercultural training. California: Sage Publications Inc.

30. Benet-Martinez, V., Lee, F., \& Leu, J. (2006). Biculturalism and cognitive complexity: Expertise in cultural representations. Journal of Cross-Cultural Psychology, 37, 386-407. doi:10.1177/0022022106288476.

31. Leung, A. K., \& Chiu, C.-Y. (2010). Multicultural experience, idea receptiveness, and creativity. Journal of Cross-Cultural Psychology, 41, 723-741. doi:10.1177/0022022110361707.

32. Tadmor, C. T., Tetlock, P. E., \& Peng, K. (2009). Acculturation strategies and integrative complexity: The cognitive implications of biculturalism. Journal of Cross-Cultural Psychology, 40, 105-139. doi:10.1177/0022022108326279.

33. Tadmor, C. T., \& Tetlock, P. E. (2006). Biculturalism: A model of the effects of secondculture exposure on acculturation and integrative complexity. Journal of Cross-Cultural Psychology, 37, 173-190. doi:10.1177/0022022105284495.

34. Saudi Ministry of Education, http://www.mohe.gov.sa/ar/Ministry/International/Pages/ default.aspx

35. University of Copenhagen, Wikipedia, the free encyclopedia. http://international.ku.dk/ International_Cooperation

36. International Cooperation, University of Copenhagen. http://international.ku.dk/ International_Cooperation

37. Academic Ranking of World Universities-2014, Top 500 universities. 2014 World University Rankings, Academic Ranking of World Universities. The Academic Ranking of World Universities (ARWU), 2014. Retrieved March 22, 2014 from http://www.topuniversities.com/ university-rankings/world-university-rankings/2014?page $=1 \&$ search_theme_form $=$ campinas\&op=Search\&form_build_id=form-8573010647160d79d0ba13e30d05f98a\& form_id=search_theme_form 
38. http://ed.sjtu.edu.cn/ranking.htm.

39. http://www.timeshighereducation.co.uk/hybrid.asp?typeCode $=243 \&$ pubCode $=1 \&$ navc ode $=137$

40. http://www.timeshighereducation.co.uk/world-university-rankings

41. URAP_-University Ranking by Academic Performance. http://www.urapcenter.org/2014

42. http://introduction.ku.dk/facts_and_figures/nobel

43. UNICA, University of Copenhagen. http://www.unica-network.eu/content/unica-missionstatement

44. IARU, University of Copenhagen. http://international.ku.dk/International_Cooperation/ networks_and_alliances/iaru

45. International Alliance of Research Universities. http://www.iaruni.org/about-us/iaru

46. Research and Innovation Council. http://fi.ku.dk/english/research_and_innovation_council/

47. Fulbright Program, Wikipedia Free Encyclopedia. http://en.wikipedia.org/wiki/Fulbright_ Program, November 2014.

48. Fulbright Program Fact Sheet. U.S. Department of State. http://eca.state.gov/files/bureau/ fulbright_fact_sheets_2.pdf

49. Fulbright Sweden. (2010). Retrieved Dec 27, 2010.

50. IIE Programs. Institute of International Education. Retrieved July 28, 2014 from http://www. lie.org/What-We-Do/Fellowship-And-Scholarship-Management/Programs

51. Fulbright Scholar Program. http://cies.org/programs

52. Bureau of Educational and Cultural Affairs. U.S. Department of State. http://www.eca.state. gov/fulbright/information

53. Council for International Exchange of Scholars. http://www.cies.org/fulbright-scholars\# sthash.czSYWxav.dpuf

54. Archived: International Education Programs Service-Fulbright-Hays Programs: The World is Our Classroom. ed.gov. Retrieved June 11, 2012.

55. Which Grant Is Right For Me?-Fulbright-International Educational Exchange Program. eca.state.gov. 2008-01-31. Retrieved June 11, 2012.

56. Fulbright Scholars I Embassy of the United States La Paz, Bolivia. Bolivia.usembassy.gov. 2011-03-31. Retrieved June 11, 2012.

57. Pulitzer Prize Winners I Institute of International Education. Iie.org. Retrieved June 11, 2012. 


\title{
Change Towards Excellence
}

\author{
Jozef Ritzen
}

\section{Introduction}

This chapter deals with the challenges of change towards excellence for universities that find themselves embroiled in the turmoil of globalization and of "informatization": the intense absorption of ICT (information and communication technology) in even the tiniest blood vessels of social and economic life. External change leads to new and different demands on university output requiring welltrained graduates and research and community engagement (Sect. 2).

The university leadership plays a crucial role in ensuring that change towards excellence is achieved by developing a strategy which is owned by the university and by providing the means for that strategy's implementation (Sect. 3). In Sects. 4, 5, and 6 the elements of the strategy, involving goals in education, research, and community engagement, are discussed, as are the means to achieve these goals. Regional alliances appear to be a necessary component of a strategy leading towards excellence for most universities (Sect. 7). Section 8 discusses some questions concerning implementation, while Sect. 9 is devoted to concluding remarks.

This chapter draws on my personal, almost nine-year long, experience as minister, responsible for education, science, and culture in the Netherlands during the 1990s. The Netherlands' universities currently belong among the top 100 of most university rankings in relation to population size. The legislative changes effected in the 1990s are, according to many observers, related to the quality increase in universities that followed some 10-20 years later. Also, as President of Maastricht University in the first decade of the twenty first century, I learned a great deal about change towards excellence. The University grew to become perhaps the only university world-wide completely based on problem-based learning in all degree courses. In 2014 it was ranked 6th in the Times Higher Education Ranking of the

\footnotetext{
J. Ritzen $(\bowtie)$

Maastricht University, Maastricht, The Netherlands

e-mail: j.ritzen@maastrichtuniversity.nl 
"50 under 50" (the top 50 universities in the world younger than 50 years old), with in excess of $50 \%$ of foreign students in its student body. Strategy towards excellence, based on past performance and strength, aided in the achievement of that position. The high ranking was never the primary goal, but it turned out to be an inevitable by-product of the university's search for excellence.

\section{The Times Are Changing, and so Are Universities}

\subsection{Internal Change}

It is felt by some people that universities are the only places in the world where time stands still. They believe that someone who left the classroom 50 years ago may return and discover everything still the same. Two years ago a then recently appointed president of one of the European top universities that had been established centuries ago remarked in a private meeting that he was glad that nothing had changed in his institution during its long history. I met him again recently and his perspective had changed significantly. Certainly, the beautiful buildings were still there and many of the centuries old customs and rites were still in use. Yet under that surface of continuing age-old traditions everything had changed, or was in the process of changing.

The orientation in education has been changing its focus towards the latest skill requirements (in the broadest sense) as perceived in society and the labor market. The approach to education has been changing with the advent of student-centered and ICT-learning's integration in blended learning. The approach to research is changing, taking research increasingly in the direction of protected knowledge in patents and the use of knowledge for start-ups or spin-offs, without ignoring fundamental research. Community engagement has also been discovering new direction, as is well described by Professor Wilhelmsson in chapter Excellence in Serving Society and Mankind.

The organization of universities has also been changing in a convergence between a full recognition of the professionals and strong leadership in practically horizontal relations. Universities have increasingly become partners in regional, national, and sometimes international networks with private business and local and national governments, as is well explained by Professor $\mathrm{Su}$ in chapter Excellence in Education. Universities have started to cooperate among themselves both on the level of education and of research. University networks have been established as venues for the sharing of managerial, educational, and research experiences. This occurs at the national level and internationally, sometimes involving mergers and sometimes with joint Master's or doctoral programs.

Also, the context in which universities are operating is undergoing changes. Unfortunately, it can be seen that in many countries, society's faith in the responsibility of universities for the common good has weakened, creating a tendency for government regulatory overload and limiting universities' empowerment [1]. Universities serve an important role for society, which is the reason for substantial 
levels of government funding for university education and research. This important role for society can best be played in the form of partnerships between universities and governments, with full university empowerment and accountability; as opposed to the situation in which universities are overloaded with well-intentioned government regulations, leaving them less than adequate room for maneuver to adapt to rapidly changing external environments.

\subsection{External (to the University) Change}

The past 50 years have seen tremendous changes in our societies. No one foresaw as late as the year 1990 that the mobile phone would conquer the world. No one could have foreseen the current actuality where online web information and messages reach to and are accessible in even the most remote villages. The impact of this has forced shops to close down in some areas due to the high volume of Internet purchases in virtual shops. Neither could it have been foreseen that three terabytes of information ${ }^{1}$ could be stored on a single disk costing less than $\$ 200$ and that it could be analyzed in a few seconds, whereas in 1990 it would have taken days or weeks with a warehouse of interconnected disks. Routine work is being mechanized or robotized on a scale we never could have imagined.

Not only have we witnessed a tremendous change on the technological side, but we also have witnessed the breakdown of trust in the financial system in scandals like Enron and later the US/European Banking Crisis, where it came to be realized that even the best education did not necessarily guarantee high ethical and moral standards. We also see an increase in armed conflict in societies with highly educated populations. Apparently, we have not learned at home or in school how to resolve conflicts through peaceful means.

These changes have impacted not only the way we live, but also the way we create wealth in a hopefully sustainable manner. Innovation in products or production has become essential in order to realize the high margins associated with being first on the market. Innovation is the source of labor productivity which helps to raise wages. This can only happen sustainably with sufficient trust in the functioning of our markets and our societies.

In this context, universities have become central in generating sustainable economic growth through their graduates and through their research and are an important source of innovation. The high growth regions in Europe and the US are all located in areas that are locations of venues for the provision of quality higher education. The Boston area in the US and the Cambridge area in the UK are excellent examples. The migration of highly skilled manpower and entrepreneurship is toward such high growth regions, thus creating an upward spiral.

\footnotetext{
${ }^{1}$ A terabyte is $1000 \mathrm{~GB}$ or $1000 \times 1000 \mathrm{MB}$. The first hard disks I used in the $1980 \mathrm{~s}$ had a capacity of $5 \mathrm{MB}$.
} 


\subsection{Converting and Adapting External Change into Change Within the University}

Most universities, older and younger, were taken unawares by the tidal wave of external changes in recent years. The changes were observed by leadership, staff, students, and stakeholders, but were hardly reflected in the content or in the organization of universities. Universities themselves were fully engaged in the "going concern", making sure that "the show went on" and allowed themselves little time to reflect on the implications of the external changes for the content or the organization of their education, research, and community engagement. In the 1990s this started to change, often engendered by governments.

I was a close witness of this process in the 1990s as the minister responsible for higher education and science in the Netherlands, while being in close contact with other ministers in the European Union. In some cases the leadership of universities were willing to engage in change, yet were restrained from doing so by legislation, which proved difficult to change as it was defended by coalitions of students and staff and was sometimes reinforced by stakeholders.

Change is always fraught and problematic: you know what you have and you don't know what you will get. Conservatism and being inimical to change are very human characteristics. Change can only be brought about by dialog between all involved parties and with trust in leadership based on past performance and on the experienced empathy of leadership with staff and students. Change always has a cost in terms of readjustment and relearning. Change is also fun. It keeps you alive and presents new opportunities and horizons.

A broad dialog concerning change is necessary for change to catch on. Stakeholders are involved in this process of consultation and dialog. However, stakeholders may feel that they have a strong interest in maintaining the status quo. An example of this was in the Netherlands in the 1990s when organized employers and organized employees (trade unions) were not at that time willing to be partners with universities in change, but were rather advocates of maintaining the status quo. Technical university education (which I had myself benefited from) was organized around a curriculum of 5 years which on average would actually take 7 years, as had been the case since the early inception of technical university education in the later part of the nineteenth century. This clearly was too long a study time-frame for every student in the period of mass technical university education. Yet around the year 1995 it was employers who were the most antagonistic to the introduction of a bachelor/Master's system with a 4-year maximum duration. Several factors may explain this. First there may have been the expectation of more costs for firms for in-service training once the length of time for study courses was reduced. Second there seemed to be the psychological reason that business leaders wanted the up and coming generation to receive the same education as they had themselves received.

Change is visible in a university strategy which has "teeth" and contains choices. These choices identify what the university wants to stand for and the 
manner in which it wants to proceed to this stature. Choices are clear and cannot be everything for everyone. Choices also involve compromise and by their very nature generally barely reflect the ideal as some would like to see it.

Most universities are organizations of a substantial size. The larger the size of an organization, the less nimble it is likely to be. There are many examples of large organizations which have thought of avoiding the conservatism induced by size, through a mix of central strategy on main lines, while also leaving a lot of available room for decentralized adaptation and responsibility. I am convinced that universities, definitely the larger ones, should also opt for such an approach in order to make the strategy work.

\section{Strategies for Excellence}

\subsection{Elements}

Obviously, education and research are central in any university strategy, while community engagement might be counted as a third goal of universities. But there is also the need for inspiration, for a choice on the culture universities want to exude. Few universities or university departments have been able to encapsulate this in a single sentence or motto. Most often, vague lines are chosen like "entrepreneurial" or "innovative" university. I came across a good example of a university which found a condensed way of describing its culture at the Free University in Amsterdam. In 2013 that university selected three core values: personal (in the sense of the staff setting the examples), open (to students from all different backgrounds), and responsible (meaning: engendering a spirit of responsibility towards society among staff and students). Another good example is Harvard Business School (HBS) which stated in 2014, “... we believe that leadership and values are inseparable. The teaching of ethics is explicit, not implicit, and our community values of mutual respect, honesty and integrity, and personal accountability support the HBS ..." [2]. A university wants to make a specific choice in the cultural values it pursues. This is not a mere choice of the right words, but should be visible in the implementation of the strategy. It should be explicit and one should be accountable for it, as HBS wants to be.

The choice for HBS was not unintended. Graduates of HBS were involved in many of the financial scandals in the US. HBS wanted to demonstrate that it had learned from experience, setting in this way an example for other business schools.

\subsection{No Copycat. Differentiation Is the Name of the Game}

One of the main headaches for governments in the past decades has been, and still is, the tendency for universities to all target the comfortable middle zone of the 
student market. Universities have shown themselves to be reluctant to change in this respect, in the same manner as the ice cream sellers who all like to stand the main entrance to the beach, avoiding positioning themselves at the other entrances where perhaps fewer people are entering. The comfortable middle is one with a lot of competition (many ice cream sellers), but also with the comfort that it is a stable time-tested position, in particular when student numbers are increasing.

At the same time, there are different students with different talents and different ambitions. Also, the labor market has many dimensions. There is no "one size fits all" in the demand for graduates. Yet, the forces opposed to differentiation are considerable. Research universities often feel obliged to expand their scope by broadening the range of degree courses they offer to include non-research based elements, more appropriate for university community colleges for applied sciences, in order to attract additional students. Conversely community colleges or their equivalents feel that they are undervalued and strive for more research, for master degrees, or even for Ph.D. programs for inclusion in their proffered educational packages. Both cases involve reductions in quality for students in one way or another because the ensuing quality dilution is across the board. There is global recognition that there are at least four differentiated levels of higher education: the community colleges, the universities of applied sciences, the bachelor colleges, and the research universities. Roughly, some 60-80\% of the students are in the industrialized countries in the community colleges and universities of applied sciences and 20-40\% in colleges and research universities (OECD, Education at a Glance, 2014). It appears that in countries which follow this division the research universities are better placed in international rankings than in countries where less differentiation takes place.

Universities themselves should feel responsible for their position. Often, however, governments have to interfere to induce differentiation as universities are not able to resist the temptation of growth and universities of applied science are unable to avoid the insecurity of feeling undervalued. Increasing numbers of governments now also want to enter into performance agreements with universities so that universities choose specific profiles distinguishing them from others. Lack of clarity and visibility in universities' profiles is often due to governments' unwillingness to provide finance to universities for undifferentiated profiles.

The choice for differentiation is not only along the broad lines, but can also relate to specific student demands. Some universities seem to do very well for students from a non-traditional background (e.g., children of immigrants) and could make this a point of differentiation. Others are pioneers in new approaches to education like Olin College in Boston or Maastricht University, both utilizing a problem-based approach to learning in all of their courses. The Open Universities are examples of a differentiated approach, as are the newly emerging Internet universities such as the Khan Academy. A university can only opt for such a profile if it fits into a "business case", i.e., that the university can sustain itself financially. 


\subsection{The University Owns the Strategy}

The strategy implementation stands or falls with the process of strategy preparation. The strategy should be prepared in such a way that it is "owned" by the broader leadership of the university. These are the Board, the deans, key professors as well as some carefully selected student leaders and promising young staff. External stakeholders might also be included. The voice of alumni can also be important. Broad consultations are often viewed as a waste of time: academics are busy with education, research, or community involvement, and are not focused on or engaged in "strategy". Also external stakeholders have to be convinced that they can actively contribute to the university strategy and that doing so is in their own interest. The costs in terms of time of the leadership, of faculty, and of stakeholders, as well as the costs of organizing consultations should not be underestimated. At the same time the result, in terms of ownership, is well worth the outlay.

\subsection{Supporting the Development of a Strategy}

Naturally ("we are as a university involved in the pursuit of the truth"), the discussions on future strategy are based on extensive research on our own position and strengths and include the nature and composition of the external environment. A SWOT analysis is an important starting point, not only concerning finance, satisfaction of students and alumni, external assessment of the quality of the curricula and research quality, but also in terms of the quality and culture of the organization. Recently the University of Cologne requested an outside Agency to conduct such a SWOT analysis for its Central Organization [3]. Cultural aspects were included in the analysis.

An important part of research is the exploration of the potential scope and space for maneuver (maneuverability potential). To what extent is the present situation determined by government regulations and what is the scope and space available for change? It often happens that perceptions of maneuverability potential are based on and limited by historic personal experience. The organizational autonomy, i.e., the ability of the university to set its own goals and priorities through an adequate governance structure, may be underrated. The financial autonomy (the ability to decide on its own finances) could be undervalued. More substantial investments using borrowed funds might be possible if innovative methods of selling research products can be developed. Also, on the policy side, there might be more maneuverability available than was initially presumed to be the case.

Funding remains an important issue. What is the potential for increasing funds, through grants, through partnerships with the private sector, through partnerships with local governments or the national government, through philanthropy, and perhaps through alumni? 
International and national advisory boards may be able to widen actionable scope. As chapter International Advisory Boards in the World shows with examples: top universities, or universities which strive towards excellence, will, as a rule, try to acquire and utilize international knowledge and experience for developing and implementing strategies which imply substantial change.

\section{Strategic Positions on Education}

\subsection{Goals and Means}

Strategic positions on education center on goals (what is the purpose of our education) and means (how such goals are achieved).

\subsection{Goals}

"Demand driven" university education with elements of entrepreneurship is likely to be considered as a self-evident starting point for a debate concerning goals. Many universities view "demand driven" as being "student centered". That would do injustice to the fact that universities should have clear ideas about what students should acquire, what students should learn, and what skills students should develop. The more ambitious universities will take as their starting point in this regard the knowledge of what skills, competencies, and knowledge are required for graduates to function effectively and successfully in the labor market and in wider society:

- Cognitive achievement and knowledge of the field remain of predominant importance.

- The majority of work is done in communication and cooperation with others. Being able to work in teams and communicate effectively are essential job requirements.

- Employers like graduates to be problem solvers.

- Most graduates of internationally recognized universities work in an international environment.

- Most graduates of internationally recognized universities understand ICT.

Harvard Business School added that such graduates should have developed a strong sense of integrity.

Other universities hold that graduates' crucial attributes should include the development of social responsibility or civic engagement.

Strategic choices may be simple to state in words concerning these issues, though their integration into individual degree courses may yet prove difficult. There we see resistance to change because the integration has to render the skills 
and competency demands explicit. Let me give an example of the implementation of the strategic notion that students should be prepared to work in an international environment. In 2008, Maastricht University thought that this notion could be integrated into degree courses by formally requiring all students to spend at least one semester abroad at a foreign university. Several directors of degree courses complained. They reasoned that implementation of this requirement would be problematic and could not easily be fit into the regular curriculum and that it would result in graduates completing their courses insufficiently prepared in terms of knowledge for entry into the workplace and society. This illustrates potential pitfalls in the terrain to be covered in strategy implementation.

Universities who are free to decide the number of students to be admitted may also want to think about strategic positions in terms of the number of students to be admitted (if the government allows restrictions). They may also want to take into account the selection procedures for courses where the more academically able students may have access to "enriched" classes and they may also want to consider the throughput rate (avoiding dropout after selection or after a first trial year).

Universities may want to display excellence in the manner they assist graduates in securing gainful employment through placement services or otherwise. This process should be integrated into the degree programs themselves and should not be merely something that follows graduates' degree completion as a kind of afterthought.

Entrepreneurship education is another element of education in which the university can make choices: should such courses be offered, should participation in such courses by voluntary (not for credit or for credit), should it be compulsory, and if so, what other subjects should be dropped in degree courses to make curricular space for entrepreneurship inclusion?

\subsection{Means}

The means for delivering excellent education are people. It is important to realize time and time again that universities are a people business. It is the university staff members who make, or unfortunately possibly break, the quality of the university. Human resource policy is an important element that involves having the right people in the right places, investing in motivation and continued learning, and investing in facilities which make it possible for staff to achieve the proper life-work balance, such as by the provision of adequate child care facilities. A number of other strategic issues must also be considered here, such as tenure track careers for scientific staff, promotion possibilities, the ratio of junior to senior staff and of scientific staff to "support staff", developmental opportunities available for staff, and financial remuneration (increases) and promotion policies among other things. In many OECD universities, gender policy is an important topic: while the majority of the students are female, the majority of the senior professors are male, with 
insufficient attention having been paid to status quo change in this regard in recent decades. The supply pipeline of senior female professors is problematic: with every step taken in scientific staff seniority, the percentage of female staff falls significantly (often above $50 \%$ among post docs, decreasing to often around $20 \%$ among senior professors).

Means are also pedagogical. It is remarkable how readily the well-established learning pyramid is ignored.

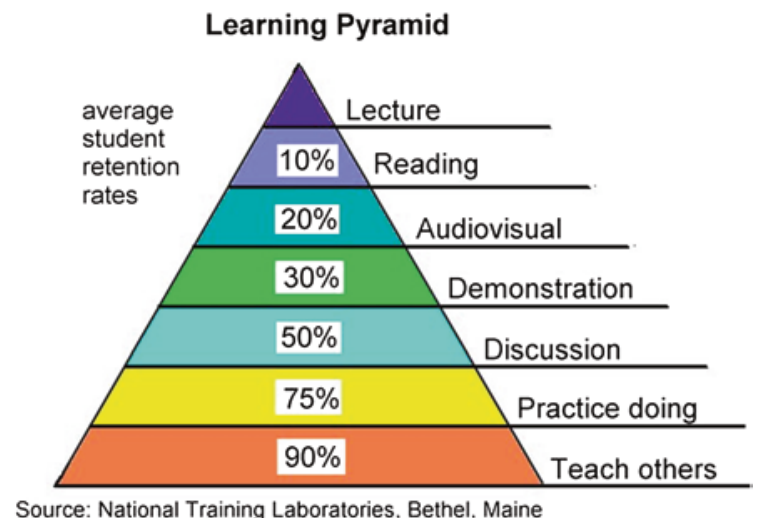

How can it be that most universities still rely mainly on large lecture hall teaching, if the efficiency in terms of retention rates is so low? Is it because universities were physically constructed with this educational method in mind? If that is so, then there is a clear case for renovation in tandem with learning process innovation through small group teaching and learning. Increasingly, universities are moving in the direction of problem- or research-based learning where small groups, practice, teaching others, and learning problem solving are blended [4].

\section{Strategic Positions on Research}

\subsection{Research for Publications}

Some universities have the idea that their research strategy should focus in particular on raising the number of publications which are cited world-wide, in order to achieve the likelihood of raising their ranking levels. Even if this is the case, substantial strategic elaboration on the manner in which this is to be accomplished is still required. It is likely to imply focus as not every department or every research group within the departments is going to be a winner in this regard. Established research groups with good track records could form part of the focus, but so might new emerging groups with potential. Strategic choices are also dependent on the 
selection of the areas universities want to excel in, in terms of their academic and social profiles and overall perspectives.

Such strategic deliberations are fraught with strife and it is generally a complex process to ascertain and enumerate how universities' research budgets are to be distributed as a result of research strategies.

Citations and potential citations should not be the sole considered criteria. Also, the contribution of universities to their immediate or wider educational, social, and commercial environments could be an important point of departure with research strategy aiming to increase the volume of public-private co-publications.

Generally research strategies would also aim to utilize universities' potential to acquire grants from a variety of other external sources.

An overriding factor for consideration concerning research is the level of its contribution to the satisfaction of societal curiosity and the level of its contribution to a problem's solution. Often universities are so deeply involved in research that they do not have time to think. A research strategy should also allow for fundamental research which may not lead instantly to publications in top journals because of its "off the beaten track" nature.

\subsection{Research Supporting the Quality of Education}

Most universities realize how important their research is to enable academic staff to guide the students' learning process, as is well explained by Professor Arthur in chapter Excellence in Research. Learning has more quality the more it is based on the creative exploration of facts and their interrelations and interconnections in what might be the most relevant theories. Research is important for staff to encourage students to refrain from rote learning and to instill in them what might be called "the Einstein attitude". He stated this attitude after having formalized the relativity theory which replaced the Newtonian way of thinking. He said, "We now have a way of interpreting more of what we see. But make no mistake: there might be even more appropriate theories". The relativity theory was thinking "out of the box", not in deepening the Newtonian theory. Learning is at its best when it leads to such an attitude, such a way of thinking.

This may be different from publishing in the majority of peer-reviewed journals with relatively low impact factors, as peers will often judge contributions by their progress along the well-travelled beaten track. This deepening of knowledge may be useful, yet for research-based education the "out of the box" thinking is of more significant importance. Top journals, such as The Lancet and Nature and their equivalents in the social sciences and humanities with high impact factors, are focusing on novel ideas and concepts. University staff accepted to publish in such journals would presumably be best equipped to guide and facilitate students' learning using methods intended to replace students' reliance on the conventional rote-learning comfort zone. 
Most universities face a dilemma as top researchers' publications are important for universities' reputations, while their contribution to education is either nonexistent, or imprecisely observed and recognized in rankings and in more qualitative peer perceptions. Researchers themselves also often face such dilemmas as they may want to actively contribute to education while they are at the same time aware that their research publications are more important for their own careers, in particular if they are still on tenure track.

Change towards excellence implies also discovering the correct balance between the involvement of the best researchers in their research undertakings and in education. The introduction of research-based learning elements in the curriculum may provide a helpful means of bridging this gap.

\section{Strategy on Community Engagement}

In parliamentary or other public discussions on higher education, the goals of universities are often laid out in three interconnected strands: education, research, and community engagement. Community engagement is closely related to what is called the social responsibility or "service" of universities as their "third mission." This role of universities is central to the educational experience of students and to the commitment of universities to wider society. There are many dimensions of the role of service [5]. The most important service universities render to society is the quantity and quality of their graduates. Also the contribution of research to regional and national economic development is highly relevant. This includes collaboration with regional and national governments and industry to improve technology, assistance to industry to improve practice, support for the integration of new technologies, and the direction of new knowledge towards societal advancement (see the following section).

Universities use different models for the "soft side" of the third mission for civic and community involvement of students and their social entrepreneurship. These contribute to the social responsibility of graduates while at the same time improving the quality of life for different sectors of society. The importance of engaging higher education students through broad-based participation in civic society for the development of the skills and attitudes of socially responsible graduates is achieved through curriculum and related projects. For this to succeed, it is crucial that university staff members are committed to the notion of socially responsible and highly productive graduates. 


\section{Strategies on Partnerships}

\subsection{Region to University Interaction}

Universities, even those with high international profiles, have a significant impact on the local regions in which they are located while the regions in turn provide fertile environments for the universities. There appears to be something of an upward causal spiral in these interrelationships. Regions considered excellent in terms of growth in regional products and labor productivity and that are highly attractive destinations for new businesses and for bright young people are generally regions with high quality universities. That is not to say that universities only operate for the benefit of their own localities or regions, and the facts show that current graduates are likely to display levels of mobility that preclude many of them from remaining in the regions in which they graduated. A substantial part of the research on this topic is in the public domain and readily accessible in relevant publications. In spite of this, high educational and academic quality universities turn out to be part of strong regions. Research facilities of private industries seek locations in close proximity to those of good universities. Princeton in USA and Louvain in Belgium provide clear examples in this regard. The regions benefit as high quality universities are attractive as sources of competent labor and as sources of inspiration in open networks, while the universities benefit as it is easier for them to attract staff and research grants in booming regions than it is for universities in other economically less-advantaged locations.

Change towards excellence for universities then is a process in which the regions and the universities have to both partake in regional strategic planning. It concerns locating, identifying, and strengthening the threads of the upward spiral, creating and working in partnerships. Formal regional partnerships, between local governments, local industries, and universities, are intrinsic to any strategy for change. Strategic options of universities are reinforced by, or may be altered according to and in alignment with, regional agreements.

Region-university interaction existed in the Netherlands in the stage of the elite universities. One of my Alma Maters, the Technical University of Delft, had been founded in part as support for the development of major Netherlands-based industries such as Shell, Philips, AKZO, and Unilever and had a tremendous impact on the region. Yet, by 1980 the university's formal and practical ties with the region and the regional government had ceased and they operated and existed as separate entities with minimal contact. From the 1960s to the 1990s new universities were established throughout Europe with low levels of formal linkage to the regions in which they were located.

It was only in the past 10-20 years that the awareness grew that change towards excellence for universities could be reinforced by strong cooperation with the regions in which universities are located, and that regions for their part came to realize the tremendous capital that universities represented for their development. 
Developing strong regional cooperation is a time-consuming and lengthy process. It is also a process with its ups and downs. Regional governments change with the political cycle and the new guard may have different notions than their predecessors. However, there are numerous examples of successful cooperation between universities and the regions, such as in the cases of Louvain or Princeton (previously mentioned), and Warwick (UK) and Copenhagen (Denmark).

\subsection{International Partnerships with Other Universities}

Most universities have extensive links with other universities in education and research. In education there are substantial levels of student exchange, sometimes as features of joint degree programs. In research, individual researchers or research groups often collaborate in joint programs or on an informal basis. These partnerships can be part of a strategic line of focus. They can be left to individual departments or degree courses or they can be decentralized under a central general framework, as is, for example, the case in Cambridge. In this case, the International Strategy Office helps coordinate and facilitate agreements between individual departments/schools/colleges and international partners under a protocol governing all such international agreements.

There were times when a university president might have informed visitors of the 300 or more signed memoranda of understanding with other universities, while being at a loss and unable to demonstrate how they actually contributed to the university's quality of research and teaching. This has changed as nowadays universities have highly selective cooperation agreements with other universities which stipulate how exactly joint degrees or joint research projects are conducted and identify their structural frameworks in terms of finance and accountability.

\section{Implementation}

\subsection{Measurement}

Successful implementation requires measurement. How well are we doing on the strategic lines we set out? Education performance, for example, can be measured approximately by:

- Graduate (un)employment rates (university role in linking with labor market);

- High levels of graduates' satisfaction with their studies 3 years subsequent to graduation;

- High levels of employers' satisfaction with graduates 3 years subsequent to graduation;

- Student questionnaires on satisfaction with education (numerous examples in Germany and the Netherlands);

- Student-course-evaluations. 
Measures of research performance are widely and readily available, such as in citations, public-private scientific publications, etc. All of these measures are to be strategically refined. Does the university want graduates to have a high level of international understanding? If the answer is in the positive, then this level of international understanding requires appropriate measurement. Qualitative scales are available. It is a challenge to show not only how graduates score, but also how scores have changed during degree courses and how this has been achieved. HBS wants to contribute to the integrity of graduates. This is required to be measurable (again, qualitative scales are available, for example the Giotto scale [6]).

\subsection{Incentives}

Incentives in education are generally the most difficult to come by, as the career of the professor seems so overwhelmingly determined by the research performance of the staff member. Education prizes and professorial education careers have turned out to be helpful instruments in incentivizing educational quality.

Incentives could also be made available in monetary terms, linking the quality of degree program to budget allocation levels. The inherent danger here that has to be acknowledged is that what are perceived as being underperforming programs face the threat of becoming financially squeezed. For such programs special treatment may be a solution, as the quality problems are often persistent and not cured by purely financial remedies, but require major staffing and structural changes. Budget allocation can also be based in part on graduate numbers or on the throughput rate in degree courses.

Personal incentives can also be applied in monetary terms for individuals, such that only those that perform well receive annual increases, while those whose performance is rated as excellent receive additional financial rewards. Dismissals for serious underperformance should also be invariably available to universities striving for excellence.

\subsection{Balanced Score Cards}

Many universities render their strategy implementation visible through the use of balanced score cards. These score cards are also a means of making universities' performance accountable to external environments. Such score cards might enumerate the aims for the number of graduates, for successful accreditation of programs, for student and graduate satisfaction, for research performance, for the attraction of international students and staff, and for female professors among other things. 


\section{Concluding Remarks}

Change towards excellence is based on a converging process of involvement of staff, students, and stakeholders in setting the goals for education, research, and community engagement in line with the rapidly changing external environment. Choices are derived from this process: where do universities want to stand in a differentiated setting in the country with some universities being more and others less research intensive, while facing various and changing demands from students and the labor market?

Most universities are seriously challenged both in relating their education to labor market demands in terms of skills and competencies and in the manner in which they organize the students' learning (with excessive predominance of large lecture hall teaching). They need to explore and implement innovative learning in small groups using blended learning tools. Teachers are required to organize learning and become visible academic and educational role models. Research- and problem-based education should be incorporated into, and become an intrinsic element in, universities' educational processes.

Both in education and in research, regional compacts are emerging as means and pathways to effectively organize the context for change to excellence.

Open Access This chapter is distributed under the terms of the Creative Commons Attribution Noncommercial License, which permits any noncommercial use, distribution, and reproduction in any medium, provided the original author(s) and source are credited.

\section{References}

1. University policy needs to beef up for Europe to be more innovative. (2014). www.empowereu.org

2. www.hbs.edu/mba/student-life/Pages/leadership-and-values.aspx

3. UzK Evaluation ZV Peer Bericht. (2014). (In German; translated: University of Cologne Peer Evaluation).

4. Soete, L. (2014). Contribution to the IECHE Conference Riyadh, April 2014.

5. Riyadh Conference Statement on the Social Responsibility of Universities, IECHE. (2013). ieche.com.sa/portal/en/2013

6. http://www.getfeedback.net/products/detail/giotto 